\title{
Scoping Analysis of Sodium Cooled Fast Spectrum Test Reactor Cores
}

\section{January 2020}

Gilles Youinou, Samuel Bays, Giuseppe Palmiotti Idaho National Laboratory

Florent Heidet, Ting Fei, Michael Smith Argonne National Laboratory

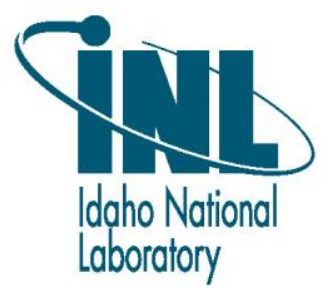


Page intentionally left blank 


\title{
Scoping Analysis of Sodium Cooled Fast Spectrum Test Reactor Cores
}

\author{
Gilles Youinou, Samuel Bays, Giuseppe Palmiotti \\ Idaho National Laboratory \\ Florent Heidet, Ting Fei, Michael Smith \\ Argonne National Laboratory
}

January 2020

\begin{abstract}
Idaho National Laboratory
Nuclear Science \& Technology Directorate

Reactor Systems Design \& Analysis Division

Idaho Falls, Idaho 83415
\end{abstract}

http://www.inl.gov

Prepared for the

U.S. Department of Energy

Office of Nuclear Energy

Under DOE Idaho Operations Office

Contract DE-AC07-05ID14517 


\section{DISCLAIMER}

This information was prepared as an account of work sponsored by an agency of the U.S. Government. Neither the U.S. Government nor any agency thereof, nor any of their employees, makes any warranty, expressed or implied, or assumes any legal liability or responsibility for the accuracy, completeness, or usefulness, of any information, apparatus, product, or process disclosed, or represents that its use would not infringe privately owned rights. References herein to any specific commercial product, process, or service by trade name, trademark, manufacturer, or otherwise, does not necessarily constitute or imply its endorsement, recommendation, or favoring by the U.S. Government or any agency thereof. The views and opinions of authors expressed herein do not necessarily state or reflect those of the U.S. Government or any agency thereof. 


\section{Content}

1. Introduction and objectives 1

2. Design variables, constraints and codes 2

2.1 Design variables 2

2.2 Design constraints for normal operation 4

$\begin{array}{ll}2.3 \text { Computer codes } & 5\end{array}$

3. Core sizes and fast flux levels 6

$\begin{array}{ll}3.1 \text { Methodology } & 6\end{array}$

3.2 Discussion $\quad 7$

3.3 Results $\quad 8$

$\begin{array}{ll}3.4 \text { Comparison with other fast test reactors } & 19\end{array}$

4. Reactivity coefficients $\quad 20$

$\begin{array}{ll}\text { 5. Reactivity control } & 23\end{array}$

5.1 Control rods worth $\quad 23$

$\begin{array}{ll}5.2 \mathrm{BOC} \text { excess reactivity mitigation } & 24\end{array}$

6. Preliminary thermal hydraulic uncertainty considerations 28

7. Fuel cycle considerations for a $300 \mathrm{MW}$ core $\quad 31$

$\begin{array}{ll}7.1 \text { Fissile material requirement } & 31\end{array}$

7.2 Fuel fabrication $\quad 32$

$\begin{array}{ll}7.3 \text { Spent fuel } & 32\end{array}$

$\begin{array}{ll}\text { 8. Conclusions } & 34\end{array}$

$\begin{array}{ll}\text { 9. References } & 35\end{array}$

$\begin{array}{ll}\text { Appendix 1. Pressure drop correlation } & 37\end{array}$

Appendix 2. Impact of the number of fuel pins per assembly on thermal hydraulics 38

Appendix 3. Examples of hot channel thermal calculations 39

Appendix 4. Review of other fast test reactors 42

$\begin{array}{ll}\text { Appendix 5. Approach to determine the reactivity coefficients } & 51\end{array}$

Appendix 6. Detailed results from parametric study 53 


\section{Introduction and Objectives}

A team from the national laboratories conducted a study [Petti, 2016] that assessed advanced reactor technology options and the irradiation needs of a broad group of stakeholders. This identified a gap in the fast neutron irradiation capability - the need for a test reactor that can deliver high neutron fluxes of fast neutrons. The study compared fast and thermal neutron irradiation technology options based on technology maturity and the ability to meet strategic objectives, along with pathways to deployment and tradeoffs in mission. It also provided a recommendation on specific technology options to address the current gap in fast neutron irradiation capabilities.

In this context, a detailed scope of work was prepared that pertains to a trade study focusing on the core of a fast neutron spectrum test reactor. This report presents the main results obtained by a team of Argonne National Laboratory (ANL) and Idaho National Laboratory (INL) scientists. It aims at developing an overall understanding of how the various areas important to the design and successful operation of such a facility interact with one another. Developing a sense of the relevant sensitivities at a systems level creates an understanding of where and how margins may be available to improve performances (e.g., flux level, capacity factor, and thermal hydraulic limits). Emphasis is given to the reactor (core design options and safety) and its fuel cycle (fuel supply and fabrication, as well as spent fuel management).

A modern fast neutron spectrum test reactor should reach fast neutron fluxes as high as practically attainable in useful experimental volumes. Peak fast neutron fluxes (with neutron energy above $0.1 \mathrm{MeV}$ ) as high as 4.0$4.5 \times 10^{15} \mathrm{n} / \mathrm{cm}^{2}$-s can be reached in high performance fast test reactors such as FFTF and JOYO. Most of the other fast test reactors currently operating (e.g., BOR-60, CEFR), or now decommissioned (e.g., Rapsodie, EBRII), or still at the planning or early construction stage (e.g., MBIR) are characterized by lower peak fast fluxes (2.5$4.0 \times 10^{15} \mathrm{n} / \mathrm{cm}^{2}-\mathrm{s}$ ). Based on these considerations a modern fast neutron spectrum test reactor should be designed to reach a peak fast flux in excess of $4 \times 10^{15} \mathrm{n} / \mathrm{cm}^{2}$-s which will position it in the upper range of fast test reactor performance.

The objective of this trade study is to develop an understanding of how the various areas important to the design and successful operation of such a facility interact with one another. Chapter 3 provides an estimation of the minimum number of fuel assemblies, the core power, and the peak fast neutron flux (above $0.1 \mathrm{MeV}$ ), given the set of design parameters and requirements specified in Chapter 2. Reactivity coefficients were calculated for several configurations as a first approach to safety analyses (Chapter 4). Chapter 5 deals with reactivity control. A discussion on thermal hydraulic uncertainties is presented in Chapter 6. Chapter 7 presents some fuel cycle considerations for a $300 \mathrm{MWth}$ core. Chapters 8 presents the conclusions. 


\section{Design Variables, Constraints, and Codes}

\subsection{Design Variables}

- Two plutonium isotopic compositions were considered: one typical weapons-grade isotopic composition and one reactor-grade. The reactor-grade isotopic composition corresponds to some of the plutonium present at INL's Zero Power Physics Reactor (ZPPR); it is representative of actual reactor-grade plutonium. ${ }^{1}$

Table 2.1. Plutonium isotopic compositions.

\begin{tabular}{|c|c|c|c|c|c|}
\hline & Pu-238 & Pu-239 & Pu-240 & Pu-241 & Pu-242 \\
\hline Pu-WG & - & 94 & 6 & - & - \\
\hline Pu-RG & 0.1 & 68.7 & 26.4 & 3.4 & 1.4 \\
\hline
\end{tabular}

- Based on the experience accumulated in the U.S., metallic fuel is the preferred fuel form. Taking into account the two plutonium isotopic compositions, a total of twelve metallic fuel compositions were considered, corresponding to several $\mathrm{U}-x \mathrm{Pu}-10 \mathrm{Zr}$ fuels and $\mathrm{U}-10 \mathrm{Zr}$ fuels. For the $\mathrm{U}-x \mathrm{Pu}-10 \mathrm{Zr}$ fuels, the trade study covered a range of plutonium content between 11.5 and 27 percent and a range of uranium enrichment between 0.3 (depleted uranium) and 19.75 percent. As specified by the Department of Energy, the U-xPu-10Zr fuels must satisfy the following criteria, with respect to mass: $\left[{ }^{235} \mathrm{U}+\mathrm{Pu}\right] /[\mathrm{U}+\mathrm{Pu}+\mathrm{Zr}] \leq 0.27$. Two $\mathrm{U}-10 \mathrm{Zr}$ fuels were also considered-one with a 19.75 percent ${ }^{235} \mathrm{U}$ enrichment and one with a 27 percent ${ }^{235} \mathrm{U}$ enrichment.

The configurations analyzed included the following:

- Two U-27Pu-10Zr fuels with ${ }^{235} \mathrm{U} / \mathrm{U}=0.3 \%$ (one with Pu-WG and one with Pu-RG); TD = $15.87 \mathrm{~g} / \mathrm{cm}^{3}$

- Six U-20Pu-10Zr fuels; two with $235 \mathrm{U} / \mathrm{U}=0.3 \%$ (one with Pu-WG and one with $\mathrm{Pu}-\mathrm{RG}$ ), two with $235 \mathrm{U} / \mathrm{U}=5 \%$ and two with ${ }^{235} \mathrm{U} / \mathrm{U}=10 \%$; TD $=15.77 \mathrm{~g} / \mathrm{cm}^{3}$

- Two U-11.5Pu-10Zr fuels with ${ }^{235} \mathrm{U} / \mathrm{U}=19.75 \%$ (one with $\mathrm{Pu}-\mathrm{WG}$ and one with $\mathrm{Pu}-\mathrm{RG}$ ); $\mathrm{TD}=15.64 \mathrm{~g} / \mathrm{cm}^{3}$

- Two U-10Zr fuels; one with ${ }^{235} \mathrm{U} / \mathrm{U}=19.75 \%$ and one with ${ }^{235} \mathrm{U} / \mathrm{U}=27 \%$; TD $=15.47 \mathrm{~g} / \mathrm{cm}^{3}$.

Irradiation-induced axial swellings of $6 \%$ and $4 \%$ were assumed for, respectively, U-10Zr and U-Pu-10Zr fuels.

- Four fuel assembly geometric configurations (Table 2.2) that are characterized by different fuel, coolant, and structure volume fractions were considered. Fuel and coolant volume fractions were chosen to cover configurations ranging from hydraulic-favorable (assemblies $A$ and $Z$, with high coolant volume fractions) to reactivity-favorable (assembly $\mathrm{C}$, with a high fuel volume fraction). Fuel pin diameters were adjusted accordingly. In terms of fuel and coolant volume fractions, the $A$ and $B$ assemblies are similar to, respectively, FFTF and PRISM, whereas the $C$ assemblies are closer to the Russian BOR-60 and BR-10 fast test reactors. The assembly $Z$ is a very hydraulic-favorable configuration with no actual existing equivalent (past or present). The cases presented here consider 271 fuel pins per assembly, but other numbers are possible (e.g., 217 and 169).

- Three active core heights were considered: $100 \mathrm{~cm}, 80 \mathrm{~cm}$, and $60 \mathrm{~cm}$. The fission gas plenum height is assumed to be equal to the active height, which is sufficient to accommodate up to a $10 \%$ peak burnup (Figure 2.1 ). These three active core heights cover a range of interest as expressed by potential users. Historically, most fast test reactors-e.g., EBR-II, JOYO, and BOR-60-have been characterized by active lengths of no more than 50 $\mathrm{cm}$; the MBIR fast test reactor currently under construction in Russia has a 55-cm active core height.

- Three numbers of in-core test positions were considered: 1, 4, and 7. The different layouts are shown in Figure 2.2; in order to carry out the trade study, these positions were selected to be as near the core center as possible,

${ }^{1}$ Reactor-grade plutonium comes with many different isotopic compositions, and this particular one was arbitrarily chosen. This plutonium was assumed to have no americium-241 in it, which means that either it was separated recently or that americium was removed from it. 
where the flux tends to be higher. Test positions were modeled as empty ducts containing $90 \%$ sodium $+10 \%$ $\mathrm{HT} 9$ with a $20-\mathrm{cm}$ reflector region at both the top and bottom $(80 \% \mathrm{HT} 9+20 \%$ sodium).

- Two average burnups at discharge were considered: $3 \%$ and $6 \%$. For higher average burnups at discharge, peak burnups may be higher than $10 \%$, which would be outside the preferred Technology Readiness Level (TRL) 8-9 range for the driver fuel [Carmack, 2017]. The number of cycles required to reach these burnups is calculated assuming 100-day cycles.

Table 2.2. Fuel assembly geometric data.

\begin{tabular}{|c|c|c|c|c|c|}
\hline & & A271 & B271 & C271 & Z271 \\
\hline \multicolumn{2}{|c|}{ Assembly pitch $(\mathrm{cm})$} & 12 & 12 & 12 & 12 \\
\hline \multicolumn{2}{|c|}{ Duct thickness $(\mathrm{cm})$} & 0.3 & 0.3 & 0.3 & 0.3 \\
\hline \multicolumn{2}{|c|}{ Assembly gap (cm) } & 0.3 & 0.3 & 0.3 & 0.3 \\
\hline \multicolumn{2}{|c|}{ Duct inside flat-to-flat $(\mathrm{cm})$} & 11.1 & 11.1 & 11.1 & 11.1 \\
\hline \multicolumn{2}{|c|}{ Pins per assembly } & 271 & 271 & 271 & 271 \\
\hline \multicolumn{2}{|c|}{ Pin diameter $(\mathrm{cm})$} & 0.53 & 0.56 & 0.59 & 0.48 \\
\hline \multirow{2}{*}{\multicolumn{2}{|c|}{$\begin{array}{c}\text { Clad thickness }(\mathrm{cm}) \\
\text { Wire wrap diameter }(\mathrm{cm})\end{array}$}} & 0.037 & 0.039 & 0.041 & 0.034 \\
\hline & & 0.126 & 0.098 & 0.070 & 0.173 \\
\hline \multicolumn{2}{|c|}{$\mathrm{p} / \mathrm{d}$} & 1.248 & 1.184 & 1.127 & 1.372 \\
\hline \multirow{4}{*}{$\begin{array}{c}\text { Fresh fuel } \\
\text { volume } \\
\text { fractions }\end{array}$} & Coolant & $39.83 \%$ & $35.33 \%$ & $30.26 \%$ & $46.03 \%$ \\
\hline & Fuel & $26.59 \%$ & $29.69 \%$ & $32.96 \%$ & $21.81 \%$ \\
\hline & Bond & $8.86 \%$ & $9.90 \%$ & $10.99 \%$ & $7.27 \%$ \\
\hline & Structure & $24.72 \%$ & $25.08 \%$ & $25.80 \%$ & $24.89 \%$ \\
\hline
\end{tabular}

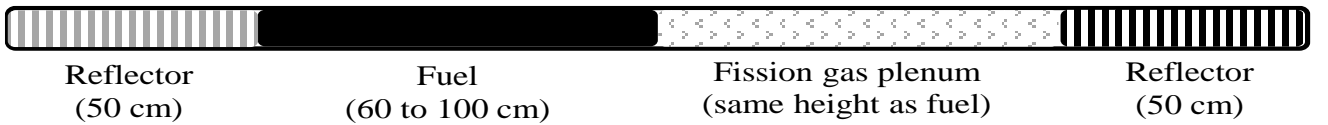

Figure 2.1. Fuel assembly axial components.

Fission gas plenum: $25 \%$ HT9 + 50\% sodium + 25\% void - Reflector: $70 \%$ HT9 + 30\% sodium

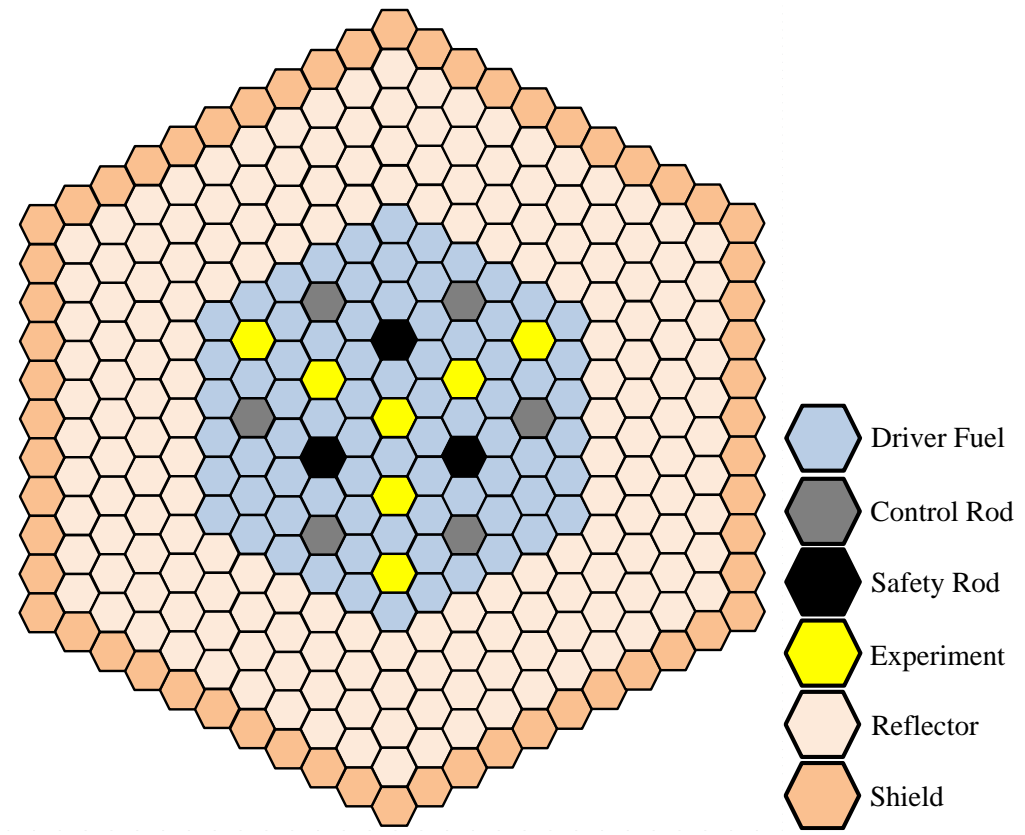

Figure 2.2. Example of a core layout with 75 fuel assemblies (actual number depends on the specific configuration). Configurations with 1, 4, and 7 test positions are obtained by adding them from the center to the periphery. 


\subsection{Design Constraints for Normal Operation}

In order to ensure the reactor is operated safely and efficiently, the design requirements discussed in this section were considered for this trade study. These values are solely used in the scope of the trade study and may be reviewed and adjusted later.

- Fuel smeared density: 75\% theoretical density

- The core reactivity is controlled with six primary control rods and three secondary safety rods. The rod locations are shown in Figure 2.2; these positions were arbitrarily selected to carry out the trade study and will need to be adjusted based on control and safety considerations (see Section 5.1).

- Sodium inlet and outlet temperatures: $350^{\circ} \mathrm{C}$ and $500^{\circ} \mathrm{C}$, i.e., representative values for sodium-cooled fast reactors. These are temperatures assumed only for this trade study. More detailed thermal and safety analyses will be required to converge on optimized values. Increasing this inlet-outlet sodium $\Delta T$ could be beneficial to increase the fast flux level by allowing increasing power density without increasing sodium velocity.

- Peak cladding temperature $\leq 650^{\circ} \mathrm{C}$. The peak cladding temperature is mostly dependent on the sodium outlet temperature. At this stage, no detailed thermal calculations and no orificing optimization have been performed, but based on experience, it is known that a $500^{\circ} \mathrm{C}$ average sodium outlet temperature will ensure the peak cladding temperature requirement is met, provided the fuel assembly is properly designed.

- Peak fuel temperature $\leq 1,121^{\circ} \mathrm{C}$ for $\mathrm{U}-20 \mathrm{Pu}-10 \mathrm{Zr}$ and $\leq 1,248^{\circ} \mathrm{C}$ for $\mathrm{U}-10 \mathrm{Zr}$. The peak linear power assumed for this parametric study $(450 \mathrm{~W} / \mathrm{cm}$, see below) should be low enough to meet this requirement with some margin. Indeed, using the fuel thermal conductivity presented in Appendix 3 [Billone, 1986], it can be shown that the linear powers corresponding to these fuel centerline temperatures (i.e., the linear power to melting) is about $970 \mathrm{~W} / \mathrm{cm}$ for U-20Pu-10Zr and higher than 1,000 W/cm for U-10Zr. The melting temperature for U-27Pu-10Zr is lower, about $1,000^{\circ} \mathrm{C}$, and consequently the linear-power-to-melting is also lower, about $600 \mathrm{~W} / \mathrm{cm}$.

- Peak pin linear power initially assumed to be $\leq 450 \mathrm{~W} / \mathrm{cm}$ but higher might be feasible with proper assembly design. Given that most operating experience with metallic fuel has been in EBR-II (and to a lesser extent, in FFTF), with peak linear powers in the 350-450 W/cm range [Crawford, 2007], this parametric study assumed 450 $\mathrm{W} / \mathrm{cm}$ as the maximum allowable fuel pin linear power. For a U-20Pu-10Zr fuel, a $450 \mathrm{~W} / \mathrm{cm}$ peak linear power corresponds to a peak fuel centerline temperature of about $840-860^{\circ} \mathrm{C}$, depending on the actual power distribution (Appendix 3). From a fuel temperature point of view, higher linear powers may be possible. More detailed thermal and safety analyses will be required to converge on a more precise value specific to the design under consideration.

- Nominal (i.e., without uncertainties) fuel bundle pressure drop $(\Delta p) \leq 0.5 \mathrm{MPa}$. Detailed analyses will be needed to ensure natural circulation can be established under acceptable temperature conditions, and that duct integrity is ensured during normal operation.

- Sodium velocity $\leq 12 \mathrm{~m} / \mathrm{s}$. Coolant velocity must be less than the limits dictated by flow-induced vibration, cavitation, and corrosion-erosion considerations. For FFTF and CRBR, these were conservatively established at $30 \mathrm{ft} / \mathrm{s}(9 \mathrm{~m} / \mathrm{s})$ for non-replaceable components, $40 \mathrm{ft} / \mathrm{s}(12 \mathrm{~m} / \mathrm{s})$ for replaceable components in the high-temperature low-pressure region, and $50 \mathrm{ft} / \mathrm{s}(15 \mathrm{~m} / \mathrm{s})$ for replaceable components in the low-temperature, high-pressure, or inlet region [Tang, 1978]. For the cases analyzed in this trade study, satisfying the limiting fuel bundle pressure drop (0.5 MPa) requirement ensures this requirement is also met. Indeed, sodium velocities between $8 \mathrm{~m} / \mathrm{s}$ and $10 \mathrm{~m} / \mathrm{s}$ were obtained for all configurations analyzed. 


\subsection{Computer Codes}

\subsection{1 $\mathrm{MC}^{2}-3$}

The MC2-3 code [Brunett, 2017] is a multigroup cross-section generation code for fast reactor analysis, developed by improving the resonance self-shielding and spectrum calculation methods of MC2-2 and integrating the onedimensional cell calculation capabilities of SDX. The code solves the consistent P1 multigroup transport equation using basic neutron data from ENDF/B-VII.1 data files to determine the fundamental mode spectra for use in generating multigroup neutron cross-sections. A homogeneous medium or a heterogeneous slab or cylindrical unit cell problem is solved in ultrafine $(\sim 2000)$ or hyperfine $(\sim 400,000)$ group levels. In the resolved resonance range, pointwise cross-sections are reconstructed with Doppler broadening at specified isotopic temperatures. The pointwise cross-sections are directly used in the hyperfine group calculation, whereas for the ultrafine group calculation, self-shielded cross-sections are prepared by numerical integration of the pointwise cross-sections based upon the narrow resonance approximation. The MC2-3 code produces a broad group set of multi-group cross-sections usable in conventional homogenized diffusion or transport paradigms, such as DIF3D. There is a considerable validation history showing both MC2-2 and MC2-3 can be used to produce cross-sections for models of fast spectrum reactor experiments and reactors that accurately predict reaction rate and eigenvalue measurements.

\subsubsection{DIF3D}

DIF3D [Brunett, 2017] provides the steady state neutron particle (neutron/gamma) flux for generic structured grid problems. Its primary use is for nuclear reactor analysis, and it contains diffusion, SPN, and PN transport solvers of the neutral particle transport equation. Both forward and adjoined multi-group flux solutions are provided by all solvers in DIF3D. DIF3D-FD is based upon a finite difference approximation of the diffusion equation and can be applied to one-, two-, and three-dimensional orthogonal (rectangular and cylindrical) and triangular geometry grids. DIF3D-Nodal is based upon the transverse integrated diffusion equation and can be applied to two- and three-dimensional Cartesian and hexagonal geometries. DIF3D-VARIANT is based upon a hybrid finite element method and allows both SPN and PN angular approximations to be combined with regular refinements in orthogonal spatial basis functions. DIF3D-VARIANT can be applied to two- and three-dimensional Cartesian and hexagonal geometries.

\subsubsection{REBUS}

REBUS [Brunett, 2017] is a code to model the fuel cycle of fast reactors and is built around the DIF3D capability. The REBUS software models conventional non-equilibrium reactor modes, but also repetitive fuel cycle operations, and has a search procedure to find the equilibrium cycle. REBUS allows users to model broader-scope fuel cycle analysis aspects, such as fuel fabrication, fuel recycle, fuel shuffling, and fuel storage. For recycling, the user can input multiple feed enrichments and fuel compositions, along with defining multiple paths for fuel discharge and recycle appropriate for different fuels (thorium, uranium, and plutonium dominated) where each recycle plant can have its own separation efficiency. It includes search constraints on eigenvalue, control poison, control rod, cycle length, fuel enrichment, and core geometry. The depletion chain is user-defined to allow maximum flexibility in selecting which isotopes are important and how they are tracked.

\subsubsection{SuperEnergy2-ANL}

SuperEnergy2-ANL [Brunett, 2017] is a steady-state thermal hydraulics code used to optimize flow orificing in sodium-cooled fast reactors. It assumes a hexagonal lattice of ducted fuel assemblies with wire-wrapped fuel pins. It is loosely based upon a porous body medium model and uses correlations based upon experimental measurements of wire-wrapped pin bundles to predict the pressure drop and mixing with each assembly. It has radial conduction models to handle the bypass flow and heat transfer between adjacent assemblies with different temperatures. SuperEnergy2-ANL imports DIF3D (neutron and gamma) power profile information and produces peak cladding and fuel pellet temperatures in each fuel assembly bundle. 


\subsubsection{PERSENT}

The PERSENT code (PERturbation and SENitivity for Transport) [Brunett, 2017] is based upon the variational nodal method employed in DIF3D-VARIANT. PERSENT provides perturbation theory calculation options for generating the spatial breakdown of reactivity coefficients, such as Doppler, and computing the LAMBDA and BETA kinetics parameters. PERSENT also provides a linear sensitivity calculation capability and uncertainty quantification utility for computing the total uncertainty in a parameter (such as k-effective or BETA) associated with crosssection uncertainties.

\subsubsection{ERANOS}

ERANOS [Ruggieri, 2006] has been developed and validated with the aim of providing a suitable basis for reliable neutronic calculations of currents as well as advanced fast reactor cores. It consists of data libraries, deterministic codes and calculation procedures that have been developed within the European Collaboration on Fast Reactors over approximately the past 20 years. This is intended to answer the needs of both industrial and R\&D organizations.

The main contents of the ERANOS-2.3 package are: nuclear data libraries based on JEF or ENDF nuclear data evaluated files, a cell and lattice code (ECCO), reactor flux solvers (diffusion, Sn transport, and nodal variational transport), a burn-up module, various processing modules (e.g., material and neutron balance and breeding gains), tools related to perturbation theory and sensitivity analysis, and a fine burn-up analysis subset named MECCYCO (mass balances, activities, decay heat, and dose rates). Coupled neutron/gamma calculations are also possible using specific libraries.

The ECCO cell/lattice code in the ERANOS-2.3 package uses the subgroup method to treat resonance selfshielding effects. ECCO prepares self-shielded cross-sections and matrices by combining a slowing-down treatment in many groups (1,968 groups) with the subgroup method within each fine group. The subgroup method takes into account the resonance structure of cross-sections by means of probability tables and by assuming that the neutron source is uniform in lethargy within a given fine group. Flux calculations in heterogeneous geometry are performed by means of the collision probability method.

In the reference calculation scheme, ECCO treats the heterogeneous geometry in fine groups $(1,968)$ for the most important nuclides, while broad group libraries (33 or 172 groups) are used for the less important nuclides. These calculations are very accurate as the fine group plus sub-group schemes have been set up to accurately represent the reaction thresholds and the resonances in any situation, narrow or wide. Self-shielded cross-sections and matrices are condensed and smeared to provide effective cross-sections and matrices in the user required broad group scheme. The neutron balance is preserved in ECCO after condensation and smearing. The effective crosssections and matrices produced by ECCO are subsequently used in full-core ERANOS calculations.

\section{Core Sizes and Fast Flux Levels}

\subsection{Methodology}

Given the above fuel assembly geometric data in Table 2.2, as well as the Cheng-Todreas pressure drop correlation (Appendix 1) [Cheng, 1986] implemented in most sub-channel codes, such as SE2-ANL, the sodium velocity satisfying the peak linear power and fuel bundle pressure drop requirements-or at least the most penalizing -is calculated for each assembly configuration resulting from the combinations of volume fractions (i.e., the A, B, and $\mathrm{C}$ assembly configurations) and fuel pin heights (active heights $=100,80$, and $60 \mathrm{~cm}+$ fission gas plenum). Once this maximum sodium velocity (in $\mathrm{m} / \mathrm{s}$ ) is known, the maximum sodium mass flow ( $\dot{m}$ in $\mathrm{kg} / \mathrm{s}$ ) can be calculated, and from that, the maximum assembly power $\left(P=\dot{m} C_{p} \Delta T\right)$. Since the number of fuel pins and the active height is known, the average linear power in the hottest assembly is readily calculated. Furthermore, assuming a peaking factor of 1.25 - mostly axial - within the hottest assembly, the peak linear power is also readily calculated. Note 
that actual peaking factors can vary between 1.1 and 1.4 depending on, for example, core active height or control rod position; more detailed calculations are necessary to obtain case-specific peaking factors.

This simple approach proved a very useful way to frame the neutronics calculations by allowing calculation of the maximum assembly power, not to be exceeded as a function of the assembly type and fuel height (Table 3.1), and consequently, to normalize the core power for each core configuration. In order to ensure a consistent comparison of the various cores, the neutronics parametric calculations reproduced the maximum assembly powers; this way, all the configurations satisfy the thermal hydraulic design constraints considered here-pressure drop and linear power. Table 3.1 also shows, for each configuration, the average fuel power density in the assembly characterized by the highest power; everything else being held constant, the fast neutron flux level is proportional to the power density. As mentioned in the previous section, all cases presented here are for 271 fuel pins per assembly, but other numbers, such as 217 and 169, are also possible; Appendix 2 presents some thermal hydraulic results obtained with different pin numbers.

Table 3.1. Maximum assembly power not to be exceeded as a function of the assembly type and fuel height

\begin{tabular}{|c|c|c|c|c|c|c|}
\hline $\begin{array}{c}\text { Assembly } \\
\text { type }\end{array}$ & $\begin{array}{l}\text { Fuel height } \\
\text { (cm) }\end{array}$ & $\begin{array}{l}\text { Max. Passembly } \\
\text { (MW) }\end{array}$ & $\begin{array}{l}\text { Fuel bundle } \Delta p \\
\quad(\mathrm{MPa})\end{array}$ & $\begin{array}{c}\text { Peak LHR* }^{\star} \\
(\mathrm{W} / \mathrm{cm})\end{array}$ & $\begin{array}{c}\text { Limiting } \\
\text { characteristic }\end{array}$ & $\begin{array}{l}\text { Power density } \\
\left.\text { (W/cm }^{3} \text {-fuel }{ }^{\star *}\right)\end{array}$ \\
\hline A271 & 100 & 6.3 & 0.50 & 292 & $\Delta p$ & 1430 \\
\hline A271 & 80 & 7.2 & 0.50 & 416 & $\Delta p$ & 2030 \\
\hline A271 & 60 & 5.8 & 0.26 & 450 & LHR & 2210 \\
\hline B271 & 100 & 5.1 & 0.50 & 233 & $\Delta p$ & 1025 \\
\hline B271 & 80 & 5.8 & 0.50 & 332 & $\Delta p$ & 1455 \\
\hline B271 & 60 & 5.8 & 0.37 & 450 & LHR & 1970 \\
\hline C271 & 100 & 3.7 & 0.50 & 172 & $\Delta p$ & 680 \\
\hline $\mathrm{C} 271$ & 80 & 4.2 & 0.50 & 245 & $\Delta p$ & 960 \\
\hline C271 & 60 & 5.0 & 0.50 & 387 & $\Delta p$ & 1530 \\
\hline Z271 & 100 & 8.2 & 0.50 & 378 & $\Delta p$ & 2255 \\
\hline Z271 & 80 & 7.8 & 0.36 & 450 & LHR & 2690 \\
\hline Z271 & 60 & 5.9 & 0.27 & 450 & LHR & 2690 \\
\hline
\end{tabular}

* Assumes a peaking factor equal to 1.25 .

** Average power density in the assembly characterized by the highest power. Fuel volume is defined as the volume inside the cladding.

For a given configuration, the inlet-outlet sodium $\Delta \mathrm{T}$ is proportional to the sodium velocity, whereas the pressure drop $\Delta p$ increases approximately as the square of the sodium velocity. Hence, the same assembly power and fuel power density —and consequently, fast flux level—could be obtained with different combinations of $\Delta T$ and $\Delta p$. For example, the combinations $\left\{160^{\circ} \mathrm{C} ; 0.44 \mathrm{MPa}\right\}$ and $\left\{170^{\circ} \mathrm{C} ; 0.39 \mathrm{MPa}\right\}$ would provide the same fuel power density as the reference $\left\{150^{\circ} \mathrm{C} ; 0.50 \mathrm{MPa}\right\}$ combinations shown in Table 3.1. Indeed, for the same assembly power, increasing $\Delta \mathrm{T}$ from $\Delta \mathrm{T}_{1}$ to $\Delta \mathrm{T}_{2}$ allows a decrease in the sodium velocity from $\mathrm{V}_{1}$ to $\mathrm{V}_{2}=\left(\Delta \mathrm{T}_{1} / \Delta \mathrm{T}_{2}\right) \times \mathrm{V}_{1}$; consequently, the pressure drop decreases from $\Delta \mathrm{p}_{1}$ to $\Delta \mathrm{p}_{2} \sim\left(\Delta \mathrm{T}_{1} / \Delta \mathrm{T}_{2}\right)^{2} \times \Delta \mathrm{p}_{1}$.

\subsection{Discussion}

As evidenced in Table 3.1, the $0.5 \mathrm{MPa}$ pressure drop limit requirement proves to be the most limiting with regard to increasing the core specific power, and with it, fast flux level. Except for the $Z$ assembly, only the $60-\mathrm{cm}$-high configurations can reach the fuel full potential for providing neutrons by reaching the assigned maximum linear power $(450 \mathrm{~W} / \mathrm{cm})$ before reaching the $0.5 \mathrm{MPa}$ pressure drop limit. Table 3.2 shows the impact of increasing the assembly power to the point at which the sodium velocity generates a pressure drop of $0.5 \mathrm{MPa}$ for the $60-\mathrm{cm}$ configurations $(11-12 \mathrm{~m} / \mathrm{s})$. For example, the power densities presented in Table 3.2 indicate that it may be 
possible to increase the fast flux in a core using $60-\mathrm{cm}$ A271 assemblies by about $44 \%$ (3185/2205) by increasing the power-and sodium velocity - until the pressure drop reaches $0.5 \mathrm{MPa}$. In this case-assuming a peaking factor of 1.25-the peak linear power would reach about $650 \mathrm{~W} / \mathrm{cm}$, and the peak fuel centerline temperature would reach about $960-980^{\circ} \mathrm{C}$ (without uncertainties, i.e., still about $140-160^{\circ} \mathrm{C}$ below the $\mathrm{U}-20 \mathrm{Pu}-10 \mathrm{Zr}$ solidus temperature).

Table 3.2. Impact of increasing fuel bundle pressure drop up to $0.5 \mathrm{MPa}$ on linear power

\begin{tabular}{|c|c|c|c|c|c|}
\hline $\begin{array}{l}\text { Assembly } \\
\text { type }\end{array}$ & $\begin{array}{l}\text { Fuel height } \\
\text { (cm) }\end{array}$ & $\begin{array}{l}\text { Max. Passembly } \\
\text { (MW) }\end{array}$ & $\begin{array}{l}\text { Fuel bundle } \Delta p \\
\text { (MPa) }\end{array}$ & $\begin{array}{l}\text { Peak LHR }{ }^{*} \\
(\mathrm{~W} / \mathrm{cm})\end{array}$ & $\begin{array}{l}\text { Power density } \\
\left(\text { W/cm } \text { cm }^{3} \text {-fuel }{ }^{\star \star}\right)\end{array}$ \\
\hline \multirow{2}{*}{ A271 } & \multirow{2}{*}{60} & 5.8 & 0.26 & 450 & 2205 \\
\hline & & 8.4 & 0.50 & 650 & 3185 \\
\hline \multirow{2}{*}{ B271 } & \multirow{2}{*}{60} & 5.8 & 0.37 & 450 & 1965 \\
\hline & & 6.9 & 0.50 & 530 & 2325 \\
\hline \multirow{2}{*}{ C217 } & \multirow{2}{*}{60} & 4.7 & 0.35 & 450 & 1425 \\
\hline & & 5.7 & 0.50 & 545 & 1725 \\
\hline \multirow{2}{*}{ Z271 } & \multirow{2}{*}{60} & 5.9 & 0.27 & 450 & 2690 \\
\hline & & 7.9 & 0.50 & 605 & 3605 \\
\hline \multirow{2}{*}{ Z271 } & \multirow{2}{*}{80} & 7.8 & 0.36 & 450 & 2690 \\
\hline & & 9.3 & 0.50 & 535 & 3200 \\
\hline
\end{tabular}

* Assumes a peaking factor equal to 1.25.

** Average power density in the assembly characterized by the highest power. Fuel volume is defined as the volume inside the cladding.

\subsection{Results}

For each of the permutations presented in Section 2.1 (assembly type, fuel height, number of test locations, and average discharge burnup) the various types and concentrations of fissile materials have been explored. For each case, the minimum number of fuel assemblies required to make the core critical is determined, and the power level is adjusted so as not to exceed the maximum assembly power provided in Table 3.1. The number of batches is adjusted so as to yield a cycle length as close as possible to 100 effective full-power days (EFPD) while achieving the target average burnup. This is an iterative process, since changing the number of batches affects the average burnup (i.e., composition) of the fuel present in the core, as well as the number of fuel assemblies needed to make the core critical for a given fissile type and concentration. For most of the cases, it took between five and 10 iterations to obtain the so-called converged configuration.

Given the large number of cases studied, only a summary of the results is provided here. Detailed results for all cases are provided in Appendix 6. The most important results obtained from this trade study are the achievable peak fast flux as a function of the core power for the different fissile material and concentrations considered. These results are illustrated in Figure 3.1, in which the curves shown represent the general trend observed for each fuel considered. The results shown in Figure 3.1 are for reactor-grade plutonium, the composition of which was provided in Table 2.1. It is important to note that the actual data can be significantly scattered and does not fit perfectly on the curve, as illustrated in Figure 3.2a for the fuel containing $20 \%$ plutonium (RG) and natural uranium. When different flux levels are shown for a similar core power, this is due to using a different assembly type, fuel height, number of test locations, and/or average discharge burnup. When fewer parameters are included, the scatter is significantly reduced (Figure 3.2b). For clarity, only trend lines are shown throughout this report, but all results are in fact a collection of scattered data points. 


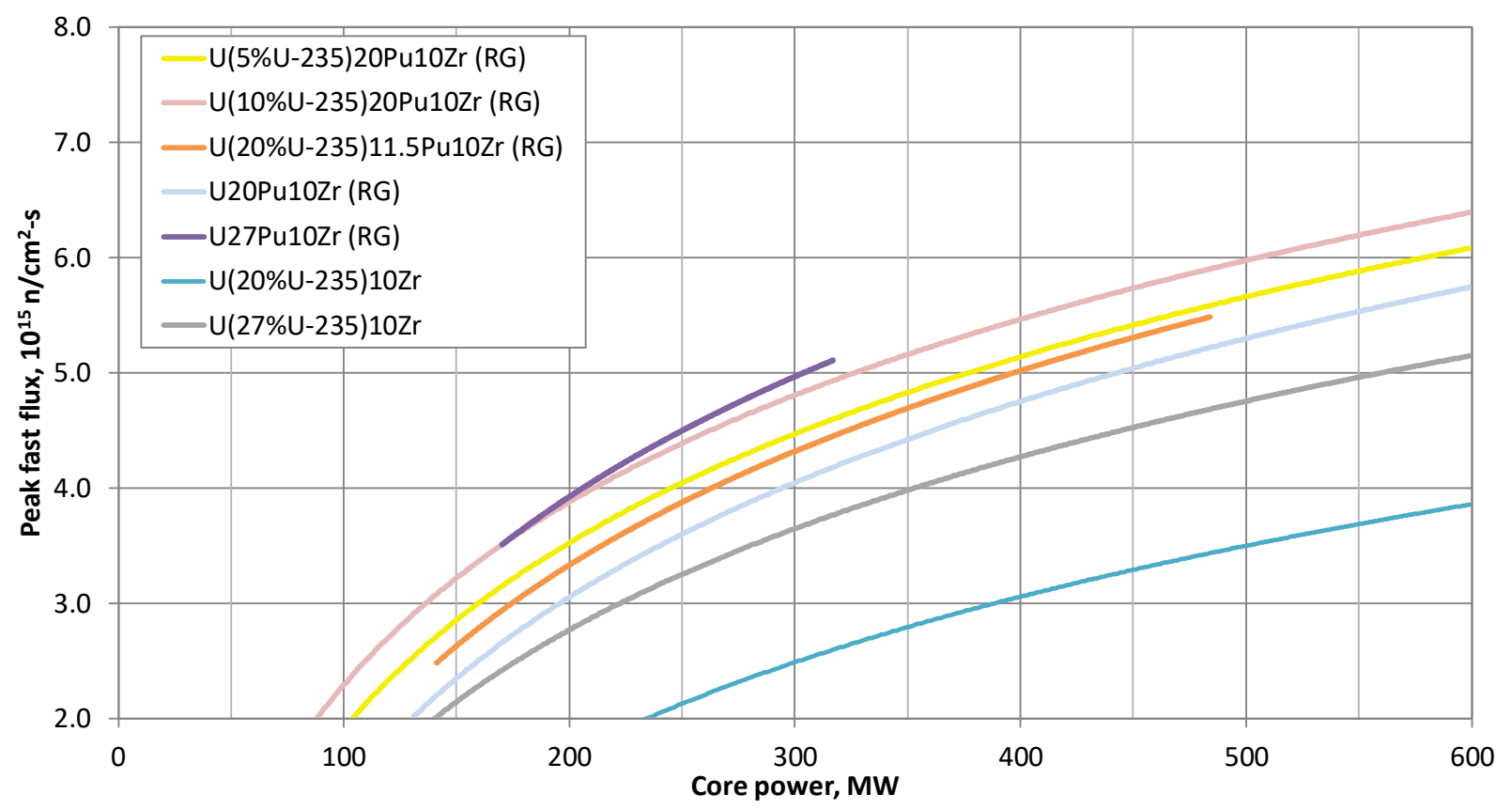

Figure 3.1: Peak fast flux vs. core power for various fissile type and concentrations.

The general observation from these results is that fuels containing more fissile material are able to achieve higher peak fast flux levels for a given core power. This must not be confused with the fact that, for a given configuration (i.e., active core height, assembly type, number of test locations, and fuel burnup), fuels containing a lower concentration of fissile material will give a higher flux level [Heidet, 2017]. They will, however, require more fuel assemblies to make the core critical, therefore resulting in a larger core size and power. In addition, fissile plutonium is a better fissile material than ${ }^{235} \mathrm{U}$ and allows higher peak fast flux levels for a given core power.

With the exception of the LEU fuel, critical core configurations can be achieved for all fuels for power levels lower than $100 \mathrm{MW}_{\text {th. }}$. For LEU fuel, the minimum size to make the core critical for the active fuel heights considered corresponds to about $230 \mathrm{MW}_{\text {th. }}$. These power levels are obtained by adjusting the core power so as to achieve the maximum assembly power, and therefore, the maximum fast flux level for a given configuration. For all cases, the power level could be derated, but the fast flux level being directly proportional to the power level, this would mean reducing the achievable fast flux.

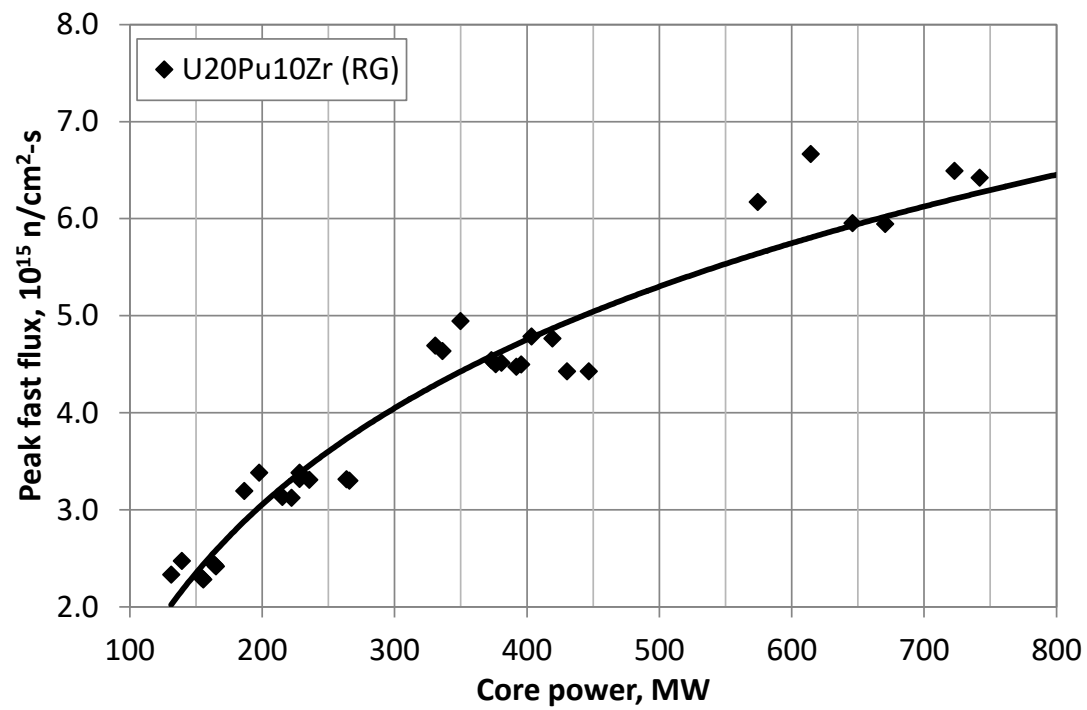

(a) 


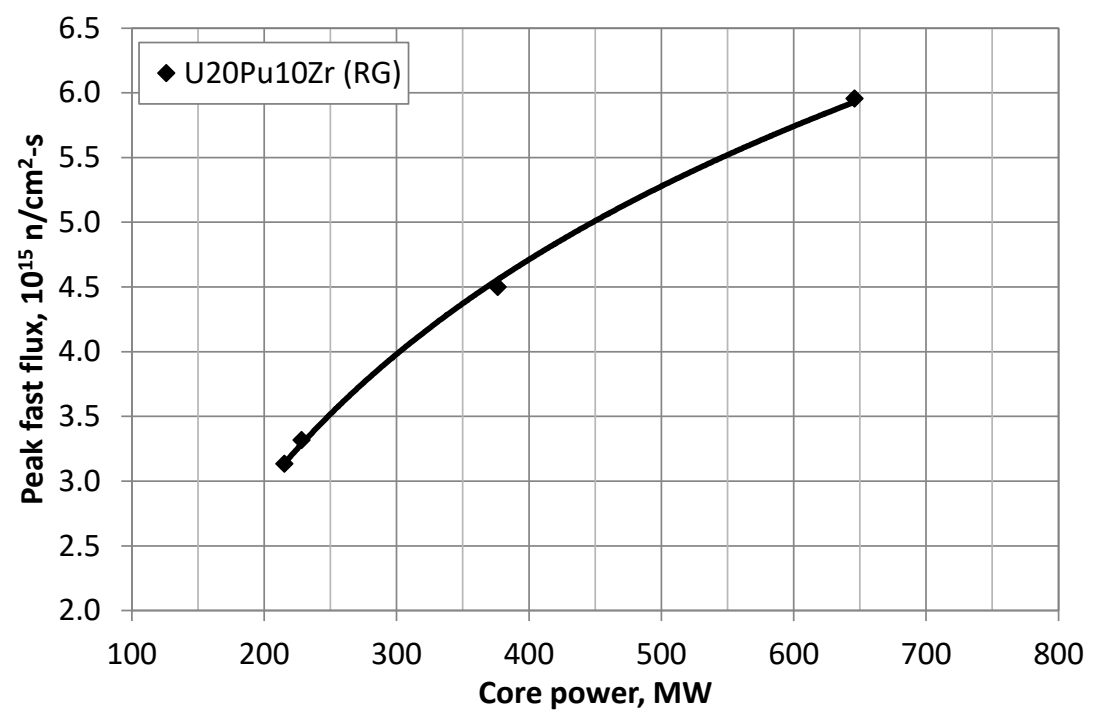

(b)

Figure 3.2: Data distribution and matching trend line for U20Pu10Zr (RG).

(a) includes results for all configurations, i.e., four assembly types (A, B, C, and Z), three core heights (60, 80, and $100 \mathrm{~cm}$ ), $3 \%$ and $6 \%$ burnup, and 1-4-7 test locations; (b) includes only results for the $80-\mathrm{cm}$ high, $6 \%$

burnup, and four test location configurations

\subsubsection{Flux Level Vs. Specific Power}

The relation between power and flux is very simple and is expressed by Equation (1), where $E_{f}$ is the energy released per fission, $\mathrm{N}_{\mathrm{f}}$ is the concentration of fissile atoms $(\mathrm{at} / \mathrm{b}-\mathrm{cm}), \phi$ is the flux, $\sigma_{\mathrm{f}}$ is the fission cross-section, and $V$ is the volume of interest. $E_{f}$ is effectively constant, and Equation (1) can be rewritten as Equation (2). The atomic mass, $A$, and Avogadro's number, $N_{A}$, are constants being introduced, making the left-hand term of this equation become the fissile specific power ( $\left.\mathrm{W} / \mathrm{g}_{\text {fissile }}\right)$.

$$
\begin{gathered}
P \propto \phi * \sigma_{\mathrm{f}} * N_{f} * E_{f} * V \\
\frac{P}{N_{f}\left[\frac{a t}{\mathrm{~cm}^{3}}\right] * V\left[\mathrm{~cm}^{3}\right] * \frac{A\left[\frac{g}{\mathrm{~mol}}\right]}{N_{A}\left[\frac{a t}{m o l}\right]}} \propto \phi * \sigma_{\mathrm{f}}
\end{gathered}
$$

When looking at a single fissile type and concentration at a time, focusing only on the 6\% FIMA cases, the fraction of fissile material in the fuel is about the same for the various assembly types and core heights considered, making it possible to use the fuel specific power in Equation (2) instead of the fissile specific power, which gives Equation (3) where SP is the specific power. As shown, the flux also depends on the inverse of the fission cross-section, meaning that differences in spectrum will affect the flux level achieved. However, in fast spectrum systems, crosssections have only limited sensitivity to small spectral changes. Therefore, as a first order approximation, the achievable flux level is directly proportional to the specific power.

$$
\phi \propto \frac{S P}{\sigma_{\mathrm{f}}}
$$

Figure 3.3 shows the peak achievable fast flux over a $20 \mathrm{~cm}$ axial section of the central test location, as a function of the specific power. As shown by the trend lines, the relationship is nearly linear, as expected. The small divergence from being perfectly linear can be attributed to (1) the slight spectral difference for different core configurations (active core height and number of fuel assemblies), and (2) the slightly different fuel compositions, which was assumed to be identical in Equation (2). 


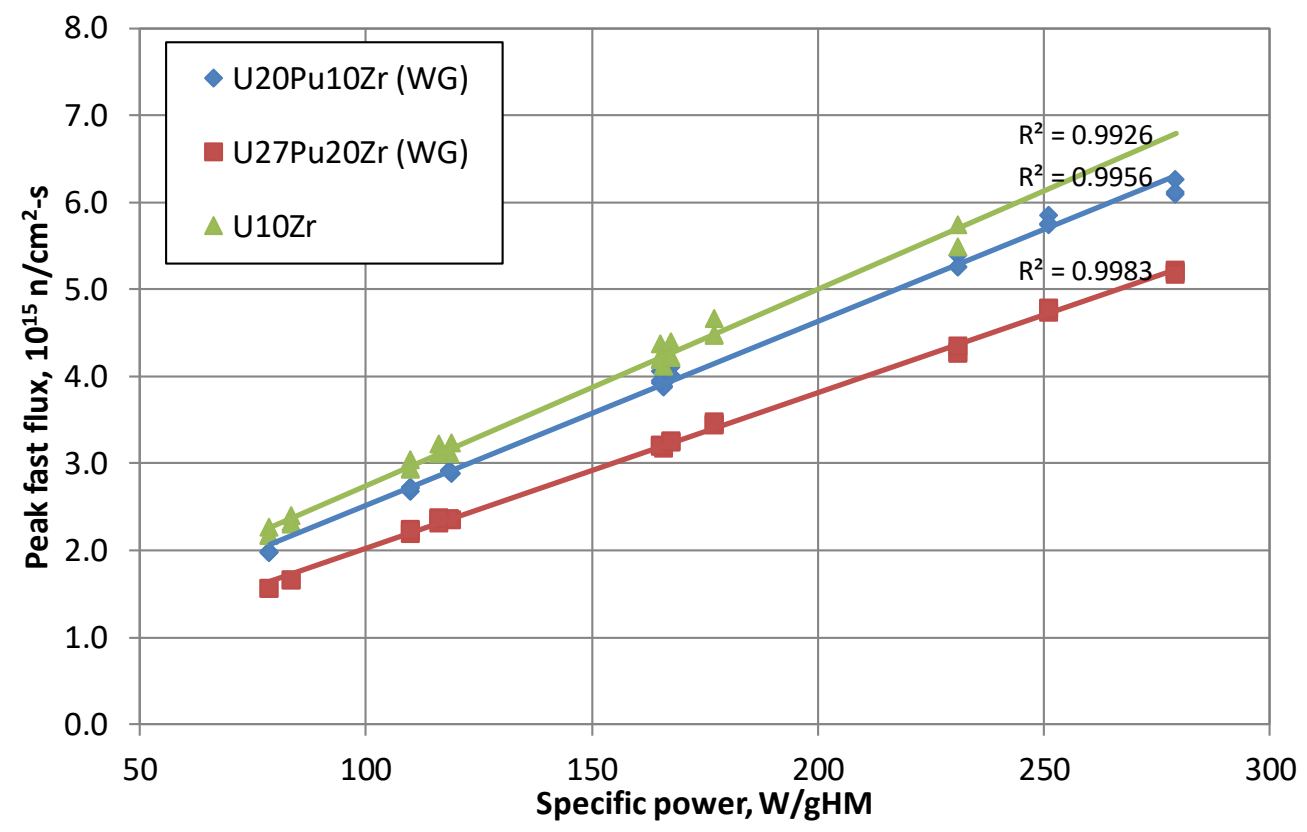

Figure 3.3: Achievable peak fast flux as a function of the specific power for various fissile types/concentrations

For a given fuel enrichment, if an increase in core power (i.e., core size) is obtained by simply adding more fuel assemblies of the same design (i.e., same fuel volume fraction) the flux level will not increase because the specific power will remain unchanged. On the other hand if an increase in core power is obtained (1) by redesigning the fuel assembly so that the fuel volume fraction is reduced and (2) by increasing core size to decrease neutron leakage, experience shows that the flux level can be increased. The reason is that the increase in core size necessary to compensate for the decreased fuel volume fraction (i.e., to maintain criticality) is slower than the decrease of the fuel volume itself, hence the specific power increases.

At a given power level (i.e., core size) a higher enrichment allows criticality at a lower fuel volume fraction hence the specific power is increased. Furthermore, experience shows that a fuel assembly can be designed so that the higher specific power dominates the change in enrichment (with higher fission cross-section) resulting in a higher flux level.

\subsubsection{Impact of Active Core Height}

The choice of a core active height—or a height-over-diameter ratio-impacts both neutronics and thermal hydraulics.

Impact on neutronics. For a given core volume, the critical mass is smallest for cores characterized by a heightover-diameter ratio close to unity. The more the core shape departs from this ratio, the larger the critical mass, i.e., either the fuel volume fraction and/or the core volume must be increased. The reason is that when the core departs from a height-over-diameter ratio close to unity-for a given core volume-the surface-to-volume ratio increases and, with it, neutron leakage. Hence, if the height-over-diameter ratio of a given configuration is higher than 1 , decreasing the core height will decrease the critical mass, whereas if it is already lower than one, decreasing the core height further will increase the critical mass.

Impact on thermal hydraulics. The impact of core height on thermal hydraulics is demonstrated in Table 3.1. For a given pressure drop, decreasing the core height allows increasing the sodium velocity and, consequently, linear power-or, what is equivalent, specific power. This leads to an increase in neutron flux. When the core is short enough that the fuel linear power-or, what is equivalent, fuel temperature-has reached its upper limit, there is no more incentive to decrease the core height further, as it will not lead to any further increase in neutron flux. 
For all assembly types, reducing the active core height from $100 \mathrm{~cm}$ to $80 \mathrm{~cm}$ allows for achieving a larger maximum power per assembly. This, in addition to the larger number of fuel assemblies, results in a larger core power when reducing the active fuel height (and without changing the assembly type). Reducing the core height further from $80 \mathrm{~cm}$ to $60 \mathrm{~cm}$, the maximum assembly power is reduced because of the maximum linear power being reached. Although this tends to reduce the core power, the increase in the number of fuel assembly remains the dominant effect and an overall increase of core power is observed when reducing the active fuel height. Some values are provided in Table 3.3 for cases with 6\% FIMA and four test locations.

As the core height is reduced, if the assembly power and assembly type (i.e., fuel volume fraction) was unchanged, the specific power would be increased, and the resulting flux levels would be increased accordingly. For instance, looking in Table 3.3 at assembly type A271 for active core heights of $100 \mathrm{~cm}$ and $60 \mathrm{~cm}$, the maximum assembly power is changed by only $\sim 8 \%$, but the fast flux level is increased by about $33 \%$. This is consistent with the reduction of the fuel volume in a given assembly of $40 \%$.

The change of the active core height has a direct impact of the flux axial distribution. The normalized axial flux distribution is shown in Figure 3.4 for the central test assembly, for a representative case using active core lengths of $60 \mathrm{~cm}, 80 \mathrm{~cm}$ and $100 \mathrm{~cm}$. This shows that if the same peak fast flux is obtained regardless of the core height, a longer effective irradiation length can be achieved. For instance, if interested in the length where the fast flux is at least $10 \%$ of the peak value, the $60 \mathrm{~cm}, 80 \mathrm{~cm}$, and $100 \mathrm{~cm}$ core configurations have effective irradiation lengths of $125 \mathrm{~cm}, 145 \mathrm{~cm}$, and $155 \mathrm{~cm}$, respectively.

However, as shown in Figure 3.1 and in Table 3.3, the peak fast flux achievable with different fissile types and concentrations is not always the same. Using the values from Table 3.3 from the U20Pu10Zr (RG) cases (with the B271 assembly type), the axial flux distribution is shown in Figure 3.5 for the different core height considered. Because a larger peak fast flux can typically be achieved with a shorter active core height, the length over which a given flux level is achieved (e.g., $10^{15} \mathrm{n} / \mathrm{cm}^{2}$-s) is about the same for the different active core heights considered. It is important to note that this observation is made for cores of different power levels, as shown in Table 3.3.

Table 3.3: Important configuration parameters for selected fissiles (6\% FIMA and four test locations)

\begin{tabular}{|c|c|c|c|c|c|c|c|c|c|}
\hline & \multicolumn{3}{|c|}{ A271 } & \multicolumn{3}{|c|}{ B271 } & \multicolumn{3}{|c|}{$\mathrm{C} 271$} \\
\hline & $60 \mathrm{~cm}$ & $80 \mathrm{~cm}$ & $100 \mathrm{~cm}$ & $60 \mathrm{~cm}$ & $80 \mathrm{~cm}$ & $100 \mathrm{~cm}$ & $60 \mathrm{~cm}$ & $80 \mathrm{~cm}$ & $100 \mathrm{~cm}$ \\
\hline & \multicolumn{9}{|c|}{ U20Pu10Zr (RG) } \\
\hline Number of assemblies & 200 & 120 & 90 & 140 & 86 & 69 & 100 & 67 & 54 \\
\hline Core power, $\mathrm{MW}_{\text {th }}$ & 893 & 646 & 430 & 623 & 376 & 264 & 381 & 215 & 154 \\
\hline Max. assy. power, $\mathrm{MW}_{\text {th }}$ & 5.85 & 7.21 & 6.34 & 5.85 & 5.76 & 5.06 & 5.03 & 4.25 & 3.73 \\
\hline \multirow[t]{2}{*}{ Peak fast flux, $10^{15} \mathrm{n} / \mathrm{cm}^{2}-\mathrm{s}$} & 5.88 & 5.96 & 4.43 & 5.59 & 4.50 & 3.32 & 4.52 & 3.13 & 2.30 \\
\hline & \multicolumn{9}{|c|}{$\mathrm{U}(5 \% \mathrm{U}-235) 20 \mathrm{Pu} 10 \mathrm{Zr}$ (RG) } \\
\hline Number of assemblies & 130 & 81 & 65 & 95 & 62 & 49 & 71 & 47 & 38 \\
\hline Core power, $\mathrm{MW}_{\text {th }}$ & 577 & 450 & 316 & 422 & 273 & 197 & 269 & 157 & 115 \\
\hline Max. assy. power & 5.85 & 7.21 & 6.34 & 5.85 & 5.76 & 5.06 & 5.03 & 4.25 & 3.73 \\
\hline \multirow[t]{2}{*}{ Peak fast flux } & 5.45 & 5.50 & 4.07 & 5.15 & 4.12 & 3.05 & 4.16 & 2.84 & 2.10 \\
\hline & \multicolumn{9}{|c|}{$\mathrm{U}(20 \% U-235)-10 \mathrm{Zr}$} \\
\hline Number of assemblies & n.a. & n.a. & 182 & n.a. & 190 & 135 & n.a. & 143 & 103 \\
\hline Core power, $\mathrm{MW}_{\text {th }}$ & n.a. & n.a. & 835 & n.a. & 800 & 501 & n.a. & 446 & 286 \\
\hline Max. assy. power & n.a. & n.a. & 6.34 & n.a. & 5.76 & 5.06 & n.a. & 4.25 & 3.73 \\
\hline Peak fast flux & n.a. & n.a. & 4.26 & n.a. & 4.33 & 3.22 & n.a. & 3.04 & 2.25 \\
\hline
\end{tabular}




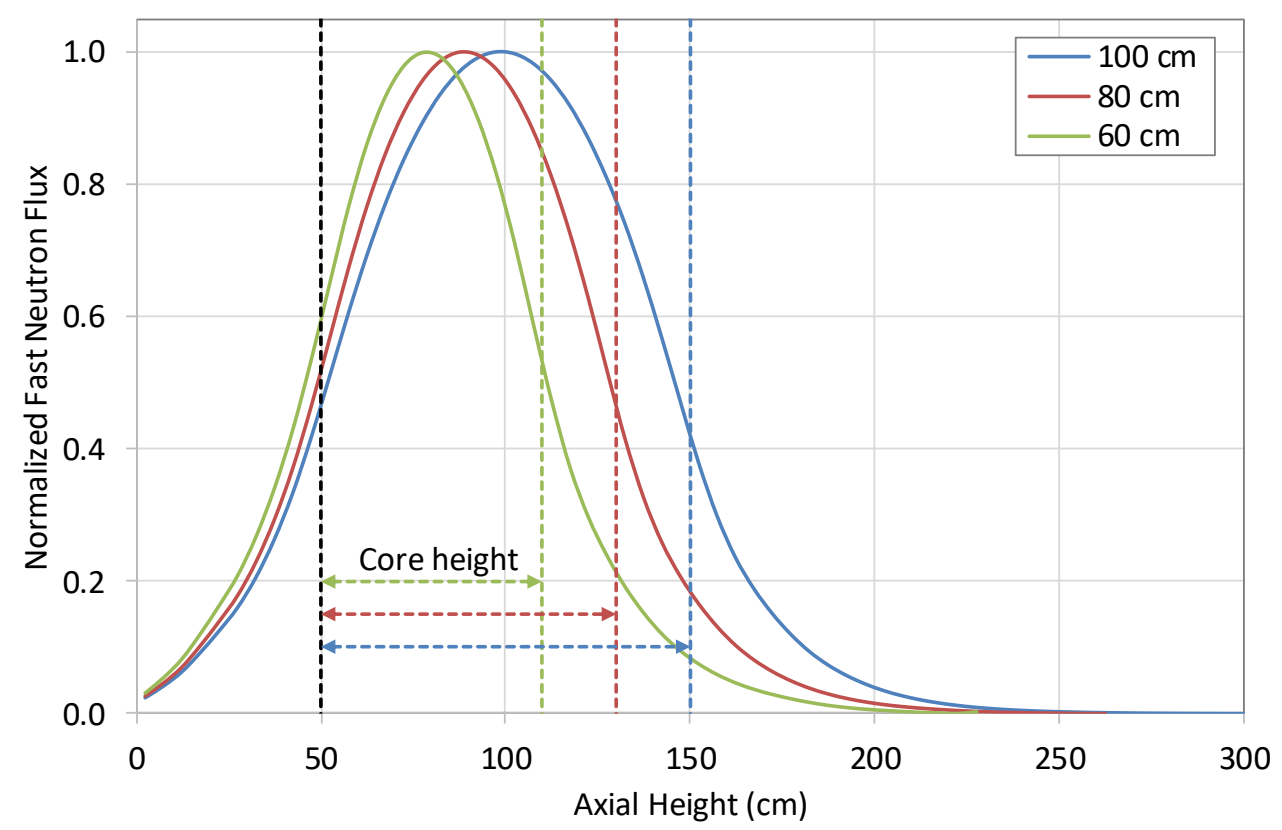

Figure 3.4: Normalized radial flux distributions for various active core heights.

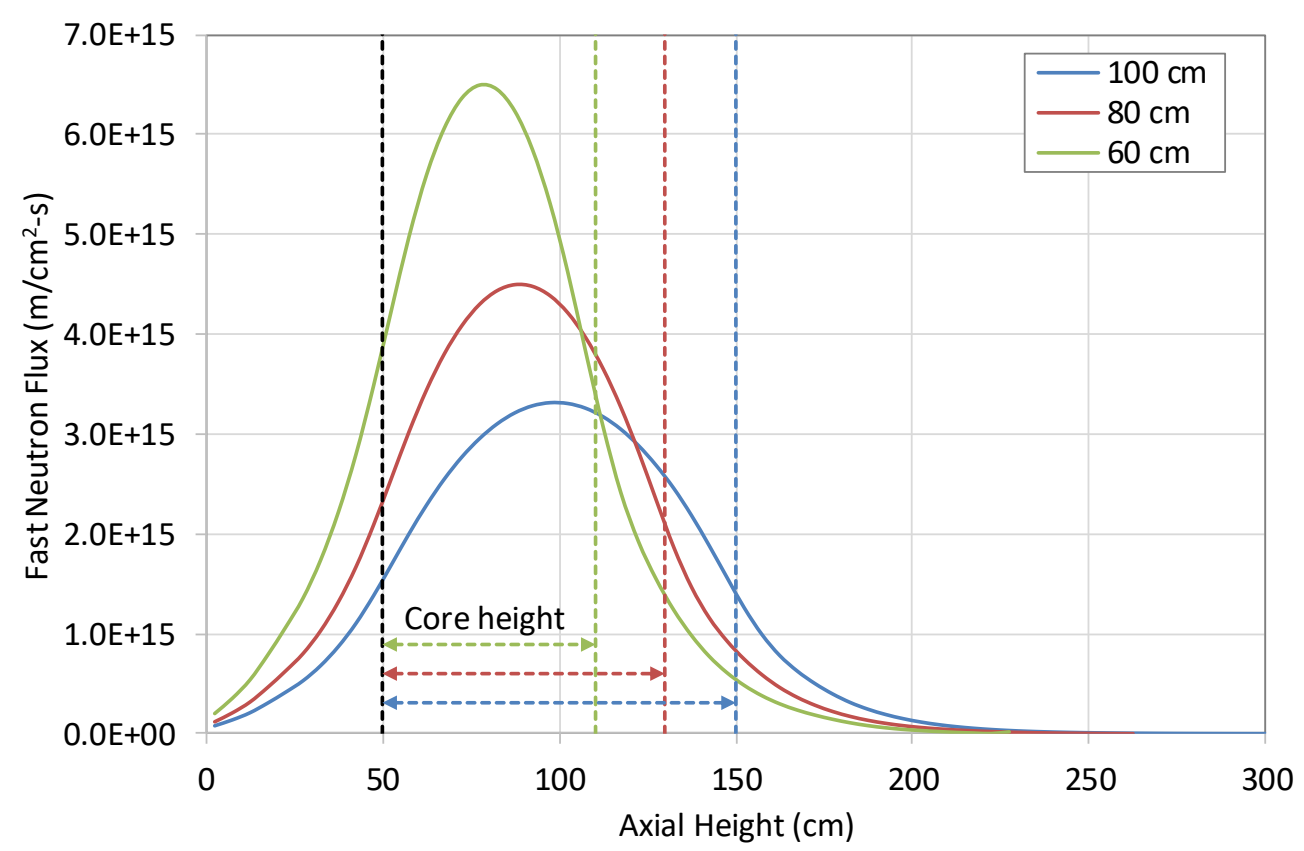

Figure 3.5: Scaled radial flux distributions for various active core heights.

\subsubsection{Reactor-Grade Vs. Weapon-Grade Plutonium}

The source of plutonium material being uncertain at this time, its isotopic composition could range from weapongrade (WG) plutonium to reactor-grade (RG) plutonium of relatively low fissile quality. The isotopic compositions considered for the WG and RG plutonium have been provided in Table 2.1. All cases containing plutonium as part of the fuel have been studied with both WG and RG plutonium.

The achievable fast flux level as a function of the core power is shown in Figure 3.6 when using WG plutonium and RG plutonium, for three fuels: (a) $20 \%$ plutonium, (b) $20 \%$ plutonium and $5 \%$ LEU, and (c) $20 \%$ plutonium 
and $10 \%$ LEU. As the plutonium represents a lower fraction of the fissile material, when using LEU, the impact of switching from RG plutonium to WG plutonium is reduced. For fuel (a), using WG plutonium allows an increase in the flux level, for a given power level, by about $20 \%$. For fuel (b) this increase is about $15 \%$, and for fuel (c) it is about $10 \%$. Alternately, if the objective is to achieve a given flux level with the smallest core power, the use of WG would allow a reduction in core power of about $30 \%, 20 \%$, and $15 \%$ when using fuel (a), (b), and (c), respectively.

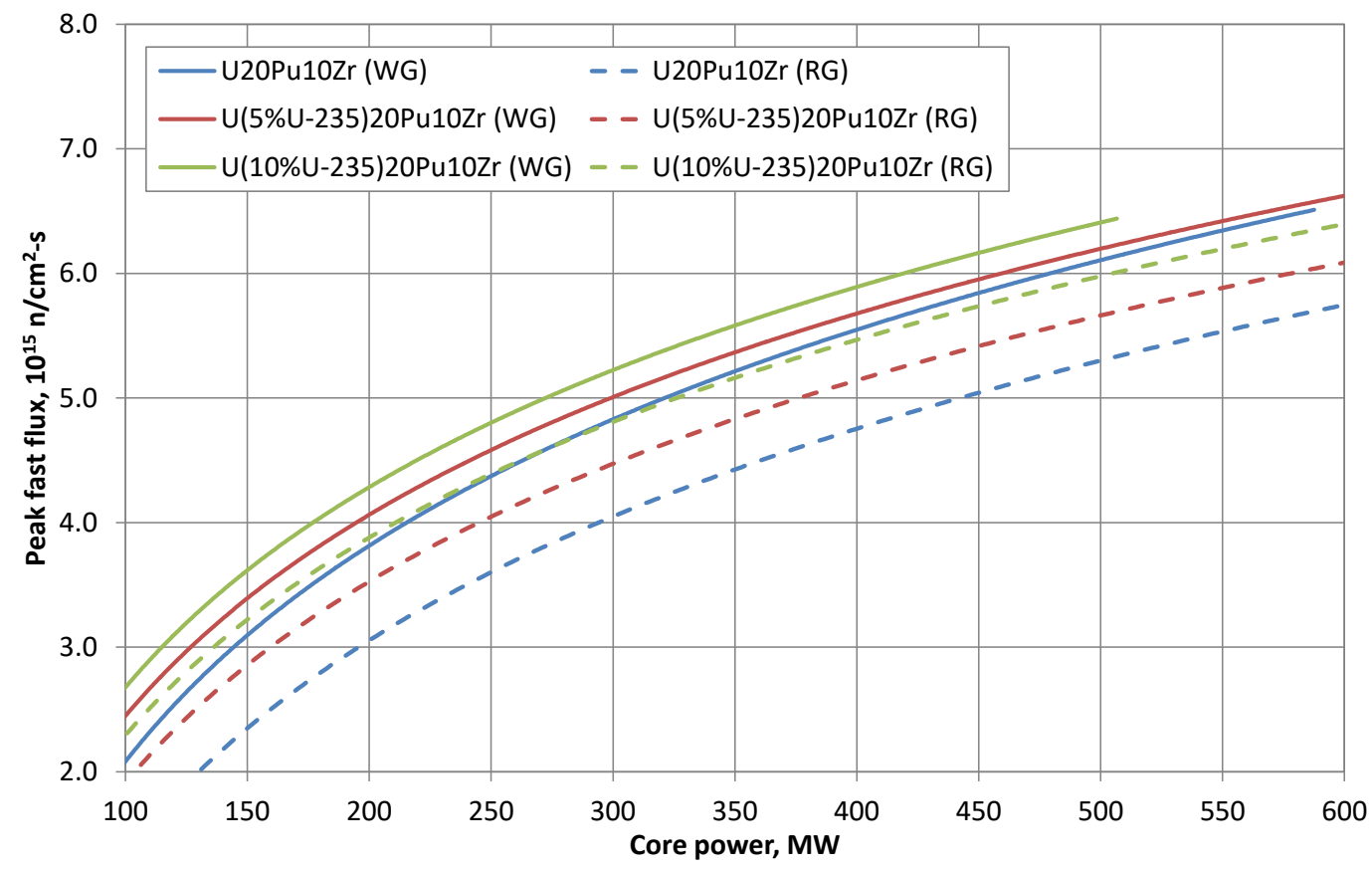

Figure 3.6: Achievable peak fast flux vs. core power using WG and RG plutonium.

\subsubsection{Impact of Americium in Plutonium Vector}

In Section 3.3.2, the plutonium vectors considered did not contain any americium. However, ${ }^{241} \mathrm{Pu}$ has a 14.4year half-life, which means that most of the existing plutonium vectors existing will contain some level of ${ }^{241} \mathrm{Am}$ based on how long the material was left to decay. A representative plutonium isotopic composition is provided in Table 3.4.

Table 3.4. Plutonium isotopic compositions with americium.

\begin{tabular}{|c|c|c|c|c|c|c|}
\hline & Pu-238 & Pu-239 & Pu-240 & Pu-241 & Pu-242 & Am-241 \\
\hline Pu-RGAm & 0.47 & 67.8 & 24.6 & 1.24 & 2.38 & 3.47 \\
\hline
\end{tabular}

Calculations have been performed using the Pu-RGAm composition for the fuel containing $20 \%$ plutonium. The results obtained are compared in Figure 3.7 with the other two plutonium isotopic compositions (WG and RG). It is observed that, due to the slightly smaller fissile fraction and parasitic absorption in ${ }^{241} \mathrm{Am}$, the achievable fast flux level for a given power is about $4 \%$ lower than for the RG plutonium. If looking at achieving the same fast flux level, the core using the plutonium with americium would need to have about $8 \%$ higher power than when using the RG plutonium composition. 


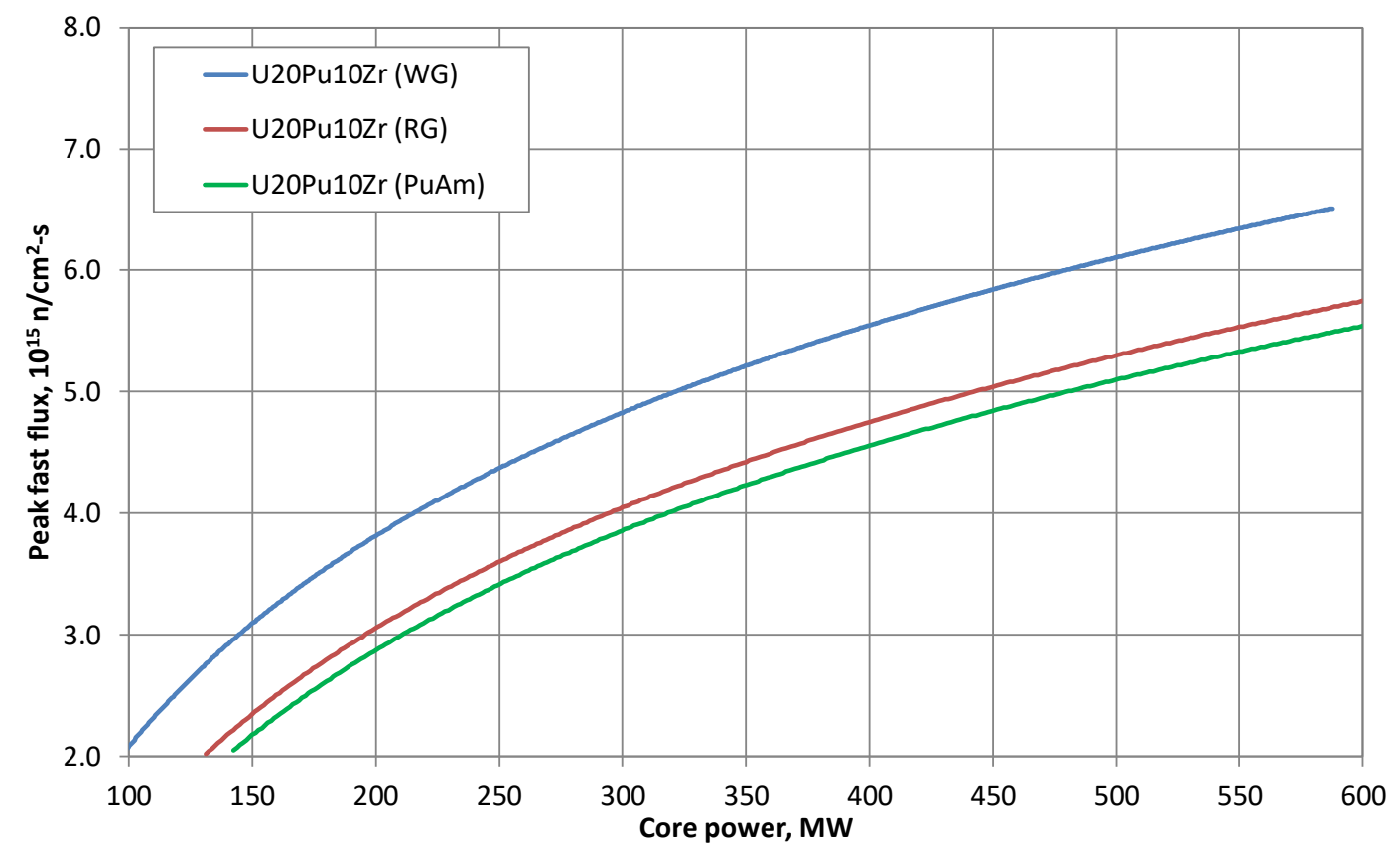

Figure 3.7: Achievable peak fast flux vs. core power using americium-bearing plutonium.

\subsubsection{Impact of Number of Test Locations}

When the number of test locations in the fuel region is increased, the neutron leakage is increased because of neutrons streaming through the locations not containing fuel. The calculations were performed assuming the test locations are filled with $90 \%$ sodium and $10 \% \mathrm{HT}$. This is a conservative assumption, as most materials or fuels loaded in the test locations will act as reflectors and will reduce the neutron leakage probability (except for highly absorbent materials, which might further increase the neutron loss). The penalty for increasing the number of test locations in the fuel region depends on many factors but is primarily dependent on the active fuel height and number of fuel assemblies used. The type of fuel assembly used also affects the penalty observed because of the different fuel volume fractions for different assembly types.

The achievable fast flux as a function of the core power is shown in Figure 3.8 for the different number of test locations considered, when using fuel made of $20 \%$ plutonium (WG) and when using LEU fuel. The trends observed are the same as for other fissile types and concentrations considered. It is found that when going from one to four test locations, the core power required to achieve a same fast flux level is increased by about $20 \%$, and that when going from four to seven test locations, the core power has to be increased by only $2-3 \%$. If the core power is to be kept constant, going from one to four test locations results in a reduction of the fast flux level of about $11 \%$, and going from four to seven test locations results in a reduction of the fast flux level of only $1-2 \%$.

Test locations in the reflector region have almost no impact on core reactivity, as long as most of the reflector assemblies are not replaced by test locations and as long as reflector assemblies located next to fuel assemblies are not replaced. This could allow for a very large number of test locations, although the flux level in the reflector region is only 5 to $50 \%$ of that achieved in the fuel region. The radial flux gradient might be important based on the locations considered. 

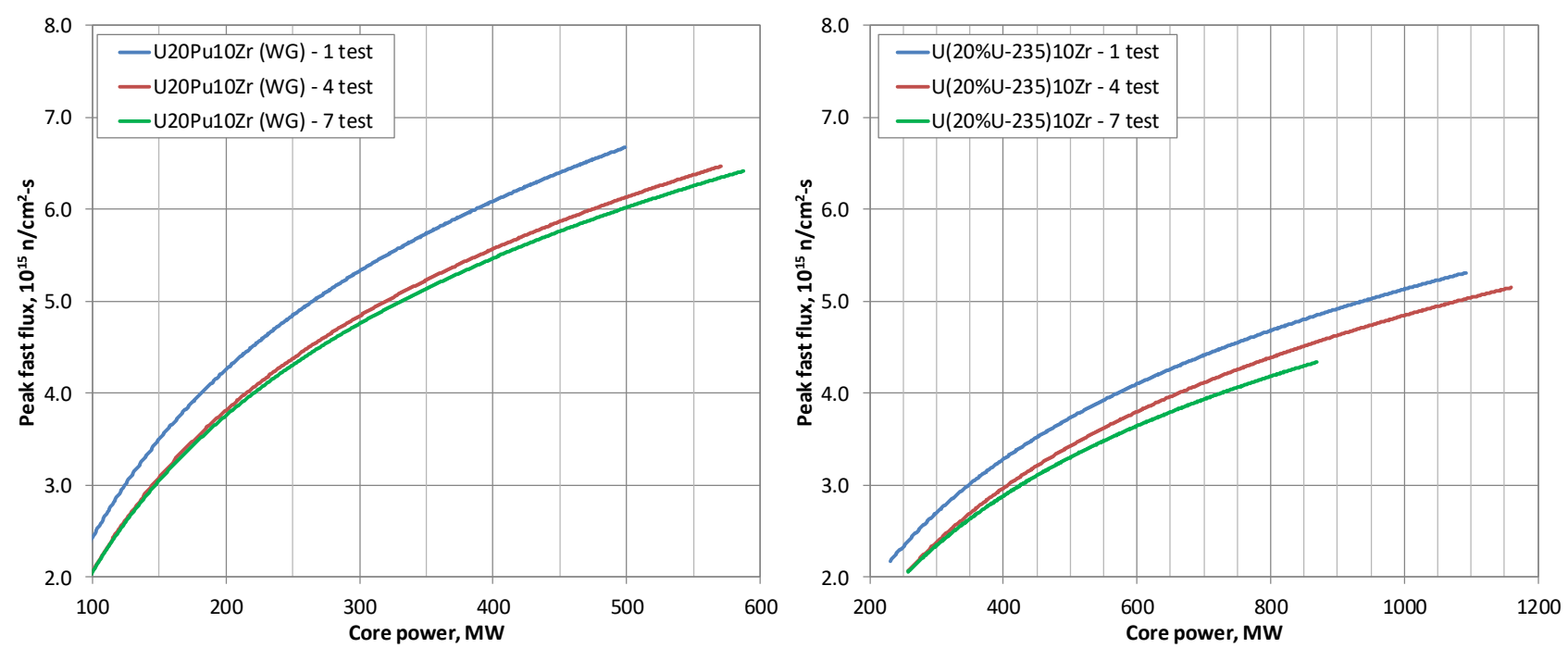

Figure 3.8: Achievable peak fast flux vs. core power for various test locations.

\subsubsection{Impact of Average Fuel Discharge Burnup}

Two average discharge burnups have been considered in this tradeoff study. The 3\% FIMA average discharge burnup corresponds to a peak burnup of about $5 \%$ FIMA. It has been selected based on the consideration that, with such a low burnup, the parasitic neutron absorption in the fission products will be limited, therefore allowing enhanced performance. The 6\% FIMA average discharge burnup corresponds on a peak burnup of about $10 \%$ FIMA. Doubling the average discharge burnup will allow a $50 \%$ reduction in the yearly fuel requirements (and, therefore, fissile material requirements). The peak burnup value had to be limited to $10 \%$ in order to remain in a space where fuel performance is well known and has been demonstrated. Although higher burnup could be possible, in part due to the low impact of parasitic neutron absorption in fission products, it would make it more challenging to license the fuel in the very near future.

The achievable fast flux as a function of the core power is compared in Figure 3.9 for the $3 \%$ FIMA cases and for the $6 \%$ FIMA cases. The curves are shown for the fuel containing $20 \%$ plutonium (WG), the fuel containing $27 \%$ plutonium, (WG) and the fuel made of LEU. The trends observed for other fuel considered in the study, with respect to the impact of the average discharge burnup, are similar. For fuels containing about $20 \%$ fissile material, the achievable fast flux is reduced by about $5 \%$ when going from 3\% FIMA to $6 \%$ FIMA, for a similar core power. (Assembly type and active fuel height are not kept the same.) For fuels containing around $27 \%$ fissile material, the achievable fast flux is reduced by about $2.5 \%$ for a given core power. The smaller impact of the burnup increase with a higher concentration of fissile material is because the fission products concentration is fixed for a given burnup, meaning the ratio between fissile and fission products is larger. 


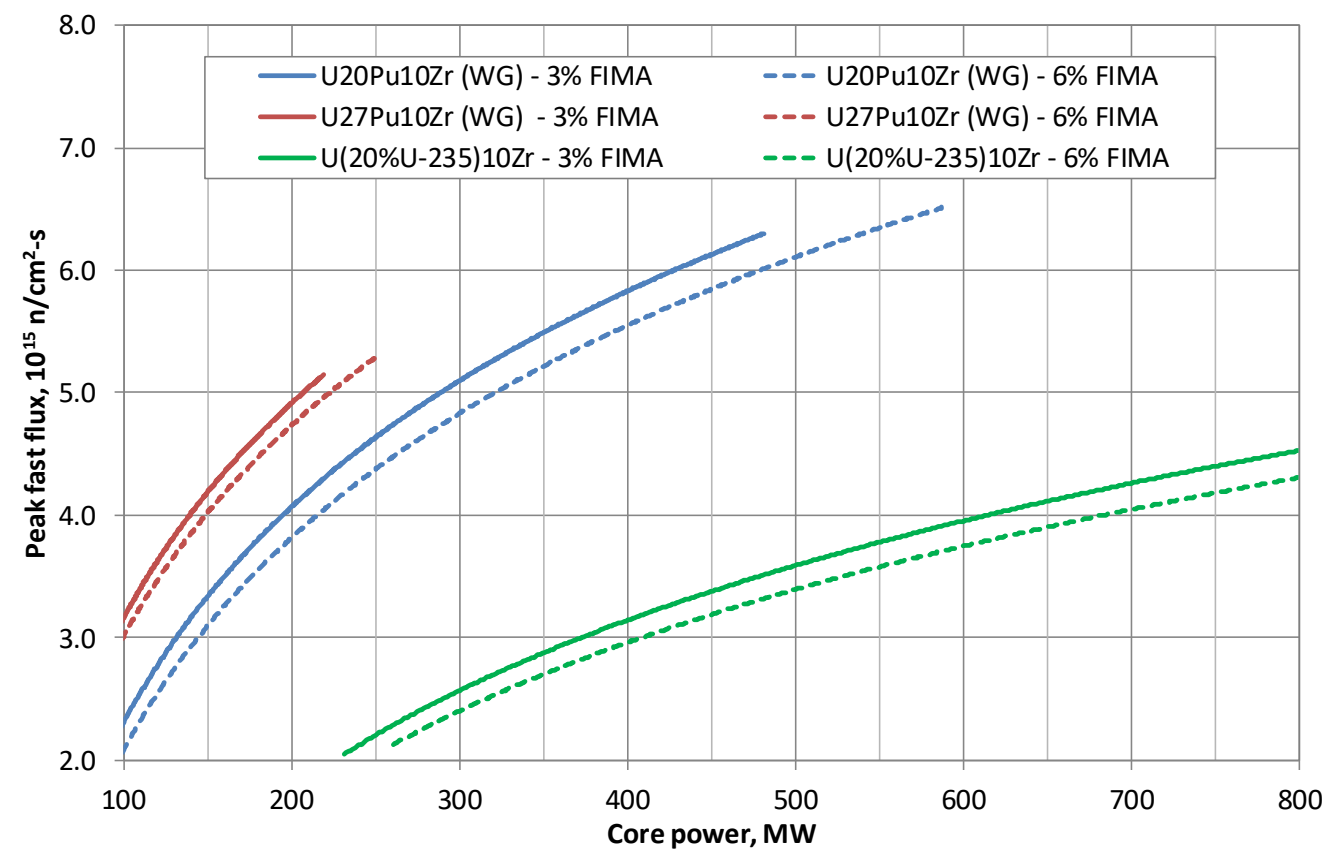

Figure 3.9: Achievable peak fast flux vs. core power for $3 \%$ and $6 \%$ FIMA burnup.

\subsubsection{Sodium Void Reactivity Effects}

The effect of a sodium void on the reactivity was calculated for two configurations characterized by very different plutonium inventories; the first one uses a LEU-11.5PuRG-10Zr fuel, whereas the second one uses a DU27PuWG-10Zr fuel (Figure 3.10). The extent of the voided region is progressively reduced from the whole reactor (core as well as radial and axial reflectors) to only $40 \mathrm{~cm}$ about core mid-plane in the six fuel assemblies of Ring 2. As expected, the reactivity effect is very negative when the whole reactor is voided ( -9400 to $-10200 \mathrm{pcm})$ and becomes less and less negative as the voided region is reduced until it becomes slightly positive when only the central region of the six fuel assemblies of Ring 2 are voided (Table 3.5). In the latter case, the reactivity effect is $+19 \mathrm{pcm}$ and $+96 \mathrm{pcm}$ for, respectively, the LEU-11.5PuRG-10Zr and DU-27PuWG-10Zr cores. The delayed neutron fractions of these two core configurations being respectively $540 \mathrm{pcm}$ and $300 \mathrm{pcm}$, it corresponds to about $+0.6 \$$ and $+5.3 \notin$ per assembly partially voided in Ring 2 of, respectively, the LEU-11.5PuRG-10Zr and DU27PuWG-10Zr cores.

Table 3.5. Sodium void reactivity effects (pcm).

\begin{tabular}{|c|c|c|}
\hline Voided regions & $\begin{array}{c}\text { LEU-11.5PuRG-10Zr } \\
\text { (A271) }\end{array}$ & $\begin{array}{c}\text { DU-27PuWG-10Zr } \\
\text { (D271) }\end{array}$ \\
\hline Whole reactor & -9375 & -10221 \\
\hline Core + axial regions & -3282 & -2912 \\
\hline Core & -1432 & -1212 \\
\hline $\begin{array}{c}\text { Six assemblies from Ring 2 } \\
\text { (core only) }\end{array}$ & -74 & -24 \\
\hline $\begin{array}{c}\text { Six assemblies from Ring 2 } \\
(40 \mathrm{~cm} \text { about core mid-plane) }\end{array}$ & +19 & +96 \\
\hline
\end{tabular}



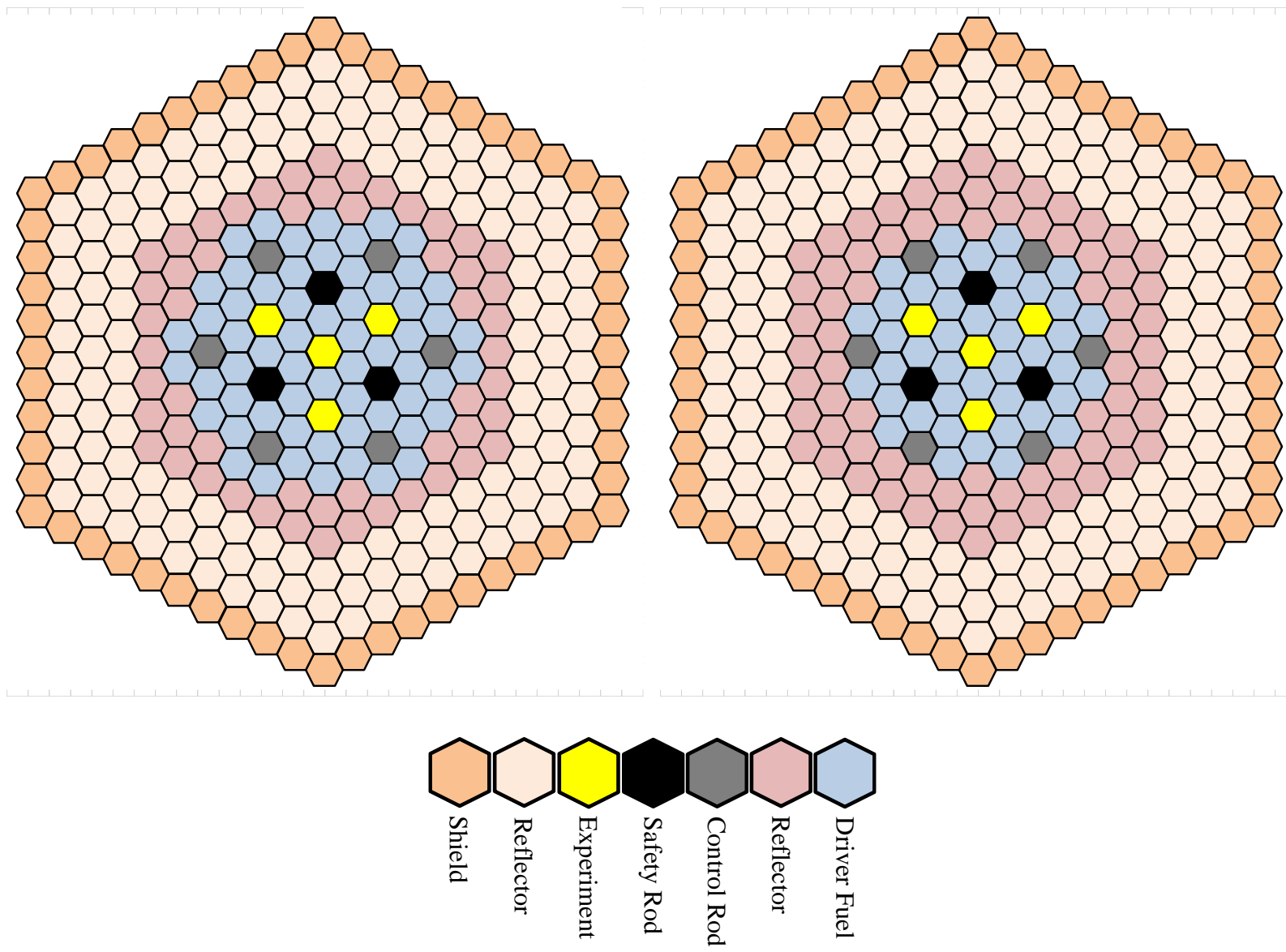

Figure 3.10: LEU-11.5PuRG-10Zr (left) and DU-27Pu-10Zr (right) core configurations.

\subsubsection{MOX Fuel Vs. Metallic Fuel}

A few calculations were performed to quantify the differences with metallic fuel. The same approach of estimating the minimum number of fuel assemblies, core power, and peak fast neutron flux, given the set of design parameters and requirements provided in Chapter 2, was also applied to a few MOX configurations. A 27\% Pu MOX fuel theoretical density of $11.1 \mathrm{~g} / \mathrm{cm}^{3}$ and an $85 \%$ smeared density were assumed. With $27 \% \mathrm{Pu}-\mathrm{RG}$ MOX fuel, the core power necessary to reach a peak fast flux of $4 \times 10^{15} \mathrm{n} / \mathrm{cm}^{2}-\mathrm{s}$ is about $400 \mathrm{MW}$, whereas it is about $230 \mathrm{MW}$ with U-27PuRG-10Zr; the use of enriched uranium in the MOX fuel would allow decreasing core power while maintaining the peak fast flux at $4 \times 10^{15} \mathrm{n} / \mathrm{cm}^{2}-\mathrm{s}$. With Pu-WG, a $300 \mathrm{MW}$ MOX core could reach a peak fast flux of $4 \times 10^{15} \mathrm{n} / \mathrm{cm}^{2}-\mathrm{s}$, whereas about $160 \mathrm{MW}$ would suffice for the metallic fuel.

\subsubsection{Example of $60-\mathrm{cm}-H i g h$ Cores with Increased Liner Power}

As discussed in Section 3.2, 60-cm-high cores can be designed so they reach the assumed maximum peak linear power $(450 \mathrm{~W} / \mathrm{cm})$ with a relatively low fuel bundle pressure drop (Table 3.2). For a U-20Pu-10Zr fuel, a $450 \mathrm{~W} / \mathrm{cm}$ peak linear power corresponds to a peak fuel centerline temperature of about $840-860^{\circ} \mathrm{C}$, depending on the actual power distribution (Appendix 3; i.e., significantly below the solidus temperature). The results presented in Table 3.2 showed that it may be possible to increase the fast flux in a core using $60-\mathrm{cm}$ A271 assemblies by about $44 \%$ by increasing the power-and sodium velocity—until the pressure drop reaches $0.5 \mathrm{MPa}$. In this case-assuming a peaking factor of 1.25-the peak linear power reaches about $650 \mathrm{~W} / \mathrm{cm}$, and the peak fuel centerline temperature reaches about $960-980^{\circ} \mathrm{C}$ (without uncertainties; i.e., still about $140-160^{\circ} \mathrm{C}$ below the U-20Pu-10Zr solidus temperature). As an example-and assuming these peak fuel temperatures are acceptable-Table 3.7 shows that the peak fast flux $(>0.1 \mathrm{MeV})$ could be increased to almost $7 \times 10^{15} \mathrm{n} / \mathrm{cm}^{2}-\mathrm{s}$. 
Table 3.6. MOX fuel vs. metallic fuel (A271 assembly design; Fuel height: $80-100 \mathrm{~cm}$; average burnup $=6 \%$ ).

\begin{tabular}{|c|c|c|c|}
\hline & & MOX (27\% Pu) & U-27Pu-10Zr \\
\hline \multirow{4}{*}{ RG } & Core power (MW) & $620-380$ & $270-200$ \\
\cline { 2 - 4 } & Number of FA & $120-84$ & $48-39$ \\
\cline { 2 - 4 } & Maximum FA power (MW) & $6.3-7.2$ & $6.3-7.2$ \\
\cline { 2 - 4 } & Peak fast flux (10 $\left.15 \mathrm{n} / \mathrm{cm}^{2}-\mathrm{s}\right)$ & $5.2-3.8$ & $4.7-3.5$ \\
\cline { 2 - 4 } & $\begin{array}{c}\text { Core power to reach peak } \\
\text { fast flux of } 4 \times 10^{15} \mathrm{n} / \mathrm{cm}^{2}-\mathrm{s}\end{array}$ & $\sim 400 \mathrm{MW}$ & $\sim 230 \mathrm{MW}$ \\
\hline \multirow{5}{*}{ WG } & Core power (MW) & $365-245$ & $30-27$ \\
\cline { 2 - 4 } & Number of FA & $81-51$ & $6.3-7.2$ \\
\cline { 2 - 4 } & Maximum FA power (MW) & $6.3-7.2$ & $4.3-3.1$ \\
\cline { 2 - 4 } & Peak fast flux $\left(10^{15} \mathrm{n} / \mathrm{cm}^{2}-\mathrm{s}\right)$ & $4.8-3.6$ & $\sim 160 \mathrm{MW}$ \\
\cline { 2 - 4 } & $\begin{array}{c}\text { Core power to reach peak } \\
\text { fast flux of } 4 \times 10^{15} \mathrm{n} / \mathrm{cm}^{2}-\mathrm{s}\end{array}$ & $\sim 300 \mathrm{MW}$ & 35 \\
\hline
\end{tabular}

Table 3.7. Example of $60-\mathrm{cm}$ high core configurations using LEU-20PuWG-10Zr fuel (burnup $=6 \%$ ) and satisfying different thermal hydraulic constraints.

\begin{tabular}{|c|c|c|}
\hline & \multicolumn{2}{|c|}{ LEU(10\% $\left.{ }^{235} \mathrm{U}\right)-20 \mathrm{PuWG}-10 \mathrm{Zr}$; Assembly A271 } \\
\hline Peak LHR; $\Delta p$ & $450 \mathrm{~W} / \mathrm{cm} ; 0.26 \mathrm{MPa}$ & $650 \mathrm{~W} / \mathrm{cm} ; 0.50 \mathrm{MPa}$ \\
\hline Core power (MW) & 272 & 392 \\
\hline Number of FA & 60 & 60 \\
\hline Maximum FA power (MW) & 5.85 & 8.44 \\
\hline \multirow[t]{2}{*}{ Peak fast flux $\left(10^{15} \mathrm{n} / \mathrm{cm}^{2}-\mathrm{s}\right)$} & 4.7 & 6.8 \\
\hline & \multicolumn{2}{|c|}{ LEU(20\%235U)-20PuWG-10Zr; Assembly A271 } \\
\hline Peak LHR; $\Delta p$ & $450 \mathrm{~W} / \mathrm{cm} ; 0.26 \mathrm{MPa}$ & $650 \mathrm{~W} / \mathrm{cm} ; 0.50 \mathrm{MPa}$ \\
\hline Core power (MW) & 180 & 260 \\
\hline Number of FA & 37 & 37 \\
\hline Maximum FA power (MW) & 5.85 & 8.44 \\
\hline \multirow[t]{2}{*}{ Peak fast flux $\left(10^{15} \mathrm{n} / \mathrm{cm}^{2}-\mathrm{s}\right)$} & 4.1 & 5.9 \\
\hline & \multicolumn{2}{|c|}{ LEU(10\% $\left.{ }^{235} \mathrm{U}\right)-20 \mathrm{PuWG}-10 \mathrm{Zr} ;$ Assembly B271 } \\
\hline Peak LHR; $\Delta p$ & $450 \mathrm{~W} / \mathrm{cm} ; 0.37 \mathrm{MPa}$ & $530 \mathrm{~W} / \mathrm{cm} ; 0.50 \mathrm{MPa}$ \\
\hline Core power (MW) & 210 & 248 \\
\hline Number of FA & 45 & 45 \\
\hline Maximum FA power (MW) & 5.85 & 6.90 \\
\hline Peak fast flux $\left(10^{15} \mathrm{n} / \mathrm{cm}^{2}-\mathrm{s}\right)$ & 4.4 & 5.2 \\
\hline
\end{tabular}

\subsection{Comparison with Other Fast Test Reactors}

Several fast reactors have been built and operated around the word, some of which are still operational, and some of which are being constructed. Core models were developed for three fast reactors, which are reported to have relatively high fast flux. This comparison is motivated by the desire to verify that the flux level reported in the literature for these reactors is consistent with the results obtained using the tools and analysis techniques used in this study and described in this document. A third motivation for this task is to identify and evaluate if specific design techniques were utilized in order to increase the PFF in these other reactor designs.

The first fast reactor considered is the Fast Flux Test Facility (FFTF), which was operated in the U.S. in the 80s and 90s. The second one is the JOYO reactor, which is located in Japan and should soon resume operation, although with a reduced power level of about $100 \mathrm{MW}$ and, therefore, flux levels reduced by about $28 \%$. The third 
reactor of interest is the multipurpose sodium-cooled fast neutron research reactor (MBIR) being built in Russia. It is expected to be completed by 2020 . Some of the design parameters for these three fast reactors are provided in Table 3.8. The results of the neutronics calculations are reported in Appendix 4.

Table 3.8 Summary of FFTF, JOYO, and MBIR design parameters.

\begin{tabular}{|c|c|c|c|}
\hline & FFTF & JOYO & MBIR \\
\hline Power (MWth) & 400 & 140 & 150 \\
\hline Mean cycle length (EFPDs) & 107 & 60 & 100 \\
\hline Primary circuit & Loop & Loop & Loop \\
\hline Fuel type & $\mathrm{PuO}_{2}-\mathrm{UO}_{2}$ & $\mathrm{PuO}_{2}-\mathrm{UO}_{2}(\mathrm{LEU})$ & $\mathrm{PuO}_{2}-\mathrm{UO}_{2}$ \\
\hline Fissile type & $\mathrm{Pu}\left(87 \%{ }^{239} \mathrm{Pu}\right)$ & $\begin{array}{l}\mathrm{Pu}\left(68 \%{ }^{239} \mathrm{Pu}\right) \\
\text { LEU }\left(18 \%{ }^{235} \mathrm{U}\right)\end{array}$ & $\mathrm{Pu}\left(94 \%{ }^{239} \mathrm{Pu}\right)$ \\
\hline Core-average Pu content & $\sim 25 \%$ & $28.3 \%$ & $34.8 \%$ \\
\hline Number of driver assemblies & 82 & $\leq 85$ & 93 \\
\hline Assembly pitch (cm) & 12.04 & 8.20 & 7.40 \\
\hline Number fuel pins per assembly & 217 & 127 & 91 \\
\hline Fuel height $(\mathrm{cm})$ & 91.44 & 50 & 55 \\
\hline Clad material & SS316 & SS316 & Austenitic Steel ChS-68 \\
\hline Duct material & SS316 & SS316 & - \\
\hline Wire material & SS316 & SS316 & Martensitic Steel EP-450sh \\
\hline Peak linear power & 41.3 & 42.0 & 48.0 \\
\hline Radial power peaking factor & 1.38 & - & 1.31 \\
\hline Inlet/outlet temperature $\left({ }^{\circ} \mathrm{C}\right)$ & $360 / 503$ & $350 / 500$ & $330 / 512$ \\
\hline Coolant mass flow rate $(\mathrm{kg} / \mathrm{s})$ & 2,180 & 750 & 650 \\
\hline Experimental capabilities highlight & $\begin{array}{l}\text { Four closed-loop po- } \\
\text { sitions, four open } \\
\text { test positions }\end{array}$ & $\begin{array}{l}\text { Six open test loca- } \\
\text { tions }\end{array}$ & $\begin{array}{l}\text { Three loop channels, three in- } \\
\text { strumented experimental } \\
\text { channels, } 14 \text { material test as- } \\
\text { semblies. } \\
\text { Outside the reactor vessel: } \\
\text { six horizontal experimental } \\
\text { channels, eight vertical exper- } \\
\text { imental channels }\end{array}$ \\
\hline
\end{tabular}

\section{Reactivity Coefficients and Reactivity Balance}

Although a complete safety analysis study could not be reasonably performed as part of the tradeoff study, reactivity coefficients were calculated for the different fuel types and used to perform the quasi-static reactivity balance [Wade, 1989]. The objective here is not necessarily to design a passively safe test reactor, but rather to get a feel as to where some of the preliminary configurations studied stand with respect to passive safety. Reactivity coefficients will be the basis of any safety analysis, and it is desirable to assess them early on to ensure no design change is needed to favor safety performance.

\subsection{Reactivity Coefficients}

The reactivity coefficients were determined using the PERSENT code for a single core configuration for each of the fissile materials and concentrations considered in this study. The core configuration for each fissile mate$\mathrm{rial} /$ concentration was simply selected as the one being the closest to $300 \mathrm{MW}_{\text {th }}$ (when reaching the maximum assembly power as provided in Table 3.1). Assumptions used to calculate the various reactivity coefficients are provided in Appendix 5. 
The reactivity coefficient values, expressed in cents per Kelvin, are provided in Table 4.1 for all the fissile material and concentrations considered in this study. All cases considered were taken to have an average fuel discharge burnup of $6 \%$ FIMA, and the results are provided at the beginning of equilibrium cycle (BOEC). All these reactivity coefficients are consistent among the various cases considered. The differences observed in the values for a given coefficient are primarily due to the $\beta_{\text {eff }}$ value and the active core height not being the same for all cases.

Table 4.1: Reactivity coefficients for various fissile types and concentrations.

\begin{tabular}{|l|c|c|c|c|c|c|c|c|c|c|}
\hline Uranium enrichment, $\%$ & 20 & 27 & 20 & 5 & 5 & 10 & 10 & 0.71 & 0.71 & 0.71 \\
\hline Plutonium wt\% & 0 & 0 & 11.5 & 20 & 20 & 20 & 20 & 20 & 20 & 27 \\
\hline Plutonium type & n.a. & n.a. & RG & RG & WG & RG & WG & RG & WG & WG \\
\hline Assembly type & C217 & B271 & A271 & C217 & B271 & B271 & A271 & C271 & C217 & C271 \\
\hline Active core height, cm & 100 & 80 & 80 & 60 & 60 & 60 & 60 & 60 & 60 & 60 \\
\hline Number of test assemblies & 4 & 1 & & 7 & 4 & 1 & 4 & 1 & 7 & 7 \\
\hline Core power, MWth & 304 & 311 & 360 & 297 & 319 & 293 & 314 & 331 & 260 & 251 \\
\hline \multicolumn{7}{|c|}{ Reactivity coefficients } \\
\hline Beta, pcm & 675 & 695 & 540 & 372 & 351 & 405 & 381 & 338 & 321 & 298 \\
\hline Doppler, cents/K & -0.05 & -0.03 & -0.04 & -0.06 & -0.07 & -0.05 & -0.06 & -0.08 & -0.08 & -0.07 \\
\hline Axial exp., cents/K & -0.04 & -0.04 & -0.10 & -0.08 & -0.09 & -0.08 & -0.08 & -0.08 & -0.09 & -0.11 \\
\hline Sodium density, cents/K & -0.08 & -0.14 & -0.21 & -0.23 & -0.30 & -0.22 & -0.32 & - & -0.31 & -0.49 \\
\hline Radial exp., cents/K & -0.12 & -0.14 & -0.21 & -0.29 & -0.32 & -0.28 & -0.30 & -0.31 & -0.35 & -0.39 \\
\hline Driveline exp., cents/K & -0.15 & -0.17 & - & -0.30 & -0.33 & -0.26 & -0.31 & -0.32 & -0.36 & -0.37 \\
\hline
\end{tabular}

An important observation is that the sodium density coefficient is negative for all cases, including when plutonium is used. This trend is explained by the fact that for small-volume SFR cores, the leakage increase arising from the sodium density reduction offsets the reactivity increase due to spectrum hardening. Typically, larger SFR cores have a positive sodium density reactivity coefficient. A positive reactivity coefficient by itself is not prohibitive, since the overall reactivity feedback (including Doppler, expansions, and other considerations) is what needs to be negative. It has been previously shown that SFR with positive sodium density worth could still be made passively safe [Wigeland, 1994]. For the core configurations studied here, although the overall sodium density worth is negative, local values near the core center can be positive, and only a detailed safety analysis can properly inform on the safety behavior of the cores.

\subsection{Quasi-static Reactivity Balance}

The quasi-static reactivity balance [Wade, 1989] is a simple and quick way to get a first order assessment of the inherently safe behavior of a fast reactor. It does not replace a detailed safety analysis, but is a useful tool to ensure design of a core that will have good chances for favorable safety behavior. This approach relies on calculating three coefficients, $\mathrm{A}, \mathrm{B}$, and $\mathrm{C}$, using reactivity coefficients such as those provided in Table 4.1, and verifying that the combination of these three coefficients meets a number of constraints. The quasi-reactivity balance and the $\mathrm{A}, \mathrm{B}$, and $\mathrm{C}$ coefficients are defined as:

$$
\delta \rho=[\mathrm{P}(\mathrm{t})-1] \mathbf{A}+[\mathrm{P}(\mathrm{t}) / \mathrm{F}(\mathrm{t})-1] \mathbf{B}+\left[\delta \mathrm{T}_{\text {in }}(\mathrm{t})\right] \mathbf{C}+\delta \rho_{\text {external }}
$$

where $P(t)=$ normalized reactor power

$F(t)=$ normalized core coolant flow

$\delta \mathrm{T}_{\text {in }}(\mathrm{t})=$ change in coolant temperature at the core inlet

$\delta \rho_{\text {external }}=$ externally applied change in reactivity (e.g., control rods) 
The relative importance of each of these terms is determined by the grouped reactivity feedback parameters $A$, $B$, and $C$. The reactivity feedback coefficients that form the three parameters $A, B$, and $C$ are associated with the reactor core and depend on fuel type, fuel volume fraction, coolant volume fraction, and other considerations.

where

$$
\begin{aligned}
& \mathrm{A}=\alpha \text { Doppler } \Delta \mathrm{T}_{\mathrm{FC}}(\mathrm{t}=0) \\
& \mathrm{B}=\left[\alpha \text { Doppler }+\alpha \text { NaCoolant }+\alpha_{\text {AxialExp }}+\mathrm{a}_{1} \alpha_{\text {RadialExp }}+\mathrm{a}_{2} \alpha \text { ControlRod }\right] \Delta \mathrm{T}_{\mathrm{C}}(\mathrm{t}=0) / 2 \\
& \mathrm{C}=\left[\alpha \text { Doppler }+\alpha \text { NaCoolant }+\alpha_{\text {AxialExp }}+\mathrm{b}_{1} \alpha_{\text {RadialExp }}+\mathrm{b}_{2} \alpha \text { ControlRod }\right]
\end{aligned}
$$

$\alpha$ Doppler $=$ Doppler coefficient

$\alpha$ NaCoolant $=$ Sodium coolant density coefficient

$\alpha_{\text {AxialExp. }}=$ Fuel axial expansion coefficient

$\alpha$ RadialExp $=$ Core radial expansion coefficient

$\alpha$ ControlRod $=$ Control rod driveline expansion coefficient

$\Delta \mathrm{T}_{\mathrm{FC}}(\mathrm{t}=0)=$ Steady-state temperature difference, fuel to coolant

$\Delta \mathrm{T}_{\mathrm{c}}(\mathrm{t}=0)=$ Steady-state coolant temperature rise, inlet to outlet

$\mathrm{a}_{1}, \mathrm{a}_{2}, \mathrm{~b}_{1}, \mathrm{~b}_{2}=$ geometric parameters

In order to have favorable safety behavior the A, B, and C coefficients should satisfy the following [Wade, 1989]:

$$
\begin{gathered}
\mathrm{A} / \mathrm{B} \leq 1 \\
1 \leq \mathrm{C} \Delta \mathrm{T}_{\mathrm{c}} / \mathrm{B} \leq 2 \\
\Delta \text { ртор } / \mathrm{B} \leq 1
\end{gathered}
$$

$\Delta \rho$ тор (in \$) is the assumed reactivity inserted during a transient overpower such as an inadvertent rod withdrawal.

The values obtained from the quasi-static reactivity balance at BOEC are provided in Table 4.2. It is found that the first two criteria are met for all cases, but that the third criterion is only met for the two core configurations not containing plutonium. This result is not alarming, as it pertains to the reactivity worth of the most reactive control

\begin{tabular}{|c|c|c|c|c|c|c|c|c|c|c|}
\hline U enrichment, \% & 20 & 27 & 20 & 5 & 5 & 10 & 10 & 0.71 & 0.71 & 0.71 \\
\hline Plutonium wt\% & 0 & 0 & 11.5 & 20 & 20 & 20 & 20 & 20 & 20 & 27 \\
\hline Plutonium type & n.a. & n.a. & $R G$ & $R G$ & WG & $R G$ & WG & $R G$ & WG & $W G$ \\
\hline Assembly type & $\mathrm{C} 217$ & B271 & A271 & $\mathrm{C} 217$ & B271 & B271 & A271 & $\mathrm{C} 271$ & $\mathrm{C} 217$ & $\mathrm{C} 271$ \\
\hline Core power, $\mathrm{MW}_{\text {th }}$ & 304 & 311 & 360 & 297 & 319 & 293 & 314 & 331 & 260 & 251 \\
\hline \multicolumn{11}{|c|}{ Quasi-static reactivity balance coefficients } \\
\hline A, cents & -6.92 & -4.68 & & -9.51 & -10.02 & -7.26 & -8.40 & -11.46 & -11.88 & -10.38 \\
\hline B, cents & -41.0 & -49.2 & & -93.8 & -107.6 & -87.4 & -103.0 & - & -114.7 & -137.4 \\
\hline $\mathrm{C}$, cents/K & -0.28 & -0.35 & & -0.66 & -0.78 & -0.63 & -0.76 & - & -0.83 & -1.07 \\
\hline$\Delta \rho_{\text {top }}$, cents & 19.5 & 37.0 & & 104.1 & 144.7 & 115.3 & 165.2 & 95.1 & 134.2 & 216.9 \\
\hline \multicolumn{11}{|c|}{ Conditions to be met } \\
\hline$A / B \leq 1$ & 0.17 & 0.09 & & 0.10 & 0.09 & 0.08 & 0.08 & - & 0.10 & 0.08 \\
\hline $1 \leq \mathrm{C} \Delta \mathrm{T} / \mathrm{B} \leq 2$ & 1.04 & 1.06 & & 1.06 & 1.08 & 1.07 & 1.11 & - & 1.08 & 1.16 \\
\hline$\Delta \rho_{\text {top }} /|\mathrm{B}| \leq 1$ & 0.48 & 0.75 & & 1.11 & 1.35 & 1.32 & 1.60 & - & 1.17 & 1.58 \\
\hline
\end{tabular}
rod and to the excess reactivity of the core. This means that the worth of a single control rod might need to be reduced in order to meet the third criterion. This is discussed further in Section 5. Other options to meet this criterion could consist of increasing B by operating with a larger coolant temperature rise along the core, or finding ways to make the reactivity coefficients more negative.

Table 4.2: Quasi-static reactivity balance results for various fissile types and concentrations. 


\section{Reactivity Control}

\subsection{Control Rods Worth}

A fast neutron spectrum test reactor should use two independent reactivity control systems: a primary and a secondary reactivity control system. The primary system will be required to have sufficient reactivity worth to bring the reactor from any operating condition to cold sub-critical at the refueling temperature with the most reactive control assembly stuck $(\mathrm{N}-1)$ at the full power operating position. Any operating condition means an overpower condition together with a reactivity fault. The maximum worth of a control assembly will be used as the base of this reactivity fault. The primary system will also serve to compensate for the reactivity effects of the fuel burnup and axial growth of metallic fuel. The reactivity associated with uncertainties in criticality and fissile loading will be accommodated by the primary control system. Assuming $2,750 \mathrm{pcm}$ of excess reactivity are necessary for a 100 day cycle, a typical temperature defect of about $700 \mathrm{pcm}$, a $500 \mathrm{pcm}$ reactivity fault, a 20 percent uncertainty (i.e., $790 \mathrm{pcm}$ ), and a $500 \mathrm{pcm}$ margin, the minimum N-1 control rod worth should be $5,240 \mathrm{pcm}$. This is only a crude estimation, and more precise evaluations will be carried out later if deemed necessary.

The secondary system will be required to shut down the reactor from any operating condition to the hot standby condition, also with the most reactive assembly inoperative. It will not have to duplicate the primary system capability to hold down the excess reactivity for the fuel cycle since this excess reactivity is not additional reactivity to be overridden at an accident. Although the secondary system must shut down the reactor without insertion of the primary control assemblies, it is not necessary to assume that the primary assemblies are removed from the core during an accident situation. Since reactivity uncertainties are accommodated by the primary system, they are not a part of the secondary system requirements. However, the reactivity fault will be included in the secondary system requirements, since the secondary system should override the uncontrollable withdrawal of one primary control assembly that is being used for burnup control. Assuming a typical temperature defect of about $350 \mathrm{pcm}$, a 500 pcm reactivity fault, a 20 percent uncertainty (i.e., $170 \mathrm{pcm}$ ), and a $500 \mathrm{pcm}$ margin, the minimum $\mathrm{N}-1$ safety rod worth should be $1,520 \mathrm{pcm}$. As for the control rods, this is only a crude estimation, and more precise evaluations will be carried out in the course of the project.

Table 5.1 presents the $\mathrm{N}-1$ control and safety rods reactivity worth obtained with the configurations illustrated in Figure 5.1. It should be noted that because the core is small-and consequently, strongly coupled neutronicallythe reactivity worth of the stuck rod (defined as the most effective) is relatively close to that of the average rod; there is no notable amplification phenomena as can be observed in larger cores [Palmiotti, 1984; Flamenbaum, 1990; Rowlands, 1985]. The safety rods have the highest reactivity worth in configuration (a), but the other configurations could also provide the estimated required reactivity worth with some level of boron enrichment. Moving the three safety rods from central positions to more peripheral positions would free these three high-flux positions for experiments. The nominal control rods' reactivity worths are sufficient to meet the estimated required worth, but some level of boron enrichment may also be necessary when uncertainties are taken into account.

Table 5.1. N-1 Primary (control) and secondary (safety) rods reactivity worth. Control and safety rods composition: $50 \%$ B4C, $25 \% \mathrm{Na}$, and 25\% HT9. Nominal values; homogeneous neutronics calculations

\begin{tabular}{|c|c|c|c|c|}
\hline Rod worth $^{*}(\mathrm{pcm})$ & a & b & c & d \\
\hline CR $(\mathrm{N}-1)$ & 6400 & 6400 & 6400 & 3670 \\
\hline SR $(\mathrm{N}-1)^{* *}$ & 5800 & 1500 & 670 & 1200 \\
\hline
\end{tabular}

* Calculated with natural boron; using $90 \%$ enriched boron approximately doubles rod worth.

** Calculated with about $2500-3000 \mathrm{pcm}$ of CR inserted to model a critical core. 


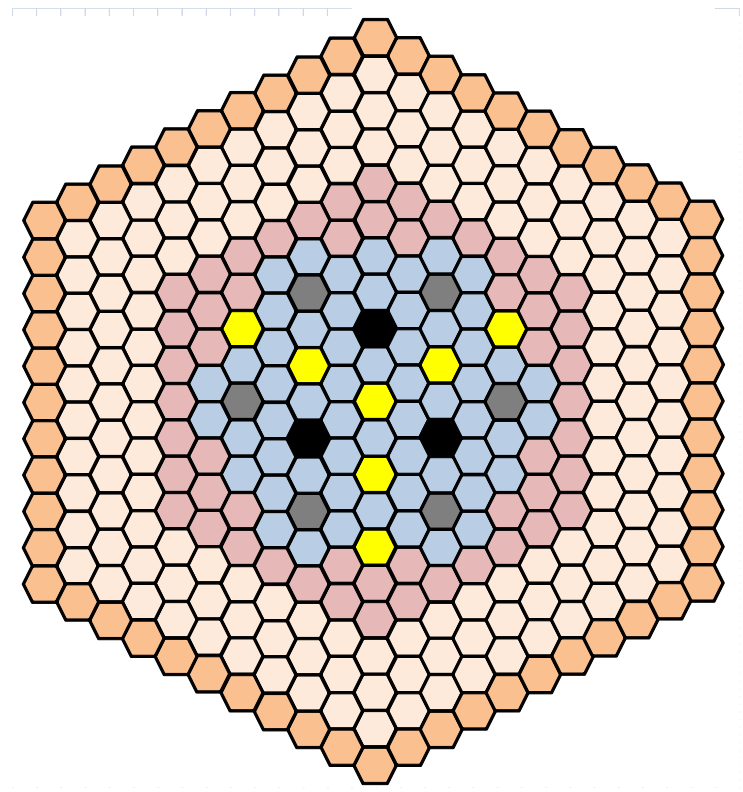

(a)

(b)
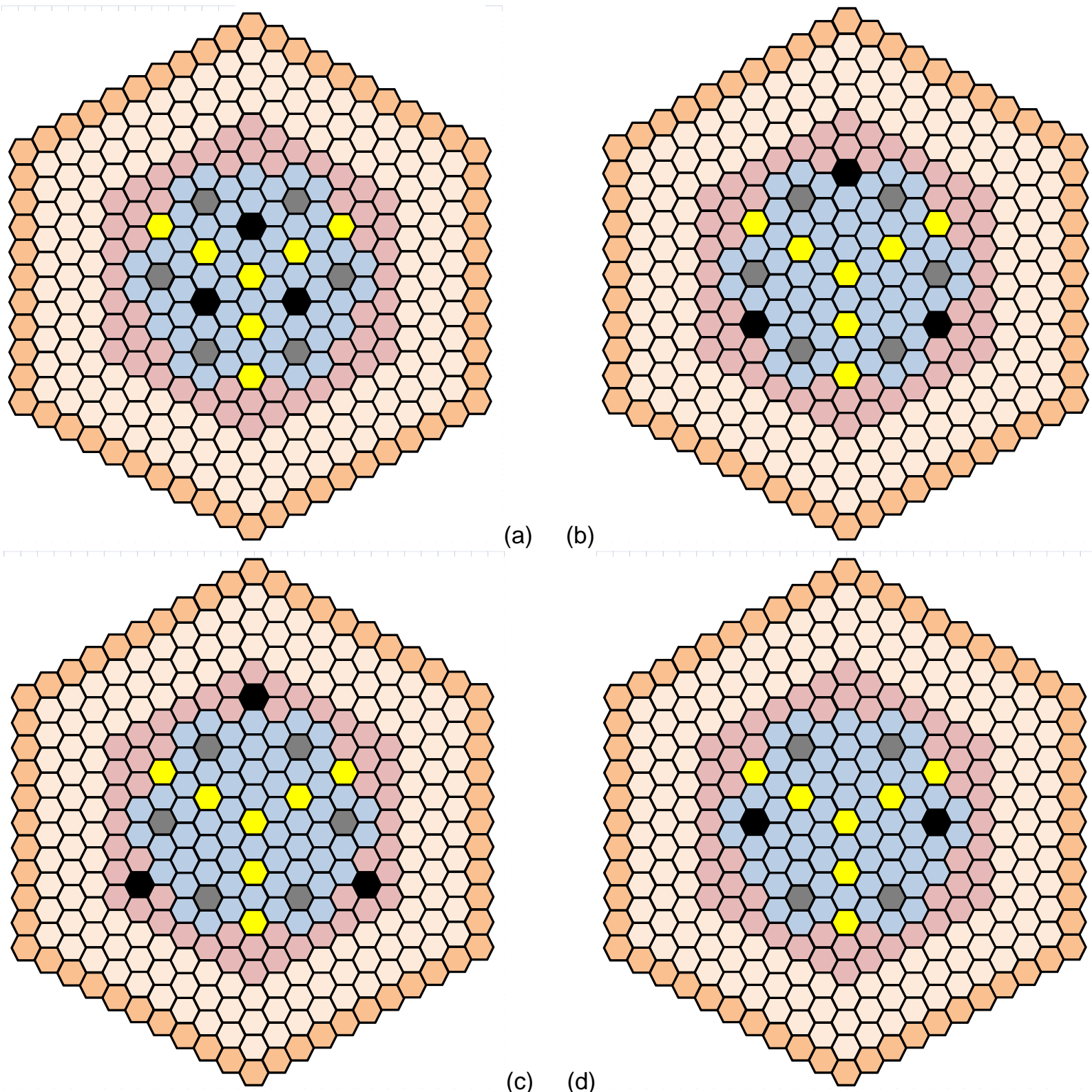

(c)
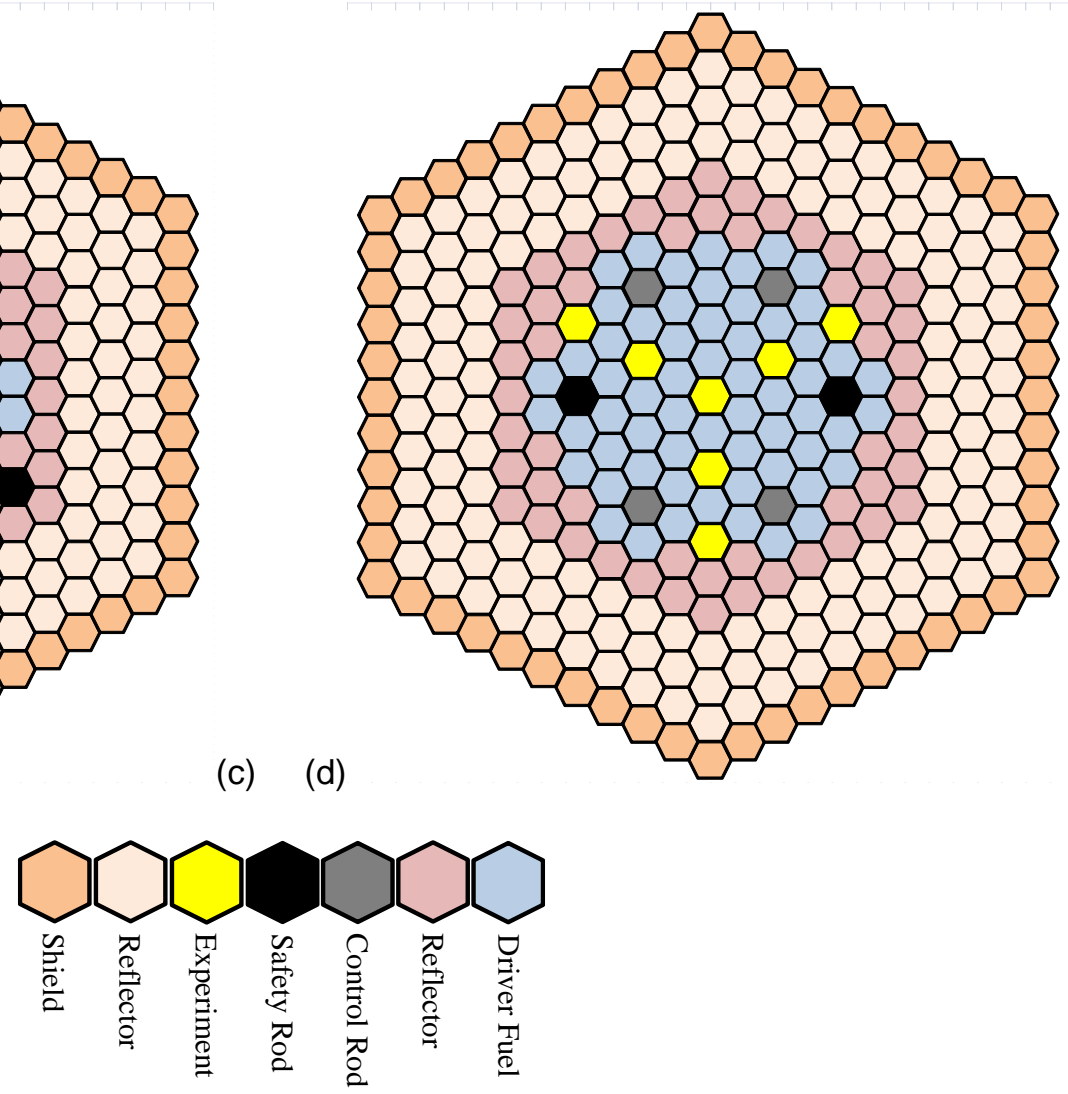

Figure 5.1. Examples of possible control and safety rod locations.

\subsection{BOC Excess Reactivity Mitigation}

The configurations exhibiting the highest peak fast flux levels are also characterized by a burnup reactivity swing on the order of 2,500-3,000 pcm over a 100-day cycle. Assuming a value of 2,750 pcm together with $20 \%$ uncertainty, the excess reactivity that must be controlled at BOC when the reactor is at nominal power is on the order of $3,300 \mathrm{pcm}$, which corresponds to about $\$ 10$ (assuming a typical delayed neutron fraction of $330 \mathrm{pcm}$ for a 
plutonium core). ${ }^{2}$ Assuming they use natural boron, the total worth of the six control rods when fully inserted is about 7,800 pcm ( $\left.\rho_{\text {all-CR-out }}-\rho_{\text {all-CR-in }}\right)$; as such, controlling these $3,300 \mathrm{pcm}$ is, in principle, doable.

If they need to compensate for the totality of the $3,300 \mathrm{pcm}$ excess reactivity, the six control rods will be inserted $30-40 \mathrm{~cm}$ into the core (assuming an active height of $80 \mathrm{~cm}$ ) at BOC and will be progressively withdrawn during the cycle, impacting, among other things, the axial flux profile in the nearby test vehicles present in the core. With enriched boron the control rods would need to be less inserted in the core but, on the other hand, would increase the reactivity ramp rate during a hypothetical inadvertent rod withdrawal $(\phi / \mathrm{sec})$.

From a safety standpoint, a general rule is that the smaller the reactivity inventory in movable absorbers the better since it limits the amount of reactivity that needs to be considered for protected and unprotected transient overpower (TOP and UTOP). It is also preferable if the most effective rod worth is less than $\$ 1$; If the core's $3,300 \mathrm{pcm}$ $(\$ 10)$ of BOC excess reactivity are controlled solely with the six movable control rods the average rod worth is about 550 pcm (i.e., \$1.67).

As an example, the normal FFTF rod withdrawal speed was between 0.36 and 9 inches per minute whereas the maximum mechanical speed of the control rod drive mechanism (CRDM) was about 70 inches per minute. Assuming the same rod withdrawal speed, the inadvertent withdrawal of the most effective rod could potentially insert about $\$ 1.67$ in as fast as about $10-12$ second (13-16 $/ \mathrm{sec})$ but most likely no faster than in about 90 seconds ( 2\$/sec). Analyses performed by GE for PRISM showed that such reactivity insertion (i.e., more than $\$ 1$ ) could lead to cladding failure and fuel dispersion if the reactor was not scrammed.

To limit the potential consequences of hypothetical unprotected reactivity events (because of the large BOC excess reactivity), the reactor could use either a rod stop system or use fixed shim absorbers or a combination of both. Shortening the cycle length would also decrease the required BOC excess reactivity. The following paragraphs briefly discuss these approaches.

\subsubsection{Rod Stop System}

For PRISM, GE used an electronically positioned, safety grade mechanical rod stop system [NUREG-1368]. This system limits control rod withdrawal to bound the amount of reactivity that can be added to the core as a result of an uncontrolled rod withdrawal event. The rod stops were to be adjusted over the fuel cycle of the reactor to account for burnup; adjustments were to be performed five to six times during the 18-month fuel cycle. This feature makes possible the passive accommodation of events that are precipitated by one or more control rod withdrawals accompanied by a failure to scram. The rod stop physically limits the withdrawal stroke of the control rod drives; it is designed to limit the reactivity insertion possible from all control rods being withdrawn from the normal power banked position until stopped by the limiter to $40 \$$ (30屯 from rods and $10 \phi$ for uncertainty) worth of reactivity. Analyses of transient overpower events indicated that the PRISM core could accommodate up to $40 \$$ of reactivity insertion from full power without scram and still meet the beyond-design-events criteria. However, if the rod stop system were to fail to perform its intended function during a UTOP event, GE estimated the maximum reactivity insertion to be $\$ 1.65$. Under such conditions, GE concluded that cladding failure and fuel dispersion could occur in less than one minute.

\subsubsection{Fixed Shim Absorber}

Part of the core BOC reactivity could also be controlled using fixed shim absorbers. ${ }^{3}$ Fixed shim could be inserted at $\mathrm{BOC}$ and withdrawn during the cycle when the fuel reactivity has sufficiently decreased. Figure 5.2 shows an example of how the use of fixed shim absorbers could impact the core reactivity during a 100-day cycle. Whereas

\footnotetext{
${ }^{2}$ A delayed neutron fraction of $330 \mathrm{pcm}$ is typical of a DU-20Pu-10Zr fuel. The value obtained for a DU-27Pu-10Zr fuel is about $300 \mathrm{pcm}$. Fuels with containing a lower Pu content together with LEU have a higher delayed neutron fraction, e.g., 540 pcm for a LEU(20\%)-11.5Pu-10Zr fuel.

3 The FFTF FSAR indicates that fixed shim absorbers were also used at least for the first and second cycles.
} 
the six control rods need to compensate $\$ 10$ worth of excess reactivity at BOC when there is no fixed shim, they would need to compensate only, respectively, $\$ 5$ and $\$ 3.33$ in the case of a 1-batch or 2-batch fixed shim approach (see Figure 3). The maximum rod worth would then drop from about $\$ 1.67$ when no fixed shim is used to about, respectively, $\$ 0.83$ and $\$ 0.55$ in the case of a 1-batch or 2-batch fixed shim approach.

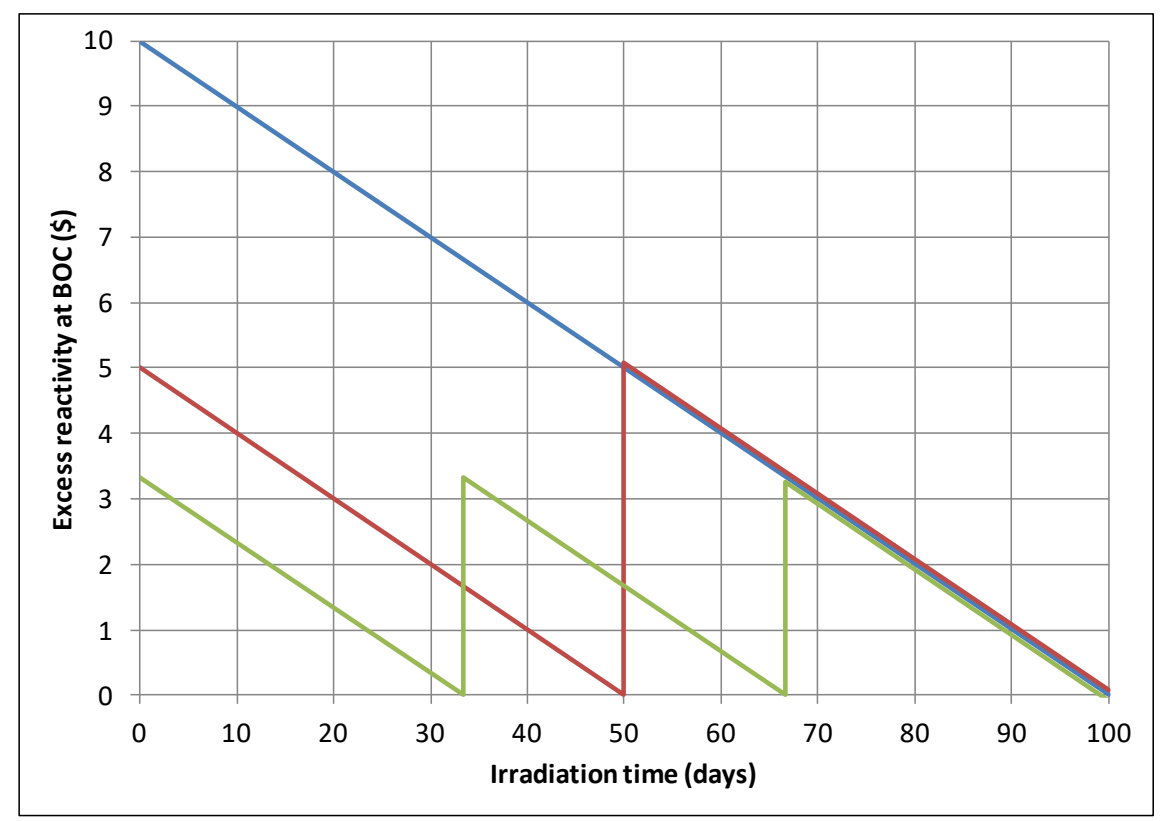

Figure 5.2. Fixed shim absorber effect on core reactivity inventory during a 100-day cycle. Blue: no fixed shim; Red: $\$ 5$ of fixed shim are inserted at BOC and withdrawn after 50 days; Green: $\$ 6.66$ of fixed shim are inserted at $\mathrm{BOC}, \$ 3.33$ are withdrawn after 33 days and the other $\$ 3.33$ are withdrawn after 66 days.

From a BOC excess reactivity point of view, the 1-batch and 2-batch fixed shim approaches are equivalent to operating with, respectively, a 50-day and a 33.3-day fuel cycle length. On the other hand, the fixed shim approach would require fewer fuel loading and unloading operations.

A few preliminary calculations performed on the core configuration shown in Figure 5.3 showed that three fixed shim absorbers made up of natural boron (with the same geometry and composition as a control rod) and located at the core periphery would lower the BOC core reactivity by $2,250 \mathrm{pcm}(\$ 6.8)$. This would be more than enough for a 1-batch fixed shim approach. For a 2-batch fixed shim approach, six fixed shim absorbers would be necessary to maintain core symmetry. More detailed neutronics calculations would need to be performed to estimate the impact of the shims on the flux distribution and achievable cycle length, if any. 


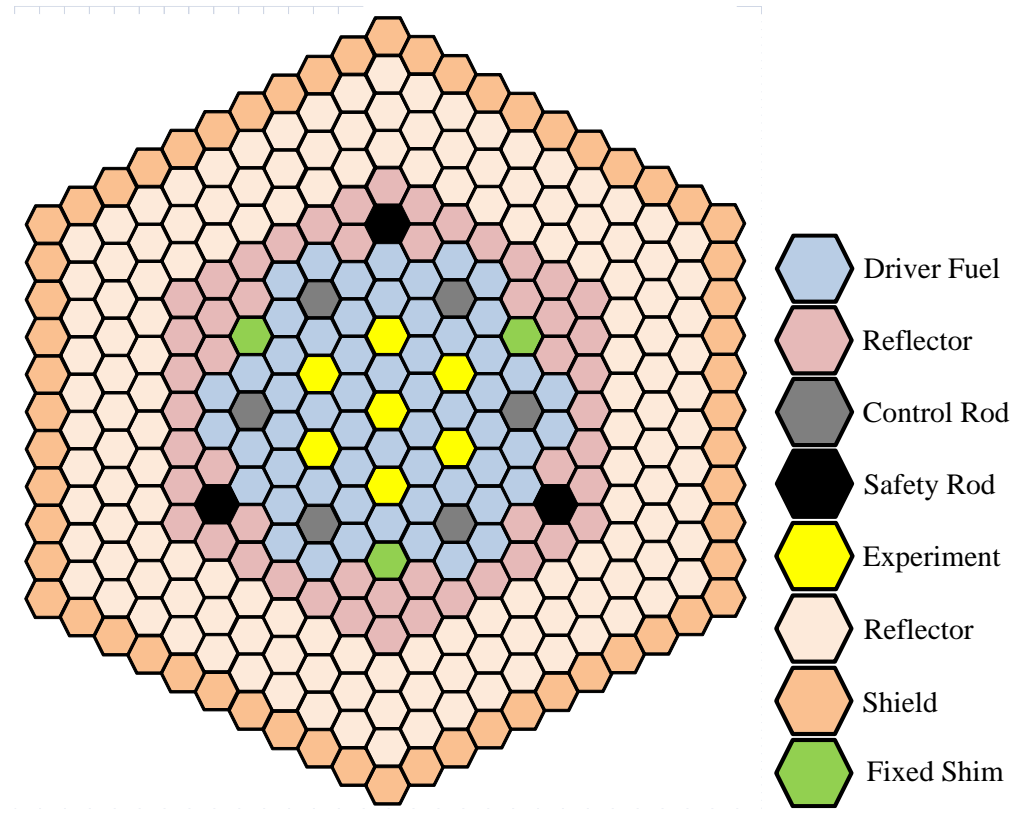

Figure 5.3. Example of fixed shim location.

\subsubsection{Shorter Cycle Lengths}

Another way to decrease the required BOC reactivity is to use shorter cycle lengths. For example, whereas, a 100-day cycle requires about $\$ 10$ of BOC excess reactivity, 50- and 33.33-day cycles will require, respectively, $\$ 5$ and $\$ 3.33$. The maximum rod worth would then drop from about $\$ 1.67$ for a 100 -day cycle to about, respectively, $\$ 0.83$ and $\$ 0.55$ for a 50 -day cycle and a 33.33 day-cycle.

Between about 400 and 500 days of irradiation are necessary to reach the target average fuel burnup of about $6 \%$. The use of 50- and 33.33-day cycle would then require, respectively $8-10$ batches and $12-15$ batches. However, since the number of driver fuel assemblies is typically between about 40 and 80 depending on the fuel composition, there is probably an upper limit on the number of batches that is reasonable for an operational standpoint.

Finally, the impact of shortening the cycle length on the capacity factor may be limited if the refueling time is also shorter. For example, assuming a 100-day cycle length and a 14-day refueling time the capacity factor is 0.88 , whereas it is 0.83 with a 33.33-day cycle length if the refueling time can be shorten to 7 days (see Table 5.2). In principle, the sensitivity of the capacity factor with regard to the cycle length decreases with the refueling time.

Table 5.2. Capacity factor as a function of cycle length and refueling time

\begin{tabular}{|c|c|c|c|}
\hline $\begin{array}{l}\text { time } \\
\text { length }\end{array}$ & 7 days & 14 days & 21 days \\
\hline 100 days & 0.94 & 0.88 & 0.83 \\
\hline 50 days & 0.88 & 0.78 & 0.70 \\
\hline 33.33 days & 0.83 & 0.70 & 0.61 \\
\hline
\end{tabular}




\section{Preliminary Thermal Hydraulics Uncertainty Considerations}

In any given channel within a fuel assembly, the sodium temperature, inside cladding temperature and fuel centerline temperature at height $z$ can be calculated as follows:

$$
\begin{gathered}
T_{N a}(z) \cong T_{N a, i n}+\frac{\int_{z_{i n}}^{z} P_{l i n}(z) d z}{\dot{m}_{N a} C_{p, N a}}+\Delta T_{T}(z) \\
T_{c i}(z)=T_{N a}(z)+\Delta T_{N a, f i l m}(z)+\Delta T_{c}(z) \\
T_{C L}(z)=T_{N a}(z)+\Delta T_{N a, f i l m}(z)+\Delta T_{c}(z)+\Delta T_{f}(z)
\end{gathered}
$$

The average sodium bulk inlet temperature, $T_{N a, i n}$, is currently assumed to be $350^{\circ} \mathrm{C}$. The term $\Delta T_{T}(z)$ takes into account the presence of a radial temperature profile within a fuel assembly due to complex transverse exchanges of mass, energy and momentum between adjacent channels. At an assembly outlet a value of $\Delta T_{T}$ of $20^{\circ} \mathrm{C}-30^{\circ} \mathrm{C}$ is typical for central channels. Hence, whereas an assembly may have an average sodium outlet temperature of $510^{\circ} \mathrm{C}$, the sodium outlet temperature of the central channels may be about $530^{\circ} \mathrm{C}-540^{\circ} \mathrm{C}$ (Figure 6.1 ).

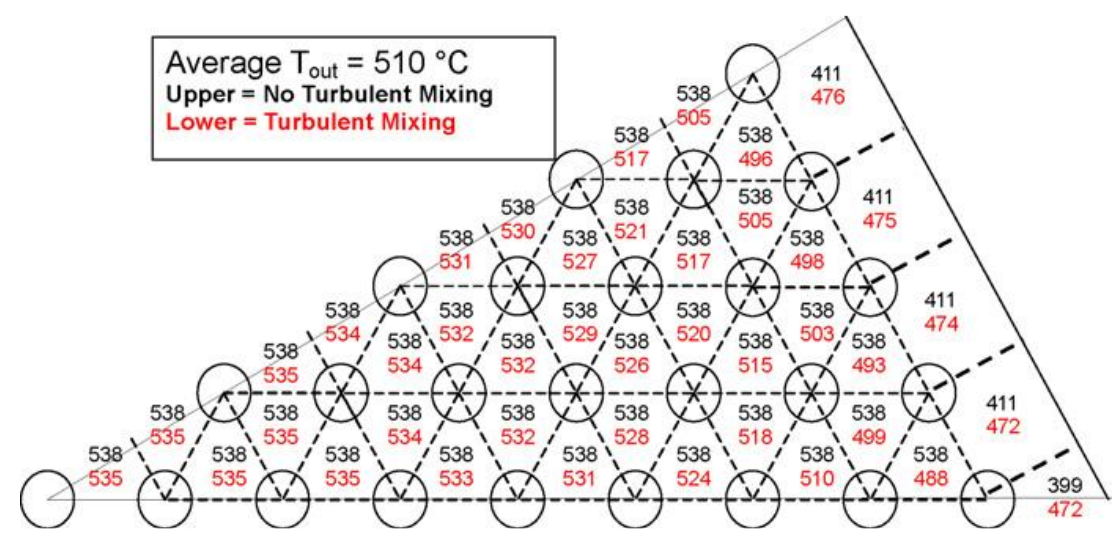

Figure 6.1. Example of sodium outlet temperatures within a fuel assembly with a flat power distribution. [Memmott, 2010]

Assuming a core average outlet sodium temperature of $500^{\circ} \mathrm{C}$, a hot channel sodium outlet temperature of $550^{\circ} \mathrm{C}$ or higher would be typical. It is the result of the core radial power distribution and also of a less than perfect orificing scheme. With a typical max-to-average assembly power of 1.33 , without orificing the average inlet-outlet sodium $\Delta \mathrm{T}$ in the hottest assembly would be $33 \%$ higher (i.e., $50^{\circ} \mathrm{C}$ higher) than the core average value of $150^{\circ} \mathrm{C}$ $\left(500^{\circ} \mathrm{C}-350^{\circ} \mathrm{C}\right.$ ) leading to an average sodium outlet temperature of $550^{\circ} \mathrm{C}$ in the hottest assembly. A perfect (but impractical) orificing scheme would ensure all fuel assemblies have the same average sodium outlet temperature of $500^{\circ} \mathrm{C}$. With an actual orificing scheme, the reality is somewhere in between (i.e., between $500^{\circ} \mathrm{C}$ and $550^{\circ} \mathrm{C}$ ).

An example of average sodium outlet temperatures in FFTF is shown on Figure 6.2; whereas the nominal core average inlet-outlet sodium $\Delta \mathrm{T}$ is $167^{\circ} \mathrm{C}\left(900^{\circ} \mathrm{F}-600^{\circ} \mathrm{F}\right)$, it reaches $215^{\circ} \mathrm{C}\left(988^{\circ} \mathrm{F}-600^{\circ} \mathrm{F}\right)$ in a central fuel assembly. On top of this core wide effect come the $20^{\circ} \mathrm{C}-30^{\circ} \mathrm{C}$ intra-assembly temperature gradients mentioned above and caused by transverse exchanges between adjacent channels within the same assembly. The combination of these two effects leads to a realistic hot channel sodium outlet temperature of $550^{\circ} \mathrm{C}$ (though higher values are possible) when the core average outlet sodium temperature is only $500^{\circ} \mathrm{C}$.

Table 6.1 shows typical nominal values of inside cladding temperatures for a hot channel assuming different linear powers at the top of the fuel column and for an assembly characterized by a hot channel sodium outlet temperature of $550^{\circ} \mathrm{C}$ (see Appendix 3 for examples of axial temperature profiles). Assuming a representative linear power of 
about $200 \mathrm{~W} / \mathrm{cm}$ at the top of a hot channel leading to an inside cladding temperature of $575^{\circ} \mathrm{C}$ (i.e., $75^{\circ} \mathrm{C}$ hotter than the core average sodium outlet temperature). Table 6.2 shows typical nominal values of fuel centerline temperatures at core mid-plane for several peak linear powers assuming a cosine power distribution. The peak linear power assumed for this study is $450 \mathrm{~W} / \mathrm{cm}$ leading to a nominal fuel centerline temperature of about $830^{\circ} \mathrm{C}$ at core mid-plane.

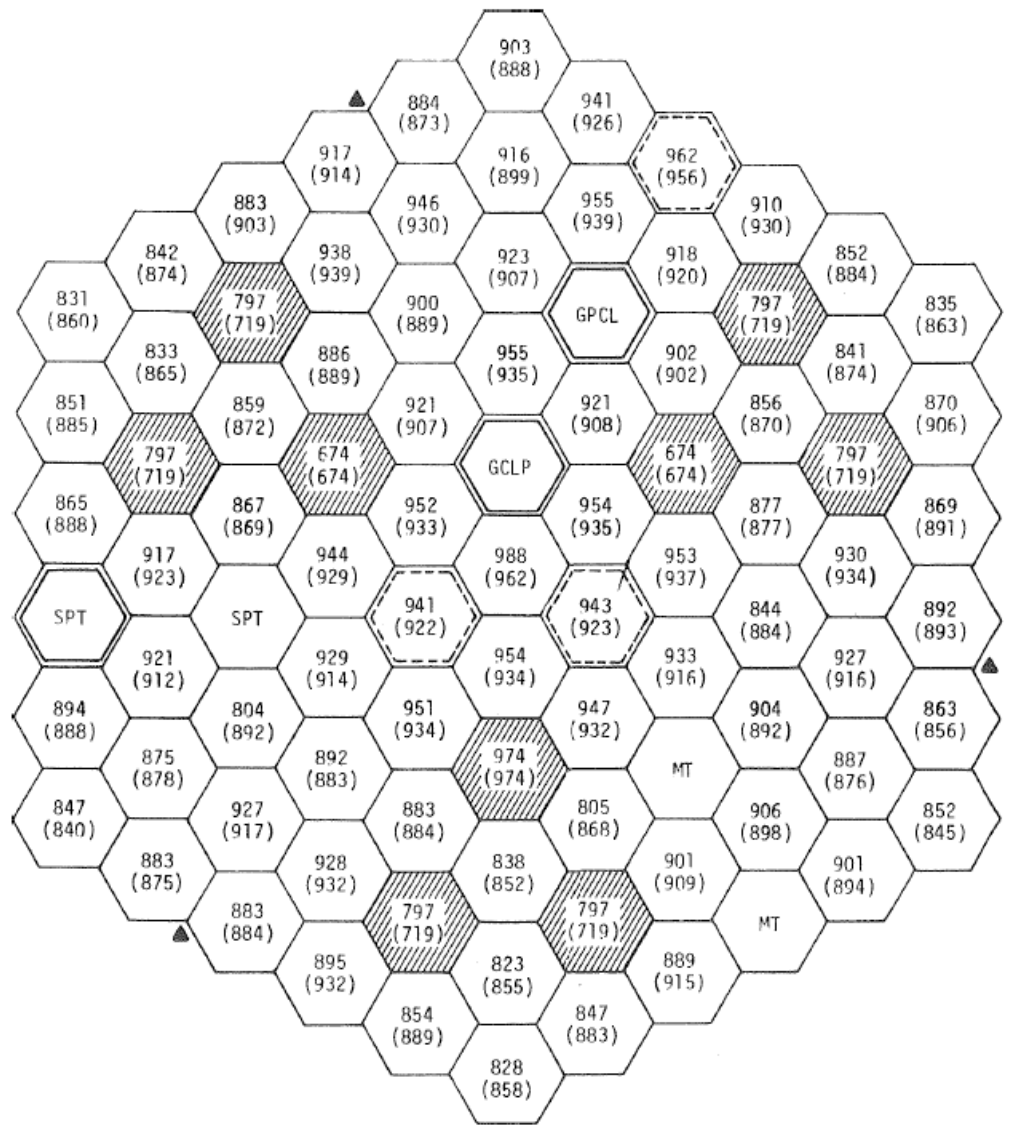

Figure 6.2. Example of nominal average sodium outlet temperatures in FFTF for a typical BOC and EOC equilibrium cycle. Core average sodium inlet and outlet temperatures are, respectively, $600^{\circ} \mathrm{F}$ and $900^{\circ} \mathrm{F}$.

Table 6.1. Typical nominal sodium, cladding, and fuel $\mathrm{CL}$ temperatures $\left({ }^{\circ} \mathrm{C}\right)$ at the outlet of a hot channel for different linear powers at the top of the fuel column

\begin{tabular}{|c|c|c|c|c|c|c|c|}
\hline$P_{\text {lin }}(\mathrm{W} / \mathrm{cm})$ & T-Na & $\Delta$ T-film & $\Delta$ T-clad & T-clad-in & T-fuel-S & $\Delta$ T-fuel & T-fuel-CL $^{*}$ \\
\hline 100 & $\mathbf{5 5 0}$ & 3 & 10 & $\mathbf{5 6 3}$ & 563 & 82 & 645 \\
\hline 200 & $\mathbf{5 5 0}$ & 6 & 19 & $\mathbf{5 7 5}$ & 575 & 154 & 729 \\
\hline 300 & $\mathbf{5 5 0}$ & 9 & 29 & $\mathbf{5 8 7}$ & 587 & 217 & 804 \\
\hline
\end{tabular}

${ }^{*} \mathrm{~T}$-fuel-CL is calculated for a U-20Pu-10Zr fuel assuming $\mathrm{k}(\mathrm{T})=0.5 \times \mathrm{k}_{0}(\mathrm{~T})$ where $\mathrm{k}_{0}(\mathrm{~T})$ and $\mathrm{k}(\mathrm{T})$ are, respectively, the fresh fuel and irradiated fuel thermal conductivities (see Appendix 3 ).

Uncertainties and limiting values can be treated through the use of hot channel factors [Waltar, 2012; Vilim, 1985; Carelli, 1980]. The hot channel factor for a particular parameter is the ratio of the maximum value of that parameter to its nominal value. Hot channel factors are based on a combination of experimental data and experimentally verified analytical methods. Justification of these factors is an important and challenging task for the reactor designer and will not be attempted here. Hence, the discussion below aims only at providing a first estimation of the uncertainties based on hot channel factors typical of PRISM, FFTF, and CRBR. 
Table 6.2. Typical nominal sodium, cladding, and fuel $\mathrm{CL}$ temperatures $\left({ }^{\circ} \mathrm{C}\right)$ at core mid-plane of a hot channel for different peak linear powers assuming a cosine power distribution.

\begin{tabular}{|c|c|c|c|c|c|c|c|}
\hline$P_{\text {lin }}(\mathrm{W} / \mathrm{cm})$ & T-Na & $\Delta$ T-film & $\Delta$ T-clad & T-clad-in & T-fuel-S & $\Delta$ T-fuel & T-fuel-CL $^{*}$ \\
\hline 400 & $\mathbf{4 5 0}$ & 12 & 38 & 500 & 500 & 290 & $\mathbf{7 9 0}$ \\
\hline 450 & $\mathbf{4 5 0}$ & 13 & 43 & 506 & 506 & 324 & $\mathbf{8 3 0}$ \\
\hline 500 & $\mathbf{4 5 0}$ & 14 & 48 & 512 & 512 & 358 & $\mathbf{8 7 0}$ \\
\hline
\end{tabular}

${ }^{*} \mathrm{~T}$-fuel-CL is calculated for a U-20Pu-10Zr fuel assuming $\mathrm{k}(\mathrm{T})=0.5 \times \mathrm{k}_{0}(\mathrm{~T})$ where $\mathrm{k}_{0}(\mathrm{~T})$ and $\mathrm{k}(\mathrm{T})$ are, respectively, the fresh fuel and irradiated fuel thermal conductivities (see Appendix 3).

To calculate a 2-sigma inside cladding temperature, the $\Delta \mathrm{T}$-film is typically multiplied by a hot channel factor of about 2.5 (corresponding to an uncertainty of $150 \%$ on the sodium heat transfer coefficient $\mathrm{h}$ ), whereas the $\Delta \mathrm{T}$ clad is multiplied by a hot channel factor of about 1.15 (corresponding to a combined $15 \%$ uncertainty on the cladding thickness and thermal conductivity). Hence, assuming a linear power of $200 \mathrm{~W} / \mathrm{cm}$ at the top of the fuel column, the $\Delta \mathrm{T}$-film is increased from its nominal value of $6^{\circ} \mathrm{C}$ (Table 6.1) to a 2-sigma value of about $15^{\circ} \mathrm{C}$ and the $\Delta \mathrm{T}$-clad nominal value of $19^{\circ} \mathrm{C}$ to a 2 -sigma value of about $22^{\circ} \mathrm{C}$. The uncertainty on the sodium outlet temperature has a larger impact on the 2-sigma inside cladding temperature than the two other terms. Indeed, a $25 \%$ uncertainty is typically assumed for the hot channel sodium temperature rise between inlet and outlet; hence a nominal hot channel $\Delta \mathrm{T}-\mathrm{Na}$ of $200^{\circ} \mathrm{C}\left(550^{\circ} \mathrm{C}-350^{\circ} \mathrm{C}\right)$ gives a 2 -sigma value of $250^{\circ} \mathrm{C}$. The hot channel outlet sodium temperature is then increased from its nominal value of $550^{\circ} \mathrm{C}$ to a 2 -sigma value of $600^{\circ} \mathrm{C}$. The nominal and 2-sigma inside cladding temperatures are then, respectively, $575^{\circ} \mathrm{C}(550+6+19)$ and $637^{\circ} \mathrm{C}(600+15+22) .^{4}$ With these assumptions the 2-sigma uncertainty on the inside cladding temperature is then $62^{\circ} \mathrm{C}$. If instead of $25 \%$, an uncertainty of $15 \%$ is assumed for the hot channel sodium temperature rise between inlet and outlet, the 2-sigma uncertainty on the inside cladding temperature would be reduced to $42^{\circ} \mathrm{C}$. This is only an example, and detailed thermal hydraulic calculations - and, in particular, appropriate orificing strategies-are necessary to determine the maximum sodium outlet temperature.

To calculate 2-sigma fuel centerline temperatures uncertainties of about, respectively, $25 \%, 15 \%$, and $15 \%$ are typically assumed on the $\Delta \mathrm{T}$-film, $\Delta \mathrm{T}$-clad, and $\Delta \mathrm{T}$-fuel. Hence, assuming a peak linear power of $450 \mathrm{~W} / \mathrm{cm}$, the $\Delta \mathrm{T}$-film is increased from its nominal value of $13^{\circ} \mathrm{C}$ (Table 6.2) to a 2 -sigma value of about $16^{\circ} \mathrm{C}$, the $\Delta \mathrm{T}$-clad nominal value of $43^{\circ} \mathrm{C}$ to a 2 -sigma value of about $49^{\circ} \mathrm{C}$ and the $\Delta \mathrm{T}$-fuel nominal value of $324^{\circ} \mathrm{C}$ to a 2 -sigma value of about $373^{\circ} \mathrm{C}$. Assuming the same $25 \%$ uncertainty on the sodium temperature rise between inlet and core mid-plane (or slightly above) the nominal channel $\Delta \mathrm{T}$-Na of $100^{\circ} \mathrm{C}\left(450^{\circ} \mathrm{C}-350^{\circ} \mathrm{C}\right)$ becomes $125^{\circ} \mathrm{C}$ which puts the sodium mid-plane temperature at $475^{\circ} \mathrm{C}$. The nominal and 2 -sigma fuel centerline temperatures are then, respectively, $830^{\circ} \mathrm{C}(450+13+43+324)$ and $913^{\circ} \mathrm{C}(475+16+49+373)$. With these assumptions the 2-sigma uncertainty on the fuel centerline temperature is then $83^{\circ} \mathrm{C}$. The $\mathrm{U}-20 \mathrm{Pu}-10 \mathrm{Zr}$ solidus temperature is about $1,121^{\circ} \mathrm{C}$ (i.e., about $200^{\circ} \mathrm{C}$ above the 2 -sigma fuel centerline temperature during normal operation).

One fuel design criterion for FFTF and CRBRP was that no fuel melting should occur at some specified overpower [Waltar, 2012]; for both reactor designs this overpower was set at $115 \%$ of rated power. Applying this criterion here leads to a 2-sigma peak fuel temperature at overpower of about $997^{\circ} \mathrm{C}(494+18+56+429)^{5}$; this is still about $120^{\circ} \mathrm{C}$ below the U-20Pu-10Zr solidus temperature. For a $15 \%$ overpower situation the 2 -sigma peak cladding temperature would be $679^{\circ} \mathrm{C}(637+17+25)$.

\footnotetext{
4 This temperature difference between the 2-sigma peak inside cladding temperature and the average sodium outlet bulk temperature, i.e., $137^{\circ} \mathrm{C}$, is consistent with that indicated in the PRISM Preliminary Safety Information Document (PSID) and in the FFTF Preliminary Safety Analysis Report (PSAR). Chapter 4 of the PRISM PSID shows an average sodium outlet bulk temperature of $875^{\circ} \mathrm{F}$ and a 2 -sigma peak cladding temperature of $1062^{\circ} \mathrm{F}$, hence a difference of $187^{\circ} \mathrm{F}\left(104^{\circ} \mathrm{C}\right)$. Table $3-I I$ in $\mathrm{Chapter} 3$ of the FFTF PSAR shows an average sodium outlet bulk temperature of $900^{\circ} \mathrm{F}$ and a steady-state 2-sigma peak cladding temperature of $1170^{\circ} \mathrm{F}$, hence a difference of $270^{\circ} \mathrm{F}\left(150^{\circ} \mathrm{C}\right)$.

5 The 2 -sigma values for $15 \%$ overpower are obtained by multiplying the 2 -sigma $\Delta$ Ts by 1.15
} 


\section{Fuel Cycle Considerations for a $\mathbf{3 0 0}$ MW Core}

\subsection{Fissile Material Requirement}

A $300 \mathrm{MW}$ core using a $70 \mathrm{U}-20 \mathrm{Pu}-10 \mathrm{Zr}$ fuel and characterized by a peak linear power of $450 \mathrm{~W} / \mathrm{cm}$ and fuel bundle pressure drop of $0.5 \mathrm{MPa}$ could reach peak fast neutron fluxes (PFF) between about $4.0 \times 10^{15} \mathrm{n} / \mathrm{cm}^{2}$-s and $5.5 \times 10^{15} \mathrm{n} / \mathrm{cm}^{2}$-s depending on the plutonium isotopic composition (weapons-grade or reactor-grade) and the uranium enrichment (up to 10 percent). The lowest value could be obtained using reactor-grade plutonium together with 5 percent enriched uranium in an $80-\mathrm{cm}$ long fuel; the highest value could be reached using weaponsgrade plutonium together with 10 percent enriched uranium in a $60-\mathrm{cm}$ long fuel. ${ }^{6}$ These PFF are still preliminary and are subject to revision as the design progresses. The use of a fuel with higher plutonium content-such as $\mathrm{U}-27 \mathrm{Pu}-10 \mathrm{Zr}$ - could reach PFF of about 4.5 to $5.0 \times 10^{15} \mathrm{n} / \mathrm{cm}^{2}$-s without enriched uranium and independently of the plutonium isotopic composition.

\subsubsection{Fissile Material Inventories for First Plutonium-Fueled Cores}

Depending on the plutonium isotopic composition and on the uranium enrichment, 70U-20Pu-10Zr fueled cores will contain between about $1,500 \mathrm{~kg}$ and $2.500 \mathrm{~kg}$ of heavy metal (uranium + plutonium). Core heavy metal inventories are dependent on fissile content and on fuel assembly and core design details. Four representative examples of first-core fissile material requirement scenarios sufficient for a $300 \mathrm{MW}$ core to yield a PFF of at least $4.0 \times 10^{15} \mathrm{n} / \mathrm{cm}^{2}$-s are listed below by order of PFF achievable:

1) $330 \mathrm{~kg}$ of weapons-grade plutonium $+1,170 \mathrm{~kg}$ of 10 percent enriched uranium; PFF $~ 5.5 \times 10^{15} \mathrm{n} / \mathrm{cm}^{2}-\mathrm{s}$

2) $510 \mathrm{~kg}$ of weapons-grade plutonium $+1,790 \mathrm{~kg}$ of depleted or natural uranium; PFF $~ 5.0 \times 10^{15} \mathrm{n} / \mathrm{cm}^{2}-\mathrm{s}$

3) $475 \mathrm{~kg}$ of reactor-grade plutonium $+1,675 \mathrm{~kg}$ of 10 percent enriched uranium; PFF $\sim 4.5-5.0 \times 10^{15} \mathrm{n} / \mathrm{cm}^{2}-\mathrm{s}$

4) $555 \mathrm{~kg}$ of reactor-grade plutonium $+1,945 \mathrm{~kg}$ of 5 percent enriched uranium; PFF $\sim 4.0-4.5 \times 10^{15} \mathrm{n} / \mathrm{cm}^{2}-\mathrm{s}$

\subsubsection{Annual Fissile Material Requirement for Plutonium-Fueled Cores}

Assuming that it operates 300 equivalent-full-power-days per year and that the fuel reaches an average burnup at discharge of 6 percent, a $300 \mathrm{MW}$ core requires $1,500 \mathrm{~kg}$ of heavy metal (uranium + plutonium) per year for the $70 \mathrm{U}-20 \mathrm{Pu}-10 \mathrm{Zr}$ fuel fabrication; $330 \mathrm{~kg} / \mathrm{y}$ of plutonium (weapons-grade or reactor-grade) and 1,170 kg/y of uranium (depleted, natural, or up to 10 percent enriched). The annual heavy metal requirement is independent of the core inventory; even though a $300 \mathrm{MW}$ core fueled with LEU $\left(5 \%{ }^{235} \mathrm{U}\right)-20 \mathrm{Pu}^{\mathrm{RG}}-10 \mathrm{Zr}$ contains about 66 percent (2500/1500) more heavy metal than a $300 \mathrm{MW}$ core fueled with LEU $\left(10 \%{ }^{235} \mathrm{U}\right)-10 \mathrm{Pu} \mathrm{WG}_{-10 \mathrm{Zr}}$, they will both require $1,500 \mathrm{~kg}$ of heavy metal per year, assuming they reach the same 6 percent burnup.

A $300 \mathrm{MW}$ core fueled with U-27Pu-10Zr and reaching an average burnup at discharge of 6 percent would also require $1,500 \mathrm{~kg}$ of heavy metal (uranium + plutonium) per year-about $450 \mathrm{~kg}$ of plutonium (weapons-grade or reactor-grade) and $1050 \mathrm{~kg}$ of depleted (or natural) uranium per year.

For a given core power, the annual mass of heavy metal necessary to manufacture the fuel is only proportional to the average fuel burnup at discharge. Hence, if necessary, the amount of plutonium disposed of could be doubled by cutting the fuel burnup in half; with a 3 percent burnup, the reactor could disposed of about 660 to $900 \mathrm{~kg}$ of plutonium per year. Annual fuel manufacturing would need to be increased from 1,500 kg heavy metal for 6 percent burnup to $3,000 \mathrm{~kg}$ heavy metal for 3 percent burnup.

${ }^{6}$ Everything else being constant, increasing the fuel enrichment would not increase the PFF (it would increase the discharge burnup). On the other hand, with higher fuel enrichment (i.e., more potential reactivity available) the fuel assembly can be designed in a way that a higher PFF is possible (e.g., shorter fuel length or more open fuel assembly). 


\subsubsection{LEU Core}

An LEU core would require a larger core heavy metal inventory than a plutonium-fueled core and yield a lower PFF. Indeed, first estimates show that a 300 MW LEU-fueled core would contain about $5,500 \mathrm{~kg}$ of uranium (19.75 percent uranium-235) for a PFF of about $2.5 \times 10^{15} \mathrm{n} / \mathrm{cm}^{2}-\mathrm{s}$. Assuming an average burnup at a discharge of 6 percent and 300 equivalent-full-power-days of operation per year, a $300 \mathrm{MW}$ LEU-fueled core would require 1,500 $\mathrm{kg}$ of uranium per year (300 kg of uranium-235 per year).

\subsection{Fuel Fabrication}

As mentioned above, a $300 \mathrm{MW}$ core will require a fuel fabrication facility throughput of about $1,500 \mathrm{~kg} / \mathrm{yr}$ of heavy metal, corresponding to about $1,665 \mathrm{~kg} / \mathrm{yr}$ of U-Pu-10Zr alloy. The plutonium isotopic composition and, in particular, the presence of americium-241 impacts the gamma and neutron radiation fields. The gamma power, as well as the neutron source for the weapons-grade and reactor-grade plutonium fuels, were calculated; an additional reactor-grade isotopic composition was also considered in which all plutonium-241 has decayed into americium241 (Table 7.1). The results presented in Table 7.2 show that reactor-grade plutonium gamma and neutron sources are, respectively, about 3 times and 5 times higher than those obtained with weapons-grade plutonium. Assuming further that the 3.4 percent of plutonium-241 present in the reactor-grade plutonium have decayed into americium-241, the gamma source is increased by a factor of about 20 (Table 7.2).

Table 7.1. Plutonium isotopic compositions.

\begin{tabular}{|c|c|c|c|c|c|c|}
\hline & Pu-238 & Pu-239 & Pu-240 & Pu-241 & Pu-242 & Am-241 \\
\hline Pu-WG & - & 94 & 6 & - & - & - \\
\hline Pu-RG & 0.1 & 68.7 & 26.4 & 3.4 & 1.4 & - \\
\hline Pu-RG' & 0.1 & 68.7 & 26.4 & - & 1.4 & 3.4 \\
\hline
\end{tabular}

Table 7.2. Neutron and gamma source for $1 \mathrm{~kg}$ of U-20Pu-10Zr alloy depending on plutonium isotopic composition (one typical fuel assembly contains approximately $40 \mathrm{~kg}$ of fuel alloy).

\begin{tabular}{|c|c|c|}
\hline & $\begin{array}{c}\text { Gamma } \\
(\mathrm{mW} / \mathrm{kg})\end{array}$ & $\begin{array}{c}\text { Neutrons } \\
\left(10^{4} \mathrm{n} / \mathrm{s}-\mathrm{kg}\right)\end{array}$ \\
\hline Pu-WG & 0.07 & 1.1 \\
\hline Pu-RG & 0.19 & 5.3 \\
\hline Pu-RG' & 3.5 & 5.3 \\
\hline
\end{tabular}

\subsection{Spent Fuel}

\subsubsection{Decay Heat}

A $300 \mathrm{MW}$ core operating 300 days per year will generate approximately 30-40 spent fuel assemblies each year containing about $1,500 \mathrm{~kg}$ of heavy metal $(\sim 1,110 \mathrm{~kg}$ of uranium, $\sim 300 \mathrm{~kg}$ of plutonium and $\sim 90 \mathrm{~kg}$ of fission products). When the reactor operates at its nominal power of $300 \mathrm{MW}$, assembly powers are typically between about $4 \mathrm{MW}$ and $7 \mathrm{MW}$. At the end of the cycle, just when the reactor is shutdown, the assembly powers will be about 6.5 percent of these values (i.e. about $260-455 \mathrm{~kW}$ ) and will subsequently decay exponentially as they are stored. Using standard empirical expressions—available in [Todreas, 1990] for example-a first estimation of the exponential decay of the fission products up to about 100 days can be obtained: 0.48 percent after 1 day, 0.26 percent after 1 week, 0.15 percent after one month, and 0.09 percent after 3 months. ${ }^{7}$ Figure 7.1 shows the decay

7 The following expression was used: $P_{r}=0.066 \times\left[t_{s}^{-0.2}-\left(t_{s}+T\right)^{-0.2}\right]$ with $\mathrm{P}_{\mathrm{r}}$ the total fission products decay heat power relative to the initial power, $t_{s}$ the time since shutdown in seconds and $T$ the length of the irradiation also in seconds (assumed to be 500 days). This expression provides the sum of beta and gamma decays which each generate about half of the total decay power. Note that, while beta decay occurs within the fuel itself, gammas may be absorbed somewhere else. 
heat in two assemblies generating, respectively, $4 \mathrm{MW}$ and $7 \mathrm{MW}$ when the reactor is operating at its nominal power of $300 \mathrm{MW}$. These assemblies have a 12-cm flat-to-flat dimension and an active height of $80 \mathrm{~cm}$ corresponding to a volume of approximately $10^{4} \mathrm{~cm}^{3}$. Hence a decay heat of $10 \mathrm{~kW}$ corresponds to a decay power density of about $1 \mathrm{~W} / \mathrm{cm}^{3}$.

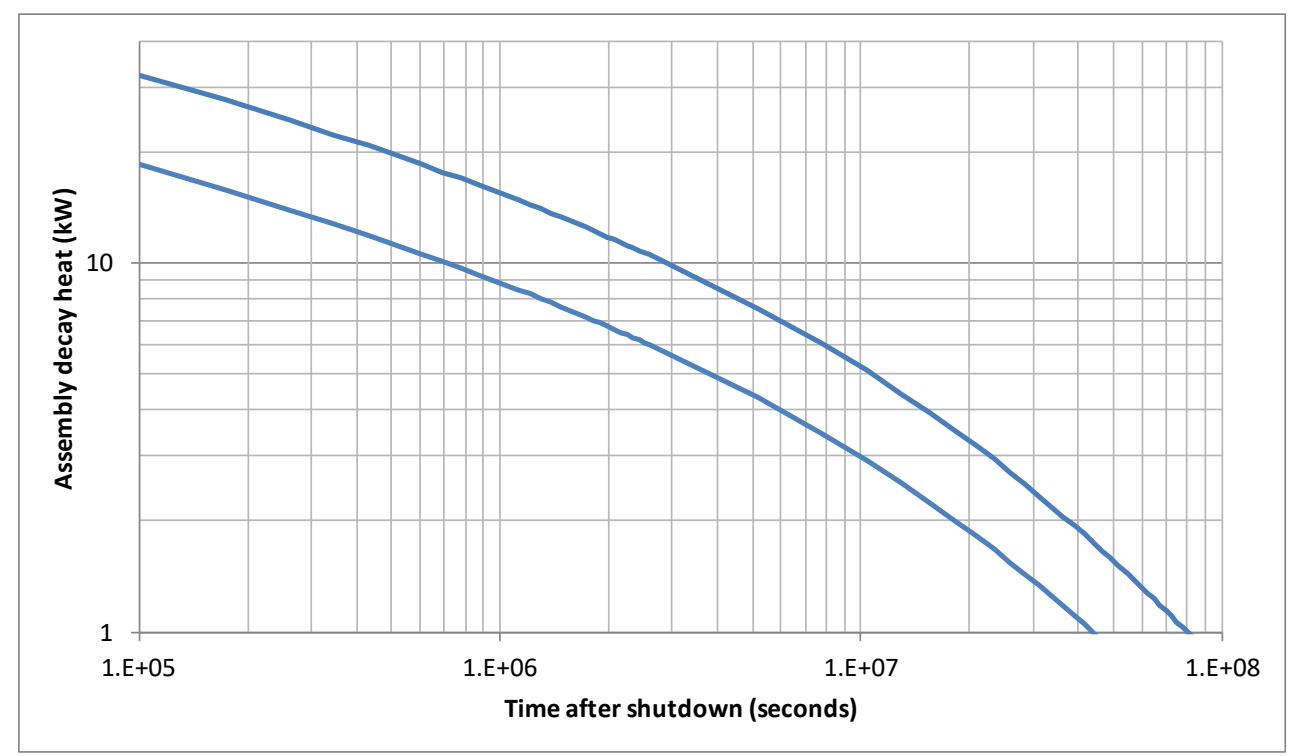

Figure 7.1. Preliminary estimation of the fission products' decay heat in two fuel assemblies generating, respectively, $4 \mathrm{MW}$ (bottom) and $7 \mathrm{MW}$ (top) when the reactor is operating at its nominal power of $300 \mathrm{MW}$

\subsubsection{Self-Protection Criteria}

If weapons-grade plutonium is used, it may be requested that the spent fuel assemblies meet the criteria described in the agreement between the government of the United States of America and the government of the Russian Federation concerning the management and disposition of plutonium designated as no longer required for defense purposes. This agreement states that "...the radiation level from each spent plutonium fuel assembly is such that it will become no less than 1 sievert per hour one meter from the accessible surface at the centerline of the assembly 30 years after irradiation has been completed."

The radiation level coming from a spent fuel assembly 30 years after the end of its irradiation comes essentially from the gamma field resulting from the decay of a single fission product, cesium-137, and is only weakly dependent on the total mass of heavy metal, the fuel form, the fissioning isotope (uranium-235 or plutonium-239), or the fuel assembly geometry. Furthermore, since the amount of cesium-137 in a fuel assembly increases linearly with the burnup, as a first approximation, a fuel assembly containing initially $100 \mathrm{~kg}$ of heavy metal and irradiated to a $3 \%$ burnup will have the same amount of cesium-137 as a fuel assembly containing initially $50 \mathrm{~kg}$ of heavy metal and irradiated to a $6 \%$ burnup. These simple physics considerations are useful to compare options without having to carry out detailed calculations.

A 2014 DOE report presents several options for the disposition of surplus weapon-grade plutonium including irradiation in a fast reactor similar to GE's PRISM ModB [DOE, 2014]. The fuel assemblies considered in this study contained about $40 \mathrm{~kg}$ of heavy metal, which is about the same as that in the fuel assemblies considered here. The results presented in this report show that a burnup of $2.5 \%$ is sufficient to build up enough cesium- 137 to meet the 1-Sv-per-hour-at-one-meter criteria. Based on these analyses it can be concluded that the fuel assemblies considered here will also meet the 1-Sv-per-hour-at-one-meter criteria. 


\section{Conclusions}

The objective of this trade study was to develop an understanding of how the various areas important to the design and successful operation of a fast neutron spectrum test reactor interact with one another. The main part of the work was to provide an estimation of the minimum number of fuel assemblies, core power, and peak fast neutron flux (above $0.1 \mathrm{MeV}$ ) given a set of design parameters and requirements-the most important of which being the use of U-Pu-10Zr or U-10Zr metallic fuels. Furthermore, as specified by the Department of Energy, the U-Pu-10Zr fuels must satisfy the following criteria, with respect to mass: $\left[{ }^{235} \mathrm{U}+\mathrm{Pu}\right] /[\mathrm{U}+\mathrm{Pu}+\mathrm{Zr}] \leq 0.27$. Reactivity coefficients and reactivity control were calculated for several configurations. A very preliminary estimation of thermal hydraulic uncertainties based on typical hot channel factors was attempted. Finally, some fuel cycle considerations that pertain to fissile material requirement, fuel fabrication, and spent fuel management were presented.

Depending on fissile type and enrichment level, the core power necessary to reach a peak fast flux of $4 \times 10^{15}$ $\mathrm{n} / \mathrm{cm}^{2}$-s can be as low as $150 \mathrm{MW}$ (using U-27PuWG-10Zr fuel) or as large as $700 \mathrm{MW}$ (using U-10Zr fuel and ${ }^{235} \mathrm{U} / \mathrm{U}=19.75 \%$ ). When targeting a peak fast flux of $5 \times 10^{15} \mathrm{n} / \mathrm{cm}^{2}-\mathrm{s}$, the core power can be as low as $200 \mathrm{MW}$ (using U-27PuWG-10Zr fuel) or in excess of $1,000 \mathrm{MW}$ (using $\mathrm{U}-10 \mathrm{Zr}$ fuel and ${ }^{235} \mathrm{U} / \mathrm{U}=19.75 \%$ ). A relatively small core $(\sim 150 \mathrm{MW})$ could be designed that would require a fuel with high fissile content such as U-27PuWG-10Zr and about $200-250 \mathrm{~kg}$ of weapons-grade plutonium per year. By increasing core power to about $300 \mathrm{MW}$ other fuel forms with higher TRL, such as various $\mathrm{U}-x \mathrm{Pu}-10 \mathrm{Zr}$ combinations with $10 \% \leq x \leq 20 \%$ and $0.3 \% \leq 235 \mathrm{U} / \mathrm{U} \leq$ $19.75 \%$ could be used. A $300 \mathrm{MW}$ core using a $70 \mathrm{U}-20 \mathrm{Pu}-10 \mathrm{Zr}$ fuel could reach peak fast neutron fluxes between about $4.0 \times 10^{15} \mathrm{n} / \mathrm{cm}^{2}-\mathrm{s}$ and $5.5 \times 10^{15} \mathrm{n} / \mathrm{cm}^{2}$-s depending on the plutonium isotopic composition (weapons-grade or reactor-grade) and the uranium enrichment (up to 10 percent). With regard to material availability, it is important to note that both weapons-grade and reactor-grade plutonium could be used. A $300 \mathrm{MW}$ core could also accommodate $\mathrm{U}-10 \mathrm{Zr}$ fuel with ${ }^{235} \mathrm{U} / \mathrm{U}=19.75 \%$ and reach peak fast fluxes of about $2.5 \times 10^{15} \mathrm{n} / \mathrm{cm}^{2}-\mathrm{s}$. Increasing core power from 300 to $400 \mathrm{MW}$, the peak fast flux could be increased by about 15-20\% for any fuel type.

The core should use two independent reactivity control systems: a primary (control) and a secondary (safety) reactivity control system. A preliminary estimation shows that their required worths can easily be met with six control rods and three safety rods. The configurations exhibiting the highest peak fast flux levels are also characterized by a burnup reactivity swing of the order of $2,500-3,000 \mathrm{pcm}$ over a 100 -day cycle. Assuming a value of $2,750 \mathrm{pcm}$ together with $20 \%$ uncertainty, the excess reactivity that must be controlled at BOC when the reactor is at nominal power is of the order of $3,300 \mathrm{pcm}$ which corresponds to about $\$ 10$. The use of fixed shim or rod stop may be necessary to lower the BOC excess reactivity and ensure no single rod is worth more than $\$ 1$.

Assuming a core average outlet sodium temperature of $500^{\circ} \mathrm{C}$, a hot channel sodium outlet temperature of $550^{\circ} \mathrm{C}$ or higher would be typical. It is the result of the core radial power distribution and also of a less than perfect orificing scheme. The nominal inside peak cladding temperature would then be about $575^{\circ} \mathrm{C}$. Assuming a typical $25 \%$ uncertainty for the hot channel sodium temperature rise between inlet and outlet lead to a 2-sigma uncertainty on the inside cladding temperature of about $60^{\circ} \mathrm{C}$. If instead of $25 \%$, an uncertainty of $15 \%$ is assumed for the hot channel sodium temperature rise between inlet and outlet, the 2-sigma uncertainty on the inside cladding temperature would be reduced to about $40^{\circ} \mathrm{C}$.

Depending on the plutonium isotopic composition and on the uranium enrichment, a $300 \mathrm{MW} 70 \mathrm{U}-20 \mathrm{Pu}-10 \mathrm{Zr}$ fueled core would contain between about $1,500 \mathrm{~kg}$ and $2,500 \mathrm{~kg}$ of heavy metal (uranium + plutonium) including between 330 and $555 \mathrm{~kg}$ of plutonium. Assuming that it operates 300 equivalent-full-power-days per year and that the fuel reaches an average burnup at discharge of 6 percent, a $300 \mathrm{MW}$ core requires $1,500 \mathrm{~kg}$ of heavy metal (uranium + plutonium) per year for the $70 \mathrm{U}-20 \mathrm{Pu}-10 \mathrm{Zr}$ fuel fabrication, $330 \mathrm{~kg} / \mathrm{yr}$ of plutonium (weapons-grade or reactor-grade), and $1,170 \mathrm{~kg} / \mathrm{yr}$ of uranium (depleted, natural, or up to 10 percent enriched).

The plutonium isotopic composition and in particular the presence of americium-241 impacts the gamma and neutron radiation fields at fabrication. Reactor-grade plutonium gamma and neutron sources are, respectively, about 3 times and 5 times higher than those obtained with weapons-grade plutonium. If weapons-grade plutonium is used, it may be requested that the spent fuel meet the criteria described in the agreement between the 
government of the United States of America and the government of the Russian Federation concerning the management and disposition of plutonium designated as no longer required for defense purposes (i.e. the 1-Sv-perhour-at-one-meter after 30 years criteria). A preliminary analysis shows that the spent fuel assemblies should easily meet this criterion if the average burnup at discharge is 6 percent.

\section{References}

M. C. Billone, Y. Y. Liu, E. E. Gruber, T. H. Hughes, J. M. Kramer, "Status of fuel element modeling codes for metallic fuels", International conference on Reliable Fuels for Liquid Metal Reactors, Tucson, Arizona, 1986

A. J. Brunett, and T. H. Fanning, U.S. Sodium Fast Reactor Codes and Methods: Current Capabilities and Path Forward, International Conference on Fast Reactors and Related Fuel Cycles, FR17, 26-29 June 2017 Yekaterinburg, Russian Federation

M. D. Carelli and A. J. Friedland, "Hot channel factors for rod temperature calculations in LMFBR assemblies", Nuclear Engineering and Design 62 (1980) 155-180

W.J. Carmack, L.A. Braase, R.A. Wigeland, M. Todosow, "Technology readiness levels for advanced nuclear fuels and materials development", Nuclear Engineering and Design 313 (2017) 177-184

S.K. Cheng, N.E. Todreas, Hydrodynamic models and correlations for bare and wire-wrapped hexagonal rod bundles-bundle friction factors, sub-channel friction factors and mixing parameters, Nuclear Engineering and Design 92 (1986) 227-251

D. C. Crawford, D. L. Porter, S. L. Hayes, Fuels for sodium-cooled fast reactors: US perspective, Journal of Nuclear Materials 371 (2007) 202-231

DOE, 2014, Analysis of Surplus Weapon-Grade Plutonium Disposition Options

G. Flamenbaum, A. Zaetta, M. Martini, M. Michenot, T. Newton, H. Sztark, "Analysis of specific control rod experiments involving highly distorted flux distributions”, Nuclear Science and Engineering 106 (1990) 64-68

F. Heidet and R. N. Hill, Reactor Neutronics: Impact of Fissile Material, Nuclear Science and Engineering, 187:2, p. 202-211 (2017)

M. Memmott, J. Buongiorno, P. Hejzlar, "On the use of RELAP5-3D as a subchannel analysis code", Nuclear Engineering and Design 240 (2010) 807-815

NUREG-1368, Preapplication Safety Evaluation Report for the Power Reactor Innovative Small Module (PRISM) Liquid-Metal Reactor

G. Palmiotti, M. Salvatores, "Use of integral experiments in the assessment of large liquid-metal fast breeder reactor basic design parameters", Nuclear Science and Engineering: 87, 333-348 (1984)

D. Petti., et al., Advanced Demonstration and Test Reactor Options Study, INL/EXT-16-37867, Revision 2, July 2016.

J. L. Rowlands, "Physics of fast reactor control rods", Progress in Nuclear Energy, vol. 16, no 3, pp 287-321, 1985

J.M. Ruggieri, J. Tommasi, J.F. Lebrat, C. Suteau, D. Plisson-Rieunier, C. De Saint Jean G. Rimpault, J.C. Sublet, "ERANOS 2.1 : International Code System for GEN IV Fast Reactor Analysis", Proceedings of ICAPP '06 Reno, NV USA, June 4-8, 2006 Paper 6360

Y. Tang, R. Coffield, R. Markley, Thermal Analysis of Liquid Metal Fast Breeder Reactors, page 79, published by the American Nuclear Society, 1978

N. E. Todreas, M. S. Kazimi, "Nuclear Systems I: Thermal Hydraulic Fundamentals”, MIT, 1990 
R. Vilim, "Reactor hot spot analyses", ANL FRA technical memorandum \# 152, 1985

D. C. Wade and E. K. Fujita, Trends Versus Reactor Size of Passive Reactivity Shutdown and Control Performance, Nuclear Science and Engineering, 103, p. 182-195 (1989)

A. E. Waltar, D. R. Todd, P. V. Tsvetkov, Fast Spectrum Reactors, Springer, 2012

R. A. Wigeland, R. B. Turski and P. A. Pizzica, Impact of Reducing Sodium Void Worth on the Severe Accident Response of Metallic-Fueled Sodium-Cooled Reactors, International Meeting on Advanced Reactor Safety, American Nuclear Society, April 17-21, 1994, Pittsburgh, PA 


\section{Appendix 1: Pressure Drop Correlation}

The pressure drop correlation for wire wrapped fuel pins arranged on a triangular pitch given below is based the well-known work of Cheng and Todreas [Cheng, 1986].

$$
\begin{gathered}
\Delta p=\left(f \frac{L}{D_{h}}\right) \rho_{N a} \frac{v_{N a}^{2}}{2} \\
D_{h}=\frac{4 A_{\text {flow }}}{P_{\text {wet }}} \\
f=C_{f} \operatorname{Re}^{-0.18} \\
C_{f}=\left\{0.8063-0.9022 \log \left(\frac{H}{D}\right)+0.3526 \log ^{2}\left(\frac{H}{D}\right)\right\}\left(\frac{P}{D}\right)^{9.7}\left(\frac{H}{D}\right)^{1.78-2\left(\frac{P}{D}\right)}
\end{gathered}
$$

Applicability range: $400 \leq \mathrm{Re} \leq 100,000 ; 1.067 \leq \mathrm{P} / \mathrm{D} \leq 1.35 ; 4.0 \leq \mathrm{H} / \mathrm{D} \leq 52.0$

$D_{h}$ is the hydraulic diameter. Aflow is the sodium flow area within the fuel bundle. $P_{\text {wet }}$ is the pin and wire perimeter plus that of the inside of the duct. Re is the Reynolds number. P/D is the pin pitch over diameter ratio and $H / D$ is the wire axial pitch over fuel pin diameter ratio

The assemblies analyzed in the trade study have hydraulic diameters between $2.1 \mathrm{~mm}$ and $2.9 \mathrm{~mm}$. Sodium velocities are between $8 \mathrm{~m} / \mathrm{s}$ and $10 \mathrm{~m} / \mathrm{s}$ corresponding to Reynolds numbers between about 50,000 and 100,000. 
Table A2.1 presents three examples of assemblies with similar fuel, coolant and structure volume fractions but different number of fuel pins (271, 217 and 169). The methodology presented in Section 3 was used to calculate the maximum assembly power not to be exceeded as a function of the number of fuel pins and fuel height for similar fuel, coolant and structure volume fractions. Results presented in Table A2.2 show that the impact is very case specific. For example for a 100-cm fuel height, going from 271 fuel pins to 217 fuel pins would allow increasing the power density (and consequently the fast flux level) by about $5 \%$ whereas in the $80-\mathrm{cm}$ case it would decrease the power density by about $14 \%$.

Table A2.1. Fuel assembly geometric data

\begin{tabular}{|c|c|c|c|c|}
\hline \multicolumn{2}{|c|}{ Case } & A271 & $\mathrm{A} 217$ & A169 \\
\hline \multicolumn{2}{|c|}{ Assembly pitch $(\mathrm{cm})$} & 12 & 12 & 12 \\
\hline \multicolumn{2}{|c|}{ Duct thickness $(\mathrm{cm})$} & 0.3 & 0.3 & 0.3 \\
\hline \multicolumn{2}{|c|}{ Assembly gap (cm) } & 0.3 & 0.3 & 0.3 \\
\hline \multicolumn{2}{|c|}{ Duct inside flat-to-flat (cm) } & 11.1 & 11.1 & 11.1 \\
\hline \multicolumn{2}{|c|}{ Pins per assembly } & 271 & 217 & 169 \\
\hline \multicolumn{2}{|c|}{ Pin diameter $(\mathrm{cm})$} & 0.53 & 0.595 & 0.67 \\
\hline \multicolumn{2}{|c|}{ Clad thickness $(\mathrm{cm})$} & 0.037 & 0.0414 & 0.0467 \\
\hline \multicolumn{2}{|c|}{ Wire wrap diameter $(\mathrm{cm})$} & 0.126 & 0.138 & 0.1594 \\
\hline \multicolumn{2}{|c|}{$\mathrm{p} / \mathrm{d}$} & 1.238 & 1.232 & 1.238 \\
\hline \multirow{4}{*}{$\begin{array}{c}\text { Fresh } \\
\text { fuel vol- } \\
\text { ume frac- } \\
\text { tions }\end{array}$} & Coolant & $39.83 \%$ & $39.51 \%$ & $40.02 \%$ \\
\hline & Fuel & $26.59 \%$ & $26.88 \%$ & $26.54 \%$ \\
\hline & Bond & $8.86 \%$ & $8.96 \%$ & $8.85 \%$ \\
\hline & Structure & $24.72 \%$ & $24.65 \%$ & $24.60 \%$ \\
\hline
\end{tabular}

Table A2.2. Maximum assembly power not to be exceeded as a function of the assembly type, fuel pin number, and fuel height.

\begin{tabular}{|c|c|c|c|c|c|c|}
\hline $\begin{array}{l}\text { Assembly } \\
\text { Type }\end{array}$ & $\begin{array}{l}\text { Fuel height } \\
\text { (cm) }\end{array}$ & $\begin{array}{l}\text { Max. Passembly } \\
\text { (MW) }\end{array}$ & $\begin{array}{l}\text { Fuel bundle } \Delta p \\
\quad(\mathrm{MPa})\end{array}$ & $\begin{array}{l}\text { Peak LHR* }^{\star} \\
(\mathrm{W} / \mathrm{cm})\end{array}$ & $\begin{array}{c}\text { Limiting } \\
\text { characteristic }\end{array}$ & $\begin{array}{l}\text { Power density } \\
\left.\text { (W/cm }^{3} \text {-fuel }{ }^{\star *}\right)\end{array}$ \\
\hline A271 & \multirow{3}{*}{100} & 6.3 & 0.50 & 292 & $\Delta p$ & 1430 \\
\hline A217 & & 6.7 & 0.50 & 387 & $\Delta p$ & 1505 \\
\hline A169 & & 6.1 & 0.35 & 450 & LHR & 1380 \\
\hline A271 & \multirow{3}{*}{80} & 7.2 & 0.50 & 416 & $\Delta p$ & 2030 \\
\hline A217 & & 6.3 & 0.35 & 450 & LHR & 1750 \\
\hline A169 & & 4.9 & 0.19 & 450 & LHR & 1380 \\
\hline
\end{tabular}

${ }^{*}$ Assumes a peaking factor equal to 1.25 .

** Average power density in the assembly characterized by the highest power. Fuel volume is defined as the volume inside the cladding. 


\section{Appendix 3. Examples of Hot Channel Thermal Calculations}

In any given channel within a fuel assembly, the sodium temperature, outside cladding temperature, inside cladding temperature and fuel centerline temperature at height $z$ are given by the following expressions:

Sodium bulk temperature $T_{N a, b}(z)$ is obtained from:

$$
\int_{z_{i n}}^{z} P_{l i n}(z) d z+W_{T}=\int_{T_{N a, b, i n}}^{T_{N a, b}(z)} \dot{m}_{N a} C_{p, N a} d T_{N a, b} \cong \dot{m}_{N a} C_{p, N a}\left(T_{N a, b}(z)-T_{N a, b, i n}\right)
$$

Outside cladding temperature $T_{c o}(z)$ is obtained from:

$$
h_{N a}\left(T_{c o}(z)-T_{N a, b}(z)\right)=\frac{P_{l i n}(z)}{2 \pi r_{c o}}
$$

Inside cladding temperature $T_{c i}(z)$ is obtained from:

$$
T_{c i}(z)-T_{c o}(z)=\frac{P_{l i n}(z)}{2 \pi k_{c}(z)} \ln \frac{r_{c o}}{r_{c i}}
$$

Fuel centerline temperature $T_{C L}(z)$ is obtained from:

$$
P_{l i n}(z)=4 \pi \int_{T_{S}(z)}^{T_{C L}(z)} k(T) d T
$$

with $k(T)=f_{p} \times k_{0}=f_{p} \times\left[A+B \cdot T+C \cdot T^{2}\right]$ in $\mathrm{W} / \mathrm{m}-\mathrm{K}$ for $\mathrm{U}-\mathrm{Zr}$ and $\mathrm{U}-\mathrm{Pu}-\mathrm{Zr}$ irradiated fuel [Billone, 1986] and

$f_{p}=0.5$

$A=17.5 \times\left\{\frac{1-2.23 \cdot w_{Z r}}{1+1.61 \cdot w_{Z r}}-2.62 \cdot w_{P u}\right\}$

$B=1.54 \times 10^{-2} \times\left\{\frac{1+0.061 \cdot w_{Z r}}{1+1.61 \cdot w_{Z r}}+0.90 \cdot w_{P u}\right\}$

$C=9.38 \times 10^{-6} \times\left\{1-2.70 \cdot w_{P u}\right\}$

Based on in-reactor thermal conductivity studies it appears that $f_{p}$ has a minimum of $\sim 0.5 \pm 0.05$ in the range of 1 2 at.\% burnup and achieves a long-time steady value of $\sim 0.7 \pm 0.1$ [Billone, 1986]. A $f_{p}$ value of 0.5 was used for all fuel temperature calculations shown in this report.

For $\mathrm{U}-20 \mathrm{Pu}-10 \mathrm{Zr}$ the expression for the thermal conductivity is

$$
k(T)=0.5 \times\left[2.54+1.61 \cdot 10^{-2} \cdot T+4.31 \cdot 10^{-6} \cdot T^{2}\right] .
$$

Using this expression for the thermal conductivity-and assuming a representative fuel surface temperature of $510^{\circ} \mathrm{C}$ - the linear-power-to-melting can be calculated as:

$$
P_{\text {lin }, \text { melt }}=4 \pi \int_{510}^{1121} k(T) d T=972 \mathrm{~W} / \mathrm{cm}
$$


Using the same expression but with fuel surface temperatures of $460^{\circ} \mathrm{C}$ and $560^{\circ} \mathrm{C}$, the linear-power-to-melting is, respectively, $913 \mathrm{~W} / \mathrm{cm}$ and $1026 \mathrm{~W} / \mathrm{cm}$.

The following figures illustrate sodium, inside cladding and fuel centerline temperatures for three arbitrary hot channels characterized by the same peak and average linear powers-respectively $450 \mathrm{~W} / \mathrm{cm}$ and $345 \mathrm{~W} / \mathrm{cm}-$ but significantly different power distributions. One power distribution is symmetrical whereas the other two are asymmetrical and most likely bound operation conditions. The sodium mass flow in the three hot channels is the same, $0.106 \mathrm{~kg} / \mathrm{s}$, which corresponds to sodium inlet and outlet temperatures of, respectively, $350^{\circ} \mathrm{C}$ and $550^{\circ} \mathrm{C}$. The cladding inside and outside diameters are, respectively, $4.7 \mathrm{~mm}$ and $5.5 \mathrm{~mm}$. The assumed values for irradiated U-20Pu-10Zr fuel and cladding thermal conductivities are, respectively, $0.109 \mathrm{~W} / \mathrm{cm}-\mathrm{K}$ and $0.262 \mathrm{~W} / \mathrm{cm}-\mathrm{K}$. The assumed value for the sodium heat transfer coefficient is $20 \mathrm{~W} / \mathrm{cm}^{2}-\mathrm{K}$. With these assumptions, the peak inside cladding temperature is about $560-585^{\circ} \mathrm{C}$ and the peak fuel centerline temperature is $840-860^{\circ} \mathrm{C}$. As mentioned above, a $f_{p}$ value of 0.5 was used; using a $f_{p}$ value of 0.7 would lower the peak fuel centerline temperature by about $80^{\circ} \mathrm{C}$.

Subsequently the linear power profiles were renormalized so that the peak is $650 \mathrm{~W} / \mathrm{cm}$ and the sodium mass flow was also renormalized $(0.153 \mathrm{~kg} / \mathrm{s})$ so that the sodium outlet temperature is still $550^{\circ} \mathrm{C}$. With these new assumptions, the peak inside cladding temperature is about $560-600^{\circ} \mathrm{C}$ and the peak fuel centerline temperature is $960-980^{\circ} \mathrm{C}$. The $\mathrm{U}-20 \mathrm{Pu}-10 \mathrm{Zr}$ fuel thermal conductivity is higher than in the previous case, $0.121 \mathrm{~W} / \mathrm{cm}-\mathrm{K}$, because the fuel temperature is higher.

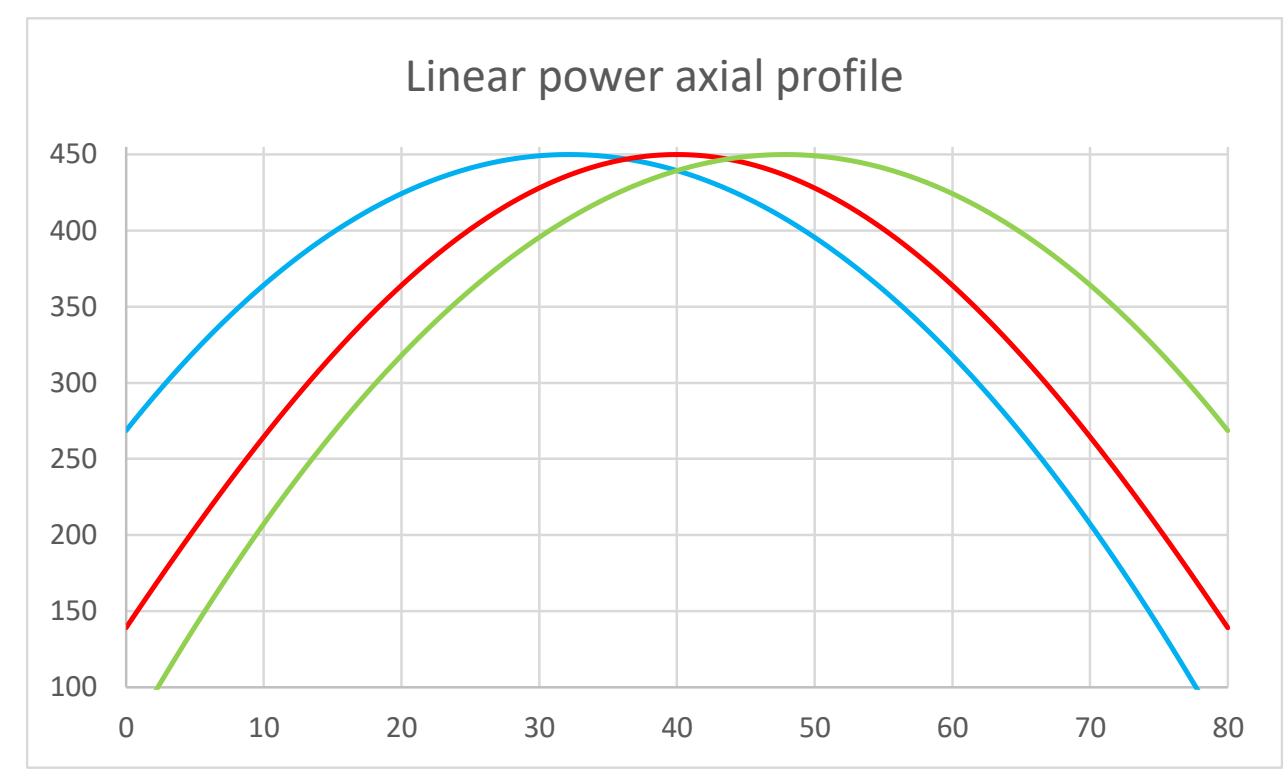




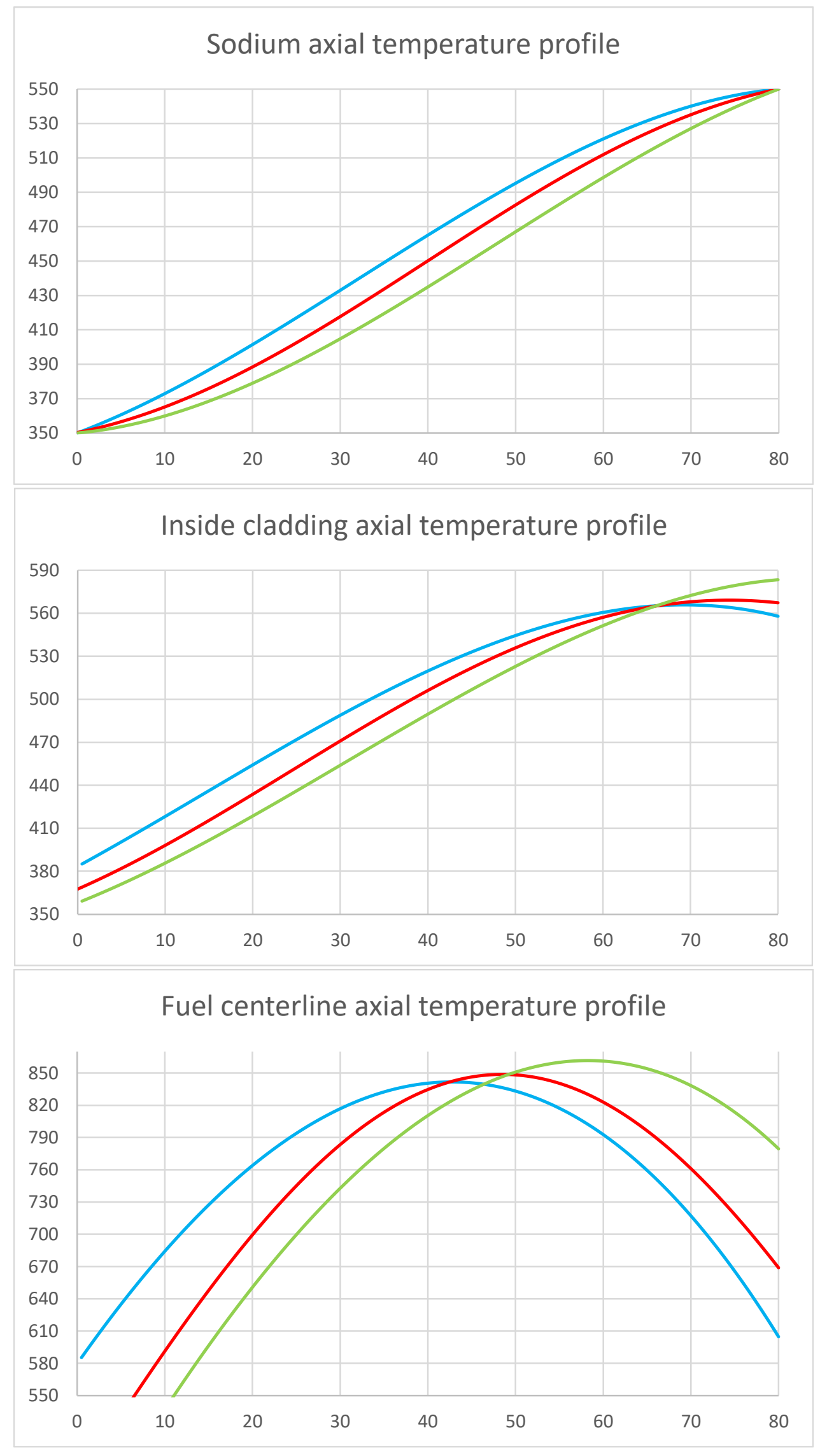




\section{Appendix 4. Review of Other Fast Test Reactors}

\section{A4.1. FFTF}

The Fast Flux Test Facility (FFTF) operated as an irradiation facility from 1982 to 1992. It is a loop-type sodiumcooled fast reactor. More design parameters of the FFTF are provided in Table XX. The flux level inside the FFTF core was assessed in this study. The core model was mainly based on Ref. [2]. The Argonne neutronics tool suite was employed for the analysis. The multi-group neutron cross-section was generated by MC2 3 . The DIF3DVARIANT code was employed to solve the neutron flux. Figure A4.1.1 presents the core layout of FFTF for the configuration studied, corresponding to that from the reference document. There are four driver fuel types (fuel32, fuel42, fuel31, and fuel41 shown in Figure A4.1.1), each of which has different plutonium content ranging from $22.43 \%$ to $29.28 \%$.

$\begin{array}{llr}\text { fuel32 } & : & 28 \\ \text { fuel42 } & : & 6 \\ \text { cr/sr } & : & 9 \\ \text { fuel31 } & : & 37 \\ \text { fuel41 } & : & 11 \\ \text { row 7 refl. } & : & 27 \\ \text { gem } & : & 9 \\ \text { row 8, } 9 \text { refl. } & : & 72 \\ \text { shield } & : & 132\end{array}$

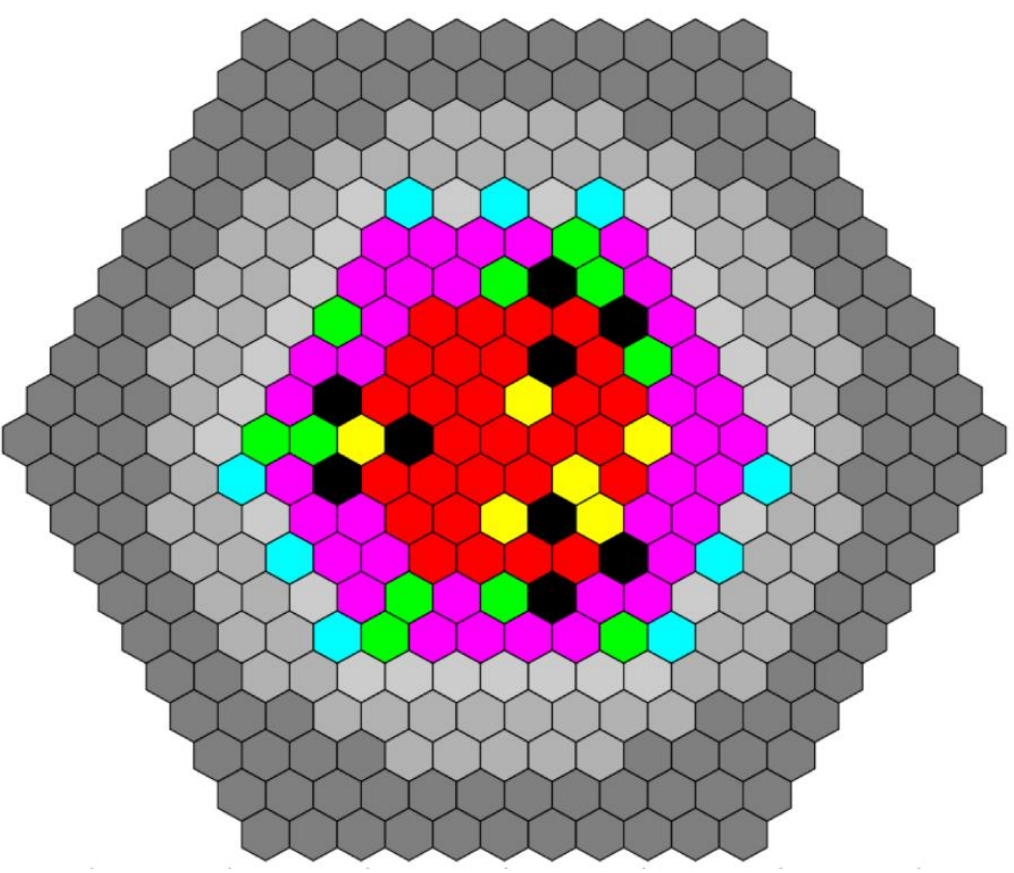

Figure A4.1.1 FFTF core layout.

Three cases were evaluated, all using a single fuel composition in order to simplify the model. Case 1 uses the average irradiated fuel composition obtained from Ref. [2]. Case 2 is similar to Case 1 with the difference that the control assemblies are fully inserted. Case 3 is similar to Case 1 except that the fresh fuel composition was used everywhere in the core. The eigenvalue and flux levels for all three cases are summarized in Table A4.1.1. The flux level provided in the literature for FFTF and obtained from Ref. [3] is also given as the reference value.

Table A4.1.1 k-eff and flux comparison.

\begin{tabular}{|c|c|c|c|c|}
\hline Case & k-eff & $\begin{array}{c}\text { Total Flux } \\
\left(10^{15} \mathrm{n} / \mathrm{cm}^{2}-\mathrm{s}\right)\end{array}$ & $\begin{array}{c}\text { Fast Flux } \\
\left(10^{15} \mathrm{n} / \mathrm{cm}^{2}-\mathrm{s}\right)\end{array}$ & $\begin{array}{c}\text { Fast Flux Frac- } \\
\text { tion }\end{array}$ \\
\hline 1 & 1.0167 & 7.59 & 4.75 & $62.6 \%$ \\
\hline 2 & 0.9611 & 8.38 & 5.34 & $63.7 \%$ \\
\hline 3 & 1.1111 & 6.61 & 4.19 & $63.4 \%$ \\
\hline $\begin{array}{c}\text { Literature refer- } \\
\text { ence }\end{array}$ & - & 7.0 & - & $60-65 \%$ \\
\hline
\end{tabular}


It is observed that the calculated flux levels can vary by up to $20 \%$ due to the burnt vs. fresh fuel composition and because of the control rod position. For Case 1 the obtained core multiplication factor is not equal to unity (while the reactor was critical) because of the use of a single fuel composition. In the work reported in Ref. [2] the core multiplication factor was obtained to be equal to unity within uncertainties, because the 640 different fuel compositions were used. As part of the study reported in Ref. [2] a MCNP model of the FFTF core was developed and the results shown to be consistent with the results obtained with DIF3D/REBUS/MC ${ }^{2}-3$.

The flux values summarized in Table A4.1.1 show a range with includes the value reported in the literature. Not knowing for which core configuration, control position, and fuel composition the literature value was reported for, it is concluded that the results obtained with our model are consistent with the literature value.

Additional independent neutronic calculations were performed (John Bess, INL, personal communication) using an existing benchmark model of the FFTF to verify reported literature values of a peak total neutron flux of $7 \times 10^{15}$ $\mathrm{n} / \mathrm{cm}^{2}$-s with $60-65 \%$ of the neutrons in the fast neutron spectra (>0.1 MeV). Monte Carlo N-Particle (MCNP version 6.1.1) simulations using a modified FFTF-LMFR-RESR-001 benchmark model from the International Handbook of Evaluated Reactor Physics Benchmark Experiments (IRPhEP Handbook) with the ENDF/B-VII.1 nuclear data library were utilized to obtain the following results:

Table A4.1.2. MCNP results obtained for the FFTF-LMFR-RESR-001 benchmark model.

\begin{tabular}{l|cccc} 
Parameter & Value & $\mathbf{\pm}$ & $\mathbf{1 \sigma}$ & Units \\
\hline $\mathrm{k}_{\text {eff }}$ & 0.99929 & $\mathbf{1}$ & 0.00005 & -- \\
$\mathrm{V}$ & 2.929 & -- & -- & $\mathrm{n} /$ fission \\
Neutron < 0.1 MeV (full core) & 40.82 & -- & -- & $\%$ \\
Neutron > 0.1 MeV (full core) & 59.18 & -- & -- & $\%$ \\
Neutron < 0.1 MeV (near core center) & 36.7 & \pm & 0.3 & $\%$ \\
Neutron > 0.1 MeV (near core center) & 63.3 & \pm & 0.3 & $\%$ \\
Peak Total Neutron Flux (near core center) & $7.38 \times 10^{15}$ & \pm & $1.41 \times 10^{13}$ & $\mathrm{n} / \mathrm{cm}^{2} / \mathrm{s}$
\end{tabular}

Assumptions implemented in this analysis include used of a heating value, $\mathrm{Q}$, of $210 \mathrm{MeV} / \mathrm{fission}$. The FFTF benchmark model calculations are performed at $478 \mathrm{~K}$. The ENDF/B-VII.1 cross-section data were available and utilized at $600 \mathrm{~K}$. However, repeated calculations with nuclear data at $300 \mathrm{~K}$ provided nearly identical results, within statistical uncertainty, to those obtained and presented herein. Simulated flux measurements were tallied in the Fueled Open Test Assembly (FOTA) located adjacent to the center core assembly in the Inner Enrichment Zone (Figure A4.1.2) within $\pm 10 \mathrm{~cm}$ of the vertical centerline of the active region of the core in the centermost fuel pin of the FOTA. It should be noted that an increase in the Q-value to $215 \mathrm{MeV} / \mathrm{fission}$ reduces the peak total neutron flux to $7.21 \times 10^{15} \pm 1.39 \times 10^{13} \mathrm{n} / \mathrm{cm}^{2}-\mathrm{s}$.

Calculated results match well against the reported literature values for FFTF peak total neutron flux and the percentage of fast-spectra neutrons, which confirms the ability to calculate historical values with modern nuclear data and neutronics software.

\section{Reference}

1. Fast Reactor Database, 2006 Update, IAEA-TECDOC-1531 (2006).

2. T. Sumner, et al., "Benchmark Specification for FFTF LOFWOS Test \#13," ANL-ART-84, Jan. 31, 2017.

3. C.P. Cabell, "A Summary Description of the Fast Flux Test Facility," Hanford Engineering Development Laboratory, HEDL-400, December 1980. 


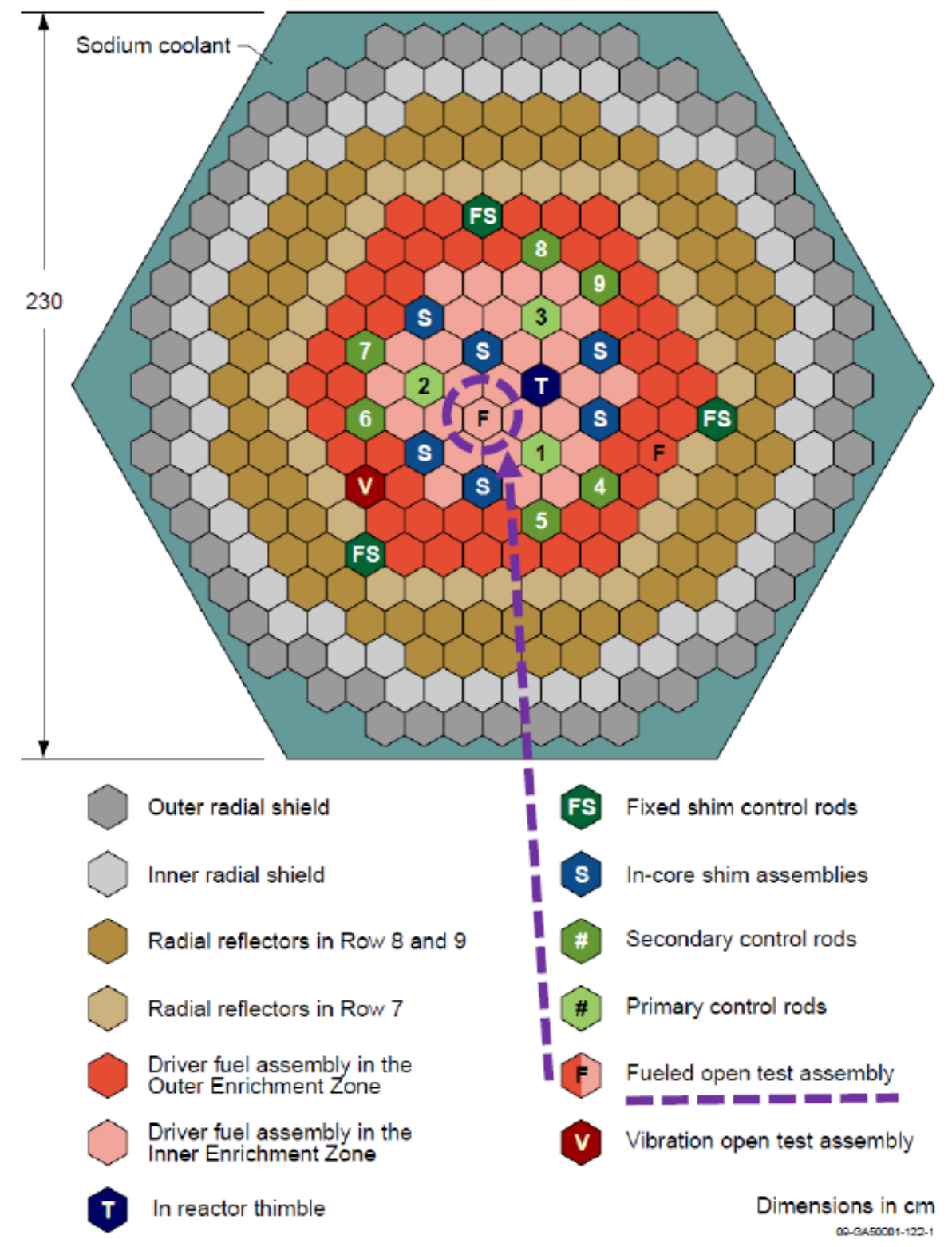

Figure A4.1.2. Diagram of FFTF fully loaded critical configuration.

\section{A4.2. JOYO}

Figure 1 shows the core layout of the MK-III loaded JOYO reactor [1-5]. Both a model of the MK-I loaded and MKIII loaded JOYO reactor were built. The MK-I model was simply used to verify against a reference critical configuration for which more details are available in the open literature than for the MK-III configuration. The primary differences between the MK-I and MK-III fuel loading focused on removal of radial blankets, changes in U/Pu enrichment, and alterations to the assembly pin geometry. The purpose of the MK-III loaded system was to drive up assembly power and facilitate higher irradiation capabilities.

From Figure A4.2.1, one can see that the reactor has a two region loading (inner and outer), no radial blankets and relatively compact radial reflector and shielding regions. Reference 3 states the reactor properties best which are reproduced in Table A4.2.1. The MK-III loaded JOYO reactor should provide a $4.0 \times 10^{15} \mathrm{n} / \mathrm{cm}^{2}-\mathrm{s}$ fast flux irradiation capability in the irradiation rig with a peak assembly averaged burnup of $90 \mathrm{GWd} / \mathrm{t}$ at a core thermal 
power level of $140 \mathrm{MW}_{\text {th }}$ and cycle length of 60 days. Additional details were provided in the references as to the geometric changes from MK-I and MK-III except for the height of the axial "insulator" pellets which were deemed not important for assessing the flux level.
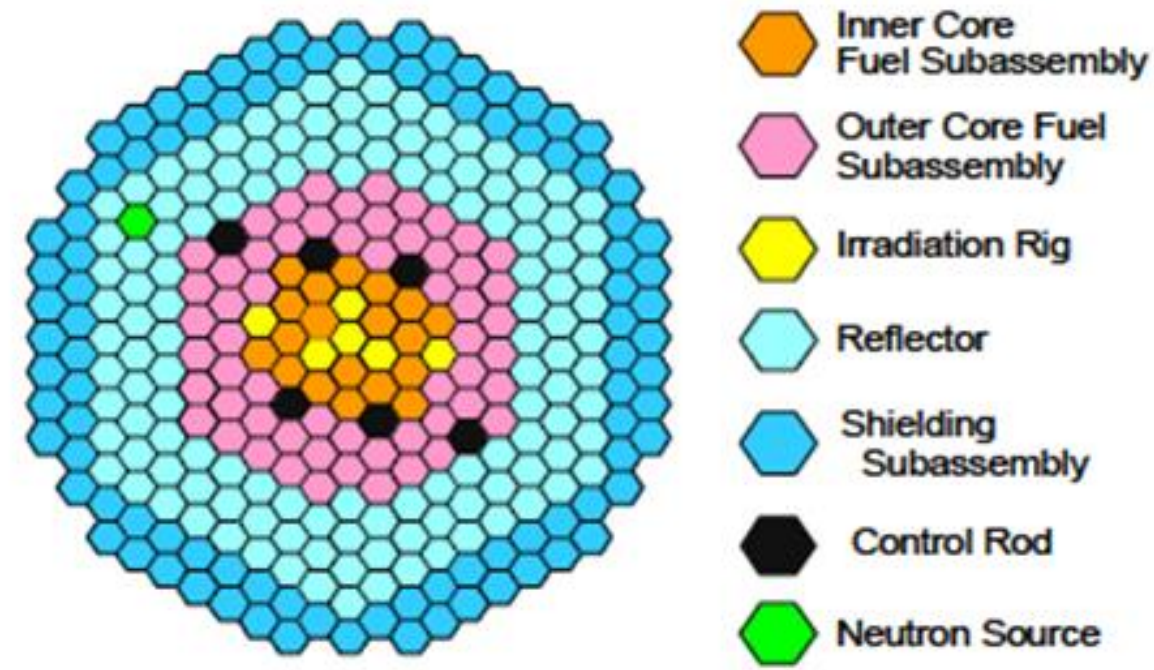

Figure A4.2.1. Radial core layout of the MK-III Loaded JOYO Reactor.

Table A4.2.1. Reproduced core details from Reference 3.

\begin{tabular}{|c|c|}
\hline Reactor Thermal Power & $140 \mathrm{MWt}$ \\
\hline Max Driver Assemblies & 85 \\
\hline Equivalent Core Diameter & $80 \mathrm{~cm}$ \\
\hline Core Height & $50 \mathrm{~cm}$ \\
\hline${ }^{235} \mathrm{U}$ Enrichment $(\mathrm{wt} \%)$ & 18 \\
\hline $\mathrm{Pu} /(\mathrm{Pu}+\mathrm{U})(\mathrm{wt} \%)$ & $23 \%$ inner $\& 30 \%$ outer \\
\hline$\left({ }^{239} \mathrm{Pu}+{ }^{241} \mathrm{Pu}\right) /(\mathrm{Pu}+\mathrm{U})$ & $16 \%$ inner $\& 21 \%$ outer \\
\hline Max Linear Heat Rate & $420 \mathrm{~W} / \mathrm{cm}$ \\
\hline Max pin average burnup & $90 \mathrm{GWd} / \mathrm{ton}$ \\
\hline Total neutron flux & $5.7 \cdot 10^{15}\left(\mathrm{n} / \mathrm{cm}^{2} / \mathrm{s}\right)$ \\
\hline Fast neutron flux & $4.0 \cdot 10^{15}\left(\mathrm{n} / \mathrm{cm}^{2} / \mathrm{s}\right)$ \\
\hline Flow rate of primary sodium & 2700 tonnes/hour \\
\hline Inlet coolant temperature & $350 \mathrm{C}$ \\
\hline Outlet coolant temperature & $500 \mathrm{C}$ \\
\hline Operational Cycle Length & 60 days \\
\hline Cycles per year & 5 \\
\hline
\end{tabular}

A MC2-3/DIF3D model was constructed using the combined geometric information from all four references. In this approach, the stated required enrichment could be reproduced although insufficient detail was given on the plutonium isotopic composition. The plutonium feed vector was thus determined to be about $68 \%, 27 \%, 1.7 \%$, and $1 \%$ of ${ }^{239} \mathrm{Pu},{ }^{240} \mathrm{Pu},{ }^{241} \mathrm{Pu}$, and ${ }^{242} \mathrm{Pu}$, respectively. An additional $0.8 \%$ of ${ }^{241} \mathrm{Am}$ was assumed to be present.

Using the stated inputs, the core performance characteristics summarized in Table A4.2.2 were determined for various number of fuel batches. Looking at the first four rows of data in table A4.2.2, all of the results were computed using diffusion theory using the loading information provided by Table A4.2.1 and Figure A4.2.1. The discharge burnup provided is the equilibrium discharge burnup (JOYO likely never reached a "perfect" equilibrium during its operation) for the respective regions. Based on crossing the information available from the different sources, the fuel residence time should be 5 or 6 cycles for the inner core and 6 or 7 cycles for the outer core. 
Table A4.2.2. Impact of fuel residence time on core performance parameters.

\begin{tabular}{|c|c|c|c|c|c|c|c|}
\hline \multirow{2}{*}{$\begin{array}{c}\text { Inner } \\
\text { Core } \\
\text { Batch }\end{array}$} & $\begin{array}{c}\text { Outer } \\
\text { Core } \\
\text { Batch }\end{array}$ & BOEC & EOEC & $\begin{array}{c}\text { BOEC } \\
\text { Peak irradiation rig } \\
\text { fast flux } \\
\left(10^{15} \mathrm{n} / \mathrm{cm}^{2} / \mathrm{s}\right)\end{array}$ & \multicolumn{2}{c|}{$\begin{array}{c}\text { Discharge burnup } \\
(\mathrm{GWd} / \mathrm{t})\end{array}$} \\
\hline 1 & 1 & 1.02168 & 1.00647 & 3.3 & 3.4 & 11.9 & 10.3 \\
\hline 4 & 4 & 0.99756 & 0.98221 & 3.4 & 3.5 & 47.3 & 41.1 \\
\hline 5 & 6 & 0.98408 & 0.96863 & 3.5 & 3.5 & 59.5 & 61.4 \\
\hline 6 & 7 & 0.99167 & 0.96025 & 3.5 & 3.6 & 71.2 & 71.7 \\
\hline \multicolumn{8}{|c|}{ Transport } \\
\hline 6 & 7 & 0.98353 & 0.97594 & 3.4 & 3.4 & 70.9 & 71.9 \\
\hline \multicolumn{8}{|c|}{ Fill the Three Irradiation Rigs in Ring Two with Fuel } \\
\hline 6 & 7 & 1.01948 & 1.00392 & 3.8 & 3.8 & 70.0 & 68.1 \\
\hline
\end{tabular}

From the first four rows of Table A4.2.2, using the assumed of residence times and number of batches, it was found that our model yielded a core multiplication factor lower than unity and it does not achieve the fast flux level $\left(4.0 \times 10^{15} \mathrm{n} / \mathrm{cm}^{2}\right.$-s) reported in the literature. The data provided in Table 2 under the section labeled "Transport" was added to show that using transport versus diffusion theory, while increasing the minimum keff value observed by $+1500 \mathrm{pcm}$, is not enough to not resolve the criticality issue.

One thing that was not clearly stated in all the references available about JOYO is whether the "irradiation rig" positions were filled with fuel or left empty. In the results discussed so far, it had been assumed that these locations where filled with an assembly similar to the reflector assembly, possibly mimicking a test assembly containing irradiation specimens (non-fuel). This assumption appearing to be overly conservative, it was then assumed that some of the irradiation rig positions would contain some fuel. The three irradiation rigs in ring two were therefore filled with inner core fuel in our model and the results obtained are shown in the last line of Table A4.2.2.

Making this change was enough to obtain a critical core configuration while maintaining all other design parameters described in the literature. The peak fast flux obtained in the irradiation rig was found to be about $3.8 \times 10^{15}$ $\mathrm{n} / \mathrm{cm}^{2}-\mathrm{s}$, just $5 \%$ lower than the value provided in the literature. This discrepancy is likely due to not knowing with certainty what is loaded in the irradiation rigs.

In summary, this work demonstrates that the MC²-3 + DIF3D can be used to produce a good model of the MK-III JOYO reactor. Furthermore, these results were compared with those obtained with a MCNP model of JOYO and were found to be identical. While the details on the MK-I reactor fuel are much clearer than the MK-III reactor fuel, it is believed that the preceding work constructs a reasonable approximation of the JOYO reactor with MK-III fuel.

\section{References}

1. K. Yokoyama, A. Shono, "Japan Experimental Fast Reactor JOYO MK-I Core: Sodium-cooled UraniumPlutonium Mixed Oxide Fueled Fast Core Surrounded by UO 2 Blanket," JOYO-LMFR-RESR-001, International Handbook of Evaluated Criticality Safety Benchmark Experiments, Nuclear Energy Agency, NEA/NSC/DOC (2006).

2. Fast Reactor Database, 2006 Update, IAEA-TECDOC-1531 (2006).

3. T. Aoyama, T. Sekine, S. Maeda, A. Yoshida, Y. Maeda, S. Suzuki, T. Takeda, "Core Performance Tests for the JOYO MK-III upgrade," Nuclear Engineering and Design 237, pages 353-368 (2007).

4. G. Chiba, K. Yokoyama, S. Maeda, and T. Sekine, "JOYO MK-III Performance Test at Low Power and Its Analysis," PHYSOR 2004, April 25-29 (2004). 


\section{A4.3. MBIR}

The multipurpose Sodium-cooled fast neutron research reactor (MBIR) has received its construction license in 2015 and is now in construction phase. A neutronics analysis was performed to assess the neutron flux level and compare it to the claimed values for the MBIR. The calculation model of the MBIR was constructed based on information available publically [1-5]. Some design parameters of the MBIR are provided in Table 3.7.

The Argonne neutronics tool suite was employed for the calculations. $\mathrm{MC}^{2}-3$ was employed to prepare the neutron cross-section. REBUS-3 was used to find the required plutonium content of fresh fuel for an equilibrium cycle. DIF3D-VARIANT was employed to solve the neutron flux.

There are several experimental volumes in the core as shown in Figure A4.3.1. There are three loop channels for testing different coolants, 14 in-core non-instrumented material test assemblies (MTA), and 3 experiment channels for instrumented experimental assemblies. These experimental volumes can be loaded with materials such as fuel, structural, absorber, etc. For the REBUS-3 calculations, the material test assemblies were assumed to be filled with fuel assemblies, while other experimental volumes were filled with sodium in an empty duct. Several DIF3D-VARIANT calculations were performed to evaluate the peak flux level in the experimental volumes. The results obtained are summarized in Table A4.3.1.

There are three cases summarized in Table A4.3.1. Case 1 corresponds to the core model with fuel assemblies filled in the 14 MTA locations at the beginning of an equilibrium cycle. Case 2 is similar to Case 1 with the difference that the results correspond to the end of an equilibrium cycle. Case 3 assumed that a standard fuel assembly (pitch $=7.4 \mathrm{~cm}$ ) is loaded in the center of the loop channel 1 (LC1), and the calculation correspond to the beginning of an equilibrium cycle. In reality, the loop channel design may only contain a smaller fuel assembly (pitch $<6.3$ $\mathrm{cm})$. However, Case 3 should provide an upper bound of possible flux levels.

Due to a number of unknown details associated with the input parameters (dimensions, material composition, etc), the flux levels differ slightly from the claimed values. However, these calculation cases provide a range that is consistent with the values claimed in the literature (second column or Table A4.3.1). 


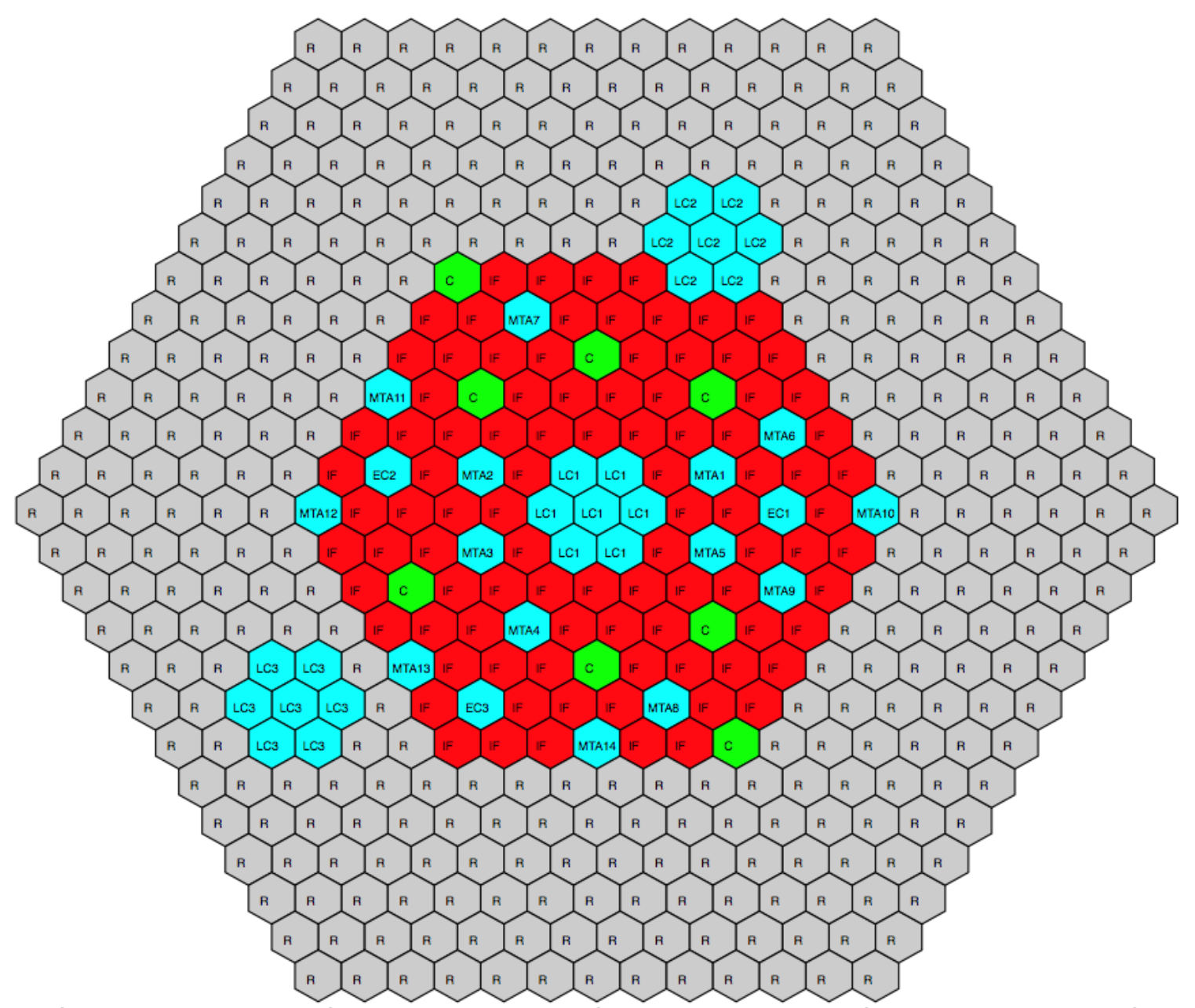

Figure A4.3.1. Core layout of MBIR: IF = fuel assembly, $C=$ control assembly, $R=$ reflector assembly, MTA = material test assembly, EC = experimental channel, and LC = loop channel.

Table A4.3.1. Evaluated total flux levels $\left(10^{15} \mathrm{n} / \mathrm{cm}^{2}-\mathrm{s}\right)$ in different experimental volumes.

\begin{tabular}{|c|c|c|c|c|}
\hline \multirow{2}{*}{ Location (total flux) } & \multirow{2}{*}{ Literature Value } & \multicolumn{3}{|c|}{ Calculated } \\
\hline & & Case 1 & Case 2 & Case 3 \\
\hline LC 1 & 5.0 & 4.73 & 4.90 & 4.92 \\
\hline LC 2 & 2.0 & 1.92 & 1.99 & 2.01 \\
\hline LC 3 & 1.3 & 1.33 & 1.38 & 1.31 \\
\hline MTA 1 & \multirow{13}{*}{$<4.9$} & 4.84 & 5.00 & 4.79 \\
\hline MTA 2 & & 4.84 & 5.01 & 4.80 \\
\hline MTA 3 & & 4.90 & 5.07 & 4.87 \\
\hline MTA 4 & & 4.79 & 4.95 & 4.73 \\
\hline MTA 5 & & 4.90 & 5.07 & 4.83 \\
\hline MTA 6 & & 3.94 & 4.08 & 3.87 \\
\hline MTA 7 & & 3.63 & 3.77 & 3.59 \\
\hline MTA 8 & & 3.82 & 3.96 & 3.72 \\
\hline MTA 9 & & 4.04 & 4.18 & 3.93 \\
\hline MTA 10 & & 2.71 & 2.82 & 2.64 \\
\hline MTA 11 & & 3.22 & 3.34 & 3.16 \\
\hline MTA 12 & & 2.64 & 2.74 & 2.60 \\
\hline MTA 13 & & 3.13 & 3.25 & 3.16 \\
\hline
\end{tabular}




\begin{tabular}{|l|c|c|c|c|}
\hline MTA 14 & & 3.31 & 3.44 & 3.23 \\
\hline EC 1 & 4.12 & 4.26 & 4.03 \\
\hline EC 2 & \multirow{3}{*}{$3.2-4.0$} & 3.64 & 3.77 & 3.58 \\
\cline { 1 - 4 } EC 3 & 3.36 & 3.48 & 3.31 \\
\cline { 3 - 5 } & & Core & 5.03 \\
\hline Peak total flux & 5.20 & 5.03 & 5.21 & 3.95 \\
\hline Peak fast flux & 3.96 & 3.95 & 4.07 & \\
\hline
\end{tabular}

Besides the test locations inside the core, the flux levels in other test locations outside the core are also obtained from publically available information for MBIR. The MCNP6 code was used to evaluate the flux level in the test locations outside the core. The MCNP model is shown in Figure A4.3.2 for the core center plane. Detailed shielding information is not available and a best engineering judgement was used instead. The shielding dimensions used in the MCNP model are listed in Table A4.3.2. Some of the dimensions have been assumed, while other were obtained from publically available sources.

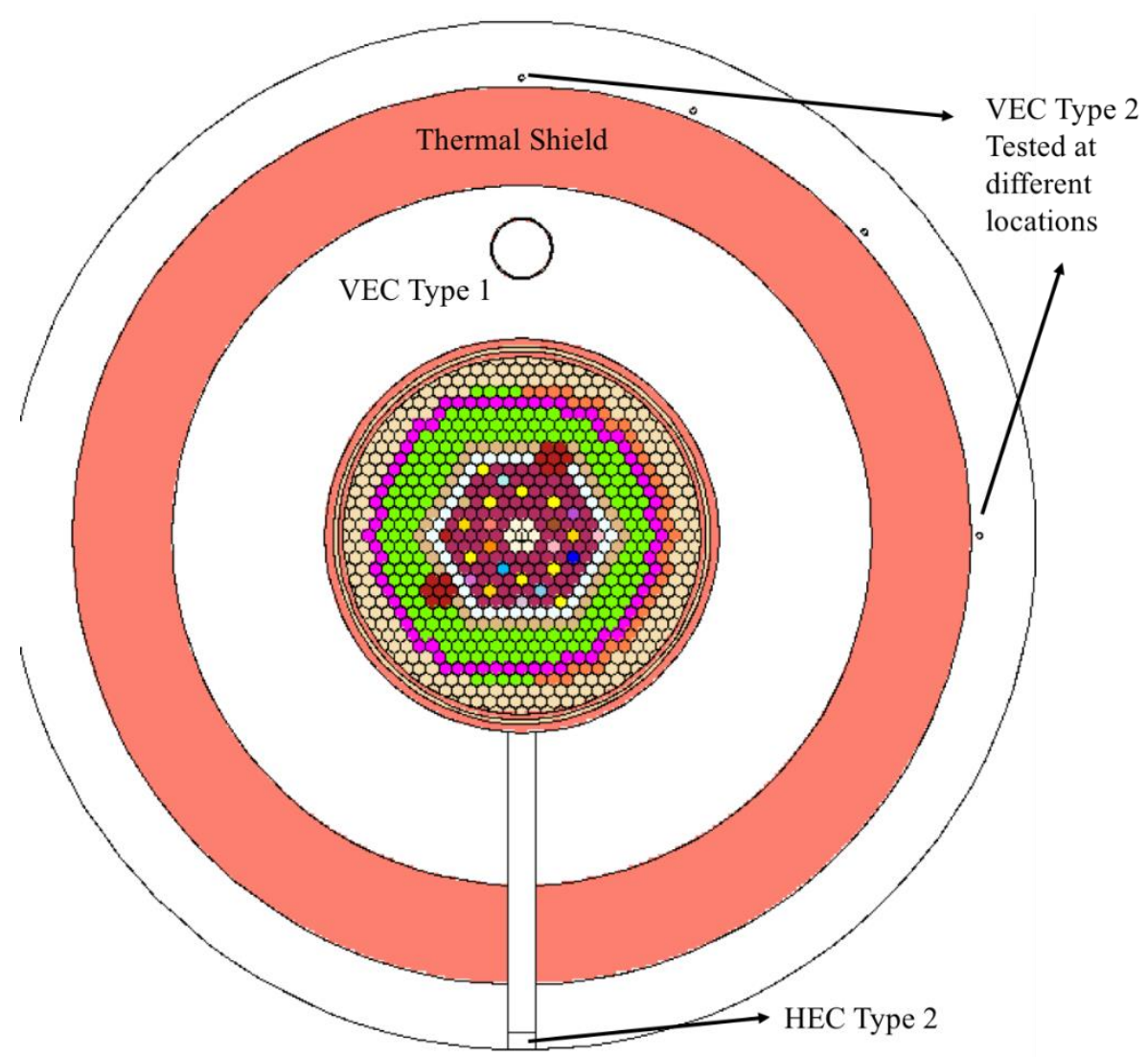

Figure A4.3.2 MCNP model for MBIR core and surrounding shield.

Table A4.3.2 Parameters used in the MCNP model (all dimensions are in $\mathrm{cm}$ ).

\begin{tabular}{|l|r|r|}
\hline Parameters & Assumed Value & Ref. Value \\
\hline Barrel wall inner radius & 104.3 & - \\
\hline Barrel wall thickness & 3.0 & - \\
\hline Barrel wall material & SS316 & - \\
\hline Vessel wall inner radius & 110.0 & - \\
\hline Vessel wall thickness & 5.0 & - \\
\hline Vessel wall material & SS316 & - \\
\hline Thermal shield inner radius & - & 204.0 \\
\hline Thermal shield thickness & - & 58.0 \\
\hline
\end{tabular}




\begin{tabular}{|l|r|r|}
\hline Thermal shield material & SS316 & Iron cast \\
\hline VEC Type 1 radius & - & 17.1 \\
\hline VEC Type 1 radial location & - & 167.5 \\
\hline VEC Type 1 shell thickness & 1.0 & - \\
\hline VEC Type 2 radius & - & 1.7 \\
\hline VEC Type 2 radial location & - & 267.0 \\
\hline VEC Type 2 shell thickness & 0.1 & - \\
\hline HEC radius & 10.0 & $10-15$ \\
\hline HEC radial location & 300.0 & - \\
\hline
\end{tabular}

Based on these parameters, several MCNP cases with different assumptions were evaluated. The differences in these cases are described in Table A4.3.3. The results are summarized in Table A4.3.4. For the flux level in VEC type 1, the values predicted by MCNP calculation agree well with the reference values. The flux levels at the other two channels (VEC type 2 and HEC) show large differences between the reference and calculated values. For the flux level in HEC, the detailed shielding design outside the reactor vessel is unknown and the detailed location of the HEC relative to the core center is unknown. For the flux level in VEC Type 2, there are too many uncertainties associated with the model, but the calculation predicts a much higher flux level than that referenced. This seems to indicate means that the MBIR could achieve the claimed flux level in the VEC Type 2. However, for a complete validation the detailed shielding information (dimension and material) would be required.

Table A4.3.3 MBIR cases evaluated.

\begin{tabular}{|c|l|}
\hline Cases & \multicolumn{1}{c|}{ Description } \\
\hline A & $\begin{array}{l}\text { Based on the parameters listed in Table 3. Concrete is filled outside the thermal } \\
\text { shield. }\end{array}$ \\
\hline B & Similar to Case 1 except air is filled outside the thermal shield. \\
\hline C & Similar to Case 1 except the thermal shield is 10cm thicker. \\
\hline D & $\begin{array}{l}\text { Similar to Case 2 except VEC Type 2 flux is evaluated at different azimuthal loca- } \\
\text { tions. }\end{array}$ \\
\hline
\end{tabular}

Table A4.3.4 Flux level comparison in VEC and HEC.

\begin{tabular}{|c|c|c|c|c|c|}
\hline \multirow{2}{*}{ Channel } & \multirow{2}{*}{ Reference } & \multicolumn{4}{|c|}{ Calculated } \\
\cline { 3 - 5 } & & Case A & Case B & Case C & Case D \\
\hline VEC 1 & $1.24 \mathrm{E}+13$ & $7.83 \mathrm{E}+12$ & $7.90 \mathrm{E}+12$ & $8.89 \mathrm{E}+12$ & $7.87 \mathrm{E}+12$ \\
\hline VEC 2 & $1.59 \mathrm{E}+09$ & $8.56 \mathrm{E}+10$ & $3.26 \mathrm{E}+10$ & $4.67 \mathrm{E}+10$ & $2.03 \mathrm{E}+10$ \\
\hline HEC 1 & $5.06 \mathrm{E}+10$ & $3.30 \mathrm{E}+11$ & $1.76 \mathrm{E}+11$ & $2.55 \mathrm{E}+11$ & $1.68 \mathrm{E}+11$ \\
\hline \multicolumn{7}{|c|}{ Differences (calculated/reference) } \\
\hline VEC 1 & - & 0.63 & 0.64 & 0.72 & 0.64 \\
\hline VEC 2 & - & 53.8 & 20.5 & 29.4 & $12.8-23.5$ \\
\hline HEC 1 & - & 6.52 & 3.48 & 5.03 & 3.32 \\
\hline
\end{tabular}




\section{Appendix 5. Approach to Determine the Reactivity Coefficients}

This note provides a description of the approach to be used to determine the reactivity coefficients.

\section{Radial expansion:}

The radial expansion reactivity feedback coefficient is determined using a direct comparison of the core multiplication factors for unperturbed and perturbed cores. To generate the perturbed core multiplication factor, the pitch of all assemblies is increased by $1 \%$, which corresponds to a $2.01 \%$ volume increase. To conserve mass, the densities of all solid materials present in the core are reduced by $1.97 \%$. The density of sodium is not reduced. The resulting coefficient represents the reactivity feedback due to uniform radial expansion of the whole core.

\section{Axial expansion:}

The axial expansion reactivity feedback coefficient is determined using a direct comparison of the core multiplication factors for unperturbed and perturbed cores. To generate the perturbed core multiplication factor, the height of all fuel zones is increased by $1 \%$, which corresponds to a $1 \%$ fuel volume increase. To conserve mass, the densities of all solid materials present in the fuel regions are reduced by $1 \%$. The density of sodium is not reduced. Regions located above the fuel region are shifted based on the fuel axial expansion, but their composition and heights are unchanged. The resulting coefficient represents the reactivity feedback due to uniform axial expansion of all the fuel regions.

\section{Fuel density:}

Fuel density reactivity feedback coefficients are calculated using first order perturbation theory. Coefficients are generated for each axial region of the driver fuel assemblies containing fuel, including the insulator pellet regions. To calculate the fuel density coefficient for a single axial node, the densities of all fuel isotopes, including zirconium, in that node are reduced by $1 \%$. The geometry and density of all other components in the core are unchanged. Note that fuel mass is not conserved when calculating the fuel density coefficient. However the SAS4A/SASSYS-1 axial fuel expansion reactivity feedback model accounts for mass changes throughout the entire axial length of an assembly and therefore conserves mass.

\section{Structure density:}

Structure density reactivity feedback coefficients are calculated using first order perturbation theory, with a similar method as the fuel density coefficients. For the structure density coefficients, the densities of all structural material, including the duct, cladding, and wire wrap, are increased by $5 \%$ in all regions of the core. Geometry is not changed and therefore the mass of structural material is not conserved. The mass of all other materials remained unchanged.

\section{Sodium density:}

Sodium density reactivity feedback coefficients are calculated using first order perturbation theory, with a similar method as the fuel and structure density coefficients. The density of the flowing coolant is reduced by $1 \%$ in each region of the core. This includes fuel, reflector, control rods assemblies and regions located above and below the fuel. Sodium between assemblies and the mass of all other materials remain unchanged.

\section{Sodium void:}

The sodium void reactivity feedback coefficients are calculated using first order perturbation theory. The entirety of the flowing coolant is voided in all the fuel regions as well as in all regions located directly above the fuel regions (plenum, upper reflector, upper plug/socket). Sodium between assemblies and the mass of all other materials 
remain unchanged. A new set of cross-sections corresponding to these voided conditions is generated and used to calculate the sodium void worth for each region.

\section{Fuel Doppler:}

Fuel Doppler coefficients are calculated using first order perturbation theory. For each fueled region of the core, fuel temperatures are doubled. A new set of cross-sections corresponding to these conditions is generated and used to calculate the Doppler coefficient for each region in units of $\Delta k / k$.

SAS4A/SASSYS-1 accounts for the effect of sodium voiding on the Doppler reactivity feedback effect so a second set of Doppler coefficients is generated for voided conditions. Complete voiding of the core is unrealistic so these calculations are performed for a small void. As with the unvoided calculations, fuel temperatures are doubled, with the difference being that the mass of sodium in the fuel regions and regions directly above the fuel regions is first reduced by $10 \%$. A new set of cross-sections is generated for the "voided" core with nominal fuel temperatures.

\section{Primary and secondary control rods:}

The worth curve for the control rods is calculated by incrementally changing the insertion depth of all the rods from their upper most position to their lower most position. The change in reactivity is calculated for each insertion depth by direct comparison of the core multiplication factors. A different set of calculations is performed for the primary and secondary control rods system. 


\section{Appendix 6. Detailed results from parametric study}

\section{U-20PuRG-10Zr fuel with ${ }^{235} \mathrm{U} / \mathrm{U}=0.3 \%$}

\begin{tabular}{|c|c|c|c|c|c|c|c|c|c|c|c|c|c|c|c|c|c|c|c|}
\hline & Assembly Type & \multicolumn{18}{|c|}{ A271 } \\
\hline & Core Height $(\mathrm{cm})$ & \multicolumn{6}{|c|}{60} & \multicolumn{6}{|c|}{80} & \multicolumn{6}{|c|}{100} \\
\hline & Number of Test assemblies & \multicolumn{2}{|c|}{1} & \multicolumn{2}{|c|}{4} & \multicolumn{2}{|c|}{7} & \multicolumn{2}{|c|}{1} & \multicolumn{2}{|c|}{4} & \multicolumn{2}{|c|}{7} & \multicolumn{2}{|c|}{1} & \multicolumn{2}{|c|}{4} & \multicolumn{2}{|c|}{7} \\
\hline & Average burnup (\% FIMA) & $3 \%$ & $6 \%$ & $3 \%$ & $6 \%$ & $3 \%$ & $6 \%$ & $3 \%$ & $6 \%$ & $3 \%$ & $6 \%$ & $3 \%$ & $6 \%$ & $3 \%$ & $6 \%$ & $3 \%$ & $6 \%$ & $3 \%$ & $6 \%$ \\
\hline & Number of batches & & 3 & & 3 & & 3 & & 4 & & 4 & & 4 & & 6 & & 6 & & 6 \\
\hline & Cycle length (days) & & 131 & & 124 & & 125 & & 105 & & 103 & & 104 & & 99 & & 97 & & 97 \\
\hline & Number of fuel assemblies & & 185 & & 200 & & 210 & & 109 & & 120 & & 125 & & 80 & & 90 & & 94 \\
\hline \multirow{3}{*}{ Max. values } & Thermal Power (MW) & & 787 & & 893 & & 936 & & 574 & & 646 & & 670 & & 373 & & 430 & & 447 \\
\hline & Max Assembly Power (MW) & & 5.9 & & 5.9 & & 5.8 & & 7.2 & & 7.2 & & 7.2 & & 6.3 & & 6.3 & & 6.3 \\
\hline & $20 \mathrm{~cm}$ peak avg. Fast Flux (*10E15) & & 6.1 & & 5.9 & & 5.8 & & 6.2 & & 6.0 & & 5.9 & & 4.5 & & 4.4 & & 4.4 \\
\hline \multirow{3}{*}{ 5.0e15 fast flux } & Thermal Power (MW) & $\mathrm{N} / \mathrm{A}$ & 648 & $\mathrm{~N} / \mathrm{A}$ & 760 & $\mathrm{~N} / \mathrm{A}$ & 802 & $\mathrm{~N} / \mathrm{A}$ & 465 & $\mathrm{~N} / \mathrm{A}$ & 542 & $\mathrm{~N} / \mathrm{A}$ & 564 & $\mathrm{~N} / \mathrm{A}$ & $\mathrm{N} / \mathrm{A}$ & $\mathrm{N} / \mathrm{A}$ & $\mathrm{N} / \mathrm{A}$ & N/A & N/A \\
\hline & Max Assembly Power (MW) & $\mathrm{N} / \mathrm{A}$ & 4.8 & $\mathrm{~N} / \mathrm{A}$ & 5.0 & $\mathrm{~N} / \mathrm{A}$ & 5.0 & $\mathrm{~N} / \mathrm{A}$ & 5.8 & $\mathrm{~N} / \mathrm{A}$ & 6.1 & N/A & 6.1 & $\mathrm{~N} / \mathrm{A}$ & $\mathrm{N} / \mathrm{A}$ & $\mathrm{N} / \mathrm{A}$ & $\mathrm{N} / \mathrm{A}$ & N/A & $\mathrm{N} / \mathrm{A}$ \\
\hline & $20 \mathrm{~cm}$ peak avg. Fast Flux ( $\left.{ }^{*} 10 \mathrm{E} 15\right)$ & 5 & 5 & 5 & 5 & 5 & 5 & 5 & 5 & 5 & 5 & 5 & 5 & 5 & 5 & 5 & 5 & 5 & 5 \\
\hline \multirow{3}{*}{$4.0 \mathrm{e} 15$ fast flux } & Thermal Power (MW) & $\mathrm{N} / \mathrm{A}$ & 518 & $\mathrm{~N} / \mathrm{A}$ & 608 & $\mathrm{~N} / \mathrm{A}$ & 642 & $\mathrm{~N} / \mathrm{A}$ & 372 & $\mathrm{~N} / \mathrm{A}$ & 434 & $\mathrm{~N} / \mathrm{A}$ & 451 & $\mathrm{~N} / \mathrm{A}$ & 328 & $\mathrm{~N} / \mathrm{A}$ & 389 & $\mathrm{~N} / \mathrm{A}$ & 403 \\
\hline & Max Assembly Power (MW) & $\mathrm{N} / \mathrm{A}$ & 3.9 & $\mathrm{~N} / \mathrm{A}$ & 4.0 & $\mathrm{~N} / \mathrm{A}$ & 4.0 & N/A & 4.7 & $\mathrm{~N} / \mathrm{A}$ & 4.8 & $\mathrm{~N} / \mathrm{A}$ & 4.9 & $\mathrm{~N} / \mathrm{A}$ & 5.6 & $\mathrm{~N} / \mathrm{A}$ & 5.7 & N/A & 5.7 \\
\hline & $20 \mathrm{~cm}$ peak avg. Fast Flux $\left({ }^{*} 10 \mathrm{E} 15\right)$ & 4 & 4 & 4 & 4 & 4 & 4 & 4 & 4 & 4 & 4 & 4 & 4 & 4 & 4 & 4 & 4 & 4 & 4 \\
\hline
\end{tabular}

\begin{tabular}{|c|c|c|c|c|c|c|c|c|c|c|c|c|c|c|c|c|c|c|c|}
\hline & Assembly Type & \multicolumn{18}{|c|}{ B271 } \\
\hline & Core Height $(\mathrm{cm})$ & \multicolumn{6}{|c|}{60} & \multicolumn{6}{|c|}{80} & \multicolumn{6}{|c|}{100} \\
\hline & Number of Test assemblies & \multicolumn{2}{|c|}{1} & \multicolumn{2}{|c|}{4} & \multicolumn{2}{|c|}{7} & \multicolumn{2}{|c|}{1} & \multicolumn{2}{|c|}{4} & \multicolumn{2}{|c|}{7} & \multicolumn{2}{|c|}{1} & \multicolumn{2}{|c|}{4} & \multicolumn{2}{|c|}{7} \\
\hline & Average burnup (\% FIMA) & $3 \%$ & $6 \%$ & $3 \%$ & $6 \%$ & $3 \%$ & $6 \%$ & $3 \%$ & $6 \%$ & $3 \%$ & $6 \%$ & $3 \%$ & $6 \%$ & $3 \%$ & $6 \%$ & $3 \%$ & $6 \%$ & $3 \%$ & $6 \%$ \\
\hline & Number of batches & & 4 & & 4 & & 4 & & 6 & & 6 & & 6 & & 8 & & 8 & & 8 \\
\hline & Cycle length (days) & & 109 & & 104 & & 105 & & 98 & & 94 & & 96 & & 102 & & 101 & & 102 \\
\hline & Number of fuel assemblies & & 125 & & 140 & & 145 & & 80 & & 86 & & 91 & & 60 & & 69 & & 70 \\
\hline \multirow{3}{*}{ Max. values } & Thermal Power (MW) & & 532 & & 626 & & 642 & & 336 & & 376 & & 392 & & 228 & & 264 & & 266 \\
\hline & Max Assembly Power (MW) & & 5.9 & & 5.9 & & 5.9 & & 5.8 & & 5.8 & & 5.8 & & 5.1 & & 5.1 & & 5.1 \\
\hline & $20 \mathrm{~cm}$ peak avg. Fast Flux (*10E15) & & 5.8 & & 5.6 & & 5.6 & & 4.6 & & 4.5 & & 4.5 & & 3.4 & & 3.3 & & 3.3 \\
\hline \multirow{3}{*}{ 5.0e15 fast flux } & Thermal Power (MW) & $\mathrm{N} / \mathrm{A}$ & 461 & $\mathrm{~N} / \mathrm{A}$ & 557 & $\mathrm{~N} / \mathrm{A}$ & 578 & $\mathrm{~N} / \mathrm{A}$ & $\mathrm{N} / \mathrm{A}$ & $\mathrm{N} / \mathrm{A}$ & $\mathrm{N} / \mathrm{A}$ & $\mathrm{N} / \mathrm{A}$ & $\mathrm{N} / \mathrm{A}$ & $\mathrm{N} / \mathrm{A}$ & N/A & $\mathrm{N} / \mathrm{A}$ & $\mathrm{N} / \mathrm{A}$ & $\mathrm{N} / \mathrm{A}$ & $\mathrm{N} / \mathrm{A}$ \\
\hline & Max Assembly Power (MW) & $\mathrm{N} / \mathrm{A}$ & 5.1 & $\mathrm{~N} / \mathrm{A}$ & 5.2 & $\mathrm{~N} / \mathrm{A}$ & 5.3 & $\mathrm{~N} / \mathrm{A}$ & $\mathrm{N} / \mathrm{A}$ & $\mathrm{N} / \mathrm{A}$ & $\mathrm{N} / \mathrm{A}$ & $\mathrm{N} / \mathrm{A}$ & $\mathrm{N} / \mathrm{A}$ & $\mathrm{N} / \mathrm{A}$ & N/A & $\mathrm{N} / \mathrm{A}$ & $\mathrm{N} / \mathrm{A}$ & $\mathrm{N} / \mathrm{A}$ & $\mathrm{N} / \mathrm{A}$ \\
\hline & $20 \mathrm{~cm}$ peak avg. Fast Flux ( $\left.{ }^{*} 10 \mathrm{E} 15\right)$ & 5 & 5 & 5 & 5 & 5 & 5 & 5 & 5 & 5 & 5 & 5 & 5 & 5 & 5 & 5 & 5 & 5 & 5 \\
\hline \multirow{3}{*}{ 4.0e15 fast flux } & Thermal Power (MW) & $\mathrm{N} / \mathrm{A}$ & 369 & $\mathrm{~N} / \mathrm{A}$ & 445 & $\mathrm{~N} / \mathrm{A}$ & 462 & $\mathrm{~N} / \mathrm{A}$ & 290 & $\mathrm{~N} / \mathrm{A}$ & 334 & $\mathrm{~N} / \mathrm{A}$ & 350 & $\mathrm{~N} / \mathrm{A}$ & N/A & $\mathrm{N} / \mathrm{A}$ & N/A & $\mathrm{N} / \mathrm{A}$ & $\mathrm{N} / \mathrm{A}$ \\
\hline & Max Assembly Power (MW) & $\mathrm{N} / \mathrm{A}$ & 4.1 & $\mathrm{~N} / \mathrm{A}$ & 4.2 & $\mathrm{~N} / \mathrm{A}$ & 4.2 & $\mathrm{~N} / \mathrm{A}$ & 5.0 & $\mathrm{~N} / \mathrm{A}$ & 5.1 & $\mathrm{~N} / \mathrm{A}$ & 5.1 & $\mathrm{~N} / \mathrm{A}$ & N/A & $\mathrm{N} / \mathrm{A}$ & N/A & $\mathrm{N} / \mathrm{A}$ & $\mathrm{N} / \mathrm{A}$ \\
\hline & $20 \mathrm{~cm}$ peak avg. Fast Flux (*10E15) & 4 & 4 & 4 & 4 & 4 & 4 & 4 & 4 & 4 & 4 & 4 & 4 & 4 & 4 & 4 & 4 & 4 & 4 \\
\hline
\end{tabular}

\begin{tabular}{|c|c|c|c|c|c|c|c|c|c|c|c|c|c|c|c|c|c|c|c|}
\hline & Assembly Type & \multicolumn{18}{|c|}{ C271 } \\
\hline & Core Height $(\mathrm{cm})$ & \multicolumn{6}{|c|}{60} & \multicolumn{6}{|c|}{80} & \multicolumn{6}{|c|}{100} \\
\hline & Number of Test assemblies & \multicolumn{2}{|c|}{1} & \multicolumn{2}{|c|}{4} & \multicolumn{2}{|c|}{7} & \multicolumn{2}{|c|}{1} & \multicolumn{2}{|c|}{4} & \multicolumn{2}{|c|}{7} & \multicolumn{2}{|c|}{1} & \multicolumn{2}{|c|}{4} & \multicolumn{2}{|c|}{7} \\
\hline & Average burnup (\% FIMA) & $3 \%$ & $6 \%$ & $3 \%$ & $6 \%$ & $3 \%$ & $6 \%$ & $3 \%$ & $6 \%$ & $3 \%$ & $6 \%$ & $3 \%$ & $6 \%$ & $3 \%$ & $6 \%$ & $3 \%$ & $6 \%$ & $3 \%$ & $6 \%$ \\
\hline & Number of batches & & 6 & & 5 & & 5 & & 9 & & 9 & & 9 & & 12 & & 12 & & 12 \\
\hline & Cycle length (days) & & 94 & & 109 & & 110 & & 97 & & 95 & & 96 & & 98 & & 100 & & 101 \\
\hline & Number of fuel assemblies & & 90 & & 100 & & 105 & & 59 & & 67 & & 70 & & 45 & & 54 & & 55 \\
\hline \multirow{3}{*}{ Max. values } & Thermal Power (MW) & & 331 & & 381 & & 396 & & 186 & & 215 & & 222 & & 131 & & 154 & & 155 \\
\hline & Max Assembly Power (MW) & & 5.0 & & 5.0 & & 5.0 & & 4.3 & & 4.3 & & 4.3 & & 3.7 & & 3.7 & & 3.7 \\
\hline & $20 \mathrm{~cm}$ peak avg. Fast Flux ( $* 10 \mathrm{E} 15)$ & & 4.7 & & 4.5 & & 4.5 & & 3.2 & & 3.1 & & 3.1 & & 2.3 & & 2.3 & & 2.3 \\
\hline \multirow{3}{*}{ 5.0e15 fast flux } & Thermal Power (MW) & $\mathrm{N} / \mathrm{A}$ & $\mathrm{N} / \mathrm{A}$ & $\mathrm{N} / \mathrm{A}$ & N/A & $\mathrm{N} / \mathrm{A}$ & $\mathrm{N} / \mathrm{A}$ & $\mathrm{N} / \mathrm{A}$ & $\mathrm{N} / \mathrm{A}$ & $\mathrm{N} / \mathrm{A}$ & $\mathrm{N} / \mathrm{A}$ & $\mathrm{N} / \mathrm{A}$ & $\mathrm{N} / \mathrm{A}$ & $\mathrm{N} / \mathrm{A}$ & N/A & $\mathrm{N} / \mathrm{A}$ & $\mathrm{N} / \mathrm{A}$ & $\mathrm{N} / \mathrm{A}$ & $\mathrm{N} / \mathrm{A}$ \\
\hline & Max Assembly Power (MW) & $\mathrm{N} / \mathrm{A}$ & N/A & N/A & N/A & N/A & $\mathrm{N} / \mathrm{A}$ & $\mathrm{N} / \mathrm{A}$ & $\mathrm{N} / \mathrm{A}$ & $\mathrm{N} / \mathrm{A}$ & $\mathrm{N} / \mathrm{A}$ & N/A & N/A & $\mathrm{N} / \mathrm{A}$ & $\mathrm{N} / \mathrm{A}$ & $\mathrm{N} / \mathrm{A}$ & N/A & $\mathrm{N} / \mathrm{A}$ & $\mathrm{N} / \mathrm{A}$ \\
\hline & $20 \mathrm{~cm}$ peak avg. Fast Flux ( $\left.{ }^{*} 10 \mathrm{E} 15\right)$ & 5 & 5 & 5 & 5 & 5 & 5 & 5 & 5 & 5 & 5 & 5 & 5 & 5 & 5 & 5 & 5 & 5 & 5 \\
\hline \multirow{3}{*}{ 4.0e15 fast flux } & Thermal Power (MW) & $\mathrm{N} / \mathrm{A}$ & 282 & N/A & 337 & $\mathrm{~N} / \mathrm{A}$ & 352 & $\mathrm{~N} / \mathrm{A}$ & $\mathrm{N} / \mathrm{A}$ & $\mathrm{N} / \mathrm{A}$ & $\mathrm{N} / \mathrm{A}$ & $\mathrm{N} / \mathrm{A}$ & $\mathrm{N} / \mathrm{A}$ & $\mathrm{N} / \mathrm{A}$ & $\mathrm{N} / \mathrm{A}$ & $\mathrm{N} / \mathrm{A}$ & $\mathrm{N} / \mathrm{A}$ & $\mathrm{N} / \mathrm{A}$ & $\mathrm{N} / \mathrm{A}$ \\
\hline & Max Assembly Power (MW) & $\mathrm{N} / \mathrm{A}$ & 4.3 & N/A & 4.5 & $\mathrm{~N} / \mathrm{A}$ & 4.5 & $\mathrm{~N} / \mathrm{A}$ & $\mathrm{N} / \mathrm{A}$ & $\mathrm{N} / \mathrm{A}$ & N/A & N/A & $\mathrm{N} / \mathrm{A}$ & $\mathrm{N} / \mathrm{A}$ & N/A & $\mathrm{N} / \mathrm{A}$ & N/A & $\mathrm{N} / \mathrm{A}$ & $\mathrm{N} / \mathrm{A}$ \\
\hline & $20 \mathrm{~cm}$ peak avg. Fast Flux ( $\left.{ }^{*} 10 \mathrm{E} 15\right)$ & 4 & 4 & 4 & 4 & 4 & 4 & 4 & 4 & 4 & 4 & 4 & 4 & 4 & 4 & 4 & 4 & 4 & 4 \\
\hline
\end{tabular}




\begin{tabular}{|c|c|c|c|c|c|c|c|c|c|c|c|c|c|c|c|c|c|c|c|}
\hline & Assembly Type & \multicolumn{18}{|c|}{ A271 } \\
\hline & Core Height $(\mathrm{cm})$ & \multicolumn{6}{|c|}{60} & \multicolumn{6}{|c|}{80} & \multicolumn{6}{|c|}{100} \\
\hline & Number of Test assemblies & \multicolumn{2}{|c|}{1} & \multicolumn{2}{|c|}{4} & \multicolumn{2}{|c|}{7} & \multicolumn{2}{|c|}{1} & \multicolumn{2}{|c|}{4} & \multicolumn{2}{|c|}{7} & \multicolumn{2}{|c|}{1} & \multicolumn{2}{|c|}{4} & \multicolumn{2}{|c|}{7} \\
\hline & Average burnup (\% FIMA) & $3 \%$ & $6 \%$ & $3 \%$ & $6 \%$ & $3 \%$ & $6 \%$ & $3 \%$ & $6 \%$ & $3 \%$ & $6 \%$ & $3 \%$ & $6 \%$ & $3 \%$ & $6 \%$ & $3 \%$ & $6 \%$ & $3 \%$ & $6 \%$ \\
\hline & Number of batches & & 3 & & 3 & & 3 & & 4 & & 4 & & 4 & & 6 & & & & \\
\hline & Cycle length (days) & & 132 & & 125 & & 125 & & 107 & & 103 & & 104 & & 99 & & & & \\
\hline & Number of fuel assemblies & & 215 & & 215 & & 210 & & 125 & & 135 & & 145 & & 90 & & & & \\
\hline \multirow{3}{*}{ Max. values } & Thermal Power (MW) & & 908 & & 955 & & 936 & & 648 & & 727 & & 773 & & 421 & & & & \\
\hline & Max Assembly Power (MW) & & 5.9 & & 5.9 & & 5.8 & & 7.2 & & 7.2 & & 7.2 & & 6.3 & & & & \\
\hline & $20 \mathrm{~cm}$ peak avg. Fast Flux ( $\left.{ }^{*} 10 \mathrm{E} 15\right)$ & & 6.2 & & 5.9 & & 5.8 & & 6.3 & & 6.1 & & 6.0 & & 4.6 & & & & \\
\hline \multirow{3}{*}{ 5.0e15 fast flux } & Thermal Power (MW) & $\mathrm{N} / \mathrm{A}$ & 737 & $\mathrm{~N} / \mathrm{A}$ & 810 & $\mathrm{~N} / \mathrm{A}$ & 805 & $\mathrm{~N} / \mathrm{A}$ & 517 & $\mathrm{~N} / \mathrm{A}$ & 598 & $\mathrm{~N} / \mathrm{A}$ & 639 & $\mathrm{~N} / \mathrm{A}$ & $\mathrm{N} / \mathrm{A}$ & $\mathrm{N} / \mathrm{A}$ & $\mathrm{N} / \mathrm{A}$ & $\mathrm{N} / \mathrm{A}$ & $\mathrm{N} / \mathrm{A}$ \\
\hline & Max Assembly Power (MW) & $\mathrm{N} / \mathrm{A}$ & 4.8 & N/A & 5.0 & $\mathrm{~N} / \mathrm{A}$ & 5.0 & $\mathrm{~N} / \mathrm{A}$ & 5.7 & $\mathrm{~N} / \mathrm{A}$ & 5.9 & $\mathrm{~N} / \mathrm{A}$ & 6.0 & N/A & $\mathrm{N} / \mathrm{A}$ & $\mathrm{N} / \mathrm{A}$ & N/A & N/A & $\mathrm{N} / \mathrm{A}$ \\
\hline & $20 \mathrm{~cm}$ peak avg. Fast Flux ( $\left.{ }^{*} 10 \mathrm{E} 15\right)$ & 5 & 5 & 5 & 5 & 5 & 5 & 5 & 5 & 5 & 5 & 5 & 5 & 5 & 5 & 5 & 5 & 5 & 5 \\
\hline \multirow{3}{*}{ 4.0e15 fast flux } & Thermal Power (MW) & $\mathrm{N} / \mathrm{A}$ & 589 & $\mathrm{~N} / \mathrm{A}$ & 648 & $\mathrm{~N} / \mathrm{A}$ & 644 & $\mathrm{~N} / \mathrm{A}$ & 414 & $\mathrm{~N} / \mathrm{A}$ & 479 & $\mathrm{~N} / \mathrm{A}$ & 512 & $\mathrm{~N} / \mathrm{A}$ & 362 & $\mathrm{~N} / \mathrm{A}$ & N/A & $\mathrm{N} / \mathrm{A}$ & $\mathrm{N} / \mathrm{A}$ \\
\hline & Max Assembly Power (MW) & $\mathrm{N} / \mathrm{A}$ & 3.8 & $\mathrm{~N} / \mathrm{A}$ & 4.0 & $\mathrm{~N} / \mathrm{A}$ & 4.0 & $\mathrm{~N} / \mathrm{A}$ & 4.6 & $\mathrm{~N} / \mathrm{A}$ & 4.8 & $\mathrm{~N} / \mathrm{A}$ & 4.8 & $\mathrm{~N} / \mathrm{A}$ & 5.5 & $\mathrm{~N} / \mathrm{A}$ & $\mathrm{N} / \mathrm{A}$ & $\mathrm{N} / \mathrm{A}$ & $\mathrm{N} / \mathrm{A}$ \\
\hline & $20 \mathrm{~cm}$ peak avg. Fast Flux ( $\left.{ }^{*} 10 \mathrm{E} 15\right)$ & 4 & 4 & 4 & 4 & 4 & 4 & 4 & 4 & 4 & 4 & 4 & 4 & 4 & 4 & 4 & 4 & 4 & 4 \\
\hline
\end{tabular}

\begin{tabular}{|c|c|c|c|c|c|c|c|c|c|c|c|c|c|c|c|c|c|c|c|}
\hline & Assembly Type & \multicolumn{18}{|c|}{ B271 } \\
\hline & Core Height $(\mathrm{cm})$ & \multicolumn{6}{|c|}{60} & \multicolumn{6}{|c|}{80} & \multicolumn{6}{|c|}{100} \\
\hline & Number of Test assemblies & \multicolumn{2}{|c|}{1} & \multicolumn{2}{|c|}{4} & \multicolumn{2}{|c|}{7} & \multicolumn{2}{|c|}{1} & \multicolumn{2}{|c|}{4} & \multicolumn{2}{|c|}{7} & \multicolumn{2}{|c|}{1} & \multicolumn{2}{|c|}{4} & \multicolumn{2}{|c|}{7} \\
\hline & Average burnup (\% FIMA) & $3 \%$ & $6 \%$ & $3 \%$ & $6 \%$ & $3 \%$ & $6 \%$ & $3 \%$ & $6 \%$ & $3 \%$ & $6 \%$ & $3 \%$ & $6 \%$ & $3 \%$ & $6 \%$ & $3 \%$ & $6 \%$ & $3 \%$ & $6 \%$ \\
\hline & Number of batches & & 4 & & 4 & & 4 & & 6 & & 6 & & 6 & & 8 & & 8 & & 8 \\
\hline & Cycle length (days) & & 110 & & 104 & & 104 & & 98 & & 95 & & 96 & & 104 & & 103 & & 103 \\
\hline & Number of fuel assemblies & & 150 & & 160 & & 170 & & 90 & & 99 & & 104 & & 69 & & 76 & & 80 \\
\hline \multirow{3}{*}{ Max. values } & Thermal Power (MW) & & 635 & & 717 & & 759 & & 379 & & 430 & & 446 & & 257 & & 287 & & 302 \\
\hline & Max Assembly Power (MW) & & 5.9 & & 5.9 & & 5.9 & & 5.8 & & 5.8 & & 5.8 & & 5.1 & & 5.1 & & 5.1 \\
\hline & $20 \mathrm{~cm}$ peak avg. Fast Flux (*10E15) & & 5.9 & & 5.7 & & 5.7 & & 4.7 & & 4.6 & & 4.6 & & 3.5 & & 3.4 & & 3.4 \\
\hline \multirow{3}{*}{ 5.0e15 fast flux } & Thermal Power (MW) & $\mathrm{N} / \mathrm{A}$ & 539 & $\mathrm{~N} / \mathrm{A}$ & 629 & $\mathrm{~N} / \mathrm{A}$ & 670 & $\mathrm{~N} / \mathrm{A}$ & $\mathrm{N} / \mathrm{A}$ & $\mathrm{N} / \mathrm{A}$ & $\mathrm{N} / \mathrm{A}$ & $\mathrm{N} / \mathrm{A}$ & $\mathrm{N} / \mathrm{A}$ & $\mathrm{N} / \mathrm{A}$ & $\mathrm{N} / \mathrm{A}$ & $\mathrm{N} / \mathrm{A}$ & $\mathrm{N} / \mathrm{A}$ & $\mathrm{N} / \mathrm{A}$ & $\mathrm{N} / \mathrm{A}$ \\
\hline & Max Assembly Power (MW) & $\mathrm{N} / \mathrm{A}$ & 5.0 & N/A & 5.2 & N/A & 5.2 & $\mathrm{~N} / \mathrm{A}$ & $\mathrm{N} / \mathrm{A}$ & $\mathrm{N} / \mathrm{A}$ & N/A & $\mathrm{N} / \mathrm{A}$ & N/A & N/A & $\mathrm{N} / \mathrm{A}$ & $\mathrm{N} / \mathrm{A}$ & N/A & N/A & $\mathrm{N} / \mathrm{A}$ \\
\hline & $20 \mathrm{~cm}$ peak avg. Fast Flux (*10E15) & 5 & 5 & 5 & 5 & 5 & 5 & 5 & 5 & 5 & 5 & 5 & 5 & 5 & 5 & 5 & 5 & 5 & 5 \\
\hline \multirow{3}{*}{ 4.0e15 fast flux } & Thermal Power (MW) & $\mathrm{N} / \mathrm{A}$ & 431 & $\mathrm{~N} / \mathrm{A}$ & 503 & $\mathrm{~N} / \mathrm{A}$ & 536 & $\mathrm{~N} / \mathrm{A}$ & 320 & $\mathrm{~N} / \mathrm{A}$ & 374 & $\mathrm{~N} / \mathrm{A}$ & 391 & $\mathrm{~N} / \mathrm{A}$ & $\mathrm{N} / \mathrm{A}$ & $\mathrm{N} / \mathrm{A}$ & $\mathrm{N} / \mathrm{A}$ & $\mathrm{N} / \mathrm{A}$ & $\mathrm{N} / \mathrm{A}$ \\
\hline & Max Assembly Power (MW) & $\mathrm{N} / \mathrm{A}$ & 4.0 & N/A & 4.1 & N/A & 4.2 & $\mathrm{~N} / \mathrm{A}$ & 4.9 & $\mathrm{~N} / \mathrm{A}$ & 5.0 & $\mathrm{~N} / \mathrm{A}$ & 5.1 & N/A & $\mathrm{N} / \mathrm{A}$ & $\mathrm{N} / \mathrm{A}$ & N/A & N/A & $\mathrm{N} / \mathrm{A}$ \\
\hline & $20 \mathrm{~cm}$ peak avg. Fast Flux (*10E15) & 4 & 4 & 4 & 4 & 4 & 4 & 4 & 4 & 4 & 4 & 4 & 4 & 4 & 4 & 4 & 4 & 4 & 4 \\
\hline
\end{tabular}

\begin{tabular}{|c|c|c|c|c|c|c|c|c|c|c|c|c|c|c|c|c|c|c|c|}
\hline & Assembly Type & \multicolumn{18}{|c|}{ C271 } \\
\hline & Core Height $(\mathrm{cm})$ & \multicolumn{6}{|c|}{60} & \multicolumn{6}{|c|}{80} & \multicolumn{6}{|c|}{100} \\
\hline & Number of Test assemblies & \multicolumn{2}{|c|}{1} & \multicolumn{2}{|c|}{4} & \multicolumn{2}{|c|}{7} & \multicolumn{2}{|c|}{1} & \multicolumn{2}{|c|}{4} & \multicolumn{2}{|c|}{7} & \multicolumn{2}{|c|}{1} & \multicolumn{2}{|c|}{4} & \multicolumn{2}{|c|}{7} \\
\hline & Average burnup (\% FIMA) & $3 \%$ & $6 \%$ & $3 \%$ & $6 \%$ & $3 \%$ & $6 \%$ & $3 \%$ & $6 \%$ & $3 \%$ & $6 \%$ & $3 \%$ & $6 \%$ & $3 \%$ & $6 \%$ & $3 \%$ & $6 \%$ & $3 \%$ & $6 \%$ \\
\hline & Number of batches & & 6 & & 5 & & 5 & & 9 & & 9 & & 9 & & 12 & & 12 & & 12 \\
\hline & Cycle length (days) & & 95 & & 109 & & 110 & & 98 & & 97 & & 97 & & 101 & & 102 & & 103 \\
\hline & Number of fuel assemblies & & 104 & & 115 & & 125 & & 66 & & 75 & & 80 & & 50 & & 60 & & 61 \\
\hline \multirow{3}{*}{ Max. values } & Thermal Power (MW) & & 376 & & 438 & & 471 & & 205 & & 238 & & 252 & & 142 & & 169 & & 170 \\
\hline & Max Assembly Power (MW) & & 5.0 & & 5.0 & & 5.0 & & 4.3 & & 4.3 & & 4.3 & & 3.7 & & 3.7 & & 3.7 \\
\hline & $20 \mathrm{~cm}$ peak avg. Fast Flux (*10E15) & & 4.7 & & 4.6 & & 4.6 & & 3.2 & & 3.2 & & 3.2 & & 2.4 & & 2.3 & & 2.3 \\
\hline \multirow{3}{*}{ 5.0e15 fast flux } & Thermal Power (MW) & $\mathrm{N} / \mathrm{A}$ & $\mathrm{N} / \mathrm{A}$ & $\mathrm{N} / \mathrm{A}$ & $\mathrm{N} / \mathrm{A}$ & $\mathrm{N} / \mathrm{A}$ & $\mathrm{N} / \mathrm{A}$ & $\mathrm{N} / \mathrm{A}$ & $\mathrm{N} / \mathrm{A}$ & $\mathrm{N} / \mathrm{A}$ & $\mathrm{N} / \mathrm{A}$ & $\mathrm{N} / \mathrm{A}$ & $\mathrm{N} / \mathrm{A}$ & $\mathrm{N} / \mathrm{A}$ & $\mathrm{N} / \mathrm{A}$ & $\mathrm{N} / \mathrm{A}$ & $\mathrm{N} / \mathrm{A}$ & $\mathrm{N} / \mathrm{A}$ & $\mathrm{N} / \mathrm{A}$ \\
\hline & Max Assembly Power (MW) & $\mathrm{N} / \mathrm{A}$ & $\mathrm{N} / \mathrm{A}$ & $\mathrm{N} / \mathrm{A}$ & $\mathrm{N} / \mathrm{A}$ & N/A & $\mathrm{N} / \mathrm{A}$ & $\mathrm{N} / \mathrm{A}$ & $\mathrm{N} / \mathrm{A}$ & $\mathrm{N} / \mathrm{A}$ & $\mathrm{N} / \mathrm{A}$ & $\mathrm{N} / \mathrm{A}$ & $\mathrm{N} / \mathrm{A}$ & $\mathrm{N} / \mathrm{A}$ & $\mathrm{N} / \mathrm{A}$ & N/A & N/A & $\mathrm{N} / \mathrm{A}$ & $\mathrm{N} / \mathrm{A}$ \\
\hline & $20 \mathrm{~cm}$ peak avg. Fast Flux ( $\left.{ }^{*} 10 \mathrm{E} 15\right)$ & 5 & 5 & 5 & 5 & 5 & 5 & 5 & 5 & 5 & 5 & 5 & 5 & 5 & 5 & 5 & 5 & 5 & 5 \\
\hline \multirow{3}{*}{ 4.0e15 fast flux } & Thermal Power (MW) & $\mathrm{N} / \mathrm{A}$ & 317 & $\mathrm{~N} / \mathrm{A}$ & 380 & $\mathrm{~N} / \mathrm{A}$ & 408 & $\mathrm{~N} / \mathrm{A}$ & $\mathrm{N} / \mathrm{A}$ & $\mathrm{N} / \mathrm{A}$ & $\mathrm{N} / \mathrm{A}$ & $\mathrm{N} / \mathrm{A}$ & $\mathrm{N} / \mathrm{A}$ & $\mathrm{N} / \mathrm{A}$ & $\mathrm{N} / \mathrm{A}$ & $\mathrm{N} / \mathrm{A}$ & $\mathrm{N} / \mathrm{A}$ & $\mathrm{N} / \mathrm{A}$ & $\mathrm{N} / \mathrm{A}$ \\
\hline & Max Assembly Power (MW) & $\mathrm{N} / \mathrm{A}$ & 4.2 & N/A & 4.4 & N/A & 4.4 & $\mathrm{~N} / \mathrm{A}$ & $\mathrm{N} / \mathrm{A}$ & $\mathrm{N} / \mathrm{A}$ & $\mathrm{N} / \mathrm{A}$ & $\mathrm{N} / \mathrm{A}$ & $\mathrm{N} / \mathrm{A}$ & $\mathrm{N} / \mathrm{A}$ & $\mathrm{N} / \mathrm{A}$ & N/A & N/A & $\mathrm{N} / \mathrm{A}$ & $\mathrm{N} / \mathrm{A}$ \\
\hline & $20 \mathrm{~cm}$ peak avg. Fast Flux (*10E15) & 4 & 4 & 4 & 4 & 4 & 4 & 4 & 4 & 4 & 4 & 4 & 4 & 4 & 4 & 4 & 4 & 4 & 4 \\
\hline
\end{tabular}




\begin{tabular}{|c|c|c|c|c|c|c|c|c|c|c|c|c|c|c|c|c|c|c|c|}
\hline & Assembly Type & \multicolumn{18}{|c|}{ A271 } \\
\hline & Core Height $(\mathrm{cm})$ & \multicolumn{6}{|c|}{60} & \multicolumn{6}{|c|}{80} & \multicolumn{6}{|c|}{100} \\
\hline & Number of Test assemblies & \multicolumn{2}{|c|}{1} & \multicolumn{2}{|c|}{4} & \multicolumn{2}{|c|}{7} & \multicolumn{2}{|c|}{1} & \multicolumn{2}{|c|}{4} & \multicolumn{2}{|c|}{7} & \multicolumn{2}{|c|}{1} & \multicolumn{2}{|c|}{4} & \multicolumn{2}{|c|}{7} \\
\hline & Average burnup (\% FIMA) & $3 \%$ & $6 \%$ & $3 \%$ & $6 \%$ & $3 \%$ & $6 \%$ & $3 \%$ & $6 \%$ & $3 \%$ & $6 \%$ & $3 \%$ & $6 \%$ & $3 \%$ & $6 \%$ & $3 \%$ & $6 \%$ & $3 \%$ & $6 \%$ \\
\hline & Number of batches & 2 & 3 & 2 & 3 & 2 & 3 & 2 & 4 & 2 & 4 & 2 & 4 & 3 & 6 & 3 & 6 & 3 & 6 \\
\hline & Cycle length (days) & 98 & 129 & 95 & 124 & 95 & 126 & 101 & 102 & 102 & 101 & 103 & 102 & 90 & 92 & 92 & 93 & 93 & 94 \\
\hline & Number of fuel assemblies & 80 & 100 & 90 & 110 & 95 & 115 & 54 & 65 & 62 & 71 & 65 & 75 & 41 & 48 & 47 & 55 & 49 & 57 \\
\hline \multirow{3}{*}{ Max. values } & Thermal Power (MW) & 340 & 432 & 397 & 494 & 417 & 509 & 297 & 353 & 339 & 391 & 350 & 407 & 210 & 241 & 236 & 275 & 243 & 280 \\
\hline & Max Assembly Power (MW) & 5.9 & 5.8 & 5.9 & 5.8 & 5.9 & 5.9 & 7.2 & 7.2 & 7.2 & 7.2 & 7.2 & 7.2 & 6.3 & 6.3 & 6.3 & 6.3 & 6.3 & 6.3 \\
\hline & $20 \mathrm{~cm}$ peak avg. Fast Flux (*10E15) & 5.4 & 5.6 & 5.3 & 5.4 & 5.3 & 5.4 & 5.4 & 5.6 & 5.3 & 5.4 & 5.3 & 5.4 & 4.0 & 4.1 & 3.9 & 4.0 & 3.9 & 4.0 \\
\hline \multirow{3}{*}{ 5.0e15 fast flux } & Thermal Power (MW) & 314 & 386 & 376 & 454 & 393 & 471 & 275 & 315 & 322 & 360 & 333 & 374 & $\mathrm{~N} / \mathrm{A}$ & $\mathrm{N} / \mathrm{A}$ & $\mathrm{N} / \mathrm{A}$ & N/A & N/A & $\mathrm{N} / \mathrm{A}$ \\
\hline & Max Assembly Power (MW) & 5.4 & 5.2 & 5.5 & 5.4 & 5.5 & 5.4 & 6.7 & 6.4 & 6.8 & 6.6 & 6.9 & 6.6 & $\mathrm{~N} / \mathrm{A}$ & $\mathrm{N} / \mathrm{A}$ & $\mathrm{N} / \mathrm{A}$ & N/A & N/A & $\mathrm{N} / \mathrm{A}$ \\
\hline & $20 \mathrm{~cm}$ peak avg. Fast Flux $\left({ }^{*} 10 \mathrm{E} 15\right)$ & 5 & 5 & 5 & 5 & 5 & 5 & 5 & 5 & 5 & 5 & 5 & 5 & 5 & 5 & 5 & 5 & 5 & 5 \\
\hline \multirow{3}{*}{ 4.0e15 fast flux } & Thermal Power (MW) & 251 & 309 & 301 & 363 & 314 & 377 & 220 & 252 & 258 & 288 & 267 & 299 & $\mathrm{~N} / \mathrm{A}$ & 235 & $\mathrm{~N} / \mathrm{A}$ & 272 & $\mathrm{~N} / \mathrm{A}$ & 279 \\
\hline & Max Assembly Power (MW) & 4.3 & 4.2 & 4.4 & 4.3 & 4.4 & 4.3 & 5.3 & 5.1 & 5.5 & 5.3 & 5.5 & 5.3 & $\mathrm{~N} / \mathrm{A}$ & 6.2 & $\mathrm{~N} / \mathrm{A}$ & 6.3 & N/A & 6.3 \\
\hline & $20 \mathrm{~cm}$ peak avg. Fast Flux $\left({ }^{*} 10 \mathrm{E} 15\right)$ & 4 & 4 & 4 & 4 & 4 & 4 & 4 & 4 & 4 & 4 & 4 & 4 & 4 & 4 & 4 & 4 & 4 & 4 \\
\hline
\end{tabular}

\begin{tabular}{|c|c|c|c|c|c|c|c|c|c|c|c|c|c|c|c|c|c|c|c|}
\hline & Assembly Type & \multicolumn{18}{|c|}{ B271 } \\
\hline & Core Height $(\mathrm{cm})$ & \multicolumn{6}{|c|}{60} & \multicolumn{6}{|c|}{80} & \multicolumn{6}{|c|}{100} \\
\hline & Number of Test assemblies & \multicolumn{2}{|c|}{1} & \multicolumn{2}{|c|}{4} & \multicolumn{2}{|c|}{7} & \multicolumn{2}{|c|}{1} & \multicolumn{2}{|c|}{4} & \multicolumn{2}{|c|}{7} & \multicolumn{2}{|c|}{1} & \multicolumn{2}{|c|}{4} & \multicolumn{2}{|c|}{7} \\
\hline & Average burnup (\% FIMA) & $3 \%$ & $6 \%$ & $3 \%$ & $6 \%$ & $3 \%$ & $6 \%$ & $3 \%$ & $6 \%$ & $3 \%$ & $6 \%$ & $3 \%$ & $6 \%$ & $3 \%$ & $6 \%$ & $3 \%$ & $6 \%$ & $3 \%$ & $6 \%$ \\
\hline & Number of batches & 2 & 4 & 2 & 4 & 2 & 4 & 3 & 5 & 3 & 6 & 3 & 6 & 4 & 7 & 4 & 8 & 4 & 8 \\
\hline & Cycle length (days) & 107 & 107 & 106 & 102 & 107 & 104 & 90 & 109 & 91 & 92 & 91 & 94 & 93 & 107 & 94 & 95 & 94 & 95 \\
\hline & Number of fuel assemblies & 60 & 71 & 70 & 80 & 74 & 85 & 40 & 46 & 45 & 55 & 46 & 56 & 31 & 36 & 37 & 42 & 37 & 42 \\
\hline \multirow{3}{*}{ Max. values } & Thermal Power (MW) & 260 & 308 & 308 & 363 & 321 & 379 & 184 & 210 & 205 & 247 & 209 & 248 & 129 & 150 & 153 & 172 & 153 & 172 \\
\hline & Max Assembly Power (MW) & 5.9 & 5.9 & 5.9 & 5.9 & 5.9 & 5.9 & 5.8 & 5.8 & 5.8 & 5.8 & 5.8 & 5.8 & 5.1 & 5.1 & 5.1 & 5.1 & 5.1 & 5.1 \\
\hline & $20 \mathrm{~cm}$ peak avg. Fast Flux ( $\left.{ }^{*} 10 \mathrm{E} 15\right)$ & 5.1 & 5.3 & 5.0 & 5.2 & 5.0 & 5.1 & 4.1 & 4.2 & 3.9 & 4.1 & 4.0 & 4.1 & 2.9 & 3.0 & 2.9 & 3.0 & 2.9 & 3.0 \\
\hline \multirow{3}{*}{ 5.0e15 fast flux } & Thermal Power (MW) & 256 & 293 & $\mathrm{~N} / \mathrm{A}$ & 351 & N/A & 368 & $\mathrm{~N} / \mathrm{A}$ & $\mathrm{N} / \mathrm{A}$ & $\mathrm{N} / \mathrm{A}$ & $\mathrm{N} / \mathrm{A}$ & $\mathrm{N} / \mathrm{A}$ & $\mathrm{N} / \mathrm{A}$ & $\mathrm{N} / \mathrm{A}$ & $\mathrm{N} / \mathrm{A}$ & $\mathrm{N} / \mathrm{A}$ & $\mathrm{N} / \mathrm{A}$ & $\mathrm{N} / \mathrm{A}$ & $\mathrm{N} / \mathrm{A}$ \\
\hline & \begin{tabular}{|l|} 
Max Assembly Power (MW) \\
\end{tabular} & 5.8 & 5.6 & $\mathrm{~N} / \mathrm{A}$ & 5.7 & N/A & 5.7 & $\mathrm{~N} / \mathrm{A}$ & $\mathrm{N} / \mathrm{A}$ & $\mathrm{N} / \mathrm{A}$ & N/A & $\mathrm{N} / \mathrm{A}$ & N/A & N/A & $\mathrm{N} / \mathrm{A}$ & $\mathrm{N} / \mathrm{A}$ & N/A & N/A & $\mathrm{N} / \mathrm{A}$ \\
\hline & $20 \mathrm{~cm}$ peak avg. Fast Flux ( $\left.{ }^{*} 10 \mathrm{E} 15\right)$ & 5 & 5 & 5 & 5 & 5 & 5 & 5 & 5 & 5 & 5 & 5 & 5 & 5 & 5 & 5 & 5 & 5 & 5 \\
\hline \multirow{3}{*}{ 4.0e15 fast flux } & Thermal Power (MW) & 205 & 235 & 247 & 281 & 257 & 294 & 181 & 201 & $\mathrm{~N} / \mathrm{A}$ & 239 & $\mathrm{~N} / \mathrm{A}$ & 242 & $\mathrm{~N} / \mathrm{A}$ & $\mathrm{N} / \mathrm{A}$ & $\mathrm{N} / \mathrm{A}$ & $\mathrm{N} / \mathrm{A}$ & $\mathrm{N} / \mathrm{A}$ & $\mathrm{N} / \mathrm{A}$ \\
\hline & Max Assembly Power (MW) & 4.6 & 4.5 & 4.7 & 4.5 & 4.7 & 4.6 & 5.7 & 5.5 & $\mathrm{~N} / \mathrm{A}$ & 5.6 & $\mathrm{~N} / \mathrm{A}$ & 5.6 & N/A & $\mathrm{N} / \mathrm{A}$ & $\mathrm{N} / \mathrm{A}$ & N/A & N/A & $\mathrm{N} / \mathrm{A}$ \\
\hline & $20 \mathrm{~cm}$ peak avg. Fast Flux ( $\left.{ }^{*} 10 \mathrm{E} 15\right)$ & 4 & 4 & 4 & 4 & 4 & 4 & 4 & 4 & 4 & 4 & 4 & 4 & 4 & 4 & 4 & 4 & 4 & 4 \\
\hline
\end{tabular}

\begin{tabular}{|c|c|c|c|c|c|c|c|c|c|c|c|c|c|c|c|c|c|c|c|}
\hline & Assembly Type & \multicolumn{18}{|c|}{ C271 } \\
\hline & Core Height $(\mathrm{cm})$ & \multicolumn{6}{|c|}{60} & \multicolumn{6}{|c|}{80} & \multicolumn{6}{|c|}{100} \\
\hline & Number of Test assemblies & \multicolumn{2}{|c|}{1} & \multicolumn{2}{|c|}{4} & \multicolumn{2}{|c|}{7} & \multicolumn{2}{|c|}{1} & \multicolumn{2}{|c|}{4} & \multicolumn{2}{|c|}{7} & \multicolumn{2}{|c|}{1} & \multicolumn{2}{|c|}{4} & \multicolumn{2}{|c|}{7} \\
\hline & Average burnup (\% FIMA) & $3 \%$ & $6 \%$ & $3 \%$ & $6 \%$ & $3 \%$ & $6 \%$ & $3 \%$ & $6 \%$ & $3 \%$ & $6 \%$ & $3 \%$ & $6 \%$ & $3 \%$ & $6 \%$ & $3 \%$ & $6 \%$ & $3 \%$ & $6 \%$ \\
\hline & Number of batches & 3 & 5 & 3 & 5 & 3 & 5 & 4 & 8 & 4 & 8 & 4 & 8 & 6 & 11 & 6 & 11 & 6 & 11 \\
\hline & Cycle length (days) & 88 & 107 & 89 & 107 & 91 & 110 & 101 & 98 & 101 & 101 & 101 & 101 & 92 & 102 & 93 & 101 & 93 & 101 \\
\hline & Number of fuel assemblies & 43 & 51 & 51 & 61 & 54 & 65 & 30 & 34 & 36 & 41 & 36 & 42 & 26 & 29 & 29 & 33 & 29 & 34 \\
\hline \multirow{3}{*}{ Max. values } & Thermal Power (MW) & 169 & 197 & 197 & 235 & 204 & 245 & 102 & 119 & 123 & 139 & 122 & 142 & 81 & 89 & 90 & 102 & 90 & 105 \\
\hline & Max Assembly Power (MW) & 5.0 & 5.0 & 5.0 & 5.0 & 5.0 & 5.0 & 4.3 & 4.2 & 4.3 & 4.2 & 4.3 & 4.3 & 3.7 & 3.7 & 3.7 & 3.7 & 3.7 & 3.7 \\
\hline & $20 \mathrm{~cm}$ peak avg. Fast Flux ( $\left.{ }^{*} 10 \mathrm{E} 15\right)$ & 4.1 & 4.2 & 4.0 & 4.2 & 4.0 & 4.1 & 2.7 & 2.9 & 2.7 & 2.8 & 2.7 & 2.8 & 2.0 & 2.0 & 2.0 & 2.1 & 2.0 & 2.1 \\
\hline \multirow{3}{*}{ 5.0e15 fast flux } & Thermal Power (MW) & $\mathrm{N} / \mathrm{A}$ & $\mathrm{N} / \mathrm{A}$ & $\mathrm{N} / \mathrm{A}$ & $\mathrm{N} / \mathrm{A}$ & $\mathrm{N} / \mathrm{A}$ & $\mathrm{N} / \mathrm{A}$ & $\mathrm{N} / \mathrm{A}$ & $\mathrm{N} / \mathrm{A}$ & $\mathrm{N} / \mathrm{A}$ & $\mathrm{N} / \mathrm{A}$ & $\mathrm{N} / \mathrm{A}$ & $\mathrm{N} / \mathrm{A}$ & $\mathrm{N} / \mathrm{A}$ & $\mathrm{N} / \mathrm{A}$ & $\mathrm{N} / \mathrm{A}$ & $\mathrm{N} / \mathrm{A}$ & N/A & $\mathrm{N} / \mathrm{A}$ \\
\hline & Max Assembly Power (MW) & $\mathrm{N} / \mathrm{A}$ & $\mathrm{N} / \mathrm{A}$ & $\mathrm{N} / \mathrm{A}$ & $\mathrm{N} / \mathrm{A}$ & $\mathrm{N} / \mathrm{A}$ & $\mathrm{N} / \mathrm{A}$ & $\mathrm{N} / \mathrm{A}$ & $\mathrm{N} / \mathrm{A}$ & $\mathrm{N} / \mathrm{A}$ & $\mathrm{N} / \mathrm{A}$ & $\mathrm{N} / \mathrm{A}$ & $\mathrm{N} / \mathrm{A}$ & $\mathrm{N} / \mathrm{A}$ & $\mathrm{N} / \mathrm{A}$ & $\mathrm{N} / \mathrm{A}$ & $\mathrm{N} / \mathrm{A}$ & $\mathrm{N} / \mathrm{A}$ & $\mathrm{N} / \mathrm{A}$ \\
\hline & $20 \mathrm{~cm}$ peak avg. Fast Flux ( $\left.{ }^{*} 10 \mathrm{E} 15\right)$ & 5 & 5 & 5 & 5 & 5 & 5 & 5 & 5 & 5 & 5 & 5 & 5 & 5 & 5 & 5 & 5 & 5 & 5 \\
\hline \multirow{3}{*}{ 4.0e15 fast flux } & Thermal Power (MW) & 164 & 187 & 196 & 226 & 203 & 237 & $\mathrm{~N} / \mathrm{A}$ & $\mathrm{N} / \mathrm{A}$ & $\mathrm{N} / \mathrm{A}$ & $\mathrm{N} / \mathrm{A}$ & $\mathrm{N} / \mathrm{A}$ & $\mathrm{N} / \mathrm{A}$ & $\mathrm{N} / \mathrm{A}$ & $\mathrm{N} / \mathrm{A}$ & $\mathrm{N} / \mathrm{A}$ & $\mathrm{N} / \mathrm{A}$ & $\mathrm{N} / \mathrm{A}$ & $\mathrm{N} / \mathrm{A}$ \\
\hline & Max Assembly Power (MW) & 4.9 & 4.8 & 5.0 & 4.8 & 5.0 & 4.9 & $\mathrm{~N} / \mathrm{A}$ & $\mathrm{N} / \mathrm{A}$ & $\mathrm{N} / \mathrm{A}$ & N/A & N/A & $\mathrm{N} / \mathrm{A}$ & $\mathrm{N} / \mathrm{A}$ & $\mathrm{N} / \mathrm{A}$ & N/A & $\mathrm{N} / \mathrm{A}$ & $\mathrm{N} / \mathrm{A}$ & $\mathrm{N} / \mathrm{A}$ \\
\hline & $20 \mathrm{~cm}$ peak avg. Fast Flux ( $\left.{ }^{*} 10 \mathrm{E} 15\right)$ & 4 & 4 & 4 & 4 & 4 & 4 & 4 & 4 & 4 & 4 & 4 & 4 & 4 & 4 & 4 & 4 & 4 & 4 \\
\hline
\end{tabular}




\begin{tabular}{|c|c|c|c|c|c|c|c|c|c|c|c|c|c|c|c|c|c|c|c|}
\hline & Assembly Type & \multicolumn{18}{|c|}{ A271 } \\
\hline & Core Height $(\mathrm{cm})$ & \multicolumn{6}{|c|}{60} & \multicolumn{6}{|c|}{80} & \multicolumn{6}{|c|}{100} \\
\hline & Number of Test assemblies & \multicolumn{2}{|c|}{1} & \multicolumn{2}{|c|}{4} & \multicolumn{2}{|c|}{7} & \multicolumn{2}{|c|}{1} & \multicolumn{2}{|c|}{4} & \multicolumn{2}{|c|}{7} & \multicolumn{2}{|c|}{1} & \multicolumn{2}{|c|}{4} & \multicolumn{2}{|c|}{7} \\
\hline & Average burnup (\% FIMA) & $3 \%$ & $6 \%$ & $3 \%$ & $6 \%$ & $3 \%$ & $6 \%$ & $3 \%$ & $6 \%$ & $3 \%$ & $6 \%$ & $3 \%$ & $6 \%$ & $3 \%$ & $6 \%$ & $3 \%$ & $6 \%$ & $3 \%$ & $6 \%$ \\
\hline & Number of batches & 2 & 3 & 2 & 3 & 2 & 3 & 2 & 4 & 2 & 4 & 2 & 4 & 3 & 5 & 3 & 5 & 3 & 5 \\
\hline & Cycle length (days) & 87 & 119 & 89 & 119 & 89 & 121 & 93 & 91 & 93 & 91 & 93 & 91 & 84 & 102 & 85 & 105 & 85 & 105 \\
\hline & Number of fuel assemblies & 33 & 39 & 40 & 46 & 40 & 47 & 25 & 28 & 28 & 32 & 29 & 32 & 21 & 24 & 24 & 26 & 24 & 27 \\
\hline \multirow{3}{*}{ Max. values } & Thermal Power (MW) & 159 & 184 & 189 & 216 & 189 & 217 & 151 & 171 & 168 & 196 & 175 & 196 & 116 & 131 & 132 & 139 & 132 & 144 \\
\hline & Max Assembly Power (MW) & 5.9 & 5.8 & 5.9 & 5.9 & 5.9 & 5.9 & 7.2 & 7.2 & 7.2 & 7.2 & 7.2 & 7.2 & 6.3 & 6.4 & 6.3 & 6.3 & 6.3 & 6.3 \\
\hline & $20 \mathrm{~cm}$ peak avg. Fast Flux (*10E15) & 4.5 & 4.6 & 4.5 & 4.6 & 4.5 & 4.6 & 4.3 & 4.6 & 4.3 & 4.6 & 4.4 & 4.6 & 3.2 & 3.3 & 3.2 & 3.2 & 3.2 & 3.2 \\
\hline \multirow{3}{*}{ 5.0e15 fast flux } & Thermal Power (MW) & $\mathrm{N} / \mathrm{A}$ & $\mathrm{N} / \mathrm{A}$ & $\mathrm{N} / \mathrm{A}$ & $\mathrm{N} / \mathrm{A}$ & $\mathrm{N} / \mathrm{A}$ & $\mathrm{N} / \mathrm{A}$ & $\mathrm{N} / \mathrm{A}$ & $\mathrm{N} / \mathrm{A}$ & $\mathrm{N} / \mathrm{A}$ & N/A & $\mathrm{N} / \mathrm{A}$ & N/A & $\mathrm{N} / \mathrm{A}$ & $\mathrm{N} / \mathrm{A}$ & $\mathrm{N} / \mathrm{A}$ & $\mathrm{N} / \mathrm{A}$ & N/A & $\mathrm{N} / \mathrm{A}$ \\
\hline & Max Assembly Power (MW) & $\mathrm{N} / \mathrm{A}$ & N/A & $\mathrm{N} / \mathrm{A}$ & $\mathrm{N} / \mathrm{A}$ & $\mathrm{N} / \mathrm{A}$ & N/A & N/A & $\mathrm{N} / \mathrm{A}$ & $\mathrm{N} / \mathrm{A}$ & N/A & $\mathrm{N} / \mathrm{A}$ & N/A & $\mathrm{N} / \mathrm{A}$ & $\mathrm{N} / \mathrm{A}$ & $\mathrm{N} / \mathrm{A}$ & $\mathrm{N} / \mathrm{A}$ & N/A & $\mathrm{N} / \mathrm{A}$ \\
\hline & $20 \mathrm{~cm}$ peak avg. Fast Flux $\left({ }^{*} 10 \mathrm{E} 15\right)$ & 5 & 5 & 5 & 5 & 5 & 5 & 5 & 5 & 5 & 5 & 5 & 5 & 5 & 5 & 5 & 5 & 5 & 5 \\
\hline \multirow{3}{*}{ 4.0e15 fast flux } & Thermal Power (MW) & 141 & 158 & 168 & 188 & 168 & 190 & 141 & 150 & 158 & 171 & 161 & 171 & $\mathrm{~N} / \mathrm{A}$ & $\mathrm{N} / \mathrm{A}$ & $\mathrm{N} / \mathrm{A}$ & $\mathrm{N} / \mathrm{A}$ & $\mathrm{N} / \mathrm{A}$ & $\mathrm{N} / \mathrm{A}$ \\
\hline & Max Assembly Power (MW) & 5.2 & 5.0 & 5.2 & 5.1 & 5.2 & 5.1 & 6.7 & 6.3 & 6.8 & 6.3 & 6.6 & 6.3 & $\mathrm{~N} / \mathrm{A}$ & $\mathrm{N} / \mathrm{A}$ & $\mathrm{N} / \mathrm{A}$ & $\mathrm{N} / \mathrm{A}$ & N/A & $\mathrm{N} / \mathrm{A}$ \\
\hline & $20 \mathrm{~cm}$ peak avg. Fast Flux $\left({ }^{*} 10 \mathrm{E} 15\right)$ & 4 & 4 & 4 & 4 & 4 & 4 & 4 & 4 & 4 & 4 & 4 & 4 & 4 & 4 & 4 & 4 & 4 & 4 \\
\hline
\end{tabular}

\begin{tabular}{|c|c|c|c|c|c|c|c|c|c|c|c|c|c|c|c|c|c|c|c|}
\hline & Assembly Type & \multicolumn{18}{|c|}{ B271 } \\
\hline & Core Height $(\mathrm{cm})$ & \multicolumn{6}{|c|}{60} & \multicolumn{6}{|c|}{80} & \multicolumn{6}{|c|}{100} \\
\hline & Number of Test assemblies & \multicolumn{2}{|c|}{1} & \multicolumn{2}{|c|}{4} & \multicolumn{2}{|c|}{7} & \multicolumn{2}{|c|}{1} & \multicolumn{2}{|c|}{4} & \multicolumn{2}{|c|}{7} & \multicolumn{2}{|c|}{1} & \multicolumn{2}{|c|}{4} & \multicolumn{2}{|c|}{7} \\
\hline & Average burnup (\% FIMA) & $3 \%$ & $6 \%$ & $3 \%$ & $6 \%$ & $3 \%$ & $6 \%$ & $3 \%$ & $6 \%$ & $3 \%$ & $6 \%$ & $3 \%$ & $6 \%$ & $3 \%$ & $6 \%$ & $3 \%$ & $6 \%$ & $3 \%$ & $6 \%$ \\
\hline & Number of batches & 2 & 3 & 2 & 3 & 2 & 3 & 3 & 5 & 3 & 5 & 3 & 5 & 3 & 7 & 3 & 7 & 3 & 7 \\
\hline & Cycle length (days) & 96 & 130 & 96 & 131 & 96 & 131 & 84 & 100 & 85 & 103 & 85 & 104 & 113 & 101 & 117 & 103 & 117 & 103 \\
\hline & Number of fuel assemblies & 26 & 29 & 30 & 36 & 30 & 36 & 20 & 22 & 23 & 25 & 23 & 26 & 17 & 19 & 20 & 22 & 20 & 22 \\
\hline \multirow{3}{*}{ Max. values } & Thermal Power (MW) & 127 & 139 & 146 & 171 & 146 & 171 & 99 & 110 & 113 & 121 & 112 & 125 & 78 & 84 & 89 & 95 & 89 & 95 \\
\hline & Max Assembly Power (MW) & 5.9 & 5.9 & 5.9 & 5.9 & 5.9 & 5.9 & 5.8 & 5.8 & 5.8 & 5.6 & 5.8 & 5.8 & 5.1 & 5.1 & 5.2 & 5.1 & 5.2 & 5.1 \\
\hline & $20 \mathrm{~cm}$ peak avg. Fast Flux ( $\left.{ }^{*} 10 \mathrm{E} 15\right)$ & 4.1 & 4.2 & 4.1 & 4.3 & 4.1 & 4.3 & 3.2 & 3.3 & 3.2 & 3.3 & 3.2 & 3.3 & 2.4 & 2.4 & 2.4 & 2.4 & 2.4 & 2.4 \\
\hline \multirow{3}{*}{ 5.0e15 fast flux } & Thermal Power (MW) & $\mathrm{N} / \mathrm{A}$ & $\mathrm{N} / \mathrm{A}$ & $\mathrm{N} / \mathrm{A}$ & $\mathrm{N} / \mathrm{A}$ & $\mathrm{N} / \mathrm{A}$ & $\mathrm{N} / \mathrm{A}$ & $\mathrm{N} / \mathrm{A}$ & $\mathrm{N} / \mathrm{A}$ & $\mathrm{N} / \mathrm{A}$ & $\mathrm{N} / \mathrm{A}$ & $\mathrm{N} / \mathrm{A}$ & $\mathrm{N} / \mathrm{A}$ & $\mathrm{N} / \mathrm{A}$ & $\mathrm{N} / \mathrm{A}$ & $\mathrm{N} / \mathrm{A}$ & $\mathrm{N} / \mathrm{A}$ & $\mathrm{N} / \mathrm{A}$ & $\mathrm{N} / \mathrm{A}$ \\
\hline & Max Assembly Power (MW) & $\mathrm{N} / \mathrm{A}$ & $\mathrm{N} / \mathrm{A}$ & N/A & $\mathrm{N} / \mathrm{A}$ & $\mathrm{N} / \mathrm{A}$ & $\mathrm{N} / \mathrm{A}$ & $\mathrm{N} / \mathrm{A}$ & N/A & N/A & N/A & N/A & N/A & N/A & N/A & $\mathrm{N} / \mathrm{A}$ & N/A & N/A & $\mathrm{N} / \mathrm{A}$ \\
\hline & $20 \mathrm{~cm}$ peak avg. Fast Flux ( $\left.{ }^{*} 10 \mathrm{E} 15\right)$ & 5 & 5 & 5 & 5 & 5 & 5 & 5 & 5 & 5 & 5 & 5 & 5 & 5 & 5 & 5 & 5 & 5 & 5 \\
\hline \multirow{3}{*}{ 4.0e15 fast flux } & Thermal Power (MW) & 123 & 134 & 141 & 160 & 141 & 161 & $\mathrm{~N} / \mathrm{A}$ & $\mathrm{N} / \mathrm{A}$ & $\mathrm{N} / \mathrm{A}$ & $\mathrm{N} / \mathrm{A}$ & $\mathrm{N} / \mathrm{A}$ & $\mathrm{N} / \mathrm{A}$ & $\mathrm{N} / \mathrm{A}$ & $\mathrm{N} / \mathrm{A}$ & $\mathrm{N} / \mathrm{A}$ & $\mathrm{N} / \mathrm{A}$ & $\mathrm{N} / \mathrm{A}$ & $\mathrm{N} / \mathrm{A}$ \\
\hline & Max Assembly Power (MW) & 5.7 & 5.6 & 5.7 & 5.5 & 5.7 & 5.5 & $\mathrm{~N} / \mathrm{A}$ & $\mathrm{N} / \mathrm{A}$ & $\mathrm{N} / \mathrm{A}$ & N/A & $\mathrm{N} / \mathrm{A}$ & $\mathrm{N} / \mathrm{A}$ & N/A & $\mathrm{N} / \mathrm{A}$ & $\mathrm{N} / \mathrm{A}$ & N/A & $\mathrm{N} / \mathrm{A}$ & $\mathrm{N} / \mathrm{A}$ \\
\hline & $20 \mathrm{~cm}$ peak avg. Fast Flux ( $\left.{ }^{*} 10 \mathrm{E} 15\right)$ & 4 & 4 & 4 & 4 & 4 & 4 & 4 & 4 & 4 & 4 & 4 & 4 & 4 & 4 & 4 & 4 & 4 & 4 \\
\hline
\end{tabular}

\begin{tabular}{|c|c|c|c|c|c|c|c|c|c|c|c|c|c|c|c|c|c|c|c|}
\hline & Assembly Type & \multicolumn{18}{|c|}{ C271 } \\
\hline & Core Height $(\mathrm{cm})$ & \multicolumn{6}{|c|}{60} & \multicolumn{6}{|c|}{80} & \multicolumn{6}{|c|}{100} \\
\hline & Number of Test assemblies & \multicolumn{2}{|c|}{1} & \multicolumn{2}{|c|}{4} & \multicolumn{2}{|c|}{7} & \multicolumn{2}{|c|}{1} & \multicolumn{2}{|c|}{4} & \multicolumn{2}{|c|}{7} & \multicolumn{2}{|c|}{1} & \multicolumn{2}{|c|}{4} & \multicolumn{2}{|c|}{7} \\
\hline & Average burnup (\% FIMA) & $3 \%$ & $6 \%$ & $3 \%$ & $6 \%$ & $3 \%$ & $6 \%$ & $3 \%$ & $6 \%$ & $3 \%$ & $6 \%$ & $3 \%$ & $6 \%$ & $3 \%$ & $6 \%$ & $3 \%$ & $6 \%$ & $3 \%$ & $6 \%$ \\
\hline & Number of batches & 2 & 5 & 2 & 5 & 2 & 5 & 4 & 7 & 4 & 8 & 4 & 8 & & 1 & 5 & 10 & 5 & 11 \\
\hline & Cycle length (days) & 122 & 99 & 124 & 101 & 124 & 101 & 89 & 104 & 93 & 97 & 94 & 97 & & 97 & 106 & 105 & 106 & 96 \\
\hline & Number of fuel assemblies & 21 & 23 & 24 & 27 & 24 & 27 & 15 & 18 & 19 & 21 & 19 & 21 & & 15 & 16 & 18 & 16 & 18 \\
\hline \multirow{3}{*}{ Max. values } & Thermal Power (MW) & 90 & 96 & 101 & 1111 & 101 & 111 & 59 & 69 & 71 & 75 & 70 & 75 & & 48 & 52 & 59 & 52 & 59 \\
\hline & Max Assembly Power (MW) & 5.0 & 5.0 & 5.0 & 5.0 & 5.0 & 5.0 & 4.2 & 4.4 & 4.3 & 4.3 & 4.3 & 4.2 & & 3.5 & 3.7 & 3.7 & 3.7 & 3.7 \\
\hline & $20 \mathrm{~cm}$ peak avg. Fast Flux ( $\left.{ }^{*} 10 \mathrm{E} 15\right)$ & 3.3 & 3.3 & 3.3 & 3.3 & 3.2 & 3.3 & 2.2 & 2.3 & 2.2 & 2.2 & 2.2 & 2.2 & & 1.6 & 1.6 & 1.7 & 1.6 & 1.7 \\
\hline \multirow{3}{*}{ 5.0e15 fast flux } & Thermal Power (MW) & $\mathrm{N} / \mathrm{A}$ & $\mathrm{N} / \mathrm{A}$ & $\mathrm{N} / \mathrm{A}$ & $\mathrm{N} / \mathrm{A}$ & $\mathrm{N} / \mathrm{A}$ & $\mathrm{N} / \mathrm{A}$ & $\mathrm{N} / \mathrm{A}$ & $\mathrm{N} / \mathrm{A}$ & $\mathrm{N} / \mathrm{A}$ & $\mathrm{N} / \mathrm{A}$ & $\mathrm{N} / \mathrm{A}$ & $\mathrm{N} / \mathrm{A}$ & $\mathrm{N} / \mathrm{A}$ & $\mathrm{N} / \mathrm{A}$ & $\mathrm{N} / \mathrm{A}$ & $\mathrm{N} / \mathrm{A}$ & $\mathrm{N} / \mathrm{A}$ & $\mathrm{N} / \mathrm{A}$ \\
\hline & Max Assembly Power (MW) & $\mathrm{N} / \mathrm{A}$ & $\mathrm{N} / \mathrm{A}$ & $\mathrm{N} / \mathrm{A}$ & $\mathrm{N} / \mathrm{A}$ & N/A & $\mathrm{N} / \mathrm{A}$ & $\mathrm{N} / \mathrm{A}$ & $\mathrm{N} / \mathrm{A}$ & $\mathrm{N} / \mathrm{A}$ & $\mathrm{N} / \mathrm{A}$ & $\mathrm{N} / \mathrm{A}$ & $\mathrm{N} / \mathrm{A}$ & $\mathrm{N} / \mathrm{A}$ & $\mathrm{N} / \mathrm{A}$ & N/A & N/A & $\mathrm{N} / \mathrm{A}$ & $\mathrm{N} / \mathrm{A}$ \\
\hline & $20 \mathrm{~cm}$ peak avg. Fast Flux ( $\left.{ }^{*} 10 \mathrm{E} 15\right)$ & 5 & 5 & 5 & 5 & 5 & 5 & 5 & 5 & 5 & 5 & 5 & 5 & 5 & 5 & 5 & 5 & 5 & 5 \\
\hline \multirow{3}{*}{ 4.0e15 fast flux } & Thermal Power (MW) & $\mathrm{N} / \mathrm{A}$ & $\mathrm{N} / \mathrm{A}$ & $\mathrm{N} / \mathrm{A}$ & $\mathrm{N} / \mathrm{A}$ & $\mathrm{N} / \mathrm{A}$ & $\mathrm{N} / \mathrm{A}$ & $\mathrm{N} / \mathrm{A}$ & $\mathrm{N} / \mathrm{A}$ & $\mathrm{N} / \mathrm{A}$ & $\mathrm{N} / \mathrm{A}$ & $\mathrm{N} / \mathrm{A}$ & $\mathrm{N} / \mathrm{A}$ & $\mathrm{N} / \mathrm{A}$ & $\mathrm{N} / \mathrm{A}$ & $\mathrm{N} / \mathrm{A}$ & $\mathrm{N} / \mathrm{A}$ & $\mathrm{N} / \mathrm{A}$ & $\mathrm{N} / \mathrm{A}$ \\
\hline & Max Assembly Power (MW) & $\mathrm{N} / \mathrm{A}$ & N/A & N/A & $\mathrm{N} / \mathrm{A}$ & N/A & $\mathrm{N} / \mathrm{A}$ & $\mathrm{N} / \mathrm{A}$ & $\mathrm{N} / \mathrm{A}$ & $\mathrm{N} / \mathrm{A}$ & $\mathrm{N} / \mathrm{A}$ & $\mathrm{N} / \mathrm{A}$ & $\mathrm{N} / \mathrm{A}$ & $\mathrm{N} / \mathrm{A}$ & $\mathrm{N} / \mathrm{A}$ & N/A & N/A & $\mathrm{N} / \mathrm{A}$ & $\mathrm{N} / \mathrm{A}$ \\
\hline & $20 \mathrm{~cm}$ peak avg. Fast Flux (*10E15) & 4 & 4 & 4 & 4 & 4 & 4 & 4 & 4 & 4 & 4 & 4 & 4 & 4 & 4 & 4 & 4 & 4 & 4 \\
\hline
\end{tabular}


U-27PuRG-10Zr fuel with ${ }^{235} \mathrm{U} / \mathrm{U}=0.3 \%$

\begin{tabular}{|c|c|c|c|c|c|c|c|c|c|c|c|c|c|c|c|c|c|c|c|}
\hline & \multirow{4}{*}{\begin{tabular}{|l|} 
Assembly Type \\
Core Height $(\mathrm{cm})$ \\
Number of Test assemblies \\
Average burnun $(\%$ FIMA) \\
\end{tabular}} & \multicolumn{18}{|c|}{ A271 } \\
\hline & & & & & & & & \multicolumn{6}{|c|}{80} & \multicolumn{6}{|c|}{100} \\
\hline & & \multicolumn{2}{|c|}{1} & \multicolumn{2}{|c|}{4} & \multicolumn{2}{|c|}{7} & \multicolumn{2}{|c|}{1} & \multicolumn{2}{|c|}{4} & \multicolumn{2}{|c|}{7} & \multicolumn{2}{|c|}{1} & \multicolumn{2}{|c|}{4} & \multicolumn{2}{|c|}{7} \\
\hline & & $3 \%$ & $6 \%$ & $3 \%$ & $6 \%$ & $3 \%$ & $6 \%$ & $3 \%$ & $6 \%$ & $3 \%$ & $6 \%$ & $3 \%$ & $6 \%$ & $3 \%$ & $6 \%$ & $3 \%$ & $6 \%$ & $3 \%$ & $6 \%$ \\
\hline & Number of batches & & 4 & & 4 & & & & 4 & & 4 & & & & 6 & & 5 & & \\
\hline & Cycle length (days) & & 98 & & 97 & & & & 98 & & 101 & & & & 100 & & 110 & & \\
\hline & Number of fuel assemblies & & 63 & & 72 & & & & 42 & & 48 & & & & 33 & & 39 & & \\
\hline \multirow{3}{*}{ Max. values } & Thermal Power (MW) & & 273 & & 317 & & & & 243 & & 270 & & & & 170 & & 201 & & \\
\hline & Max Assembly Power (MW) & & 5.9 & & 5.9 & & & & 7.2 & & 7.2 & & & & 6.3 & & 6.3 & & \\
\hline & $20 \mathrm{~cm}$ peak avg. Fast Flux (*10E15) & & 4.9 & & 4.8 & & & & 4.9 & & 4.7 & & & & 3.6 & & 3.5 & & \\
\hline \multirow{3}{*}{ 5.0e15 fast flux } & Thermal Power (MW) & $\mathrm{N} / \mathrm{A}$ & $\mathrm{N} / \mathrm{A}$ & $\mathrm{N} / \mathrm{A}$ & $\mathrm{N} / \mathrm{A}$ & $\mathrm{N} / \mathrm{A}$ & $\mathrm{N} / \mathrm{A}$ & $\mathrm{N} / \mathrm{A}$ & $\mathrm{N} / \mathrm{A}$ & $\mathrm{N} / \mathrm{A}$ & $\mathrm{N} / \mathrm{A}$ & $\mathrm{N} / \mathrm{A}$ & $\mathrm{N} / \mathrm{A}$ & $\mathrm{N} / \mathrm{A}$ & $\mathrm{N} / \mathrm{A}$ & $\mathrm{N} / \mathrm{A}$ & $\mathrm{N} / \mathrm{A}$ & $\mathrm{N} / \mathrm{A}$ & $\mathrm{N} / \mathrm{A}$ \\
\hline & Max Assembly Power (MW) & $\mathrm{N} / \mathrm{A}$ & $\mathrm{N} / \mathrm{A}$ & $\mathrm{N} / \mathrm{A}$ & $\mathrm{N} / \mathrm{A}$ & $\mathrm{N} / \mathrm{A}$ & $\mathrm{N} / \mathrm{A}$ & $\mathrm{N} / \mathrm{A}$ & $\mathrm{N} / \mathrm{A}$ & $\mathrm{N} / \mathrm{A}$ & $\mathrm{N} / \mathrm{A}$ & $\mathrm{N} / \mathrm{A}$ & $\mathrm{N} / \mathrm{A}$ & $\mathrm{N} / \mathrm{A}$ & $\mathrm{N} / \mathrm{A}$ & $\mathrm{N} / \mathrm{A}$ & $\mathrm{N} / \mathrm{A}$ & $\mathrm{N} / \mathrm{A}$ & $\mathrm{N} / \mathrm{A}$ \\
\hline & $20 \mathrm{~cm}$ peak avg. Fast Flux ( $\left.{ }^{*} 10 \mathrm{E} 15\right)$ & 5 & 5 & 5 & 5 & 5 & 5 & 5 & 5 & 5 & 5 & 5 & 5 & 5 & 5 & 5 & 5 & 5 & 5 \\
\hline \multirow{3}{*}{ 4.0e15 fast flux } & Thermal Power (MW) & $\mathrm{N} / \mathrm{A}$ & 221 & $\mathrm{~N} / \mathrm{A}$ & 265 & $\mathrm{~N} / \mathrm{A}$ & N/A & $\mathrm{N} / \mathrm{A}$ & 198 & $\mathrm{~N} / \mathrm{A}$ & 228 & N/A & N/A & $\mathrm{N} / \mathrm{A}$ & $\mathrm{N} / \mathrm{A}$ & $\mathrm{N} / \mathrm{A}$ & $\mathrm{N} / \mathrm{A}$ & N/A & $\mathrm{N} / \mathrm{A}$ \\
\hline & Max Assembly Power (MW) & $\mathrm{N} / \mathrm{A}$ & 4.7 & $\mathrm{~N} / \mathrm{A}$ & 4.9 & $\mathrm{~N} / \mathrm{A}$ & N/A & N/A & 5.9 & $\mathrm{~N} / \mathrm{A}$ & 6.1 & N/A & N/A & $\mathrm{N} / \mathrm{A}$ & $\mathrm{N} / \mathrm{A}$ & N/A & N/A & N/A & $\mathrm{N} / \mathrm{A}$ \\
\hline & $20 \mathrm{~cm}$ peak avg. Fast Flux ( $\left.{ }^{*} 10 \mathrm{E} 15\right)$ & 4 & 4 & 4 & 4 & 4 & 4 & 4 & 4 & 4 & 4 & 4 & 4 & 4 & 4 & 4 & 4 & 4 & 4 \\
\hline
\end{tabular}




\begin{tabular}{|c|c|c|c|c|c|c|c|c|c|c|c|c|c|c|c|c|c|c|c|}
\hline & Assembly Type & \multicolumn{18}{|c|}{ A271 } \\
\hline & Core Height $(\mathrm{cm})$ & \multicolumn{6}{|c|}{60} & \multicolumn{6}{|c|}{80} & \multicolumn{6}{|c|}{100} \\
\hline & Number of Test assemblies & \multicolumn{2}{|c|}{1} & \multicolumn{2}{|c|}{4} & \multicolumn{2}{|c|}{7} & \multicolumn{2}{|c|}{1} & \multicolumn{2}{|c|}{4} & \multicolumn{2}{|c|}{7} & \multicolumn{2}{|c|}{1} & \multicolumn{2}{|c|}{4} & \multicolumn{2}{|c|}{7} \\
\hline & Average burnup (\% FIMA) & $3 \%$ & $6 \%$ & $3 \%$ & $6 \%$ & $3 \%$ & $6 \%$ & $3 \%$ & $6 \%$ & $3 \%$ & $6 \%$ & $3 \%$ & $6 \%$ & $3 \%$ & $6 \%$ & $3 \%$ & $6 \%$ & $3 \%$ & $6 \%$ \\
\hline & Number of batches & & 3 & & 3 & & 3 & & 4 & & 4 & & 4 & & 6 & & 6 & & 6 \\
\hline & Cycle length (days) & & 130 & & 125 & & 126 & & 104 & & 100 & & 102 & & 95 & & 95 & & 96 \\
\hline & Number of fuel assemblies & & 120 & & 130 & & 140 & & 75 & & 81 & & 86 & & 56 & & 65 & & 66 \\
\hline \multirow{3}{*}{ Max. values } & Thermal Power (MW) & & 513 & & 577 & & 617 & & 401 & & 450 & & 467 & & 274 & & 316 & & 318 \\
\hline & Max Assembly Power (MW) & & 5.9 & & 5.8 & & 5.9 & & 7.2 & & 7.2 & & 7.2 & & 6.3 & & 6.3 & & 6.3 \\
\hline & $20 \mathrm{~cm}$ peak avg. Fast Flux (*10E15) & & 5.6 & & 5.5 & & 5.4 & & 5.7 & & 5.5 & & 5.5 & & 4.2 & & 4.1 & & 4.0 \\
\hline \multirow{3}{*}{$5.0 \mathrm{e} 15$ fast flux } & Thermal Power (MW) & $\mathrm{N} / \mathrm{A}$ & 455 & $\mathrm{~N} / \mathrm{A}$ & 530 & $\mathrm{~N} / \mathrm{A}$ & 568 & N/A & 355 & $\mathrm{~N} / \mathrm{A}$ & 409 & N/A & 428 & $\mathrm{~N} / \mathrm{A}$ & $\mathrm{N} / \mathrm{A}$ & N/A & $\mathrm{N} / \mathrm{A}$ & $\mathrm{N} / \mathrm{A}$ & N/A \\
\hline & Max Assembly Power (MW) & $\mathrm{N} / \mathrm{A}$ & 5.2 & $\mathrm{~N} / \mathrm{A}$ & 5.4 & $\mathrm{~N} / \mathrm{A}$ & 5.4 & N/A & 6.4 & $\mathrm{~N} / \mathrm{A}$ & 6.5 & N/A & 6.6 & $\mathrm{~N} / \mathrm{A}$ & $\mathrm{N} / \mathrm{A}$ & N/A & $\mathrm{N} / \mathrm{A}$ & $\mathrm{N} / \mathrm{A}$ & N/A \\
\hline & $20 \mathrm{~cm}$ peak avg. Fast Flux ( $\left.{ }^{*} 10 \mathrm{E} 15\right)$ & 5 & 5 & 5 & 5 & 5 & 5 & 5 & 5 & 5 & 5 & 5 & 5 & 5 & 5 & 5 & 5 & 5 & 5 \\
\hline \multirow{3}{*}{ 4.0e15 fast flux } & Thermal Power (MW) & $\mathrm{N} / \mathrm{A}$ & 364 & $\mathrm{~N} / \mathrm{A}$ & 424 & $\mathrm{~N} / \mathrm{A}$ & 454 & N/A & 284 & $\mathrm{~N} / \mathrm{A}$ & 327 & N/A & 342 & N/A & 264 & N/A & 310 & $\mathrm{~N} / \mathrm{A}$ & 314 \\
\hline & Max Assembly Power (MW) & $\mathrm{N} / \mathrm{A}$ & 4.2 & $\mathrm{~N} / \mathrm{A}$ & 4.3 & $\mathrm{~N} / \mathrm{A}$ & 4.3 & N/A & 5.1 & $\mathrm{~N} / \mathrm{A}$ & 5.2 & $\mathrm{~N} / \mathrm{A}$ & 5.3 & $\mathrm{~N} / \mathrm{A}$ & 6.1 & $\mathrm{~N} / \mathrm{A}$ & 6.2 & N/A & 6.3 \\
\hline & $20 \mathrm{~cm}$ peak avg. Fast Flux ( $\left.{ }^{*} 10 \mathrm{E} 15\right)$ & 4 & 4 & 4 & 4 & 4 & 4 & 4 & 4 & 4 & 4 & 4 & 4 & 4 & 4 & 4 & 4 & 4 & 4 \\
\hline
\end{tabular}

\begin{tabular}{|c|c|c|c|c|c|c|c|c|c|c|c|c|c|c|c|c|c|c|c|}
\hline & Assembly Type & \multicolumn{18}{|c|}{ B271 } \\
\hline & Core Height $(\mathrm{cm})$ & \multicolumn{6}{|c|}{60} & \multicolumn{6}{|c|}{80} & \multicolumn{6}{|c|}{100} \\
\hline & Number of Test assemblies & \multicolumn{2}{|c|}{1} & \multicolumn{2}{|c|}{4} & \multicolumn{2}{|c|}{7} & \multicolumn{2}{|c|}{1} & \multicolumn{2}{|c|}{4} & \multicolumn{2}{|c|}{7} & \multicolumn{2}{|c|}{1} & \multicolumn{2}{|c|}{4} & \multicolumn{2}{|c|}{7} \\
\hline & Average burnup (\% FIMA) & $3 \%$ & $6 \%$ & $3 \%$ & $6 \%$ & $3 \%$ & $6 \%$ & $3 \%$ & $6 \%$ & $3 \%$ & $6 \%$ & $3 \%$ & $6 \%$ & $3 \%$ & $6 \%$ & $3 \%$ & $6 \%$ & $3 \%$ & $6 \%$ \\
\hline & Number of batches & & 4 & & 4 & & 4 & & 6 & & 6 & & 6 & & 8 & & 8 & & 8 \\
\hline & \begin{tabular}{|l|} 
Cycle length (days) \\
\end{tabular} & & 107 & & 104 & & 105 & & 94 & & 94 & & 95 & & 96 & & 96 & & 98 \\
\hline & Number of fuel assemblies & & 84 & & 95 & & 100 & & 54 & & 62 & & 65 & & 42 & & 49 & & 50 \\
\hline \multirow{3}{*}{ Max. values } & Thermal Power (MW) & & 366 & & 424 & & 443 & & 238 & & 273 & & 282 & & 170 & & 197 & & 198 \\
\hline & Max Assembly Power (MW) & & 5.9 & & 5.9 & & 5.9 & & 5.8 & & 5.8 & & 5.8 & & 5.1 & & 5.1 & & 5.1 \\
\hline & $20 \mathrm{~cm}$ peak avg. Fast Flux ( $\left.{ }^{*} 10 \mathrm{E} 15\right)$ & & 5.3 & & 5.2 & & 5.2 & & 4.2 & & 4.1 & & 4.1 & & 3.1 & & 3.0 & & 3.0 \\
\hline \multirow{3}{*}{ 5.0e15 fast flux } & Thermal Power (MW) & $\mathrm{N} / \mathrm{A}$ & 343 & $\mathrm{~N} / \mathrm{A}$ & 410 & $\mathrm{~N} / \mathrm{A}$ & 428 & $\mathrm{~N} / \mathrm{A}$ & $\mathrm{N} / \mathrm{A}$ & $\mathrm{N} / \mathrm{A}$ & $\mathrm{N} / \mathrm{A}$ & $\mathrm{N} / \mathrm{A}$ & $\mathrm{N} / \mathrm{A}$ & $\mathrm{N} / \mathrm{A}$ & $\mathrm{N} / \mathrm{A}$ & $\mathrm{N} / \mathrm{A}$ & $\mathrm{N} / \mathrm{A}$ & $\mathrm{N} / \mathrm{A}$ & $\mathrm{N} / \mathrm{A}$ \\
\hline & Max Assembly Power (MW) & $\mathrm{N} / \mathrm{A}$ & 5.5 & $\mathrm{~N} / \mathrm{A}$ & 5.7 & $\mathrm{~N} / \mathrm{A}$ & 5.7 & $\mathrm{~N} / \mathrm{A}$ & $\mathrm{N} / \mathrm{A}$ & $\mathrm{N} / \mathrm{A}$ & $\mathrm{N} / \mathrm{A}$ & $\mathrm{N} / \mathrm{A}$ & $\mathrm{N} / \mathrm{A}$ & $\mathrm{N} / \mathrm{A}$ & $\mathrm{N} / \mathrm{A}$ & $\mathrm{N} / \mathrm{A}$ & $\mathrm{N} / \mathrm{A}$ & $\mathrm{N} / \mathrm{A}$ & $\mathrm{N} / \mathrm{A}$ \\
\hline & $20 \mathrm{~cm}$ peak avg. Fast Flux ( $\left.{ }^{*} 10 \mathrm{E} 15\right)$ & 5 & 5 & 5 & 5 & 5 & 5 & 5 & 5 & 5 & 5 & 5 & 5 & 5 & 5 & 5 & 5 & 5 & 5 \\
\hline \multirow{3}{*}{ 4.0e15 fast flux } & Thermal Power (MW) & $\mathrm{N} / \mathrm{A}$ & 274 & $\mathrm{~N} / \mathrm{A}$ & 328 & $\mathrm{~N} / \mathrm{A}$ & 343 & $\mathrm{~N} / \mathrm{A}$ & 226 & $\mathrm{~N} / \mathrm{A}$ & 265 & $\mathrm{~N} / \mathrm{A}$ & 275 & $\mathrm{~N} / \mathrm{A}$ & N/A & N/A & $\mathrm{N} / \mathrm{A}$ & $\mathrm{N} / \mathrm{A}$ & $\mathrm{N} / \mathrm{A}$ \\
\hline & Max Assembly Power (MW) & $\mathrm{N} / \mathrm{A}$ & 4.4 & $\mathrm{~N} / \mathrm{A}$ & 4.5 & N/A & 4.5 & $\mathrm{~N} / \mathrm{A}$ & 5.5 & $\mathrm{~N} / \mathrm{A}$ & 5.6 & $\mathrm{~N} / \mathrm{A}$ & 5.6 & $\mathrm{~N} / \mathrm{A}$ & $\mathrm{N} / \mathrm{A}$ & $\mathrm{N} / \mathrm{A}$ & $\mathrm{N} / \mathrm{A}$ & $\mathrm{N} / \mathrm{A}$ & $\mathrm{N} / \mathrm{A}$ \\
\hline & $20 \mathrm{~cm}$ peak avg. Fast Flux ( $\left.{ }^{*} 10 \mathrm{E} 15\right)$ & 4 & 4 & 4 & 4 & 4 & 4 & 4 & 4 & 4 & 4 & 4 & 4 & 4 & 4 & 4 & 4 & 4 & 4 \\
\hline
\end{tabular}

\begin{tabular}{|c|c|c|c|c|c|c|c|c|c|c|c|c|c|c|c|c|c|c|c|}
\hline & Assembly Type & \multicolumn{18}{|c|}{ C271 } \\
\hline & Core Height $(\mathrm{cm})$ & \multicolumn{6}{|c|}{60} & \multicolumn{6}{|c|}{80} & \multirow{2}{*}{\multicolumn{6}{|c|}{$\frac{100}{4}$}} \\
\hline & Number of Test assemblies & \multicolumn{2}{|c|}{1} & \multicolumn{2}{|c|}{4} & \multicolumn{2}{|c|}{7} & \multicolumn{2}{|c|}{1} & \multicolumn{2}{|c|}{4} & \multicolumn{2}{|c|}{7} & & & & 4 & \multicolumn{2}{|c|}{7} \\
\hline & Average burnup (\% FIMA) & $3 \%$ & $6 \%$ & $3 \%$ & $6 \%$ & $3 \%$ & $6 \%$ & $3 \%$ & $6 \%$ & $3 \%$ & $6 \%$ & $3 \%$ & $6 \%$ & $3 \%$ & $6 \%$ & $3 \%$ & $6 \%$ & $3 \%$ & $6 \%$ \\
\hline & Number of batches & & 6 & & 5 & & 6 & & 8 & & 8 & & 8 & & 11 & & 11 & & 11 \\
\hline & Cycle length (days) & & 92 & & 109 & & 92 & & 101 & & 103 & & 105 & & 102 & & 103 & & 104 \\
\hline & Number of fuel assemblies & & 61 & & 71 & & 75 & & 40 & & 47 & & 49 & & 32 & & 38 & & 39 \\
\hline \multirow{3}{*}{ Max. values } & Thermal Power (MW) & & 227 & & 269 & & 280 & & 136 & & 157 & & 161 & & 98 & & 115 & & 117 \\
\hline & Max Assembly Power (MW) & & 5.0 & & 5.0 & & 5.0 & & 4.3 & & 4.3 & & 4.3 & & 3.7 & & 3.7 & & 3.7 \\
\hline & $20 \mathrm{~cm}$ peak avg. Fast Flux (*10E15) & & 4.3 & & 4.2 & & 4.2 & & 2.9 & & 2.8 & & 2.8 & & 2.1 & & 2.1 & & 2.1 \\
\hline \multirow{3}{*}{$5.0 \mathrm{e} 15$ fast flux } & Thermal Power (MW) & $\mathrm{N} / \mathrm{A}$ & $\mathrm{N} / \mathrm{A}$ & N/A & $\mathrm{N} / \mathrm{A}$ & $\mathrm{N} / \mathrm{A}$ & $\mathrm{N} / \mathrm{A}$ & $\mathrm{N} / \mathrm{A}$ & $\mathrm{N} / \mathrm{A}$ & N/A & $\mathrm{N} / \mathrm{A}$ & $\mathrm{N} / \mathrm{A}$ & $\mathrm{N} / \mathrm{A}$ & $\mathrm{N} / \mathrm{A}$ & $\mathrm{N} / \mathrm{A}$ & $\mathrm{N} / \mathrm{A}$ & $\mathrm{N} / \mathrm{A}$ & $\mathrm{N} / \mathrm{A}$ & $\mathrm{N} / \mathrm{A}$ \\
\hline & Max Assembly Power (MW) & N/A & $\mathrm{N} / \mathrm{A}$ & N/A & N/A & N/A & N/A & N/A & $\mathrm{N} / \mathrm{A}$ & N/A & $\mathrm{N} / \mathrm{A}$ & N/A & N/A & $\mathrm{N} / \mathrm{A}$ & N/A & $\mathrm{N} / \mathrm{A}$ & N/A & $\mathrm{N} / \mathrm{A}$ & $\mathrm{N} / \mathrm{A}$ \\
\hline & $20 \mathrm{~cm}$ peak avg. Fast Flux $\left({ }^{*} 10 \mathrm{E} 15\right)$ & 5 & 5 & 5 & 5 & 5 & 5 & 5 & 5 & 5 & 5 & 5 & 5 & 5 & 5 & 5 & 5 & 5 & 5 \\
\hline \multirow{3}{*}{ 4.0e15 fast flux } & Thermal Power (MW) & $\mathrm{N} / \mathrm{A}$ & 213.0 & N/A & 258.8 & N/A & 267.9 & $\mathrm{~N} / \mathrm{A}$ & $\mathrm{N} / \mathrm{A}$ & N/A & $\mathrm{N} / \mathrm{A}$ & $\mathrm{N} / \mathrm{A}$ & $\mathrm{N} / \mathrm{A}$ & $\mathrm{N} / \mathrm{A}$ & $\mathrm{N} / \mathrm{A}$ & $\mathrm{N} / \mathrm{A}$ & $\mathrm{N} / \mathrm{A}$ & $\mathrm{N} / \mathrm{A}$ & $\mathrm{N} / \mathrm{A}$ \\
\hline & Max Assembly Power (MW) & N/A & 4.7 & N/A & 4.8 & N/A & 4.8 & N/A & $\mathrm{N} / \mathrm{A}$ & N/A & $\mathrm{N} / \mathrm{A}$ & N/A & N/A & $\mathrm{N} / \mathrm{A}$ & N/A & $\mathrm{N} / \mathrm{A}$ & N/A & $\mathrm{N} / \mathrm{A}$ & $\mathrm{N} / \mathrm{A}$ \\
\hline & $20 \mathrm{~cm}$ peak avg. Fast Flux (*10E15) & 4 & 4 & 4 & 4 & 4 & 4 & 4 & 4 & 4 & 4 & 4 & 4 & 4 & 4 & 4 & 4 & 4 & 4 \\
\hline
\end{tabular}

\begin{tabular}{|c|c|c|c|c|c|c|c|c|c|c|c|c|c|c|c|c|c|c|c|}
\hline & \multirow{4}{*}{\begin{tabular}{|l|} 
Assembly Type \\
Core Height (cm) \\
Number of Test assemblies \\
Average burnup (\% FIMA) \\
\end{tabular}} & \multicolumn{18}{|c|}{$\mathbf{Z 2 7 1}$} \\
\hline & & & & & & & & \multicolumn{6}{|c|}{80} & \multicolumn{6}{|c|}{100} \\
\hline & & \multicolumn{2}{|c|}{1} & \multicolumn{2}{|c|}{4} & \multicolumn{2}{|c|}{7} & \multicolumn{2}{|c|}{1} & \multicolumn{2}{|c|}{4} & \multicolumn{2}{|c|}{7} & \multicolumn{2}{|c|}{1} & \multicolumn{2}{|c|}{4} & \multicolumn{2}{|c|}{7} \\
\hline & & $3 \%$ & $6 \%$ & $3 \%$ & $6 \%$ & $3 \%$ & $6 \%$ & $3 \%$ & $6 \%$ & $3 \%$ & $6 \%$ & $3 \%$ & $6 \%$ & $3 \%$ & $6 \%$ & $3 \%$ & $6 \%$ & $3 \%$ & $6 \%$ \\
\hline & Number of batches & & 3 & & 3 & & & & 3 & & 3 & & 3 & & 4 & & 4 & & 4 \\
\hline & Cycle length (days) & & 104 & & 100 & & & & 103 & & 100 & & 101 & & 89 & & 88 & & 89 \\
\hline & Number of fuel assemblies & & 225 & & 240 & & & & 130 & & 140 & & 145 & & 91 & & 100 & & 105 \\
\hline \multirow{3}{*}{ Max. values } & Thermal Power (MW) & & 947 & & 1054 & & & & 737 & & 818 & & 840 & & 560 & & 623 & & 648 \\
\hline & Max Assembly Power (MW) & & 5.8 & & 5.8 & & & & 7.8 & & 7.8 & & 7.8 & & 8.2 & & 8.2 & & 8.2 \\
\hline & $20 \mathrm{~cm}$ peak avg. Fast Flux (*10E15) & & 6.2 & & 6.0 & & & & 6.8 & & 6.6 & & 6.6 & & 6.1 & & 5.9 & & 5.8 \\
\hline \multirow{3}{*}{ 5.0e15 fast flux } & Thermal Power (MW) & $\mathrm{N} / \mathrm{A}$ & 759 & $\mathrm{~N} / \mathrm{A}$ & 876 & $\mathrm{~N} / \mathrm{A}$ & $\mathrm{N} / \mathrm{A}$ & $\mathrm{N} / \mathrm{A}$ & 538 & N/A & 618 & $\mathrm{~N} / \mathrm{A}$ & 640 & $\mathrm{~N} / \mathrm{A}$ & 462 & $\mathrm{~N} / \mathrm{A}$ & 531 & $\mathrm{~N} / \mathrm{A}$ & 555 \\
\hline & Max Assembly Power (MW) & $\mathrm{N} / \mathrm{A}$ & 4.7 & $\mathrm{~N} / \mathrm{A}$ & 4.8 & $\mathrm{~N} / \mathrm{A}$ & $\mathrm{N} / \mathrm{A}$ & $\mathrm{N} / \mathrm{A}$ & 5.7 & N/A & 5.9 & $\mathrm{~N} / \mathrm{A}$ & 5.9 & $\mathrm{~N} / \mathrm{A}$ & 6.8 & $\mathrm{~N} / \mathrm{A}$ & 7.0 & $\mathrm{~N} / \mathrm{A}$ & 7.0 \\
\hline & $20 \mathrm{~cm}$ peak avg. Fast Flux ( $\left.{ }^{*} 10 \mathrm{E} 15\right)$ & 5 & 5 & 5 & 5 & 5 & 5 & 5 & 5 & 5 & 5 & 5 & 5 & 5 & 5 & 5 & 5 & 5 & 5 \\
\hline \multirow{3}{*}{ 4.0e15 fast flux } & Thermal Power (MW) & $\mathrm{N} / \mathrm{A}$ & 607 & $\mathrm{~N} / \mathrm{A}$ & 701 & $\mathrm{~N} / \mathrm{A}$ & 0 & $\mathrm{~N} / \mathrm{A}$ & 431 & $\mathrm{~N} / \mathrm{A}$ & 494 & $\mathrm{~N} / \mathrm{A}$ & 512 & $N / A$ & 370 & $\mathrm{~N} / \mathrm{A}$ & 425 & $\mathrm{~N} / \mathrm{A}$ & 444 \\
\hline & Max Assembly Power (MW) & N/A & 3.7 & $\mathrm{~N} / \mathrm{A}$ & 5.6 & $\mathrm{~N} / \mathrm{A}$ & 0.0 & $\mathrm{~N} / \mathrm{A}$ & 4.6 & N/A & 4.7 & N/A & 4.8 & $N / A$ & 5.4 & $\mathrm{~N} / \mathrm{A}$ & 5.6 & $\mathrm{~N} / \mathrm{A}$ & 5.6 \\
\hline & $20 \mathrm{~cm}$ peak avg. Fast Flux ( $\left.{ }^{*} 10 \mathrm{E} 15\right)$ & 4 & 4 & 4 & 4 & 4 & 4 & 4 & 4 & 4 & 4 & 4 & 4 & 4 & 4 & 4 & 4 & 4 & 4 \\
\hline
\end{tabular}


U-20PuWG-10Zr fuel with $235 \mathrm{U} / \mathrm{U}=5 \%$

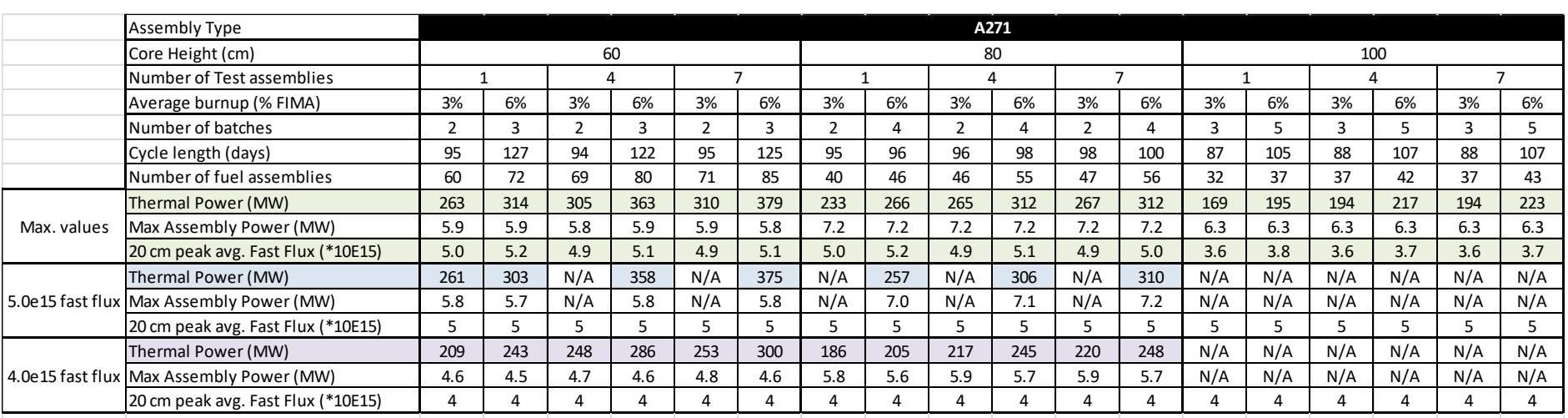

\begin{tabular}{|c|c|c|c|c|c|c|c|c|c|c|c|c|c|c|c|c|c|c|c|}
\hline & Assembly Type & \multicolumn{18}{|c|}{ B271 } \\
\hline & Core Height $(\mathrm{cm})$ & \multicolumn{6}{|c|}{60} & \multicolumn{6}{|c|}{80} & \multicolumn{6}{|c|}{100} \\
\hline & Number of Test assemblies & \multicolumn{2}{|c|}{1} & \multicolumn{2}{|c|}{4} & \multicolumn{2}{|c|}{7} & \multicolumn{2}{|c|}{1} & \multicolumn{2}{|c|}{4} & \multicolumn{2}{|c|}{7} & \multicolumn{2}{|c|}{1} & \multicolumn{2}{|c|}{4} & \multicolumn{2}{|c|}{7} \\
\hline & Average burnup (\% FIMA) & $3 \%$ & $6 \%$ & $3 \%$ & $6 \%$ & $3 \%$ & $6 \%$ & $3 \%$ & $6 \%$ & $3 \%$ & $6 \%$ & $3 \%$ & $6 \%$ & $3 \%$ & $6 \%$ & $3 \%$ & $6 \%$ & $3 \%$ & $6 \%$ \\
\hline & Number of batches & 2 & 4 & 2 & 4 & 2 & 4 & 3 & 5 & 3 & 5 & 3 & 5 & 4 & 7 & 4 & 7 & 4 & 7 \\
\hline & Cycle length (days) & 102 & 102 & 103 & 103 & 105 & 104 & 88 & 104 & 88 & 107 & 89 & 107 & 91 & 103 & 91 & 105 & 91 & 105 \\
\hline & Number of fuel assemblies & 44 & 51 & 52 & 61 & 55 & 64 & 30 & 35 & 36 & 41 & 36 & 41 & 26 & 29 & 29 & 33 & 29 & 33 \\
\hline \multirow{3}{*}{ Max. values } & Thermal Power (MW) & 201 & 233 & 235 & 276 & 244 & 286 & 141 & 168 & 168 & 191 & 168 & 190 & 111 & 125 & 123 & 139 & 123 & 139 \\
\hline & Max Assembly Power (MW) & 5.9 & 5.9 & 5.9 & 5.9 & 5.9 & 5.9 & 5.8 & 5.8 & 5.8 & 5.8 & 5.8 & 5.8 & 5.1 & 5.1 & 5.1 & 5.1 & 5.1 & 5.1 \\
\hline & $20 \mathrm{~cm}$ peak avg. Fast Flux ( $\left.{ }^{*} 10 \mathrm{E} 15\right)$ & 4.7 & 4.9 & 4.6 & 4.8 & 4.6 & 4.8 & 3.6 & 3.9 & 3.7 & 3.8 & 3.6 & 3.7 & 2.7 & 2.8 & 2.7 & 2.8 & 2.6 & 2.8 \\
\hline \multirow{3}{*}{ 5.0e15 fast flux } & Thermal Power (MW) & $\mathrm{N} / \mathrm{A}$ & $\mathrm{N} / \mathrm{A}$ & $\mathrm{N} / \mathrm{A}$ & $\mathrm{N} / \mathrm{A}$ & $\mathrm{N} / \mathrm{A}$ & $\mathrm{N} / \mathrm{A}$ & $\mathrm{N} / \mathrm{A}$ & $\mathrm{N} / \mathrm{A}$ & $\mathrm{N} / \mathrm{A}$ & $\mathrm{N} / \mathrm{A}$ & N/A & $\mathrm{N} / \mathrm{A}$ & $\mathrm{N} / \mathrm{A}$ & $\mathrm{N} / \mathrm{A}$ & $\mathrm{N} / \mathrm{A}$ & $\mathrm{N} / \mathrm{A}$ & $\mathrm{N} / \mathrm{A}$ & $\mathrm{N} / \mathrm{A}$ \\
\hline & Max Assembly Power (MW) & $\mathrm{N} / \mathrm{A}$ & $\mathrm{N} / \mathrm{A}$ & $\mathrm{N} / \mathrm{A}$ & $\mathrm{N} / \mathrm{A}$ & $\mathrm{N} / \mathrm{A}$ & $\mathrm{N} / \mathrm{A}$ & $\mathrm{N} / \mathrm{A}$ & $\mathrm{N} / \mathrm{A}$ & $\mathrm{N} / \mathrm{A}$ & $\mathrm{N} / \mathrm{A}$ & $\mathrm{N} / \mathrm{A}$ & $\mathrm{N} / \mathrm{A}$ & $\mathrm{N} / \mathrm{A}$ & $\mathrm{N} / \mathrm{A}$ & $\mathrm{N} / \mathrm{A}$ & $\mathrm{N} / \mathrm{A}$ & $\mathrm{N} / \mathrm{A}$ & $\mathrm{N} / \mathrm{A}$ \\
\hline & $20 \mathrm{~cm}$ peak avg. Fast Flux ( $\left.{ }^{*} 10 \mathrm{E} 15\right)$ & 5 & 5 & 5 & 5 & 5 & 5 & 5 & 5 & 5 & 5 & 5 & 5 & 5 & 5 & 5 & 5 & 5 & 5 \\
\hline \multirow{3}{*}{ 4.0e15 fast flux } & Thermal Power (MW) & 172 & 191 & 204 & 230 & 212 & 238 & $\mathrm{~N} / \mathrm{A}$ & $\mathrm{N} / \mathrm{A}$ & $\mathrm{N} / \mathrm{A}$ & $\mathrm{N} / \mathrm{A}$ & $\mathrm{N} / \mathrm{A}$ & $\mathrm{N} / \mathrm{A}$ & $\mathrm{N} / \mathrm{A}$ & $\mathrm{N} / \mathrm{A}$ & $\mathrm{N} / \mathrm{A}$ & $\mathrm{N} / \mathrm{A}$ & $\mathrm{N} / \mathrm{A}$ & $\mathrm{N} / \mathrm{A}$ \\
\hline & Max Assembly Power (MW) & 5.0 & 4.8 & 5.1 & 4.9 & 5.1 & 4.9 & $\mathrm{~N} / \mathrm{A}$ & $\mathrm{N} / \mathrm{A}$ & $\mathrm{N} / \mathrm{A}$ & $\mathrm{N} / \mathrm{A}$ & $\mathrm{N} / \mathrm{A}$ & $\mathrm{N} / \mathrm{A}$ & $\mathrm{N} / \mathrm{A}$ & $\mathrm{N} / \mathrm{A}$ & $\mathrm{N} / \mathrm{A}$ & $\mathrm{N} / \mathrm{A}$ & $\mathrm{N} / \mathrm{A}$ & $\mathrm{N} / \mathrm{A}$ \\
\hline & $20 \mathrm{~cm}$ peak avg. Fast Flux (*10E15) & 4 & 4 & 4 & 4 & 4 & 4 & 4 & 4 & 4 & 4 & 4 & 4 & 4 & 4 & 4 & 4 & 4 & 4 \\
\hline
\end{tabular}

\begin{tabular}{|c|c|c|c|c|c|c|c|c|c|c|c|c|c|c|c|c|c|c|c|}
\hline & \multirow{4}{*}{\begin{tabular}{|l|} 
Assembly Type \\
Core Height $(\mathrm{cm})$ \\
Number of Test assemblies \\
Average burnup (\% FIMA) \\
\end{tabular}} & \multicolumn{18}{|c|}{ C271 } \\
\hline & & & & & & & & \multicolumn{6}{|c|}{80} & \multirow{2}{*}{\multicolumn{6}{|c|}{$\frac{100}{4}$}} \\
\hline & & \multicolumn{2}{|c|}{1} & \multicolumn{2}{|c|}{4} & \multicolumn{2}{|c|}{7} & \multicolumn{2}{|c|}{1} & \multicolumn{2}{|c|}{4} & \multicolumn{2}{|c|}{7} & & & & & & \\
\hline & & $3 \%$ & $6 \%$ & $3 \%$ & $6 \%$ & $3 \%$ & $6 \%$ & $3 \%$ & $6 \%$ & $3 \%$ & $6 \%$ & $3 \%$ & $6 \%$ & $3 \%$ & $6 \%$ & $3 \%$ & $6 \%$ & $3 \%$ & $6 \%$ \\
\hline & Number of batches & 3 & 5 & 3 & 5 & 3 & 5 & 4 & 8 & 4 & 8 & 4 & 8 & 5 & 11 & 5 & 11 & 5 & 11 \\
\hline & Cycle length (days) & 85 & 103 & 86 & 104 & 86 & 104 & 98 & 96 & 98 & 96 & 99 & 97 & 107 & 99 & 108 & 100 & 108 & 101 \\
\hline & Number of fuel assemblies & 32 & 38 & 39 & 45 & 40 & 46 & 25 & 27 & 28 & 31 & 28 & 32 & 21 & 23 & 24 & 26 & 24 & 26 \\
\hline \multirow{3}{*}{ Max. values } & Thermal Power (MW) & 130 & 153 & 156 & 179 & 160 & 183 & 88 & 97 & 98 & 111 & 98 & 114 & 68 & 73 & 76 & 81 & 77 & 81 \\
\hline & Max Assembly Power (MW) & 5.0 & 5.0 & 5.0 & 5.0 & 5.0 & 5.0 & 4.3 & 4.3 & 4.3 & 4.3 & 4.3 & 4.3 & 3.7 & 3.7 & 3.7 & 3.7 & 3.7 & 3.7 \\
\hline & $20 \mathrm{~cm}$ peak avg. Fast Flux ( $\left.{ }^{*} 10 \mathrm{E} 15\right)$ & 3.7 & 3.9 & 3.7 & 3.8 & 3.8 & 3.9 & 2.5 & 2.6 & 2.5 & 2.6 & 2.5 & 2.6 & 1.8 & 1.9 & 1.8 & 1.8 & 1.8 & 1.8 \\
\hline \multirow{3}{*}{ 5.0e15 fast flux } & Thermal Power (MW) & $\mathrm{N} / \mathrm{A}$ & $\mathrm{N} / \mathrm{A}$ & $\mathrm{N} / \mathrm{A}$ & $\mathrm{N} / \mathrm{A}$ & $\mathrm{N} / \mathrm{A}$ & $\mathrm{N} / \mathrm{A}$ & N/A & $\mathrm{N} / \mathrm{A}$ & $\mathrm{N} / \mathrm{A}$ & $\mathrm{N} / \mathrm{A}$ & $\mathrm{N} / \mathrm{A}$ & $\mathrm{N} / \mathrm{A}$ & $\mathrm{N} / \mathrm{A}$ & N/A & $\mathrm{N} / \mathrm{A}$ & $\mathrm{N} / \mathrm{A}$ & $\mathrm{N} / \mathrm{A}$ & $\mathrm{N} / \mathrm{A}$ \\
\hline & Max Assembly Power (MW) & $\mathrm{N} / \mathrm{A}$ & $\mathrm{N} / \mathrm{A}$ & $\mathrm{N} / \mathrm{A}$ & $\mathrm{N} / \mathrm{A}$ & $\mathrm{N} / \mathrm{A}$ & $\mathrm{N} / \mathrm{A}$ & $\mathrm{N} / \mathrm{A}$ & $\mathrm{N} / \mathrm{A}$ & $\mathrm{N} / \mathrm{A}$ & $\mathrm{N} / \mathrm{A}$ & $\mathrm{N} / \mathrm{A}$ & $\mathrm{N} / \mathrm{A}$ & $\mathrm{N} / \mathrm{A}$ & $\mathrm{N} / \mathrm{A}$ & $\mathrm{N} / \mathrm{A}$ & $\mathrm{N} / \mathrm{A}$ & $\mathrm{N} / \mathrm{A}$ & $\mathrm{N} / \mathrm{A}$ \\
\hline & $20 \mathrm{~cm}$ peak avg. Fast Flux ( $\left.{ }^{*} 10 \mathrm{E} 15\right)$ & 5 & 5 & 5 & 5 & 5 & 5 & 5 & 5 & 5 & 5 & 5 & 5 & 5 & 5 & 5 & 5 & 5 & 5 \\
\hline \multirow{3}{*}{ 4.0e15 fast flux } & Thermal Power (MW) & $\mathrm{N} / \mathrm{A}$ & N/A & $\mathrm{N} / \mathrm{A}$ & N/A & $\mathrm{N} / \mathrm{A}$ & $\mathrm{N} / \mathrm{A}$ & N/A & $\mathrm{N} / \mathrm{A}$ & $\mathrm{N} / \mathrm{A}$ & $\mathrm{N} / \mathrm{A}$ & $\mathrm{N} / \mathrm{A}$ & $\mathrm{N} / \mathrm{A}$ & $\mathrm{N} / \mathrm{A}$ & N/A & $\mathrm{N} / \mathrm{A}$ & $\mathrm{N} / \mathrm{A}$ & $\mathrm{N} / \mathrm{A}$ & $\mathrm{N} / \mathrm{A}$ \\
\hline & Max Assembly Power (MW) & $\mathrm{N} / \mathrm{A}$ & $\mathrm{N} / \mathrm{A}$ & $\mathrm{N} / \mathrm{A}$ & N/A & $\mathrm{N} / \mathrm{A}$ & $\mathrm{N} / \mathrm{A}$ & N/A & $\mathrm{N} / \mathrm{A}$ & $\mathrm{N} / \mathrm{A}$ & $\mathrm{N} / \mathrm{A}$ & $\mathrm{N} / \mathrm{A}$ & $\mathrm{N} / \mathrm{A}$ & $\mathrm{N} / \mathrm{A}$ & N/A & $\mathrm{N} / \mathrm{A}$ & $\mathrm{N} / \mathrm{A}$ & $\mathrm{N} / \mathrm{A}$ & $\mathrm{N} / \mathrm{A}$ \\
\hline & $20 \mathrm{~cm}$ peak avg. Fast Flux ( ${ }^{* 10 \mathrm{E} 15)}$ & 4 & 4 & 4 & 4 & 4 & 4 & 4 & 4 & 4 & 4 & 4 & 4 & 4 & 4 & 4 & 4 & 4 & 4 \\
\hline
\end{tabular}

\begin{tabular}{|c|c|c|c|c|c|c|c|c|c|c|c|c|c|c|c|c|c|c|c|}
\hline & \multirow{4}{*}{\begin{tabular}{|l|} 
Assembly Type \\
Core Height $(\mathrm{cm})$ \\
Number of Test assemblies \\
Average burnup $(\%$ FIMA) \\
\end{tabular}} & \multicolumn{18}{|c|}{ Z271 } \\
\hline & & & & & & & & \multicolumn{6}{|c|}{80} & \multicolumn{6}{|c|}{100} \\
\hline & & \multicolumn{2}{|c|}{1} & \multicolumn{2}{|c|}{4} & \multicolumn{2}{|c|}{7} & \multicolumn{2}{|c|}{1} & \multicolumn{2}{|c|}{4} & \multicolumn{2}{|c|}{7} & \multicolumn{2}{|c|}{1} & \multicolumn{2}{|c|}{4} & \multicolumn{2}{|c|}{7} \\
\hline & & $3 \%$ & $6 \%$ & $3 \%$ & $6 \%$ & $3 \%$ & $6 \%$ & $3 \%$ & $6 \%$ & $3 \%$ & $6 \%$ & $3 \%$ & $6 \%$ & $3 \%$ & $6 \%$ & $3 \%$ & $6 \%$ & $3 \%$ & $6 \%$ \\
\hline & Number of batches & 1 & 3 & 1 & 3 & 1 & 3 & 1 & 3 & 1 & 3 & 1 & 3 & 2 & 3 & 2 & 3 & 2 & 3 \\
\hline & Cycle length (days) & 156 & 102 & 151 & 98 & 152 & 99 & 151 & 100 & 150 & 97 & 150 & 98 & 84 & 115 & 86 & 115 & 87 & 116 \\
\hline & Number of fuel assemblies & 110 & 125 & 120 & 135 & 125 & 140 & 70 & 80 & 79 & 85 & 81 & 90 & 50 & 60 & 59 & 69 & 60 & 70 \\
\hline \multirow{3}{*}{ Max. values } & Thermal Power (MW) & 464 & 538 & 520 & 602 & 540 & 618 & 407 & 467 & 461 & 513 & 474 & 538 & 324 & 381 & 375 & 437 & 379 & 441 \\
\hline & Max Assembly Power (MW) & 5.8 & 5.8 & 5.8 & 5.8 & 5.8 & 5.8 & 7.8 & 7.8 & 7.6 & 7.8 & 7.8 & 7.8 & 8.2 & 8.2 & 8.2 & 8.2 & 8.2 & 8.2 \\
\hline & $20 \mathrm{~cm}$ peak avg. Fast Flux ( $\left.{ }^{*} 10 \mathrm{E} 15\right)$ & 5.5 & 5.9 & $\begin{array}{clll}5.4 & & \\
\end{array}$ & 5.7 & 5.4 & 5.6 & 6.0 & 6.3 & 5.7 & 6.1 & 5.8 & 6.1 & $\begin{array}{clll}5.4 & & \\
\end{array}$ & 5.5 & 5.3 & 5.4 & 5.2 & 5.4 \\
\hline \multirow{3}{*}{$5.0 \mathrm{e} 15$ fast flux } & Thermal Power (MW) & 419 & 460 & 485 & 532 & 504 & 551 & 339 & 369 & 401 & 419 & 409 & 439 & 303 & 346 & 357 & 406 & 362 & 410 \\
\hline & Max Assembly Power (MW) & 5.3 & 5.0 & 5.4 & 5.1 & 5.4 & 5.2 & 6.5 & 6.2 & 6.7 & 6.4 & 6.7 & 6.4 & 7.7 & 7.4 & 7.8 & 7.6 & 7.8 & 7.6 \\
\hline & $20 \mathrm{~cm}$ peak avg. Fast Flux ( $\left.{ }^{*} 10 \mathrm{E} 15\right)$ & 5 & 5 & 5 & 5 & 5 & 5 & 5 & 5 & 5 & 5 & 5 & 5 & 5 & 5 & 5 & 5 & 5 & 5 \\
\hline \multirow{3}{*}{ 4.0e15 fast flux } & Thermal Power (MW) & 335 & 368 & 388 & 425 & 403 & 441 & 271 & 295 & 321 & 335 & 327 & 351 & 242 & 277 & 286 & 324 & 290 & 328 \\
\hline & Max Assembly Power (MW) & 4.2 & 4.0 & 4.3 & 4.1 & 4.3 & 4.2 & 5.2 & 4.9 & 5.3 & 5.1 & 5.4 & 5.1 & 6.1 & 6.0 & 6.2 & 6.1 & 6.3 & 6.1 \\
\hline & $20 \mathrm{~cm}$ peak avg. Fast Flux (*10E15) & 4 & 4 & 4 & 4 & 4 & 4 & 4 & 4 & 4 & 4 & 4 & 4 & 4 & 4 & 4 & 4 & 4 & 4 \\
\hline
\end{tabular}




\begin{tabular}{|c|c|c|c|c|c|c|c|c|c|c|c|c|c|c|c|c|c|c|c|}
\hline & Assembly Type & \multicolumn{18}{|c|}{ A271 } \\
\hline & Core Height $(\mathrm{cm})$ & \multicolumn{6}{|c|}{60} & \multicolumn{6}{|c|}{80} & \multicolumn{6}{|c|}{100} \\
\hline & Number of Test assemblies & \multicolumn{2}{|c|}{1} & \multicolumn{2}{|c|}{4} & \multicolumn{2}{|c|}{7} & \multicolumn{2}{|c|}{1} & \multicolumn{2}{|c|}{4} & \multicolumn{2}{|c|}{7} & \multicolumn{2}{|c|}{1} & \multicolumn{2}{|c|}{4} & \multicolumn{2}{|c|}{7} \\
\hline & Average burnup (\% FIMA) & $3 \%$ & $6 \%$ & $3 \%$ & $6 \%$ & $3 \%$ & $6 \%$ & $3 \%$ & $6 \%$ & $3 \%$ & $6 \%$ & $3 \%$ & $6 \%$ & $3 \%$ & $6 \%$ & $3 \%$ & $6 \%$ & $3 \%$ & $6 \%$ \\
\hline & Number of batches & & 3 & & 3 & & 3 & & 4 & & 4 & & 4 & & 5 & & 5 & & 5 \\
\hline & Cycle length (days) & & 129 & & 123 & & 126 & & 98 & & 99 & & 100 & & 107 & & 109 & & 109 \\
\hline & Number of fuel assemblies & & 78 & & 87 & & 92 & & 50 & & 58 & & 60 & & 40 & & 45 & & 46 \\
\hline \multirow{3}{*}{ Max. values } & Thermal Power (MW) & & 337 & & 392 & & 406 & & 282 & & 324 & & 332 & & 208 & & 230 & & 235 \\
\hline & Max Assembly Power (MW) & & 5.9 & & 5.8 & & 5.9 & & 7.2 & & 7.2 & & 7.2 & & 6.3 & & 6.3 & & 6.3 \\
\hline & $20 \mathrm{~cm}$ peak avg. Fast Flux ( $\left.{ }^{*} 10 \mathrm{E} 15\right)$ & & 5.1 & & 5.0 & & 5.0 & & 5.1 & & 5.0 & & 5.0 & & 3.8 & & 3.7 & & 3.7 \\
\hline \multirow{3}{*}{ 5.0e15 fast flux } & Thermal Power (MW) & $\mathrm{N} / \mathrm{A}$ & 328 & $\mathrm{~N} / \mathrm{A}$ & 389 & $\mathrm{~N} / \mathrm{A}$ & $\mathrm{N} / \mathrm{A}$ & $\mathrm{N} / \mathrm{A}$ & 276 & $\mathrm{~N} / \mathrm{A}$ & $\mathrm{N} / \mathrm{A}$ & $\mathrm{N} / \mathrm{A}$ & $\mathrm{N} / \mathrm{A}$ & $\mathrm{N} / \mathrm{A}$ & $\mathrm{N} / \mathrm{A}$ & $\mathrm{N} / \mathrm{A}$ & $\mathrm{N} / \mathrm{A}$ & $\mathrm{N} / \mathrm{A}$ & $\mathrm{N} / \mathrm{A}$ \\
\hline & Max Assembly Power (MW) & $\mathrm{N} / \mathrm{A}$ & 5.7 & $\mathrm{~N} / \mathrm{A}$ & 5.8 & N/A & N/A & $\mathrm{N} / \mathrm{A}$ & 7.1 & $\mathrm{~N} / \mathrm{A}$ & N/A & N/A & N/A & $\mathrm{N} / \mathrm{A}$ & $\mathrm{N} / \mathrm{A}$ & $\mathrm{N} / \mathrm{A}$ & $\mathrm{N} / \mathrm{A}$ & $\mathrm{N} / \mathrm{A}$ & $\mathrm{N} / \mathrm{A}$ \\
\hline & $20 \mathrm{~cm}$ peak avg. Fast Flux (*10E15) & 5 & 5 & 5 & 5 & 5 & 5 & 5 & 5 & 5 & 5 & 5 & 5 & 5 & 5 & 5 & 5 & 5 & 5 \\
\hline \multirow{3}{*}{ 4.0e15 fast flux } & Thermal Power (MW) & $\mathrm{N} / \mathrm{A}$ & 262 & $\mathrm{~N} / \mathrm{A}$ & 311 & $\mathrm{~N} / \mathrm{A}$ & 326 & $\mathrm{~N} / \mathrm{A}$ & 221 & $\mathrm{~N} / \mathrm{A}$ & 259 & $\mathrm{~N} / \mathrm{A}$ & 266 & $\mathrm{~N} / \mathrm{A}$ & $\mathrm{N} / \mathrm{A}$ & $\mathrm{N} / \mathrm{A}$ & $\mathrm{N} / \mathrm{A}$ & $\mathrm{N} / \mathrm{A}$ & $\mathrm{N} / \mathrm{A}$ \\
\hline & Max Assembly Power (MW) & $\mathrm{N} / \mathrm{A}$ & 4.6 & $\mathrm{~N} / \mathrm{A}$ & 4.6 & $\mathrm{~N} / \mathrm{A}$ & 4.7 & $\mathrm{~N} / \mathrm{A}$ & 5.6 & $\mathrm{~N} / \mathrm{A}$ & 5.8 & $\mathrm{~N} / \mathrm{A}$ & 5.8 & $\mathrm{~N} / \mathrm{A}$ & $\mathrm{N} / \mathrm{A}$ & $\mathrm{N} / \mathrm{A}$ & $\mathrm{N} / \mathrm{A}$ & $\mathrm{N} / \mathrm{A}$ & $\mathrm{N} / \mathrm{A}$ \\
\hline & $20 \mathrm{~cm}$ peak avg. Fast Flux (*10E15) & 4 & 4 & 4 & 4 & 4 & 4 & 4 & 4 & 4 & 4 & 4 & 4 & 4 & 4 & 4 & 4 & 4 & 4 \\
\hline
\end{tabular}

\begin{tabular}{|c|c|c|c|c|c|c|c|c|c|c|c|c|c|c|c|c|c|c|c|}
\hline & \multirow{4}{*}{\begin{tabular}{|l|} 
Assembly Type \\
Core Height $(\mathrm{cm})$ \\
Number of Test assemblies \\
\end{tabular}} & \multicolumn{18}{|c|}{ B271 } \\
\hline & & & & & & & & \multicolumn{6}{|c|}{80} & \multicolumn{6}{|c|}{100} \\
\hline & & \multicolumn{2}{|c|}{1} & \multicolumn{2}{|c|}{4} & \multicolumn{2}{|c|}{7} & \multicolumn{2}{|c|}{1} & \multicolumn{2}{|c|}{4} & \multicolumn{2}{|c|}{7} & \multicolumn{2}{|c|}{1} & \multicolumn{2}{|c|}{4} & \multicolumn{2}{|c|}{7} \\
\hline & & $3 \%$ & $6 \%$ & $3 \%$ & $6 \%$ & $3 \%$ & $6 \%$ & $3 \%$ & $6 \%$ & $3 \%$ & $6 \%$ & $3 \%$ & $6 \%$ & $3 \%$ & $6 \%$ & $3 \%$ & $6 \%$ & $3 \%$ & $6 \%$ \\
\hline & Number of batches & & 4 & & 4 & & 4 & & 5 & & 5 & & 5 & & 7 & & 7 & & 7 \\
\hline & Cycle length (days) & & 105 & & 104 & & 105 & & 106 & & 107 & & 108 & & 106 & & 107 & & 107 \\
\hline & Number of fuel assemblies & & 57 & & 66 & & 69 & & 38 & & 44 & & 45 & & 30 & & 36 & & 36 \\
\hline \multirow{3}{*}{ Max. values } & Thermal Power (MW) & & 253 & & 295 & & 306 & & 177 & & 203 & & 207 & & 125 & & 150 & & 149 \\
\hline & Max Assembly Power (MW) & & 5.9 & & 5.9 & & 5.9 & & 5.8 & & 5.8 & & 5.8 & & 5.1 & & 5.1 & & 5.1 \\
\hline & $20 \mathrm{~cm}$ peak avg. Fast Flux $\left({ }^{*} 10 \mathrm{E} 15\right)$ & & 4.9 & & 4.7 & & 4.7 & & 3.8 & & 3.8 & & 3.8 & & 2.7 & & 2.8 & & 2.7 \\
\hline \multirow{3}{*}{$5.0 \mathrm{e} 15$ fast flux } & Thermal Power (MW) & $\mathrm{N} / \mathrm{A}$ & $\mathrm{N} / \mathrm{A}$ & N/A & $\mathrm{N} / \mathrm{A}$ & N/A & $\mathrm{N} / \mathrm{A}$ & N/A & N/A & $\mathrm{N} / \mathrm{A}$ & N/A & $\mathrm{N} / \mathrm{A}$ & N/A & N/A & $\mathrm{N} / \mathrm{A}$ & N/A & $\mathrm{N} / \mathrm{A}$ & $\mathrm{N} / \mathrm{A}$ & $\mathrm{N} / \mathrm{A}$ \\
\hline & Max Assembly Power (MW) & $\mathrm{N} / \mathrm{A}$ & $\mathrm{N} / \mathrm{A}$ & N/A & $\mathrm{N} / \mathrm{A}$ & N/A & $\mathrm{N} / \mathrm{A}$ & N/A & $\mathrm{N} / \mathrm{A}$ & $\mathrm{N} / \mathrm{A}$ & $\mathrm{N} / \mathrm{A}$ & $\mathrm{N} / \mathrm{A}$ & N/A & N/A & $\mathrm{N} / \mathrm{A}$ & N/A & $\mathrm{N} / \mathrm{A}$ & $\mathrm{N} / \mathrm{A}$ & $\mathrm{N} / \mathrm{A}$ \\
\hline & $20 \mathrm{~cm}$ peak avg. Fast Flux ( $\left.{ }^{*} 10 \mathrm{E} 15\right)$ & 5 & 5 & 5 & 5 & 5 & 5 & 5 & 5 & 5 & 5 & 5 & 5 & 5 & 5 & 5 & 5 & 5 & 5 \\
\hline \multirow{3}{*}{ 4.0e15 fast flux } & Thermal Power (MW) & $\mathrm{N} / \mathrm{A}$ & 209 & N/A & 249 & $\mathrm{~N} / \mathrm{A}$ & 258 & N/A & N/A & $\mathrm{N} / \mathrm{A}$ & $\mathrm{N} / \mathrm{A}$ & $\mathrm{N} / \mathrm{A}$ & N/A & N/A & $\mathrm{N} / \mathrm{A}$ & N/A & $\mathrm{N} / \mathrm{A}$ & $\mathrm{N} / \mathrm{A}$ & $\mathrm{N} / \mathrm{A}$ \\
\hline & Max Assembly Power (MW) & $\mathrm{N} / \mathrm{A}$ & 4.8 & $\mathrm{~N} / \mathrm{A}$ & 5.0 & N/A & 5.0 & $\mathrm{~N} / \mathrm{A}$ & N/A & $\mathrm{N} / \mathrm{A}$ & $\mathrm{N} / \mathrm{A}$ & $\mathrm{N} / \mathrm{A}$ & $\mathrm{N} / \mathrm{A}$ & $\mathrm{N} / \mathrm{A}$ & $\mathrm{N} / \mathrm{A}$ & N/A & $\mathrm{N} / \mathrm{A}$ & $\mathrm{N} / \mathrm{A}$ & $\mathrm{N} / \mathrm{A}$ \\
\hline & $20 \mathrm{~cm}$ peak avg. Fast Flux (* & & & 4 & 4 & 4 & & & F & & 4 & & 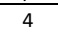 & & F & 4 & 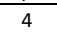 & 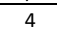 & \\
\hline
\end{tabular}

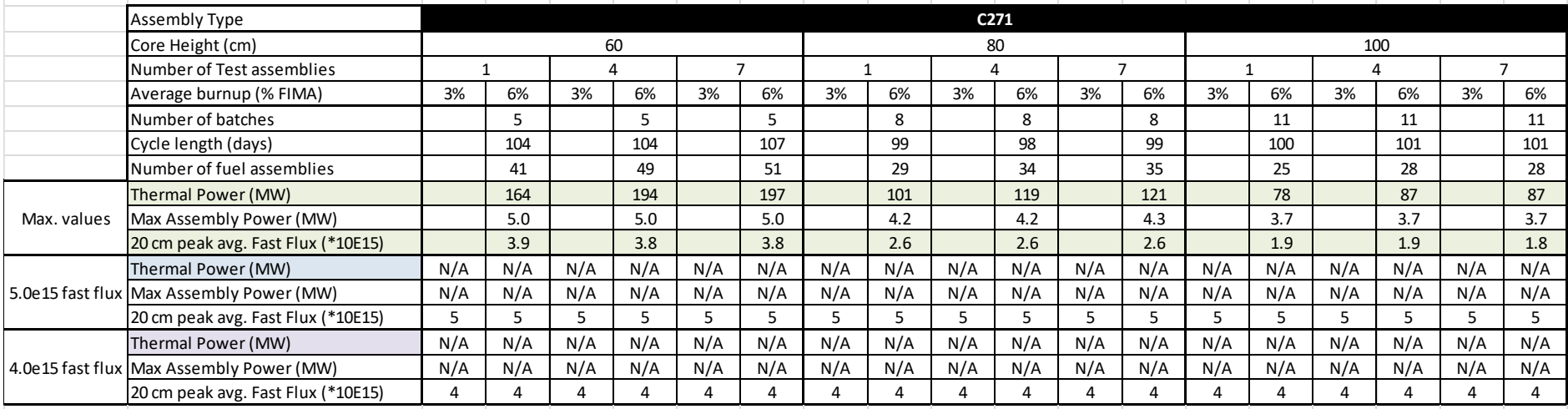

\begin{tabular}{|c|c|c|c|c|c|c|c|c|c|c|c|c|c|c|c|c|c|c|c|}
\hline & Assembly Type & \multicolumn{18}{|c|}{$\mathbf{Z 2 7 1}$} \\
\hline & Core Height $(\mathrm{cm})$ & \multicolumn{6}{|c|}{60} & \multicolumn{6}{|c|}{80} & \multicolumn{6}{|c|}{100} \\
\hline & Number of Test assemblies & \multicolumn{2}{|c|}{1} & \multicolumn{2}{|c|}{4} & \multicolumn{2}{|c|}{7} & \multicolumn{2}{|c|}{1} & \multicolumn{2}{|c|}{4} & \multicolumn{2}{|c|}{7} & \multicolumn{2}{|c|}{1} & \multicolumn{2}{|c|}{4} & \multicolumn{2}{|c|}{7} \\
\hline & Average burnup (\% FIMA) & $3 \%$ & $6 \%$ & $3 \%$ & $6 \%$ & $3 \%$ & $6 \%$ & $3 \%$ & $6 \%$ & $3 \%$ & $6 \%$ & $3 \%$ & $6 \%$ & $3 \%$ & $6 \%$ & $3 \%$ & $6 \%$ & $3 \%$ & $6 \%$ \\
\hline & Number of batches & & 3 & & 3 & & 3 & & 3 & & 3 & & 3 & & 3 & & 3 & & 4 \\
\hline & Cycle length (days) & & 103 & & 99 & & 99 & & 99 & & 97 & & 99 & & 117 & & 116 & & 88 \\
\hline & Number of fuel assemblies & & 135 & & 147 & & 156 & & 83 & & 92 & & 98 & & 66 & & 72 & & 75 \\
\hline \multirow{3}{*}{ Max. values } & Thermal Power (MW) & & 575 & & 651 & & 693 & & 492 & & 552 & & 578 & & 413 & & 454 & & 467 \\
\hline & Max Assembly Power (MW) & & 5.8 & & 5.8 & & 5.8 & & 7.8 & & 7.8 & & 7.8 & & 8.2 & & 8.2 & & 8.2 \\
\hline & $20 \mathrm{~cm}$ peak avg. Fast Flux (*10E15) & & 5.8 & & 5.6 & & 5.6 & & 6.3 & & 6.1 & & 6.0 & & 5.5 & & 5.3 & & 5.4 \\
\hline \multirow{3}{*}{ 5.0e15 fast flux } & Thermal Power (MW) & $\mathrm{N} / \mathrm{A}$ & 499 & $\mathrm{~N} / \mathrm{A}$ & 582 & $\mathrm{~N} / \mathrm{A}$ & 621 & $\mathrm{~N} / \mathrm{A}$ & 392 & $\mathrm{~N} / \mathrm{A}$ & 453 & $\mathrm{~N} / \mathrm{A}$ & 478 & $\mathrm{~N} / \mathrm{A}$ & 376 & $\mathrm{~N} / \mathrm{A}$ & 426 & $\mathrm{~N} / \mathrm{A}$ & 435 \\
\hline & Max Assembly Power (MW) & $\mathrm{N} / \mathrm{A}$ & 5.1 & $\mathrm{~N} / \mathrm{A}$ & 5.2 & $\mathrm{~N} / \mathrm{A}$ & 5.2 & $\mathrm{~N} / \mathrm{A}$ & 6.2 & $\mathrm{~N} / \mathrm{A}$ & 6.4 & $\mathrm{~N} / \mathrm{A}$ & 6.5 & $\mathrm{~N} / \mathrm{A}$ & 7.5 & $\mathrm{~N} / \mathrm{A}$ & 7.7 & $\mathrm{~N} / \mathrm{A}$ & 7.6 \\
\hline & $20 \mathrm{~cm}$ peak avg. Fast Flux (*10E15) & 5 & 5 & 5 & 5 & 5 & 5 & 5 & 5 & 5 & 5 & 5 & 5 & 5 & 5 & 5 & 5 & 5 & 5 \\
\hline \multirow{3}{*}{ 4.0e15 fast flux } & Thermal Power (MW) & $\mathrm{N} / \mathrm{A}$ & 399 & $\mathrm{~N} / \mathrm{A}$ & 466 & N/A & 497 & $\mathrm{~N} / \mathrm{A}$ & 313 & $\mathrm{~N} / \mathrm{A}$ & 363 & $\mathrm{~N} / \mathrm{A}$ & 382 & $\mathrm{~N} / \mathrm{A}$ & 301 & $\mathrm{~N} / \mathrm{A}$ & 341 & N/A & 348 \\
\hline & Max Assembly Power (MW) & $\mathrm{N} / \mathrm{A}$ & 4.0 & $\mathrm{~N} / \mathrm{A}$ & 4.2 & N/A & 4.2 & N/A & 5.0 & $\mathrm{~N} / \mathrm{A}$ & 5.1 & $\mathrm{~N} / \mathrm{A}$ & 5.2 & $\mathrm{~N} / \mathrm{A}$ & 6.0 & N/A & 6.2 & N/A & 6.1 \\
\hline & $20 \mathrm{~cm}$ peak avg. Fast Flux (*10E15) & 4 & 4 & 4 & 4 & 4 & 4 & 4 & 4 & 4 & 4 & 4 & 4 & 4 & 4 & 4 & 4 & 4 & 4 \\
\hline
\end{tabular}


U-20PuWG-10Zr fuel with $235 \mathrm{U} / \mathrm{U}=10 \%$

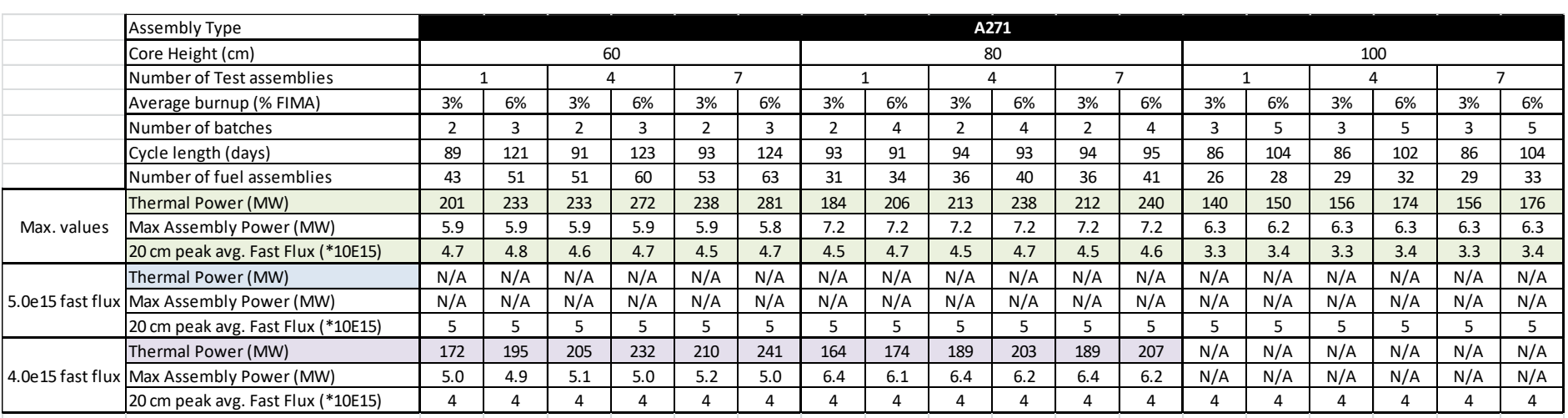

\begin{tabular}{|c|c|c|c|c|c|c|c|c|c|c|c|c|c|c|c|c|c|c|c|}
\hline & \multirow{4}{*}{\begin{tabular}{|l|} 
Assembly Type \\
Core Height (cm) \\
Number of Test assemblies \\
Average burnup (\% FIMA) \\
\end{tabular}} & \multicolumn{18}{|c|}{ B271 } \\
\hline & & \multirow{2}{*}{\multicolumn{4}{|c|}{$\frac{60}{4}$}} & & & & \multicolumn{6}{|c|}{100} \\
\hline & & & & & & \multicolumn{2}{|c|}{7} & \multicolumn{2}{|c|}{1} & \multicolumn{2}{|c|}{4} & \multicolumn{2}{|c|}{7} & \multicolumn{2}{|c|}{1} & \multicolumn{2}{|c|}{4} & \multicolumn{2}{|c|}{7} \\
\hline & & $3 \%$ & $6 \%$ & $3 \%$ & $6 \%$ & $3 \%$ & $6 \%$ & $3 \%$ & $6 \%$ & $3 \%$ & $6 \%$ & $3 \%$ & $6 \%$ & $3 \%$ & $6 \%$ & $3 \%$ & $6 \%$ & $3 \%$ & $6 \%$ \\
\hline & Number of batches & 2 & 3 & 2 & 3 & 2 & 3 & 3 & 5 & 3 & 5 & 3 & 5 & 4 & 7 & 4 & 7 & 4 & 7 \\
\hline & Cycle length (days) & 96 & 131 & 99 & 132 & 99 & 133 & 86 & 101 & 87 & 102 & 86 & 102 & 88 & 102 & 89 & 103 & 89 & 103 \\
\hline & Number of fuel assemblies & 32 & 38 & 39 & 45 & 40 & 46 & 24 & 27 & 28 & 31 & 28 & 31 & 21 & 23 & 23 & 26 & 24 & 26 \\
\hline \multirow{3}{*}{ Max. values } & Thermal Power (MW) & 154 & 180 & 184 & 211 & 189 & 215 & 115 & 133 & 134 & 151 & 134 & 151 & 93 & 100 & 100 & 112 & 104 & 111 \\
\hline & Max Assembly Power (MW) & 5.9 & 5.9 & 5.9 & 5.9 & 5.9 & 5.9 & 5.8 & 5.8 & 5.7 & 5.8 & 5.8 & 5.8 & 5.0 & 5.1 & 5.1 & 5.1 & 5.0 & 5.1 \\
\hline & $20 \mathrm{~cm}$ peak avg. Fast Flux (*10E15) & 4.3 & 4.4 & 4.3 & 4.4 & 4.3 & 4.4 & 3.3 & 3.5 & 3.3 & 3.5 & 3.3 & 3.5 & 2.4 & 2.5 & 2.4 & 2.5 & 2.4 & 2.5 \\
\hline \multirow{3}{*}{ 5.0e15 fast flux } & Thermal Power (MW) & $\mathrm{N} / \mathrm{A}$ & $\mathrm{N} / \mathrm{A}$ & $\mathrm{N} / \mathrm{A}$ & $\mathrm{N} / \mathrm{A}$ & $\mathrm{N} / \mathrm{A}$ & $\mathrm{N} / \mathrm{A}$ & $\mathrm{N} / \mathrm{A}$ & $\mathrm{N} / \mathrm{A}$ & $\mathrm{N} / \mathrm{A}$ & $\mathrm{N} / \mathrm{A}$ & $\mathrm{N} / \mathrm{A}$ & $\mathrm{N} / \mathrm{A}$ & $\mathrm{N} / \mathrm{A}$ & $\mathrm{N} / \mathrm{A}$ & $\mathrm{N} / \mathrm{A}$ & $\mathrm{N} / \mathrm{A}$ & $\mathrm{N} / \mathrm{A}$ & $\mathrm{N} / \mathrm{A}$ \\
\hline & Max Assembly Power (MW) & $\mathrm{N} / \mathrm{A}$ & $\mathrm{N} / \mathrm{A}$ & $\mathrm{N} / \mathrm{A}$ & N/A & $\mathrm{N} / \mathrm{A}$ & $\mathrm{N} / \mathrm{A}$ & $\mathrm{N} / \mathrm{A}$ & $\mathrm{N} / \mathrm{A}$ & N/A & $\mathrm{N} / \mathrm{A}$ & N/A & N/A & $\mathrm{N} / \mathrm{A}$ & $\mathrm{N} / \mathrm{A}$ & $\mathrm{N} / \mathrm{A}$ & N/A & N/A & $\mathrm{N} / \mathrm{A}$ \\
\hline & $20 \mathrm{~cm}$ peak avg. Fast Flux ( $\left.{ }^{*} 10 \mathrm{E} 15\right)$ & 5 & 5 & 5 & 5 & 5 & 5 & 5 & 5 & 5 & 5 & 5 & 5 & 5 & 5 & 5 & 5 & 5 & 5 \\
\hline \multirow{3}{*}{ 4.0e15 fast flux } & Thermal Power (MW) & 144 & 162 & 173 & 193 & 176 & 196 & $\mathrm{~N} / \mathrm{A}$ & $\mathrm{N} / \mathrm{A}$ & $\mathrm{N} / \mathrm{A}$ & $\mathrm{N} / \mathrm{A}$ & $\mathrm{N} / \mathrm{A}$ & $\mathrm{N} / \mathrm{A}$ & $\mathrm{N} / \mathrm{A}$ & $\mathrm{N} / \mathrm{A}$ & $\mathrm{N} / \mathrm{A}$ & $\mathrm{N} / \mathrm{A}$ & $\mathrm{N} / \mathrm{A}$ & $\mathrm{N} / \mathrm{A}$ \\
\hline & Max Assembly Power (MW) & 5.5 & 5.3 & 5.5 & 5.4 & 5.5 & 5.4 & $\mathrm{~N} / \mathrm{A}$ & $\mathrm{N} / \mathrm{A}$ & $\mathrm{N} / \mathrm{A}$ & $\mathrm{N} / \mathrm{A}$ & $\mathrm{N} / \mathrm{A}$ & $\mathrm{N} / \mathrm{A}$ & $\mathrm{N} / \mathrm{A}$ & $\mathrm{N} / \mathrm{A}$ & $\mathrm{N} / \mathrm{A}$ & $\mathrm{N} / \mathrm{A}$ & $\mathrm{N} / \mathrm{A}$ & $\mathrm{N} / \mathrm{A}$ \\
\hline & $20 \mathrm{~cm}$ peak avg. Fast Flux ( $\left.{ }^{*} 10 \mathrm{E} 15\right)$ & 4 & 4 & 4 & 4 & 4 & 4 & 4 & 4 & 4 & 4 & 4 & 4 & 4 & 4 & 4 & 4 & 4 & 4 \\
\hline
\end{tabular}

\begin{tabular}{|c|c|c|c|c|c|c|c|c|c|c|c|c|c|c|c|c|c|c|c|}
\hline & \multirow{4}{*}{\begin{tabular}{|l|} 
Assembly Type \\
Core Height $(\mathrm{cm})$ \\
Number of Test assemblies \\
Average burnup (\% FIMA) \\
\end{tabular}} & \multicolumn{18}{|c|}{ C271 } \\
\hline & & \multicolumn{12}{|c|}{80} & \multirow{2}{*}{\multicolumn{6}{|c|}{100}} \\
\hline & & \multicolumn{2}{|c|}{1} & \multicolumn{2}{|c|}{4} & \multicolumn{2}{|c|}{7} & \multicolumn{2}{|c|}{1} & \multicolumn{2}{|c|}{4} & \multicolumn{2}{|c|}{7} & 1 & & & & & 7 \\
\hline & & $3 \%$ & $6 \%$ & $3 \%$ & $6 \%$ & $3 \%$ & $6 \%$ & $3 \%$ & $6 \%$ & $3 \%$ & $6 \%$ & $3 \%$ & $6 \%$ & $3 \%$ & $6 \%$ & $3 \%$ & $6 \%$ & $3 \%$ & $6 \%$ \\
\hline & Number of batches & 2 & 5 & 2 & 5 & 2 & 5 & 4 & 7 & 4 & 8 & 4 & 8 & 5 & 11 & 5 & 11 & 5 & 11 \\
\hline & Cycle length (days) & 125 & 100 & 125 & 100 & 124 & 101 & 94 & 107 & 96 & 95 & 96 & 95 & 100 & 96 & 105 & 98 & 105 & 98 \\
\hline & Number of fuel assemblies & 26 & 29 & 30 & 34 & 30 & 35 & 20 & 22 & 23 & 25 & 23 & 25 & 17 & 19 & 19 & 21 & 20 & 21 \\
\hline \multirow{3}{*}{ Max. values } & Thermal Power (MW) & 108 & 119 & 124 & 141 & 124 & 143 & 73 & 81 & 82 & 91 & 83 & 91 & 59 & 62 & 62 & 67 & 66 & 67 \\
\hline & Max Assembly Power (MW) & 5.0 & 5.0 & 5.0 & 5.0 & 5.0 & 5.0 & 4.3 & 4.3 & 4.2 & 4.3 & 4.3 & 4.3 & 3.8 & 3.7 & 3.7 & 3.7 & 3.8 & 3.7 \\
\hline & $20 \mathrm{~cm}$ peak avg. Fast Flux (*10E15) & 3.4 & 3.5 & 3.4 & 3.6 & 3.4 & 3.5 & 2.3 & 2.4 & 2.3 & 2.4 & 2.3 & 2.4 & 1.7 & 1.7 & 1.7 & 1.7 & 1.7 & 1.7 \\
\hline \multirow{3}{*}{$5.0 \mathrm{e} 15$ fast flux } & Thermal Power (MW) & $\mathrm{N} / \mathrm{A}$ & $\mathrm{N} / \mathrm{A}$ & N/A & $N / A$ & $\mathrm{~N} / \mathrm{A}$ & $\mathrm{N} / \mathrm{A}$ & $\mathrm{N} / \mathrm{A}$ & $\mathrm{N} / \mathrm{A}$ & $\mathrm{N} / \mathrm{A}$ & N/A & $\mathrm{N} / \mathrm{A}$ & $N / A$ & N/A & $\mathrm{N} / \mathrm{A}$ & $\mathrm{N} / \mathrm{A}$ & $\mathrm{N} / \mathrm{A}$ & $N / A$ & $\mathrm{~N} / \mathrm{A}$ \\
\hline & Max Assembly Power (MW) & $\mathrm{N} / \mathrm{A}$ & $\mathrm{N} / \mathrm{A}$ & N/A & $\mathrm{N} / \mathrm{A}$ & $\mathrm{N} / \mathrm{A}$ & $\mathrm{N} / \mathrm{A}$ & N/A & $\mathrm{N} / \mathrm{A}$ & $\mathrm{N} / \mathrm{A}$ & N/A & $\mathrm{N} / \mathrm{A}$ & $N / A$ & N/A & $\mathrm{N} / \mathrm{A}$ & $\mathrm{N} / \mathrm{A}$ & $\mathrm{N} / \mathrm{A}$ & $N / A$ & $\mathrm{~N} / \mathrm{A}$ \\
\hline & $20 \mathrm{~cm}$ peak avg. Fast Flux ( $\left.{ }^{*} 10 \mathrm{E} 15\right)$ & 5 & 5 & 5 & 5 & 5 & 5 & 5 & 5 & 5 & 5 & 5 & 5 & 5 & 5 & 5 & 5 & 5 & 5 \\
\hline \multirow{3}{*}{ 4.0e15 fast flux } & Thermal Power (MW) & $\mathrm{N} / \mathrm{A}$ & $\mathrm{N} / \mathrm{A}$ & N/A & $\mathrm{N} / \mathrm{A}$ & N/A & $\mathrm{N} / \mathrm{A}$ & $\mathrm{N} / \mathrm{A}$ & $\mathrm{N} / \mathrm{A}$ & $\mathrm{N} / \mathrm{A}$ & N/A & $\mathrm{N} / \mathrm{A}$ & $\mathrm{N} / \mathrm{A}$ & N/A & $\mathrm{N} / \mathrm{A}$ & N/A & $\mathrm{N} / \mathrm{A}$ & $\mathrm{N} / \mathrm{A}$ & N/A \\
\hline & Max Assembly Power (MW) & $\mathrm{N} / \mathrm{A}$ & $\mathrm{N} / \mathrm{A}$ & N/A & $\mathrm{N} / \mathrm{A}$ & $\mathrm{N} / \mathrm{A}$ & $\mathrm{N} / \mathrm{A}$ & $\mathrm{N} / \mathrm{A}$ & $\mathrm{N} / \mathrm{A}$ & $\mathrm{N} / \mathrm{A}$ & N/A & $\mathrm{N} / \mathrm{A}$ & $\mathrm{N} / \mathrm{A}$ & N/A & $\mathrm{N} / \mathrm{A}$ & $\mathrm{N} / \mathrm{A}$ & $\mathrm{N} / \mathrm{A}$ & $\mathrm{N} / \mathrm{A}$ & N/A \\
\hline & $20 \mathrm{~cm}$ peak avg. Fast Flux (*10E15) & 4 & 4 & 4 & 4 & 4 & 4 & 4 & 4 & 4 & 4 & 4 & 4 & 4 & 4 & 4 & 4 & 4 & \\
\hline
\end{tabular}

\begin{tabular}{|c|c|c|c|c|c|c|c|c|c|c|c|c|c|c|c|c|c|c|c|}
\hline & Assembly Type & \multicolumn{18}{|c|}{$\mathbf{Z 2 7 1}$} \\
\hline & \begin{tabular}{|l|} 
Core Height $(\mathrm{cm})$ \\
\end{tabular} & \multicolumn{6}{|c|}{60} & \multicolumn{6}{|c|}{80} & \multicolumn{6}{|c|}{100} \\
\hline & Number of Test assemblies & \multicolumn{2}{|c|}{1} & \multicolumn{2}{|c|}{4} & \multicolumn{2}{|c|}{7} & \multicolumn{2}{|c|}{1} & \multicolumn{2}{|c|}{4} & \multicolumn{2}{|c|}{7} & \multicolumn{2}{|c|}{1} & \multicolumn{2}{|c|}{4} & \multicolumn{2}{|c|}{7} \\
\hline & Average burnup (\% FIMA) & $3 \%$ & $6 \%$ & $3 \%$ & $6 \%$ & $3 \%$ & $6 \%$ & $3 \%$ & $6 \%$ & $3 \%$ & $6 \%$ & $3 \%$ & $6 \%$ & $3 \%$ & $6 \%$ & $3 \%$ & $6 \%$ & $3 \%$ & $6 \%$ \\
\hline & Number of batches & 1 & 3 & 1 & 3 & 1 & 3 & 1 & 3 & 1 & 3 & 1 & 3 & 2 & 3 & 2 & 3 & 2 & 3 \\
\hline & Cycle length (days) & 154 & 99 & 148 & 97 & 150 & 98 & 143 & 96 & 146 & 96 & 147 & 97 & 81 & 109 & 82 & 111 & 82 & 111 \\
\hline & Number of fuel assemblies & 78 & 84 & 87 & 96 & 90 & 99 & 51 & 57 & 60 & 64 & 61 & 66 & 39 & 44 & 44 & 51 & 44 & 52 \\
\hline \multirow{3}{*}{ Max. values } & Thermal Power (MW) & 334 & 373 & 387 & 432 & 395 & 440 & 312 & 347 & 360 & 388 & 362 & 397 & 264 & 294 & 295 & 336 & 293 & 341 \\
\hline & Max Assembly Power (MW) & 5.8 & 5.8 & 5.8 & 5.8 & 5.8 & 5.8 & 7.8 & 7.8 & 7.8 & 7.8 & 7.8 & 7.8 & 8.2 & 8.2 & 8.2 & 8.2 & 8.2 & 8.2 \\
\hline & $20 \mathrm{~cm}$ peak avg. Fast Flux ( $\left.{ }^{*} 10 \mathrm{E} 15\right)$ & 5.1 & 5.4 & 5.0 & 5.3 & 5.0 & 5.2 & 5.5 & 5.8 & 5.4 & 5.7 & 5.4 & 5.6 & 5.0 & 5.1 & 4.9 & 5.0 & 4.8 & 5.0 \\
\hline \multirow{3}{*}{ 5.0e15 fast flux } & Thermal Power (MW) & 325 & 344 & 384 & 411 & 395 & 422 & 282 & 298 & 333 & 343 & 337 & 351 & $\mathrm{~N} / \mathrm{A}$ & 291 & $\mathrm{~N} / \mathrm{A}$ & N/A & $\mathrm{N} / \mathrm{A}$ & $\mathrm{N} / \mathrm{A}$ \\
\hline & Max Assembly Power (MW) & 5.7 & 5.4 & 5.8 & 5.5 & 5.8 & 5.6 & 7.0 & 6.7 & 7.2 & 6.9 & 7.3 & 6.9 & $\mathrm{~N} / \mathrm{A}$ & 8.1 & $\mathrm{~N} / \mathrm{A}$ & N/A & $\mathrm{N} / \mathrm{A}$ & $\mathrm{N} / \mathrm{A}$ \\
\hline & $20 \mathrm{~cm}$ peak avg. Fast Flux $\left({ }^{*} 10 E 15\right)$ & 5 & 5 & 5 & 5 & 5 & 5 & 5 & 5 & 5 & 5 & 5 & 5 & 5 & 5 & 5 & 5 & 5 & 5 \\
\hline \multirow{3}{*}{ 4.0e15 fast flux } & Thermal Power (MW) & 260 & 275 & 307 & 329 & 316 & 338 & 225 & 238 & 266 & 275 & 270 & 281 & 213 & 233 & 242 & 270 & 243 & 274 \\
\hline & Max Assembly Power (MW) & 4.5 & 4.3 & 4.6 & 4.4 & 4.7 & 4.5 & 5.6 & 5.4 & 5.8 & 5.5 & 5.8 & 5.5 & 6.6 & 6.5 & 6.7 & 6.6 & 6.8 & 6.6 \\
\hline & $20 \mathrm{~cm}$ peak avg. Fast Flux (*10E15) & 4 & 4 & 4 & 4 & 4 & 4 & 4 & 4 & 4 & 4 & 4 & 4 & 4 & 4 & 4 & 4 & 4 & 4 \\
\hline
\end{tabular}




\begin{tabular}{|c|c|c|c|c|c|c|c|c|c|c|c|c|c|c|c|c|c|c|c|}
\hline & Assembly Type & \multicolumn{18}{|c|}{ A271 } \\
\hline & Core Height $(\mathrm{cm})$ & \multicolumn{6}{|c|}{60} & \multicolumn{6}{|c|}{80} & \multicolumn{6}{|c|}{100} \\
\hline & Number of Test assemblies & \multicolumn{2}{|c|}{1} & \multicolumn{2}{|c|}{4} & \multicolumn{2}{|c|}{7} & \multicolumn{2}{|c|}{1} & \multicolumn{2}{|c|}{4} & \multicolumn{2}{|c|}{7} & \multicolumn{2}{|c|}{1} & \multicolumn{2}{|c|}{4} & \multicolumn{2}{|c|}{7} \\
\hline & Average burnup (\% FIMA) & $3 \%$ & $6 \%$ & $3 \%$ & $6 \%$ & $3 \%$ & $6 \%$ & $3 \%$ & $6 \%$ & $3 \%$ & $6 \%$ & $3 \%$ & $6 \%$ & $3 \%$ & $6 \%$ & $3 \%$ & $6 \%$ & $3 \%$ & $6 \%$ \\
\hline & Number of batches & 1 & 3 & 1 & 3 & 2 & 3 & 2 & 4 & 2 & 4 & 2 & 4 & 2 & 5 & 3 & 5 & 3 & 5 \\
\hline & Cycle length (days) & 173 & 114 & 173 & 115 & 87 & 115 & 88 & 89 & 89 & 91 & 90 & 91 & 123 & 99 & 85 & 101 & 85 & 101 \\
\hline & Number of fuel assemblies & 29 & 31 & 34 & 37 & 34 & 38 & 22 & 24 & 24 & 26 & 25 & 27 & 18 & 20 & 21 & 22 & 21 & 23 \\
\hline \multirow{3}{*}{ Max. values } & Thermal Power (MW) & 140 & 151 & 164 & 179 & 163 & 183 & 139 & 149 & 149 & 158 & 155 & 164 & 102 & 113 & 115 & 121 & 115 & 127 \\
\hline & Max Assembly Power (MW) & 5.9 & 5.8 & 5.8 & 5.9 & 5.8 & 5.9 & 7.2 & 7.3 & 7.1 & 7.2 & 7.2 & 7.2 & 6.3 & 6.3 & 6.3 & 6.3 & 6.3 & 6.3 \\
\hline & $20 \mathrm{~cm}$ peak avg. Fast Flux ( $\left.{ }^{*} 10 \mathrm{E} 15\right)$ & 3.9 & 4.1 & 3.9 & 4.1 & 4.0 & 4.1 & 3.9 & 4.0 & 3.9 & 3.9 & 3.9 & 3.9 & 2.8 & 2.9 & 2.8 & 2.8 & 2.8 & 2.9 \\
\hline \multirow{3}{*}{ 5.0e15 fast flux } & Thermal Power (MW) & $\mathrm{N} / \mathrm{A}$ & $\mathrm{N} / \mathrm{A}$ & $\mathrm{N} / \mathrm{A}$ & $\mathrm{N} / \mathrm{A}$ & $\mathrm{N} / \mathrm{A}$ & $\mathrm{N} / \mathrm{A}$ & $\mathrm{N} / \mathrm{A}$ & $\mathrm{N} / \mathrm{A}$ & $\mathrm{N} / \mathrm{A}$ & $\mathrm{N} / \mathrm{A}$ & $\mathrm{N} / \mathrm{A}$ & $\mathrm{N} / \mathrm{A}$ & $\mathrm{N} / \mathrm{A}$ & $\mathrm{N} / \mathrm{A}$ & $\mathrm{N} / \mathrm{A}$ & $\mathrm{N} / \mathrm{A}$ & $\mathrm{N} / \mathrm{A}$ & $\mathrm{N} / \mathrm{A}$ \\
\hline & Max Assembly Power (MW) & $\mathrm{N} / \mathrm{A}$ & $\mathrm{N} / \mathrm{A}$ & $\mathrm{N} / \mathrm{A}$ & $\mathrm{N} / \mathrm{A}$ & N/A & $\mathrm{N} / \mathrm{A}$ & $\mathrm{N} / \mathrm{A}$ & $\mathrm{N} / \mathrm{A}$ & $\mathrm{N} / \mathrm{A}$ & $\mathrm{N} / \mathrm{A}$ & $\mathrm{N} / \mathrm{A}$ & $\mathrm{N} / \mathrm{A}$ & $\mathrm{N} / \mathrm{A}$ & $\mathrm{N} / \mathrm{A}$ & N/A & N/A & $\mathrm{N} / \mathrm{A}$ & $\mathrm{N} / \mathrm{A}$ \\
\hline & $20 \mathrm{~cm}$ peak avg. Fast Flux ( $\left.{ }^{*} 10 \mathrm{E} 15\right)$ & 5 & 5 & 5 & 5 & 5 & 5 & 5 & 5 & 5 & 5 & 5 & 5 & 5 & 5 & 5 & 5 & 5 & 5 \\
\hline \multirow{3}{*}{ 4.0e15 fast flux } & Thermal Power (MW) & $\mathrm{N} / \mathrm{A}$ & 148 & $\mathrm{~N} / \mathrm{A}$ & 174 & 163 & 177 & $\mathrm{~N} / \mathrm{A}$ & 148 & $\mathrm{~N} / \mathrm{A}$ & $\mathrm{N} / \mathrm{A}$ & $\mathrm{N} / \mathrm{A}$ & $\mathrm{N} / \mathrm{A}$ & $\mathrm{N} / \mathrm{A}$ & $\mathrm{N} / \mathrm{A}$ & $\mathrm{N} / \mathrm{A}$ & $\mathrm{N} / \mathrm{A}$ & $\mathrm{N} / \mathrm{A}$ & $\mathrm{N} / \mathrm{A}$ \\
\hline & Max Assembly Power (MW) & $\mathrm{N} / \mathrm{A}$ & 5.7 & $\mathrm{~N} / \mathrm{A}$ & 5.7 & 5.8 & 5.7 & $\mathrm{~N} / \mathrm{A}$ & 7.3 & $\mathrm{~N} / \mathrm{A}$ & $\mathrm{N} / \mathrm{A}$ & $\mathrm{N} / \mathrm{A}$ & $\mathrm{N} / \mathrm{A}$ & $\mathrm{N} / \mathrm{A}$ & $\mathrm{N} / \mathrm{A}$ & N/A & N/A & $\mathrm{N} / \mathrm{A}$ & $\mathrm{N} / \mathrm{A}$ \\
\hline & $20 \mathrm{~cm}$ peak avg. Fast Flux ( $\left.{ }^{*} 10 \mathrm{E} 15\right)$ & 4 & 4 & 4 & 4 & 4 & 4 & 4 & 4 & 4 & 4 & 4 & 4 & 4 & 4 & 4 & 4 & 4 & 4 \\
\hline
\end{tabular}

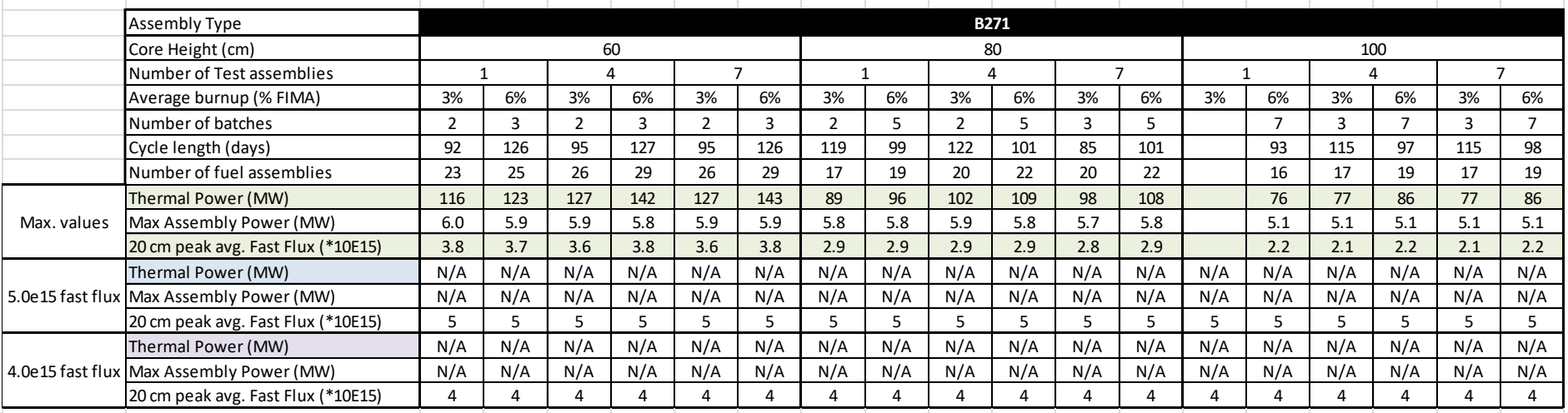

\begin{tabular}{|c|c|c|c|c|c|c|c|c|c|c|c|c|c|c|c|c|c|c|c|}
\hline & \multirow{3}{*}{\begin{tabular}{|l|} 
Assembly Type \\
Core Height (cm) \\
Number of Test assemblies \\
\end{tabular}} & \multicolumn{18}{|c|}{ C271 } \\
\hline & & \multirow{2}{*}{\multicolumn{4}{|c|}{60}} & & & \multicolumn{6}{|c|}{80} & \multicolumn{6}{|c|}{100} \\
\hline & & & & & & \multicolumn{2}{|c|}{7} & \multicolumn{2}{|c|}{1} & \multicolumn{2}{|c|}{4} & \multicolumn{2}{|c|}{7} & \multicolumn{2}{|c|}{1} & \multicolumn{2}{|c|}{4} & \multicolumn{2}{|c|}{7} \\
\hline & Average burnup (\% FIMA) & $3 \%$ & $6 \%$ & $3 \%$ & $6 \%$ & $3 \%$ & $6 \%$ & $3 \%$ & $6 \%$ & $3 \%$ & $6 \%$ & $3 \%$ & $6 \%$ & $3 \%$ & $6 \%$ & $3 \%$ & $6 \%$ & $3 \%$ & $6 \%$ \\
\hline & Number of batches & 2 & 5 & 2 & 5 & 2 & 5 & & 7 & 4 & 7 & 4 & 7 & & & & 11 & 0 & 11 \\
\hline & Cycle length (days) & 119 & 95 & 123 & 97 & 123 & 97 & & 106 & 92 & 105 & 92 & 105 & & & & 96 & 0 & 96 \\
\hline & Number of fuel assemblies & 18 & 20 & 21 & 23 & 21 & 23 & & 15 & 16 & 18 & 16 & 18 & & & & 15 & & 15 \\
\hline \multirow{3}{*}{ Max. values } & Thermal Power (MW) & 78 & 87 & 88 & 98 & 88 & 98 & & 55 & 60 & 68 & 60 & 68 & & & & 49 & & 49 \\
\hline & Max Assembly Power (MW) & 5.0 & 5.0 & 5.0 & 5.0 & 5.0 & 5.0 & & 4.0 & 4.3 & 4.2 & 4.3 & 4.3 & & & & 3.6 & & 3.6 \\
\hline & $20 \mathrm{~cm}$ peak avg. Fast Flux ( $\left.{ }^{*} 10 \mathrm{E} 15\right)$ & 2.9 & 3.0 & 2.8 & 3.0 & 2.8 & 3.0 & & 1.9 & 1.9 & 2.0 & 1.9 & 2.1 & & & & 1.4 & & 1.4 \\
\hline \multirow{3}{*}{ 5.0e15 fast flux } & Thermal Power (MW) & $\mathrm{N} / \mathrm{A}$ & $\mathrm{N} / \mathrm{A}$ & N/A & N/A & $\mathrm{N} / \mathrm{A}$ & $\mathrm{N} / \mathrm{A}$ & N/A & N/A & $\mathrm{N} / \mathrm{A}$ & $\mathrm{N} / \mathrm{A}$ & $\mathrm{N} / \mathrm{A}$ & $\mathrm{N} / \mathrm{A}$ & N/A & $\mathrm{N} / \mathrm{A}$ & $\mathrm{N} / \mathrm{A}$ & $\mathrm{N} / \mathrm{A}$ & $\mathrm{N} / \mathrm{A}$ & $\mathrm{N} / \mathrm{A}$ \\
\hline & Max Assembly Power (MW) & $\mathrm{N} / \mathrm{A}$ & $\mathrm{N} / \mathrm{A}$ & N/A & N/A & N/A & $\mathrm{N} / \mathrm{A}$ & $\mathrm{N} / \mathrm{A}$ & N/A & $\mathrm{N} / \mathrm{A}$ & N/A & $\mathrm{N} / \mathrm{A}$ & $\mathrm{N} / \mathrm{A}$ & N/A & $\mathrm{N} / \mathrm{A}$ & $\mathrm{N} / \mathrm{A}$ & N/A & N/A & $\mathrm{N} / \mathrm{A}$ \\
\hline & $20 \mathrm{~cm}$ peak avg. Fast Flux ( $\left.{ }^{*} 10 \mathrm{E} 15\right)$ & 5 & 5 & 5 & 5 & 5 & 5 & 5 & 5 & 5 & 5 & 5 & 5 & 5 & 5 & 5 & 5 & 5 & 5 \\
\hline \multirow{3}{*}{ 4.0e15 fast flux } & Thermal Power (MW) & $\mathrm{N} / \mathrm{A}$ & $\mathrm{N} / \mathrm{A}$ & N/A & N/A & $\mathrm{N} / \mathrm{A}$ & $\mathrm{N} / \mathrm{A}$ & $\mathrm{N} / \mathrm{A}$ & N/A & $\mathrm{N} / \mathrm{A}$ & $\mathrm{N} / \mathrm{A}$ & $\mathrm{N} / \mathrm{A}$ & $\mathrm{N} / \mathrm{A}$ & N/A & $\mathrm{N} / \mathrm{A}$ & $\mathrm{N} / \mathrm{A}$ & $\mathrm{N} / \mathrm{A}$ & $\mathrm{N} / \mathrm{A}$ & $\mathrm{N} / \mathrm{A}$ \\
\hline & Max Assembly Power (MW) & $\mathrm{N} / \mathrm{A}$ & N/A & N/A & N/A & N/A & $\mathrm{N} / \mathrm{A}$ & $\mathrm{N} / \mathrm{A}$ & N/A & N/A & N/A & $\mathrm{N} / \mathrm{A}$ & $\mathrm{N} / \mathrm{A}$ & N/A & $\mathrm{N} / \mathrm{A}$ & N/A & $\mathrm{N} / \mathrm{A}$ & $\mathrm{N} / \mathrm{A}$ & $\mathrm{N} / \mathrm{A}$ \\
\hline & $20 \mathrm{~cm}$ peak avg. Fast Flux ( $\left.{ }^{*} 10 \mathrm{E} 15\right)$ & 4 & 4 & 4 & 4 & 4 & 4 & 4 & 4 & 4 & 4 & 4 & 4 & 4 & 4 & 4 & 4 & 4 & \\
\hline
\end{tabular}

\begin{tabular}{|c|c|c|c|c|c|c|c|c|c|c|c|c|c|c|c|c|c|c|c|}
\hline & \multirow{4}{*}{\begin{tabular}{|l|} 
Assembly Type \\
Core Height $(\mathrm{cm})$ \\
Number of Test assemblies \\
Average burnup $(\%$ FIMA) \\
\end{tabular}} & \multicolumn{18}{|c|}{$\mathbf{Z 2 7 1}$} \\
\hline & & \multicolumn{6}{|c|}{60} & \multicolumn{6}{|c|}{80} & \multicolumn{6}{|c|}{100} \\
\hline & & & & & & & & \multicolumn{4}{|c|}{4} & \multicolumn{2}{|c|}{7} & \multicolumn{2}{|c|}{1} & \multicolumn{2}{|c|}{4} & \multicolumn{2}{|c|}{7} \\
\hline & & $3 \%$ & $6 \%$ & $3 \%$ & $6 \%$ & $3 \%$ & $6 \%$ & $3 \%$ & $6 \%$ & $3 \%$ & $6 \%$ & $3 \%$ & $6 \%$ & $3 \%$ & $6 \%$ & $3 \%$ & $6 \%$ & $3 \%$ & $6 \%$ \\
\hline & Number of batches & 1 & 2 & 1 & 2 & 1 & 3 & 1 & 2 & 1 & 2 & 1 & 3 & 2 & 3 & 2 & 3 & 2 & 3 \\
\hline & Cycle length (days) & 141 & 142 & 144 & 143 & 146 & 97 & 133 & 134 & 135 & 136 & 136 & 91 & 76 & 104 & 77 & 104 & 77 & 104 \\
\hline & Number of fuel assemblies & 46 & 51 & 54 & 60 & 56 & 61 & 32 & 36 & 38 & 41 & 38 & 41 & 26 & 29 & 29 & 33 & 29 & 33 \\
\hline \multirow{3}{*}{ Max. values } & Thermal Power (MW) & 214 & 236 & 246 & 275 & 251 & 276 & 211 & 235 & 246 & 264 & 246 & 264 & 187 & 204 & 205 & 231 & 205 & 231 \\
\hline & Max Assembly Power (MW) & 5.8 & 5.9 & 5.8 & 5.9 & 5.8 & 5.8 & 7.8 & 7.8 & 7.8 & 7.8 & 7.8 & 7.8 & 8.3 & 8.2 & 8.2 & 8.2 & 8.2 & 8.2 \\
\hline & $20 \mathrm{~cm}$ peak avg. Fast Flux (*10E15) & 4.6 & 4.7 & 4.4 & 4.6 & 4.4 & 4.6 & 4.8 & 5.0 & 4.8 & 4.9 & 4.8 & 5.0 & 4.3 & 4.3 & 4.2 & 4.3 & 4.2 & 4.3 \\
\hline \multirow{3}{*}{ 5.0e15 fast flux } & Thermal Power (MW) & $\mathrm{N} / \mathrm{A}$ & $\mathrm{N} / \mathrm{A}$ & $\mathrm{N} / \mathrm{A}$ & $\mathrm{N} / \mathrm{A}$ & N/A & $\mathrm{N} / \mathrm{A}$ & $\mathrm{N} / \mathrm{A}$ & $\mathrm{N} / \mathrm{A}$ & $\mathrm{N} / \mathrm{A}$ & $\mathrm{N} / \mathrm{A}$ & $\mathrm{N} / \mathrm{A}$ & 264 & $\mathrm{~N} / \mathrm{A}$ & $\mathrm{N} / \mathrm{A}$ & $\mathrm{N} / \mathrm{A}$ & N/A & $\mathrm{N} / \mathrm{A}$ & $\mathrm{N} / \mathrm{A}$ \\
\hline & Max Assembly Power (MW) & N/A & N/A & N/A & $\mathrm{N} / \mathrm{A}$ & N/A & N/A & N/A & N/A & N/A & N/A & N/A & 7.8 & N/A & $\mathrm{N} / \mathrm{A}$ & N/A & N/A & N/A & $\mathrm{N} / \mathrm{A}$ \\
\hline & $20 \mathrm{~cm}$ peak avg. Fast Flux (*10E15) & 5 & 5 & 5 & 5 & 5 & 5 & 5 & 5 & 5 & 5 & 5 & 5 & 5 & 5 & 5 & 5 & 5 & 5 \\
\hline \multirow{3}{*}{ 4.0e15 fast flux } & Thermal Power (MW) & 188 & 202 & 222 & 239 & 227 & 238 & 175 & 188 & 205 & 216 & 205 & 212 & 175 & 189 & 196 & 213 & 196 & 214 \\
\hline & Max Assembly Power (MW) & 5.1 & 5.0 & 5.3 & 5.1 & 5.3 & 5.0 & 6.5 & 6.2 & 6.5 & 6.4 & 6.5 & 6.3 & 7.8 & 7.6 & 7.8 & 7.6 & 7.8 & 7.6 \\
\hline & $20 \mathrm{~cm}$ peak avg. Fast Flux (*10E15) & 4 & 4 & 4 & 4 & 4 & 4 & 4 & 4 & 4 & 4 & 4 & 4 & 4 & 4 & 4 & 4 & 4 & 4 \\
\hline
\end{tabular}


U-11.5PuRG-10Zr fuel with $235 \mathrm{U} / \mathrm{U}=20 \%$

\begin{tabular}{|c|c|c|c|c|c|c|c|c|c|c|c|c|c|c|c|c|c|c|c|}
\hline & Assembly Type & \multicolumn{18}{|c|}{ A271 } \\
\hline & Core Height $(\mathrm{cm})$ & \multicolumn{6}{|c|}{60} & \multicolumn{6}{|c|}{80} & \multicolumn{6}{|c|}{100} \\
\hline & Number of Test assemblies & \multicolumn{2}{|c|}{1} & \multicolumn{2}{|c|}{4} & \multicolumn{2}{|c|}{7} & \multicolumn{2}{|c|}{1} & \multicolumn{2}{|c|}{4} & \multicolumn{2}{|c|}{7} & \multicolumn{2}{|c|}{1} & \multicolumn{2}{|c|}{4} & \multicolumn{2}{|c|}{7} \\
\hline & Average burnup (GWd/t) & 29.5 & 59 & 29.5 & 60 & 29.5 & 59 & 29.5 & 59 & 29.5 & 60 & 29.5 & 59 & 29.5 & 59 & 29.5 & 60 & 29.5 & 59 \\
\hline & Number of batches & & & & 4 & & & 2 & 5 & 2 & 5 & 2 & 4 & & & & 5 & & \\
\hline & Cycle length (days) & & & & 96 & & & 97 & 83 & 100 & 82 & 97 & 100 & & & & 104 & & \\
\hline & Number of fuel assemblies & & & & 96 & & & 48 & 57 & 57 & 66 & 60 & 66 & & & & 48 & & \\
\hline \multirow{3}{*}{ Max. values } & Thermal Power (MW) & & & & 419 & & & 276 & 309 & 320 & 359 & 335 & 371 & & & & 243 & & \\
\hline & Max Assembly Power (MW) & & & & 5.9 & & & 7.2 & 7.2 & 7.2 & 7.2 & 7.2 & 7.2 & & & & 6.3 & & \\
\hline & $20 \mathrm{~cm}$ peak avg. Fast Flux ( $\left.{ }^{*} 10 \mathrm{E} 15\right)$ & & & & 4.6 & & & 4.8 & 4.7 & 4.6 & 4.6 & 4.6 & 4.6 & & & & 3.4 & & \\
\hline \multirow{3}{*}{ 5.0e15 fast flux } & Thermal Power (MW) & $\mathrm{N} / \mathrm{A}$ & N/A & N/A & N/A & $\mathrm{N} / \mathrm{A}$ & $\mathrm{N} / \mathrm{A}$ & $\mathrm{N} / \mathrm{A}$ & $\mathrm{N} / \mathrm{A}$ & N/A & $\mathrm{N} / \mathrm{A}$ & $\mathrm{N} / \mathrm{A}$ & N/A & $\mathrm{N} / \mathrm{A}$ & $\mathrm{N} / \mathrm{A}$ & $\mathrm{N} / \mathrm{A}$ & N/A & $\mathrm{N} / \mathrm{A}$ & N/A \\
\hline & Max Assembly Power (MW) & $\mathrm{N} / \mathrm{A}$ & $\mathrm{N} / \mathrm{A}$ & $\mathrm{N} / \mathrm{A}$ & $\mathrm{N} / \mathrm{A}$ & $\mathrm{N} / \mathrm{A}$ & $\mathrm{N} / \mathrm{A}$ & $\mathrm{N} / \mathrm{A}$ & $\mathrm{N} / \mathrm{A}$ & $\mathrm{N} / \mathrm{A}$ & $\mathrm{N} / \mathrm{A}$ & $\mathrm{N} / \mathrm{A}$ & $\mathrm{N} / \mathrm{A}$ & $\mathrm{N} / \mathrm{A}$ & $\mathrm{N} / \mathrm{A}$ & $\mathrm{N} / \mathrm{A}$ & $\mathrm{N} / \mathrm{A}$ & $\mathrm{N} / \mathrm{A}$ & $\mathrm{N} / \mathrm{A}$ \\
\hline & $20 \mathrm{~cm}$ peak avg. Fast Flux ( $\left.{ }^{*} 10 \mathrm{E} 15\right)$ & 5 & 5 & 5 & 5 & 5 & 5 & 5 & 5 & 5 & 5 & 5 & 5 & 5 & 5 & 5 & 5 & 5 & 5 \\
\hline \multirow{3}{*}{ 4.0e15 fast flux } & Thermal Power (MW) & $\mathrm{N} / \mathrm{A}$ & N/A & $\mathrm{N} / \mathrm{A}$ & 364 & $\mathrm{~N} / \mathrm{A}$ & N/A & 232 & 262 & 276 & 311 & 291 & 324 & $\mathrm{~N} / \mathrm{A}$ & N/A & N/A & N/A & $\mathrm{N} / \mathrm{A}$ & $\mathrm{N} / \mathrm{A}$ \\
\hline & Max Assembly Power (MW) & $\mathrm{N} / \mathrm{A}$ & $\mathrm{N} / \mathrm{A}$ & $\mathrm{N} / \mathrm{A}$ & 5.1 & $\mathrm{~N} / \mathrm{A}$ & $\mathrm{N} / \mathrm{A}$ & 6.1 & 6.1 & 6.2 & 6.3 & 6.3 & 6.3 & $\mathrm{~N} / \mathrm{A}$ & N/A & $\mathrm{N} / \mathrm{A}$ & N/A & $\mathrm{N} / \mathrm{A}$ & $\mathrm{N} / \mathrm{A}$ \\
\hline & $20 \mathrm{~cm}$ peak avg. Fast Flux ( $\left.{ }^{*} 10 \mathrm{E} 15\right)$ & 4 & 4 & 4 & 4 & 4 & 4 & 4 & 4 & 4 & 4 & 4 & 4 & 4 & 4 & 4 & 4 & 4 & 4 \\
\hline
\end{tabular}

\begin{tabular}{|c|c|c|c|c|c|c|c|c|c|c|c|c|c|c|c|c|c|c|c|}
\hline & Assembly Type & \multicolumn{18}{|c|}{ B271 } \\
\hline & Core Height $(\mathrm{cm})$ & \multicolumn{6}{|c|}{60} & \multicolumn{6}{|c|}{80} & \multicolumn{6}{|c|}{100} \\
\hline & Number of Test assemblies & \multicolumn{2}{|c|}{1} & \multicolumn{2}{|c|}{4} & \multicolumn{2}{|c|}{7} & \multicolumn{2}{|c|}{1} & \multicolumn{2}{|c|}{4} & \multicolumn{2}{|c|}{7} & \multicolumn{2}{|c|}{1} & \multicolumn{2}{|c|}{4} & \multicolumn{2}{|c|}{7} \\
\hline & Average burnup (GWd/t) & 29.5 & 59 & 29.5 & 59 & 29.5 & 59 & 29.5 & 59 & 29.5 & 59 & 29.5 & 59 & 29.5 & 59 & 29.5 & 59 & 29.5 & 59 \\
\hline & Number of batches & & & & 4 & & & & & & 6 & & & & & & & & \\
\hline & Cycle length (days) & & & & 106 & & & & & & 91 & & & & & & & & \\
\hline & Number of fuel assemblies & & & & 72 & & & & & & 42 & & & & & & & & \\
\hline \multirow{3}{*}{ Max. values } & Thermal Power (MW) & & & & 320 & & & & & & 220 & & & & & & & & \\
\hline & Max Assembly Power (MW) & & & & 5.9 & & & & & & 5.8 & & & & & & & & \\
\hline & $20 \mathrm{~cm}$ peak avg. Fast Flux ( $\left.{ }^{*} 10 \mathrm{E} 15\right)$ & & & & 4.4 & & & & & & 3.5 & & & & & & & & \\
\hline \multirow{3}{*}{ 5.0e15 fast flux } & Thermal Power (MW) & N/A & N/A & N/A & N/A & N/A & $\mathrm{N} / \mathrm{A}$ & N/A & N/A & N/A & N/A & N/A & N/A & $\mathrm{N} / \mathrm{A}$ & $\mathrm{N} / \mathrm{A}$ & N/A & N/A & N/A & $\mathrm{N} / \mathrm{A}$ \\
\hline & Max Assembly Power (MW) & N/A & $\mathrm{N} / \mathrm{A}$ & N/A & N/A & $\mathrm{N} / \mathrm{A}$ & $\mathrm{N} / \mathrm{A}$ & $\mathrm{N} / \mathrm{A}$ & N/A & $\mathrm{N} / \mathrm{A}$ & N/A & $\mathrm{N} / \mathrm{A}$ & $\mathrm{N} / \mathrm{A}$ & $\mathrm{N} / \mathrm{A}$ & $\mathrm{N} / \mathrm{A}$ & N/A & N/A & N/A & $\mathrm{N} / \mathrm{A}$ \\
\hline & $20 \mathrm{~cm}$ peak avg. Fast Flux ( $\left.{ }^{*} 10 \mathrm{E} 15\right)$ & 5 & 5 & 5 & 5 & 5 & 5 & 5 & 5 & 5 & 5 & 5 & 5 & 5 & 5 & 5 & 5 & 5 & 5 \\
\hline \multirow{3}{*}{ 4.0e15 fast flux } & Thermal Power (MW) & $\mathrm{N} / \mathrm{A}$ & N/A & N/A & 293 & N/A & $\mathrm{N} / \mathrm{A}$ & $\mathrm{N} / \mathrm{A}$ & $\mathrm{N} / \mathrm{A}$ & N/A & N/A & $\mathrm{N} / \mathrm{A}$ & $\mathrm{N} / \mathrm{A}$ & $\mathrm{N} / \mathrm{A}$ & $\mathrm{N} / \mathrm{A}$ & N/A & N/A & N/A & $\mathrm{N} / \mathrm{A}$ \\
\hline & Max Assembly Power (MW) & N/A & N/A & N/A & 5.4 & N/A & $\mathrm{N} / \mathrm{A}$ & N/A & N/A & N/A & N/A & N/A & N/A & $\mathrm{N} / \mathrm{A}$ & $\mathrm{N} / \mathrm{A}$ & N/A & N/A & N/A & N/A \\
\hline & $20 \mathrm{~cm}$ peak avg. Fast Flux ( $\left.{ }^{*} 10 \mathrm{E} 15\right)$ & 4 & 4 & 4 & 4 & 4 & 4 & 4 & 4 & 4 & 4 & 4 & 4 & 4 & 4 & 4 & 4 & 4 & 4 \\
\hline & & & & & & & & & & & & & & & & & & & \\
\hline & & & & & & & & & & & & & & & & & & & \\
\hline & & & & & & & & & & & & & & & & & & & \\
\hline & Assembly Type & \multicolumn{18}{|c|}{ C271 } \\
\hline & Core Height $(\mathrm{cm})$ & \multirow{2}{*}{\multicolumn{4}{|c|}{$\frac{60}{4}$}} & & & \multicolumn{6}{|c|}{80} & \multicolumn{6}{|c|}{100} \\
\hline & Number of Test assemblies & & & & & \multicolumn{2}{|c|}{7} & & & & & & & & & & & & \\
\hline & Average burnup (GWd/t) & 29.5 & 59 & 29.5 & 59 & 29.5 & 59 & 29.5 & 59 & 29.5 & 59 & 29.5 & 59 & 29.5 & 59 & 29.5 & 59 & 29.5 & 59 \\
\hline & Number of batches & & & & & & & & & & 8 & & & & & & & & \\
\hline & Cycle length (days) & & & & & & & & & & 103 & & & & & & & & \\
\hline & Number of fuel assemblies & & & & & & & & & & 40 & & & & & & & & \\
\hline & Thermal Power (MW) & & & & & & & & & & 141 & & & & & & & & \\
\hline Max. values & Max Assembly Power (MW) & & & & & & & & & & 4.3 & & & & & & & & \\
\hline & $20 \mathrm{~cm}$ peak avg. Fast Flux ( $\left.{ }^{*} 10 \mathrm{E} 15\right)$ & & & & & & & & & & 2.4 & & & & & & & & \\
\hline & Thermal Power (MW) & $\mathrm{N} / \mathrm{A}$ & $\mathrm{N} / \mathrm{A}$ & N/A & N/A & $\mathrm{N} / \mathrm{A}$ & $\mathrm{N} / \mathrm{A}$ & $\mathrm{N} / \mathrm{A}$ & N/A & $\mathrm{N} / \mathrm{A}$ & N/A & $\mathrm{N} / \mathrm{A}$ & $\mathrm{N} / \mathrm{A}$ & $\mathrm{N} / \mathrm{A}$ & $\mathrm{N} / \mathrm{A}$ & N/A & N/A & N/A & $\mathrm{N} / \mathrm{A}$ \\
\hline 5.0e15 fast flux & Max Assembly Power (MW) & $\mathrm{N} / \mathrm{A}$ & $\mathrm{N} / \mathrm{A}$ & N/A & N/A & N/A & $\mathrm{N} / \mathrm{A}$ & $\mathrm{N} / \mathrm{A}$ & $\mathrm{N} / \mathrm{A}$ & $\mathrm{N} / \mathrm{A}$ & N/A & $\mathrm{N} / \mathrm{A}$ & $\mathrm{N} / \mathrm{A}$ & $\mathrm{N} / \mathrm{A}$ & $\mathrm{N} / \mathrm{A}$ & N/A & N/A & N/A & $\mathrm{N} / \mathrm{A}$ \\
\hline & $20 \mathrm{~cm}$ peak avg. Fast Flux ( $\left.{ }^{*} 10 \mathrm{E} 15\right)$ & 5 & 5 & 5 & 5 & 5 & 5 & 5 & 5 & 5 & 5 & 5 & 5 & 5 & 5 & 5 & 5 & 5 & 5 \\
\hline & Thermal Power (MW) & N/A & $\mathrm{N} / \mathrm{A}$ & $\mathrm{N} / \mathrm{A}$ & $\mathrm{N} / \mathrm{A}$ & $\mathrm{N} / \mathrm{A}$ & $\mathrm{N} / \mathrm{A}$ & $\mathrm{N} / \mathrm{A}$ & N/A & $\mathrm{N} / \mathrm{A}$ & $\mathrm{N} / \mathrm{A}$ & $\mathrm{N} / \mathrm{A}$ & $\mathrm{N} / \mathrm{A}$ & $\mathrm{N} / \mathrm{A}$ & $\mathrm{N} / \mathrm{A}$ & $\mathrm{N} / \mathrm{A}$ & $\mathrm{N} / \mathrm{A}$ & N/A & $\mathrm{N} / \mathrm{A}$ \\
\hline 4.0e15 fast flux & Max Assembly Power (MW) & N/A & $\mathrm{N} / \mathrm{A}$ & N/A & $\mathrm{N} / \mathrm{A}$ & N/A & $\mathrm{N} / \mathrm{A}$ & $\mathrm{N} / \mathrm{A}$ & N/A & $\mathrm{N} / \mathrm{A}$ & $\mathrm{N} / \mathrm{A}$ & $\mathrm{N} / \mathrm{A}$ & $\mathrm{N} / \mathrm{A}$ & $\mathrm{N} / \mathrm{A}$ & $\mathrm{N} / \mathrm{A}$ & N/A & N/A & N/A & $\mathrm{N} / \mathrm{A}$ \\
\hline & $20 \mathrm{~cm}$ peak avg. Fast Flux (*10E15) & 4 & 4 & 4 & 4 & 4 & 4 & 4 & 4 & 4 & 4 & 4 & 4 & 4 & 4 & 4 & 4 & 4 & 4 \\
\hline
\end{tabular}


U-11.5PuWG-10Zr fuel with $235 \mathrm{U} / \mathrm{U}=20 \%$

\begin{tabular}{|c|c|c|c|c|c|c|c|c|c|c|c|c|c|c|c|c|c|c|c|}
\hline & Assembly Type & \multicolumn{18}{|c|}{ A271 } \\
\hline & Core Height $(\mathrm{cm})$ & \multicolumn{6}{|c|}{60 (LHR) } & \multicolumn{6}{|c|}{80} & \multicolumn{6}{|c|}{100} \\
\hline & Number of Test assemblies & \multicolumn{2}{|c|}{1} & \multicolumn{2}{|c|}{4} & \multicolumn{2}{|c|}{7} & \multicolumn{2}{|c|}{1} & \multicolumn{2}{|c|}{4} & \multicolumn{2}{|c|}{7} & \multicolumn{2}{|c|}{1} & \multicolumn{2}{|c|}{4} & \multicolumn{2}{|c|}{7} \\
\hline & Average burnup (\% FIMA) & $3 \%$ & $6 \%$ & $3 \%$ & $6 \%$ & $3 \%$ & $6 \%$ & $3 \%$ & $6 \%$ & $3 \%$ & $6 \%$ & $3 \%$ & $6 \%$ & $3 \%$ & $6 \%$ & $3 \%$ & $6 \%$ & $3 \%$ & $6 \%$ \\
\hline & Number of batches & & & & 4 & & & & & & 4 & & & & & & 5 & & \\
\hline & Cycle length (days) & & & & 94 & & & & & & 101 & & & & & & 106 & & \\
\hline & Number of fuel assemblies & & & & 75 & & & & & & 54 & & & & & & 39 & & \\
\hline \multirow{3}{*}{ Max. values } & Thermal Power (MW) & & & & 336 & & & & & & 299 & & & & & & 207 & & \\
\hline & Max Assembly Power (MW) & & & & 5.9 & & & & & & 7.2 & & & & & & 6.3 & & \\
\hline & $20 \mathrm{~cm}$ peak avg. Fast Flux (*10E15) & & & & 4.5 & & & & & & 4.4 & & & & & & 3.2 & & \\
\hline \multirow{3}{*}{$5.0 \mathrm{e} 15$ fast flux } & Thermal Power (MW) & $\mathrm{N} / \mathrm{A}$ & $\mathrm{N} / \mathrm{A}$ & $\mathrm{N} / \mathrm{A}$ & $\mathrm{N} / \mathrm{A}$ & $\mathrm{N} / \mathrm{A}$ & $\mathrm{N} / \mathrm{A}$ & $\mathrm{N} / \mathrm{A}$ & $\mathrm{N} / \mathrm{A}$ & $\mathrm{N} / \mathrm{A}$ & $\mathrm{N} / \mathrm{A}$ & $\mathrm{N} / \mathrm{A}$ & $\mathrm{N} / \mathrm{A}$ & $\mathrm{N} / \mathrm{A}$ & $\mathrm{N} / \mathrm{A}$ & $\mathrm{N} / \mathrm{A}$ & $\mathrm{N} / \mathrm{A}$ & $\mathrm{N} / \mathrm{A}$ & $\mathrm{N} / \mathrm{A}$ \\
\hline & Max Assembly Power (MW) & $\mathrm{N} / \mathrm{A}$ & $\mathrm{N} / \mathrm{A}$ & $\mathrm{N} / \mathrm{A}$ & $\mathrm{N} / \mathrm{A}$ & $\mathrm{N} / \mathrm{A}$ & $\mathrm{N} / \mathrm{A}$ & $\mathrm{N} / \mathrm{A}$ & $\mathrm{N} / \mathrm{A}$ & N/A & $\mathrm{N} / \mathrm{A}$ & $\mathrm{N} / \mathrm{A}$ & $\mathrm{N} / \mathrm{A}$ & $\mathrm{N} / \mathrm{A}$ & $\mathrm{N} / \mathrm{A}$ & $\mathrm{N} / \mathrm{A}$ & N/A & $\mathrm{N} / \mathrm{A}$ & $\mathrm{N} / \mathrm{A}$ \\
\hline & $20 \mathrm{~cm}$ peak avg. Fast Flux ( $\left.{ }^{*} 10 \mathrm{E} 15\right)$ & 5 & 5 & 5 & 5 & 5 & 5 & 5 & 5 & 5 & 5 & 5 & 5 & 5 & 5 & 5 & 5 & 5 & 5 \\
\hline \multirow{3}{*}{ 4.0e15 fast flux } & Thermal Power (MW) & $\mathrm{N} / \mathrm{A}$ & $\mathrm{N} / \mathrm{A}$ & $\mathrm{N} / \mathrm{A}$ & 302 & $\mathrm{~N} / \mathrm{A}$ & $\mathrm{N} / \mathrm{A}$ & $\mathrm{N} / \mathrm{A}$ & $\mathrm{N} / \mathrm{A}$ & N/A & 272 & $\mathrm{~N} / \mathrm{A}$ & $\mathrm{N} / \mathrm{A}$ & $\mathrm{N} / \mathrm{A}$ & $\mathrm{N} / \mathrm{A}$ & $\mathrm{N} / \mathrm{A}$ & N/A & $\mathrm{N} / \mathrm{A}$ & $\mathrm{N} / \mathrm{A}$ \\
\hline & Max Assembly Power (MW) & $\mathrm{N} / \mathrm{A}$ & $\mathrm{N} / \mathrm{A}$ & $\mathrm{N} / \mathrm{A}$ & 5.3 & $\mathrm{~N} / \mathrm{A}$ & $\mathrm{N} / \mathrm{A}$ & $\mathrm{N} / \mathrm{A}$ & $\mathrm{N} / \mathrm{A}$ & N/A & 6.6 & $\mathrm{~N} / \mathrm{A}$ & $\mathrm{N} / \mathrm{A}$ & $\mathrm{N} / \mathrm{A}$ & $\mathrm{N} / \mathrm{A}$ & $\mathrm{N} / \mathrm{A}$ & N/A & $\mathrm{N} / \mathrm{A}$ & $\mathrm{N} / \mathrm{A}$ \\
\hline & $20 \mathrm{~cm}$ peak avg. Fast Flux (*10E15) & 4 & 4 & 4 & 4 & 4 & 4 & 4 & 4 & 4 & 4 & 4 & 4 & 4 & 4 & 4 & 4 & 4 & 4 \\
\hline
\end{tabular}


U-10Zr fuel with $235 \mathrm{U} / \mathrm{U}=19.75 \%$

\begin{tabular}{|c|c|c|c|c|c|c|c|c|c|c|c|c|c|c|c|c|c|c|c|}
\hline & Assembly Type & \multicolumn{18}{|c|}{ A271 } \\
\hline & Core Height $(\mathrm{cm})$ & \multicolumn{6}{|c|}{60} & \multicolumn{6}{|c|}{80} & \multicolumn{6}{|c|}{100} \\
\hline & Number of Test assemblies & \multicolumn{2}{|c|}{1} & \multicolumn{2}{|c|}{4} & \multicolumn{2}{|c|}{7} & \multicolumn{2}{|c|}{1} & \multicolumn{2}{|c|}{4} & \multicolumn{2}{|c|}{7} & \multicolumn{2}{|c|}{1} & \multicolumn{2}{|c|}{4} & \multicolumn{2}{|c|}{7} \\
\hline & Average burnup (\% FIMA) & $3 \%$ & $6 \%$ & $3 \%$ & $6 \%$ & $3 \%$ & $6 \%$ & $3 \%$ & $6 \%$ & $3 \%$ & $6 \%$ & $3 \%$ & $6 \%$ & $3 \%$ & $6 \%$ & $3 \%$ & $6 \%$ & $3 \%$ & $6 \%$ \\
\hline & Number of batches & & & & & & & 2 & & 2 & & & & 3 & 6 & 3 & 6 & 3 & 6 \\
\hline & Cycle length (days) & & & & & & & 111 & & 108 & & & & 102 & 101 & 100 & 99 & 101 & 99 \\
\hline & Number of fuel assemblies & & & & & & & 222 & & 230 & & & & 149 & 174 & 157 & 182 & 166 & 190 \\
\hline \multirow{3}{*}{ Max. values } & Thermal Power (MW) & & & & & & & 1093 & & 1161 & & & & 661 & 785 & 712 & 835 & 749 & 869 \\
\hline & Max Assembly Power (MW) & & & & & & & 7.2 & & 7.2 & & & & 6.3 & 6.3 & 6.3 & 6.3 & 6.3 & 6.3 \\
\hline & $20 \mathrm{~cm}$ peak avg. Fast Flux ( $\left.{ }^{*} 10 \mathrm{E} 15\right)$ & & & & & & & 5.7 & & 5.5 & & & & 4.3 & 4.4 & 4.1 & 4.3 & 4.1 & 4.2 \\
\hline \multirow{3}{*}{$5.0 \mathrm{e} 15$ fast flux } & Thermal Power (MW) & $\mathrm{N} / \mathrm{A}$ & $\mathrm{N} / \mathrm{A}$ & $\mathrm{N} / \mathrm{A}$ & $\mathrm{N} / \mathrm{A}$ & $\mathrm{N} / \mathrm{A}$ & $\mathrm{N} / \mathrm{A}$ & 951 & $\mathrm{~N} / \mathrm{A}$ & 1056 & $\mathrm{~N} / \mathrm{A}$ & $\mathrm{N} / \mathrm{A}$ & $\mathrm{N} / \mathrm{A}$ & $\mathrm{N} / \mathrm{A}$ & $\mathrm{N} / \mathrm{A}$ & $\mathrm{N} / \mathrm{A}$ & $\mathrm{N} / \mathrm{A}$ & $\mathrm{N} / \mathrm{A}$ & $\mathrm{N} / \mathrm{A}$ \\
\hline & Max Assembly Power (MW) & $\mathrm{N} / \mathrm{A}$ & $\mathrm{N} / \mathrm{A}$ & $\mathrm{N} / \mathrm{A}$ & $\mathrm{N} / \mathrm{A}$ & $\mathrm{N} / \mathrm{A}$ & $\mathrm{N} / \mathrm{A}$ & 6.3 & $\mathrm{~N} / \mathrm{A}$ & 6.6 & $\mathrm{~N} / \mathrm{A}$ & $\mathrm{N} / \mathrm{A}$ & $\mathrm{N} / \mathrm{A}$ & $\mathrm{N} / \mathrm{A}$ & $\mathrm{N} / \mathrm{A}$ & $\mathrm{N} / \mathrm{A}$ & $\mathrm{N} / \mathrm{A}$ & $\mathrm{N} / \mathrm{A}$ & $\mathrm{N} / \mathrm{A}$ \\
\hline & $20 \mathrm{~cm}$ peak avg. Fast Flux ( $\left.{ }^{*} 10 \mathrm{E} 15\right)$ & 5 & 5 & 5 & 5 & 5 & 5 & 5 & 5 & 5 & 5 & 5 & 5 & 5 & 5 & 5 & 5 & 5 & 5 \\
\hline \multirow{3}{*}{ 4.0e 15 fast flux } & Thermal Power (MW) & $\mathrm{N} / \mathrm{A}$ & $\mathrm{N} / \mathrm{A}$ & $\mathrm{N} / \mathrm{A}$ & $\mathrm{N} / \mathrm{A}$ & $\mathrm{N} / \mathrm{A}$ & $\mathrm{N} / \mathrm{A}$ & 761 & $\mathrm{~N} / \mathrm{A}$ & 845 & $\mathrm{~N} / \mathrm{A}$ & $\mathrm{N} / \mathrm{A}$ & $\mathrm{N} / \mathrm{A}$ & 614 & 706 & 690 & 785 & 728 & 821 \\
\hline & Max Assembly Power (MW) & $\mathrm{N} / \mathrm{A}$ & $\mathrm{N} / \mathrm{A}$ & $\mathrm{N} / \mathrm{A}$ & $\mathrm{N} / \mathrm{A}$ & N/A & $\mathrm{N} / \mathrm{A}$ & 5.0 & $\mathrm{~N} / \mathrm{A}$ & 5.2 & $\mathrm{~N} / \mathrm{A}$ & $\mathrm{N} / \mathrm{A}$ & $\mathrm{N} / \mathrm{A}$ & 5.9 & 5.7 & 6.1 & 6.0 & 6.2 & 6.0 \\
\hline & $20 \mathrm{~cm}$ peak avg. Fast Flux (*10E15) & 4 & 4 & 4 & 4 & 4 & 4 & 4 & 4 & 4 & 4 & 4 & 4 & 4 & 4 & 4 & 4 & 4 & 4 \\
\hline
\end{tabular}

\begin{tabular}{|c|c|c|c|c|c|c|c|c|c|c|c|c|c|c|c|c|c|c|c|}
\hline & Assembly Type & \multicolumn{18}{|c|}{ B271 } \\
\hline & Core Height $(\mathrm{cm})$ & \multicolumn{6}{|c|}{60} & \multicolumn{6}{|c|}{80} & \multicolumn{6}{|c|}{100} \\
\hline & Number of Test assemblies & \multicolumn{2}{|c|}{1} & \multicolumn{2}{|c|}{4} & \multicolumn{2}{|c|}{7} & \multicolumn{2}{|c|}{1} & \multicolumn{2}{|c|}{4} & \multicolumn{2}{|c|}{7} & \multicolumn{2}{|c|}{1} & \multicolumn{2}{|c|}{4} & \multicolumn{2}{|c|}{7} \\
\hline & Average burnup (\% FIMA) & $3 \%$ & $6 \%$ & $3 \%$ & $6 \%$ & $3 \%$ & $6 \%$ & $3 \%$ & $6 \%$ & $3 \%$ & $6 \%$ & $3 \%$ & $6 \%$ & $3 \%$ & $6 \%$ & $3 \%$ & $6 \%$ & $3 \%$ & $6 \%$ \\
\hline & Number of batches & & & & & & & 3 & 6 & 3 & 6 & 3 & 6 & 4 & 8 & 4 & 8 & 4 & 8 \\
\hline & Cycle length (days) & & & & & & & 101 & 99 & 98 & 96 & 98 & 97 & 105 & 104 & 103 & 103 & 104 & 103 \\
\hline & Number of fuel assemblies & & & & & & & 157 & 182 & 166 & 190 & 174 & 207 & 110 & 126 & 118 & 135 & 126 & 143 \\
\hline \multirow{3}{*}{ Max. values } & Thermal Power (MW) & & & & & & & 628 & 745 & 688 & 800 & 721 & 865 & 399 & 460 & 434 & 501 & 460 & 527 \\
\hline & Max Assembly Power (MW) & & & & & & & 5.8 & 5.8 & 5.8 & 5.8 & 5.8 & 5.8 & 5.1 & 5.1 & 5.1 & 5.1 & 5.1 & 5.1 \\
\hline & $20 \mathrm{~cm}$ peak avg. Fast Flux ( $\left.{ }^{*} 10 \mathrm{E} 15\right)$ & & & & & & & 4.4 & 4.5 & 4.2 & 4.3 & 4.2 & 4.3 & 3.2 & 3.4 & 3.1 & 3.2 & 3.1 & 3.2 \\
\hline \multirow{3}{*}{ 5.0e15 fast flux } & Thermal Power (MW) & $\mathrm{N} / \mathrm{A}$ & N/A & N/A & N/A & N/A & N/A & N/A & N/A & N/A & $\mathrm{N} / \mathrm{A}$ & N/A & N/A & N/A & N/A & N/A & N/A & $\mathrm{N} / \mathrm{A}$ & N/A \\
\hline & Max Assembly Power (MW) & N/A & $\mathrm{N} / \mathrm{A}$ & N/A & N/A & N/A & N/A & N/A & $\mathrm{N} / \mathrm{A}$ & $\mathrm{N} / \mathrm{A}$ & $\mathrm{N} / \mathrm{A}$ & $\mathrm{N} / \mathrm{A}$ & N/A & N/A & $\mathrm{N} / \mathrm{A}$ & $\mathrm{N} / \mathrm{A}$ & N/A & $\mathrm{N} / \mathrm{A}$ & $\mathrm{N} / \mathrm{A}$ \\
\hline & $20 \mathrm{~cm}$ peak avg. Fast Flux ( $\left.{ }^{*} 10 \mathrm{E} 15\right)$ & 5 & 5 & 5 & 5 & 5 & 5 & 5 & 5 & 5 & 5 & 5 & 5 & 5 & 5 & 5 & 5 & 5 & 5 \\
\hline \multirow{3}{*}{ 4.0e15 fast flux } & Thermal Power (MW) & N/A & $\mathrm{N} / \mathrm{A}$ & $\mathrm{N} / \mathrm{A}$ & N/A & N/A & $\mathrm{N} / \mathrm{A}$ & 574 & 661 & 654 & 740 & 687 & 802 & N/A & $\mathrm{N} / \mathrm{A}$ & N/A & N/A & $\mathrm{N} / \mathrm{A}$ & $\mathrm{N} / \mathrm{A}$ \\
\hline & Max Assembly Power (MW) & $\mathrm{N} / \mathrm{A}$ & $\mathrm{N} / \mathrm{A}$ & N/A & N/A & N/A & N/A & 5.3 & 5.1 & 5.5 & 5.3 & 5.5 & 5.3 & N/A & $\mathrm{N} / \mathrm{A}$ & $\mathrm{N} / \mathrm{A}$ & $\mathrm{N} / \mathrm{A}$ & $\mathrm{N} / \mathrm{A}$ & $\mathrm{N} / \mathrm{A}$ \\
\hline & $20 \mathrm{~cm}$ peak avg. Fast Flux ( $\left.{ }^{*} 10 \mathrm{E} 15\right)$ & 4 & 4 & 4 & 4 & 4 & 4 & 4 & 4 & 4 & 4 & 4 & 4 & 4 & 4 & 4 & 4 & 4 & 4 \\
\hline & & & & & & & & & & & & & & & & & & & \\
\hline & & & & & & & & & & & & & & & & & & & \\
\hline & & & & & & & & & & & & & & & & & & & \\
\hline & Assembly Type & \multicolumn{18}{|c|}{ C271 } \\
\hline & Core Height $(\mathrm{cm})$ & \multicolumn{4}{|c|}{60} & & & \multicolumn{6}{|c|}{80} & \multicolumn{6}{|c|}{100} \\
\hline & Number of Test assemblies & \multicolumn{2}{|c|}{1} & \multicolumn{2}{|c|}{4} & & & & & & & & & & & & & & \\
\hline & Average burnup (\% FIMA) & $3 \%$ & $6 \%$ & $3 \%$ & $6 \%$ & $3 \%$ & $6 \%$ & $3 \%$ & $6 \%$ & $3 \%$ & $6 \%$ & $3 \%$ & $6 \%$ & $3 \%$ & $6 \%$ & $3 \%$ & $6 \%$ & $3 \%$ & $6 \%$ \\
\hline & Number of batches & 3 & 6 & 3 & & 3 & & 4 & 9 & 4 & 9 & 4 & 9 & 6 & 12 & 6 & 12 & 6 & 12 \\
\hline & Cycle length (days) & 96 & 94 & 92 & & 92 & & 112 & 99 & 110 & 96 & 111 & 97 & 103 & 103 & 102 & 101 & 103 & 102 \\
\hline & Number of fuel assemblies & 198 & 238 & 214 & & 230 & & 111 & 134 & 126 & 143 & 134 & 149 & 85 & 95 & 94 & 103 & 94 & 110 \\
\hline & Thermal Power (MW) & 699 & 854 & 783 & & 843 & & 336 & 407 & 387 & 446 & 408 & 463 & 231 & 261 & 258 & 286 & 257 & 302 \\
\hline Max. values & Max Assembly Power (MW) & 5.0 & 5.0 & 5.0 & & 5.0 & & 4.3 & 4.3 & 4.3 & 4.3 & 4.3 & 4.3 & 3.7 & 3.7 & 3.7 & 3.7 & 3.7 & 3.7 \\
\hline & $20 \mathrm{~cm}$ peak avg. Fast Flux ( $\left.{ }^{*} 10 \mathrm{E} 15\right)$ & 4.4 & 4.5 & 4.2 & & 4.2 & & 3.0 & 3.2 & 2.9 & 3.0 & 2.9 & 3.0 & 2.3 & 2.3 & 2.2 & 2.2 & 2.2 & 2.2 \\
\hline & Thermal Power (MW) & N/A & $\mathrm{N} / \mathrm{A}$ & $\mathrm{N} / \mathrm{A}$ & N/A & N/A & N/A & $\mathrm{N} / \mathrm{A}$ & N/A & $\mathrm{N} / \mathrm{A}$ & $\mathrm{N} / \mathrm{A}$ & $\mathrm{N} / \mathrm{A}$ & $\mathrm{N} / \mathrm{A}$ & N/A & $\mathrm{N} / \mathrm{A}$ & N/A & N/A & $\mathrm{N} / \mathrm{A}$ & N/A \\
\hline 5.0e 15 fast flux & Max Assembly Power (MW) & $\mathrm{N} / \mathrm{A}$ & N/A & N/A & N/A & N/A & N/A & N/A & N/A & N/A & N/A & N/A & N/A & N/A & $\mathrm{N} / \mathrm{A}$ & N/A & N/A & $\mathrm{N} / \mathrm{A}$ & N/A \\
\hline & $20 \mathrm{~cm}$ peak avg. Fast Flux $\left({ }^{*} 10 \mathrm{E} 15\right)$ & 5 & 5 & 5 & 5 & 5 & 5 & 5 & 5 & 5 & 5 & 5 & 5 & 5 & 5 & 5 & 5 & 5 & 5 \\
\hline & Thermal Power (MW) & 634 & 754 & 739 & N/A & 798 & $\mathrm{~N} / \mathrm{A}$ & $\mathrm{N} / \mathrm{A}$ & $\mathrm{N} / \mathrm{A}$ & $\mathrm{N} / \mathrm{A}$ & $\mathrm{N} / \mathrm{A}$ & $\mathrm{N} / \mathrm{A}$ & N/A & N/A & $\mathrm{N} / \mathrm{A}$ & $\mathrm{N} / \mathrm{A}$ & $\mathrm{N} / \mathrm{A}$ & $\mathrm{N} / \mathrm{A}$ & $\mathrm{N} / \mathrm{A}$ \\
\hline 4.0e15 fast flux & Max Assembly Power (MW) & 4.6 & 4.4 & 4.7 & N/A & 4.8 & N/A & N/A & $\mathrm{N} / \mathrm{A}$ & $\mathrm{N} / \mathrm{A}$ & $\mathrm{N} / \mathrm{A}$ & $\mathrm{N} / \mathrm{A}$ & N/A & N/A & $\mathrm{N} / \mathrm{A}$ & N/A & N/A & $\mathrm{N} / \mathrm{A}$ & N/A \\
\hline & $20 \mathrm{~cm}$ peak avg. Fast Flux ( $\left.{ }^{*} 10 \mathrm{E} 15\right)$ & 4 & 4 & 4 & 4 & 4 & 4 & 4 & 4 & 4 & 4 & 4 & 4 & 4 & 4 & 4 & 4 & 4 & 4 \\
\hline
\end{tabular}


U-10Zr fuel with $235 \mathrm{U} / \mathrm{U}=27 \%$

\begin{tabular}{|c|c|c|c|c|c|c|c|c|c|c|c|c|c|c|c|c|c|c|c|}
\hline & Assembly Type & \multicolumn{18}{|c|}{ A271 } \\
\hline & Core Height $(\mathrm{cm})$ & \multicolumn{6}{|c|}{60} & \multicolumn{6}{|c|}{80} & \multicolumn{6}{|c|}{100} \\
\hline & Number of Test assemblies & \multicolumn{2}{|c|}{1} & \multicolumn{2}{|c|}{4} & \multicolumn{2}{|c|}{7} & \multicolumn{2}{|c|}{1} & \multicolumn{2}{|c|}{4} & \multicolumn{2}{|c|}{7} & \multicolumn{2}{|c|}{1} & \multicolumn{2}{|c|}{4} & \multicolumn{2}{|c|}{7} \\
\hline & Average burnup (\% FIMA) & $3 \%$ & $6 \%$ & $3 \%$ & $6 \%$ & $3 \%$ & $6 \%$ & $3 \%$ & $6 \%$ & $3 \%$ & $6 \%$ & $3 \%$ & $6 \%$ & $3 \%$ & $6 \%$ & $3 \%$ & $6 \%$ & $3 \%$ & $6 \%$ \\
\hline & Number of batches & 2 & 3 & 2 & 3 & 2 & 3 & 2 & 4 & 2 & 4 & 2 & 4 & 3 & 6 & 3 & 6 & 3 & 6 \\
\hline & Cycle length (days) & 98 & 129 & 95 & 125 & 95 & 125 & 101 & 101 & 100 & 100 & 101 & 101 & 94 & 94 & 94 & 92 & 95 & 93 \\
\hline & Number of fuel assemblies & 134 & 165 & 143 & 173 & 151 & 182 & 83 & 94 & 91 & 102 & 94 & 109 & 62 & 71 & 70 & 78 & 71 & 79 \\
\hline \multirow{3}{*}{ Max. values } & Thermal Power (MW) & 560 & 699 & 616 & 756 & 646 & 795 & 448 & 507 & 494 & 556 & 506 & 591 & 300 & 342 & 337 & 384 & 340 & 386 \\
\hline & Max Assembly Power (MW) & 5.9 & 5.9 & 5.9 & 5.9 & 5.9 & 5.9 & 7.2 & 7.2 & 7.2 & 7.2 & 7.2 & 7.2 & 6.3 & 6.3 & 6.3 & 6.5 & 6.3 & 6.3 \\
\hline & $20 \mathrm{~cm}$ peak avg. Fast Flux ( $\left.{ }^{*} 10 \mathrm{E} 15\right)$ & 5.0 & 5.1 & 4.8 & 4.9 & 4.8 & 4.9 & 5.0 & 5.2 & 4.8 & 5.0 & 4.8 & 5.0 & 3.7 & 3.8 & 3.6 & 3.8 & 3.6 & 3.7 \\
\hline \multirow{3}{*}{$5.0 \mathrm{e} 15$ fast flux } & Thermal Power (MW) & $\mathrm{N} / \mathrm{A}$ & 684 & $\mathrm{~N} / \mathrm{A}$ & $\mathrm{N} / \mathrm{A}$ & $\mathrm{N} / \mathrm{A}$ & $\mathrm{N} / \mathrm{A}$ & 446 & 491 & $\mathrm{~N} / \mathrm{A}$ & $\mathrm{N} / \mathrm{A}$ & $\mathrm{N} / \mathrm{A}$ & $\mathrm{N} / \mathrm{A}$ & $\mathrm{N} / \mathrm{A}$ & $\mathrm{N} / \mathrm{A}$ & $\mathrm{N} / \mathrm{A}$ & $\mathrm{N} / \mathrm{A}$ & $\mathrm{N} / \mathrm{A}$ & $\mathrm{N} / \mathrm{A}$ \\
\hline & Max Assembly Power (MW) & $\mathrm{N} / \mathrm{A}$ & 5.7 & N/A & $\mathrm{N} / \mathrm{A}$ & N/A & N/A & 7.2 & 7.0 & $\mathrm{~N} / \mathrm{A}$ & N/A & N/A & N/A & N/A & $\mathrm{N} / \mathrm{A}$ & $\mathrm{N} / \mathrm{A}$ & $\mathrm{N} / \mathrm{A}$ & N/A & N/A \\
\hline & $20 \mathrm{~cm}$ peak avg. Fast Flux ( $\left.{ }^{*} 10 \mathrm{E} 15\right)$ & 5 & 5 & 5 & 5 & 5 & 5 & 5 & 5 & 5 & 5 & 5 & 5 & 5 & 5 & 5 & 5 & 5 & 5 \\
\hline \multirow{3}{*}{ 4.0e15 fast flux } & Thermal Power (MW) & 449 & 547 & 513 & 617 & 539 & 651 & 356 & 393 & 408 & 448 & 420 & 474 & $\mathrm{~N} / \mathrm{A}$ & $\mathrm{N} / \mathrm{A}$ & $\mathrm{N} / \mathrm{A}$ & $\mathrm{N} / \mathrm{A}$ & $\mathrm{N} / \mathrm{A}$ & $\mathrm{N} / \mathrm{A}$ \\
\hline & Max Assembly Power (MW) & 4.7 & 4.6 & 4.9 & 4.8 & 4.9 & 4.8 & 5.7 & 5.6 & 6.0 & 5.8 & 6.0 & 5.8 & $\mathrm{~N} / \mathrm{A}$ & $\mathrm{N} / \mathrm{A}$ & $\mathrm{N} / \mathrm{A}$ & $\mathrm{N} / \mathrm{A}$ & $\mathrm{N} / \mathrm{A}$ & $\mathrm{N} / \mathrm{A}$ \\
\hline & $20 \mathrm{~cm}$ peak avg. Fast Flux ( $\left.{ }^{*} 10 \mathrm{E} 15\right)$ & 4 & 4 & 4 & 4 & 4 & 4 & 4 & 4 & 4 & 4 & 4 & 4 & 4 & 4 & 4 & 4 & 4 & 4 \\
\hline
\end{tabular}

\begin{tabular}{|c|c|c|c|c|c|c|c|c|c|c|c|c|c|c|c|c|c|c|c|}
\hline & Assembly Type & \multicolumn{18}{|c|}{ B271 } \\
\hline & Core Height $(\mathrm{cm})$ & \multicolumn{6}{|c|}{60} & \multicolumn{6}{|c|}{80} & \multicolumn{6}{|c|}{100} \\
\hline & Number of Test assemblies & \multicolumn{2}{|c|}{1} & \multicolumn{2}{|c|}{ 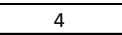 } & \multicolumn{2}{|c|}{7} & \multicolumn{2}{|c|}{1} & \multicolumn{2}{|c|}{4} & \multicolumn{2}{|c|}{7} & \multicolumn{2}{|c|}{1} & \multicolumn{2}{|c|}{4} & \multicolumn{2}{|c|}{7} \\
\hline & Average burnup (\% FIMA) & $3 \%$ & $6 \%$ & $3 \%$ & $6 \%$ & $3 \%$ & $6 \%$ & $3 \%$ & $6 \%$ & $3 \%$ & $6 \%$ & $3 \%$ & $6 \%$ & $3 \%$ & $6 \%$ & $3 \%$ & $6 \%$ & $3 \%$ & $6 \%$ \\
\hline & Number of batches & 2 & 4 & 2 & 4 & 2 & 4 & 3 & 6 & 3 & 5 & 3 & 6 & 4 & 8 & 4 & 8 & 4 & 8 \\
\hline & Cycle length (days) & 107 & 106 & 104 & 103 & 106 & 104 & 94 & 94 & 93 & 109 & 95 & 93 & 95 & 96 & 96 & 97 & 97 & 97 \\
\hline & Number of fuel assemblies & 100 & 117 & 109 & 126 & 116 & 134 & 63 & 72 & 70 & 79 & 73 & 81 & 48 & 55 & 55 & 62 & 56 & 64 \\
\hline \multirow{3}{*}{ Max. values } & Thermal Power (MW) & 427 & 502 & 478 & 556 & 500 & 587 & 273 & 311 & 304 & 351 & 313 & 355 & 192 & 217 & 218 & 244 & 219 & 250 \\
\hline & Max Assembly Power (MW) & 5.9 & 5.9 & 5.9 & 5.9 & 5.9 & 5.9 & 5.8 & 5.8 & 5.8 & 5.8 & 5.8 & 5.8 & 5.1 & 5.1 & 5.1 & 5.1 & 5.1 & 5.1 \\
\hline & $20 \mathrm{~cm}$ peak avg. Fast Flux ( $\left.{ }^{*} 10 \mathrm{E} 15\right)$ & 4.7 & 4.9 & 4.6 & 4.7 & 4.5 & 4.7 & 3.8 & 3.9 & 3.6 & 3.8 & 3.6 & 3.7 & 2.8 & 2.9 & 2.7 & 2.8 & 2.7 & 2.8 \\
\hline \multirow{3}{*}{ 5.0e15 fast flux } & Thermal Power (MW) & $\mathrm{N} / \mathrm{A}$ & $\mathrm{N} / \mathrm{A}$ & $\mathrm{N} / \mathrm{A}$ & $\mathrm{N} / \mathrm{A}$ & N/A & $\mathrm{N} / \mathrm{A}$ & $\mathrm{N} / \mathrm{A}$ & $\mathrm{N} / \mathrm{A}$ & $\mathrm{N} / \mathrm{A}$ & $\mathrm{N} / \mathrm{A}$ & $\mathrm{N} / \mathrm{A}$ & $\mathrm{N} / \mathrm{A}$ & $\mathrm{N} / \mathrm{A}$ & $\mathrm{N} / \mathrm{A}$ & N/A & N/A & $\mathrm{N} / \mathrm{A}$ & $\mathrm{N} / \mathrm{A}$ \\
\hline & Max Assembly Power (MW) & $\mathrm{N} / \mathrm{A}$ & $\mathrm{N} / \mathrm{A}$ & $\mathrm{N} / \mathrm{A}$ & $\mathrm{N} / \mathrm{A}$ & N/A & $\mathrm{N} / \mathrm{A}$ & $\mathrm{N} / \mathrm{A}$ & N/A & $\mathrm{N} / \mathrm{A}$ & $\mathrm{N} / \mathrm{A}$ & $\mathrm{N} / \mathrm{A}$ & $\mathrm{N} / \mathrm{A}$ & $\mathrm{N} / \mathrm{A}$ & $\mathrm{N} / \mathrm{A}$ & N/A & N/A & N/A & $\mathrm{N} / \mathrm{A}$ \\
\hline & $20 \mathrm{~cm}$ peak avg. Fast Flux ( $\left.{ }^{*} 10 \mathrm{E} 15\right)$ & 5 & 5 & 5 & 5 & 5 & 5 & 5 & 5 & 5 & 5 & 5 & 5 & 5 & 5 & 5 & 5 & 5 & 5 \\
\hline \multirow{3}{*}{ 4.0e15 fast flux } & Thermal Power (MW) & 361 & 412 & 419 & 473 & 440 & 501 & $\mathrm{~N} / \mathrm{A}$ & $\mathrm{N} / \mathrm{A}$ & $\mathrm{N} / \mathrm{A}$ & $\mathrm{N} / \mathrm{A}$ & $\mathrm{N} / \mathrm{A}$ & $\mathrm{N} / \mathrm{A}$ & $\mathrm{N} / \mathrm{A}$ & $\mathrm{N} / \mathrm{A}$ & N/A & N/A & $\mathrm{N} / \mathrm{A}$ & $\mathrm{N} / \mathrm{A}$ \\
\hline & Max Assembly Power (MW) & 5.0 & 4.8 & 5.1 & 5.0 & 5.2 & 5.0 & $\mathrm{~N} / \mathrm{A}$ & $\mathrm{N} / \mathrm{A}$ & $\mathrm{N} / \mathrm{A}$ & $\mathrm{N} / \mathrm{A}$ & $\mathrm{N} / \mathrm{A}$ & $\mathrm{N} / \mathrm{A}$ & $\mathrm{N} / \mathrm{A}$ & $\mathrm{N} / \mathrm{A}$ & N/A & N/A & $\mathrm{N} / \mathrm{A}$ & $\mathrm{N} / \mathrm{A}$ \\
\hline & $20 \mathrm{~cm}$ peak avg. Fast Flux ( $\left.{ }^{*} 10 \mathrm{E} 15\right)$ & 4 & 4 & 4 & 4 & 4 & 4 & 4 & 4 & 4 & 4 & 4 & 4 & 4 & 4 & 4 & 4 & 4 & 4 \\
\hline & & & & & & & & & & & & & & & & & & & \\
\hline & & & & & & & & & & & & & & & & & & & \\
\hline & Assembly Type & \multicolumn{18}{|c|}{ C271 } \\
\hline & Core Height $(\mathrm{cm})$ & \multicolumn{6}{|c|}{60} & \multicolumn{6}{|c|}{80} & \multicolumn{4}{|c|}{100} & & \\
\hline & Number of Test assemblies & \multicolumn{2}{|c|}{1} & \multicolumn{2}{|c|}{4} & & & & & & & & & & & & & & \\
\hline & Average burnup (\% FIMA) & $3 \%$ & $6 \%$ & $3 \%$ & $6 \%$ & $3 \%$ & $6 \%$ & $3 \%$ & $6 \%$ & $3 \%$ & $6 \%$ & $3 \%$ & $6 \%$ & $3 \%$ & $6 \%$ & $3 \%$ & $6 \%$ & $3 \%$ & $6 \%$ \\
\hline & Number of batches & 3 & 5 & 3 & 5 & 3 & 5 & 4 & 8 & 4 & 8 & 4 & 8 & 6 & 11 & 6 & 11 & 6 & 12 \\
\hline & Cycle length (days) & 92 & 109 & 89 & 106 & 90 & 107 & 102 & 103 & 103 & 104 & 104 & 105 & 93 & 102 & 93 & 103 & 95 & 96 \\
\hline & Number of fuel assemblies & 75 & 86 & 83 & 94 & 86 & 101 & 48 & 55 & 55 & 63 & 57 & 65 & 38 & 43 & 43 & 48 & 44 & 51 \\
\hline & Thermal Power (MW) & 275 & 320 & 314 & 359 & 321 & 384 & 159 & 180 & 181 & 206 & 184 & 210 & 115 & 130 & 129 & 143 & 131 & 150 \\
\hline Max. values & Max Assembly Power (MW) & 5.0 & 5.0 & 5.0 & 5.0 & 5.0 & 5.0 & 4.3 & 4.3 & 4.3 & 4.2 & 4.3 & 4.3 & 3.7 & 3.7 & 3.7 & 3.7 & 3.7 & 3.7 \\
\hline & $20 \mathrm{~cm}$ peak avg. Fast Flux ( $\left.{ }^{*} 10 \mathrm{E} 15\right)$ & 3.8 & 3.9 & 3.7 & 3.8 & 3.7 & 3.8 & 2.6 & 2.7 & 2.5 & 2.6 & 2.5 & 2.6 & 1.9 & 2.0 & 1.9 & 1.9 & 1.9 & 1.9 \\
\hline & Thermal Power (MW) & $\mathrm{N} / \mathrm{A}$ & $\mathrm{N} / \mathrm{A}$ & $\mathrm{N} / \mathrm{A}$ & $\mathrm{N} / \mathrm{A}$ & $\mathrm{N} / \mathrm{A}$ & $\mathrm{N} / \mathrm{A}$ & $\mathrm{N} / \mathrm{A}$ & $\mathrm{N} / \mathrm{A}$ & $\mathrm{N} / \mathrm{A}$ & $\mathrm{N} / \mathrm{A}$ & $\mathrm{N} / \mathrm{A}$ & $\mathrm{N} / \mathrm{A}$ & $\mathrm{N} / \mathrm{A}$ & $\mathrm{N} / \mathrm{A}$ & $\mathrm{N} / \mathrm{A}$ & $N / A$ & N/A & $\mathrm{N} / \mathrm{A}$ \\
\hline 5.0e15 fast flux & Max Assembly Power (MW) & $\mathrm{N} / \mathrm{A}$ & $\mathrm{N} / \mathrm{A}$ & $\mathrm{N} / \mathrm{A}$ & $\mathrm{N} / \mathrm{A}$ & $\mathrm{N} / \mathrm{A}$ & $\mathrm{N} / \mathrm{A}$ & $\mathrm{N} / \mathrm{A}$ & $\mathrm{N} / \mathrm{A}$ & $\mathrm{N} / \mathrm{A}$ & $\mathrm{N} / \mathrm{A}$ & $\mathrm{N} / \mathrm{A}$ & $\mathrm{N} / \mathrm{A}$ & $\mathrm{N} / \mathrm{A}$ & $\mathrm{N} / \mathrm{A}$ & N/A & $\mathrm{N} / \mathrm{A}$ & $\mathrm{N} / \mathrm{A}$ & $\mathrm{N} / \mathrm{A}$ \\
\hline & $20 \mathrm{~cm}$ peak avg. Fast Flux $\left({ }^{*} 10 \mathrm{E} 15\right)$ & 5 & 5 & 5 & 5 & 5 & 5 & 5 & 5 & 5 & 5 & 5 & 5 & 5 & 5 & 5 & 5 & 5 & 5 \\
\hline & Thermal Power (MW) & $\mathrm{N} / \mathrm{A}$ & $\mathrm{N} / \mathrm{A}$ & $\mathrm{N} / \mathrm{A}$ & $\mathrm{N} / \mathrm{A}$ & $\mathrm{N} / \mathrm{A}$ & $\mathrm{N} / \mathrm{A}$ & $\mathrm{N} / \mathrm{A}$ & $\mathrm{N} / \mathrm{A}$ & $\mathrm{N} / \mathrm{A}$ & $\mathrm{N} / \mathrm{A}$ & $\mathrm{N} / \mathrm{A}$ & $\mathrm{N} / \mathrm{A}$ & $\mathrm{N} / \mathrm{A}$ & $\mathrm{N} / \mathrm{A}$ & $\mathrm{N} / \mathrm{A}$ & $\mathrm{N} / \mathrm{A}$ & $\mathrm{N} / \mathrm{A}$ & $\mathrm{N} / \mathrm{A}$ \\
\hline 4.0e15 fast flux & Max Assembly Power (MW) & $\mathrm{N} / \mathrm{A}$ & $\mathrm{N} / \mathrm{A}$ & $\mathrm{N} / \mathrm{A}$ & $\mathrm{N} / \mathrm{A}$ & $\mathrm{N} / \mathrm{A}$ & $\mathrm{N} / \mathrm{A}$ & $\mathrm{N} / \mathrm{A}$ & $\mathrm{N} / \mathrm{A}$ & $\mathrm{N} / \mathrm{A}$ & $\mathrm{N} / \mathrm{A}$ & $\mathrm{N} / \mathrm{A}$ & $\mathrm{N} / \mathrm{A}$ & $\mathrm{N} / \mathrm{A}$ & $\mathrm{N} / \mathrm{A}$ & N/A & N/A & N/A & N/A \\
\hline & $20 \mathrm{~cm}$ peak avg. Fast Flux ( $\left.{ }^{*} 10 \mathrm{E} 15\right)$ & 4 & 4 & 4 & 4 & 4 & 4 & 4 & 4 & 4 & 4 & 4 & 4 & 4 & 4 & 4 & 4 & 4 & 4 \\
\hline
\end{tabular}


MOX fuel with $235 \mathrm{U} / \mathrm{U}=0.3 \%$

\begin{tabular}{|c|c|c|c|c|c|c|c|c|c|c|c|c|c|c|c|c|c|c|c|}
\hline & Assembly Type & \multicolumn{18}{|c|}{ A271 - MOX 20\% Pu-WG } \\
\hline & Core Height $(\mathrm{cm})$ & \multicolumn{6}{|c|}{60 (LHR) } & \multicolumn{6}{|c|}{80} & \multicolumn{6}{|c|}{100} \\
\hline & Number of Test assemblies & \multicolumn{2}{|c|}{1} & \multicolumn{2}{|c|}{4} & \multicolumn{2}{|c|}{7} & \multicolumn{2}{|c|}{1} & \multicolumn{2}{|c|}{4} & \multicolumn{2}{|c|}{7} & \multicolumn{2}{|c|}{1} & \multicolumn{2}{|c|}{4} & \multicolumn{2}{|c|}{7} \\
\hline & Average burnup $(\mathrm{GWd} / \mathrm{t})$ & 29.5 & 59 & 29.5 & 59 & 29.5 & 59 & 29.5 & 59 & 29.5 & 59 & 29.5 & 59 & 29.5 & 59 & 29.5 & 59 & 29.5 & 59 \\
\hline & Number of batches & & & & & & & & & & 4 & & & & & & 5 & & \\
\hline & Cycle length (days) & & & & & & & & & & 101 & & & & & & 104 & & \\
\hline & Number of fuel assemblies & & & & & & & & & & 237 & & & & & & 138 & & \\
\hline \multirow{3}{*}{ Max. values } & Thermal Power (MW) & & & & & & & & & & 1174 & & & & & & 612 & & \\
\hline & Max Assembly Power (MW) & & & & & & & & & & 7.2 & & & & & & 6.3 & & \\
\hline & $20 \mathrm{~cm}$ peak avg. Fast Flux (*10E15) & & & & & & & & & & 5.3 & & & & & & 4.0 & & \\
\hline \multirow{3}{*}{ 5.0e15 fast flux } & Thermal Power (MW) & $\mathrm{N} / \mathrm{A}$ & $\mathrm{N} / \mathrm{A}$ & $\mathrm{N} / \mathrm{A}$ & $\mathrm{N} / \mathrm{A}$ & $\mathrm{N} / \mathrm{A}$ & $\mathrm{N} / \mathrm{A}$ & $\mathrm{N} / \mathrm{A}$ & $\mathrm{N} / \mathrm{A}$ & $\mathrm{N} / \mathrm{A}$ & 1108 & $\mathrm{~N} / \mathrm{A}$ & $\mathrm{N} / \mathrm{A}$ & $\mathrm{N} / \mathrm{A}$ & $\mathrm{N} / \mathrm{A}$ & $\mathrm{N} / \mathrm{A}$ & $\mathrm{N} / \mathrm{A}$ & $\mathrm{N} / \mathrm{A}$ & $\mathrm{N} / \mathrm{A}$ \\
\hline & Max Assembly Power (MW) & $\mathrm{N} / \mathrm{A}$ & $\mathrm{N} / \mathrm{A}$ & $\mathrm{N} / \mathrm{A}$ & $\mathrm{N} / \mathrm{A}$ & $\mathrm{N} / \mathrm{A}$ & N/A & $\mathrm{N} / \mathrm{A}$ & $\mathrm{N} / \mathrm{A}$ & $\mathrm{N} / \mathrm{A}$ & 6.8 & N/A & N/A & $\mathrm{N} / \mathrm{A}$ & $\mathrm{N} / \mathrm{A}$ & $\mathrm{N} / \mathrm{A}$ & N/A & N/A & $\mathrm{N} / \mathrm{A}$ \\
\hline & $20 \mathrm{~cm}$ peak avg. Fast Flux (*10E15) & 5 & 5 & 5 & 5 & 5 & 5 & 5 & 5 & 5 & 5 & 5 & 5 & 5 & 5 & 5 & 5 & 5 & 5 \\
\hline \multirow{3}{*}{ 4.0e15 fast flux } & Thermal Power (MW) & $\mathrm{N} / \mathrm{A}$ & $\mathrm{N} / \mathrm{A}$ & $\mathrm{N} / \mathrm{A}$ & $\mathrm{N} / \mathrm{A}$ & $\mathrm{N} / \mathrm{A}$ & $\mathrm{N} / \mathrm{A}$ & $\mathrm{N} / \mathrm{A}$ & $\mathrm{N} / \mathrm{A}$ & $\mathrm{N} / \mathrm{A}$ & 886 & $\mathrm{~N} / \mathrm{A}$ & $\mathrm{N} / \mathrm{A}$ & $\mathrm{N} / \mathrm{A}$ & $\mathrm{N} / \mathrm{A}$ & $\mathrm{N} / \mathrm{A}$ & 612 & $\mathrm{~N} / \mathrm{A}$ & $\mathrm{N} / \mathrm{A}$ \\
\hline & Max Assembly Power (MW) & $\mathrm{N} / \mathrm{A}$ & $\mathrm{N} / \mathrm{A}$ & $\mathrm{N} / \mathrm{A}$ & $\mathrm{N} / \mathrm{A}$ & $\mathrm{N} / \mathrm{A}$ & $\mathrm{N} / \mathrm{A}$ & $\mathrm{N} / \mathrm{A}$ & $\mathrm{N} / \mathrm{A}$ & $\mathrm{N} / \mathrm{A}$ & 5.4 & $\mathrm{~N} / \mathrm{A}$ & $\mathrm{N} / \mathrm{A}$ & $\mathrm{N} / \mathrm{A}$ & $\mathrm{N} / \mathrm{A}$ & $\mathrm{N} / \mathrm{A}$ & 6.3 & $\mathrm{~N} / \mathrm{A}$ & $\mathrm{N} / \mathrm{A}$ \\
\hline & $20 \mathrm{~cm}$ peak avg. Fast Flux ( $\left.{ }^{*} 10 \mathrm{E} 15\right)$ & 4 & 4 & 4 & 4 & 4 & 4 & 4 & 4 & 4 & 4 & 4 & 4 & 4 & 4 & 4 & 4 & 4 & 4 \\
\hline
\end{tabular}

\begin{tabular}{|c|c|c|c|c|c|c|c|c|c|c|c|c|c|c|c|c|c|c|c|}
\hline & Assembly Type & \multicolumn{18}{|c|}{ A271 - MOX 27\% Pu-WG } \\
\hline & Core Height $(\mathrm{cm})$ & \multirow{2}{*}{\multicolumn{4}{|c|}{$\begin{array}{c}60 \text { (LHR) } \\
4\end{array}$}} & & & \multirow{2}{*}{\multicolumn{4}{|c|}{$\frac{80}{4}$}} & & & \multirow{2}{*}{\multicolumn{4}{|c|}{$\frac{100}{4}$}} & & \\
\hline & Number of Test assemblies & & & & & & & & & & & & & & & & & \multicolumn{2}{|c|}{7} \\
\hline & Average burnup $(\mathrm{GWd} / \mathrm{t}$ ) & 29.5 & 59 & 29.5 & 59 & 29.5 & 59 & 29.5 & 59 & 29.5 & 59 & 29.5 & 59 & 29.5 & 59 & 29.5 & 59 & 29.5 & 59 \\
\hline & Number of batches & & & & 3 & & & & & & 3 & & & & & & 4 & & \\
\hline & Cycle length (days) & & & & 114 & & & & & & 110 & & & & & & 104 & & \\
\hline & Number of fuel assemblies & & & & 123 & & & & & & 81 & & & & & & 51 & & \\
\hline \multirow{3}{*}{ Max. values } & Thermal Power (MW) & & & & 475 & & & & & & 366 & & & & & & 246 & & \\
\hline & Max Assembly Power (MW) & & & & 5.9 & & & & & & 7.2 & & & & & & 6.3 & & \\
\hline & $20 \mathrm{~cm}$ peak avg. Fast Flux ( $\left.{ }^{*} 10 \mathrm{E} 15\right)$ & & & & 4.9 & & & & & & 4.8 & & & & & & 3.6 & & \\
\hline \multirow{3}{*}{ 5.0e15 fast flux } & Thermal Power (MW) & N/A & $\mathrm{N} / \mathrm{A}$ & $\mathrm{N} / \mathrm{A}$ & $\mathrm{N} / \mathrm{A}$ & $\mathrm{N} / \mathrm{A}$ & $\mathrm{N} / \mathrm{A}$ & $\mathrm{N} / \mathrm{A}$ & $\mathrm{N} / \mathrm{A}$ & $\mathrm{N} / \mathrm{A}$ & $\mathrm{N} / \mathrm{A}$ & $\mathrm{N} / \mathrm{A}$ & $\mathrm{N} / \mathrm{A}$ & $\mathrm{N} / \mathrm{A}$ & $\mathrm{N} / \mathrm{A}$ & $\mathrm{N} / \mathrm{A}$ & $\mathrm{N} / \mathrm{A}$ & $\mathrm{N} / \mathrm{A}$ & $\mathrm{N} / \mathrm{A}$ \\
\hline & Max Assembly Power (MW) & N/A & $\mathrm{N} / \mathrm{A}$ & $\mathrm{N} / \mathrm{A}$ & N/A & $\mathrm{N} / \mathrm{A}$ & $\mathrm{N} / \mathrm{A}$ & $\mathrm{N} / \mathrm{A}$ & $\mathrm{N} / \mathrm{A}$ & $\mathrm{N} / \mathrm{A}$ & $\mathrm{N} / \mathrm{A}$ & $\mathrm{N} / \mathrm{A}$ & $\mathrm{N} / \mathrm{A}$ & $\mathrm{N} / \mathrm{A}$ & $\mathrm{N} / \mathrm{A}$ & $\mathrm{N} / \mathrm{A}$ & $\mathrm{N} / \mathrm{A}$ & $\mathrm{N} / \mathrm{A}$ & $\mathrm{N} / \mathrm{A}$ \\
\hline & $20 \mathrm{~cm}$ peak avg. Fast Flux ( $\left.{ }^{*} 10 \mathrm{E} 15\right)$ & 5 & 5 & 5 & 5 & 5 & 5 & 5 & 5 & 5 & 5 & 5 & 5 & 5 & 5 & 5 & 5 & 5 & 5 \\
\hline \multirow{3}{*}{ 4.0e15 fast flux } & Thermal Power (MW) & N/A & $\mathrm{N} / \mathrm{A}$ & $\mathrm{N} / \mathrm{A}$ & 392 & $\mathrm{~N} / \mathrm{A}$ & $\mathrm{N} / \mathrm{A}$ & $\mathrm{N} / \mathrm{A}$ & $\mathrm{N} / \mathrm{A}$ & $\mathrm{N} / \mathrm{A}$ & 305 & $\mathrm{~N} / \mathrm{A}$ & $\mathrm{N} / \mathrm{A}$ & $\mathrm{N} / \mathrm{A}$ & $\mathrm{N} / \mathrm{A}$ & $\mathrm{N} / \mathrm{A}$ & $\mathrm{N} / \mathrm{A}$ & $\mathrm{N} / \mathrm{A}$ & $\mathrm{N} / \mathrm{A}$ \\
\hline & Max Assembly Power (MW) & N/A & $\mathrm{N} / \mathrm{A}$ & $\mathrm{N} / \mathrm{A}$ & 4.8 & $\mathrm{~N} / \mathrm{A}$ & $\mathrm{N} / \mathrm{A}$ & $\mathrm{N} / \mathrm{A}$ & $\mathrm{N} / \mathrm{A}$ & $\mathrm{N} / \mathrm{A}$ & 6.0 & N/A & $\mathrm{N} / \mathrm{A}$ & $\mathrm{N} / \mathrm{A}$ & $\mathrm{N} / \mathrm{A}$ & $\mathrm{N} / \mathrm{A}$ & $\mathrm{N} / \mathrm{A}$ & $\mathrm{N} / \mathrm{A}$ & $\mathrm{N} / \mathrm{A}$ \\
\hline & $20 \mathrm{~cm}$ peak avg. Fast Flux ( $\left.{ }^{*} 10 \mathrm{E} 15\right)$ & 4 & 4 & 4 & 4 & 4 & 4 & 4 & 4 & 4 & 4 & 4 & 4 & 4 & 4 & 4 & 4 & 4 & 4 \\
\hline & & & & & & & & & & & & & & & & & & & \\
\hline & & & & & & & & & & & & & & & & & & & \\
\hline & Assembly Type & \multirow{2}{*}{\multicolumn{18}{|c|}{ A271 - MOX 27\% Pu-RG }} \\
\hline & Core Height $(\mathrm{cm})$ & \multirow{2}{*}{\multicolumn{4}{|c|}{$\begin{array}{c}60 \text { (LHR) } \\
4\end{array}$}} & & & & & & & & & & & & & & \\
\hline & Number of Test assemblies & & & & & & & \multicolumn{4}{|c|}{80} & & & \multicolumn{4}{|c|}{100} & \multicolumn{2}{|c|}{7} \\
\hline & Average burnup $(\mathrm{GWd} / \mathrm{t})$ & 29.5 & 59 & 29.5 & 59 & 29.5 & 59 & 29.5 & 59 & 29.5 & 59 & 29.5 & 59 & 29.5 & 59 & 29.5 & 59 & 29.5 & 59 \\
\hline & Number of batches & & & & 2 & & & & & & 3 & & & & & & 4 & & \\
\hline & Cycle length (days) & & & & 128 & & & & & & 105 & & & & & & 95 & & \\
\hline & Number of fuel assemblies & & & & 237 & & & & & & 120 & & & & & & 84 & & \\
\hline \multirow{3}{*}{ Max. values } & Thermal Power (MW) & & & & 977 & & & & & & 618 & & & & & & 382 & & \\
\hline & Max Assembly Power (MW) & & & & 5.9 & & & & & & 7.2 & & & & & & 6.3 & & \\
\hline & $20 \mathrm{~cm}$ peak avg. Fast Flux ( $\left.{ }^{*} 10 \mathrm{E} 15\right)$ & & & & 5.2 & & & & & & 5.2 & & & & & & 3.8 & & \\
\hline \multirow{3}{*}{ 5.0e15 fast flux } & Thermal Power (MW) & $\mathrm{N} / \mathrm{A}$ & $\mathrm{N} / \mathrm{A}$ & $\mathrm{N} / \mathrm{A}$ & $\mathrm{N} / \mathrm{A}$ & $\mathrm{N} / \mathrm{A}$ & $\mathrm{N} / \mathrm{A}$ & $\mathrm{N} / \mathrm{A}$ & $\mathrm{N} / \mathrm{A}$ & $\mathrm{N} / \mathrm{A}$ & $\mathrm{N} / \mathrm{A}$ & $\mathrm{N} / \mathrm{A}$ & $\mathrm{N} / \mathrm{A}$ & $\mathrm{N} / \mathrm{A}$ & $\mathrm{N} / \mathrm{A}$ & $\mathrm{N} / \mathrm{A}$ & $\mathrm{N} / \mathrm{A}$ & $\mathrm{N} / \mathrm{A}$ & $\mathrm{N} / \mathrm{A}$ \\
\hline & Max Assembly Power (MW) & N/A & $\mathrm{N} / \mathrm{A}$ & $\mathrm{N} / \mathrm{A}$ & $\mathrm{N} / \mathrm{A}$ & $\mathrm{N} / \mathrm{A}$ & $\mathrm{N} / \mathrm{A}$ & $\mathrm{N} / \mathrm{A}$ & $\mathrm{N} / \mathrm{A}$ & $\mathrm{N} / \mathrm{A}$ & $\mathrm{N} / \mathrm{A}$ & $\mathrm{N} / \mathrm{A}$ & $\mathrm{N} / \mathrm{A}$ & $\mathrm{N} / \mathrm{A}$ & $\mathrm{N} / \mathrm{A}$ & $\mathrm{N} / \mathrm{A}$ & $\mathrm{N} / \mathrm{A}$ & $\mathrm{N} / \mathrm{A}$ & $\mathrm{N} / \mathrm{A}$ \\
\hline & $20 \mathrm{~cm}$ peak avg. Fast Flux ( $\left.{ }^{*} 10 \mathrm{E} 15\right)$ & 5 & 5 & 5 & 5 & 5 & 5 & 5 & 5 & 5 & 5 & 5 & 5 & 5 & 5 & 5 & 5 & 5 & 5 \\
\hline \multirow{3}{*}{ 4.0e15 fast flux } & Thermal Power (MW) & $\mathrm{N} / \mathrm{A}$ & $\mathrm{N} / \mathrm{A}$ & $\mathrm{N} / \mathrm{A}$ & 806 & $\mathrm{~N} / \mathrm{A}$ & $\mathrm{N} / \mathrm{A}$ & $\mathrm{N} / \mathrm{A}$ & $\mathrm{N} / \mathrm{A}$ & $\mathrm{N} / \mathrm{A}$ & 515 & $\mathrm{~N} / \mathrm{A}$ & $\mathrm{N} / \mathrm{A}$ & $\mathrm{N} / \mathrm{A}$ & $\mathrm{N} / \mathrm{A}$ & $\mathrm{N} / \mathrm{A}$ & $\mathrm{N} / \mathrm{A}$ & $\mathrm{N} / \mathrm{A}$ & $\mathrm{N} / \mathrm{A}$ \\
\hline & Max Assembly Power (MW) & $\mathrm{N} / \mathrm{A}$ & $\mathrm{N} / \mathrm{A}$ & $\mathrm{N} / \mathrm{A}$ & 4.8 & $\mathrm{~N} / \mathrm{A}$ & $\mathrm{N} / \mathrm{A}$ & $\mathrm{N} / \mathrm{A}$ & N/A & N/A & 6.0 & $\mathrm{~N} / \mathrm{A}$ & N/A & $\mathrm{N} / \mathrm{A}$ & $\mathrm{N} / \mathrm{A}$ & $\mathrm{N} / \mathrm{A}$ & N/A & $\mathrm{N} / \mathrm{A}$ & $\mathrm{N} / \mathrm{A}$ \\
\hline & $20 \mathrm{~cm}$ peak avg. Fast Flux $\left({ }^{*} 10 \mathrm{E} 15\right)$ & 4 & 4 & 4 & 4 & 4 & 4 & 4 & 4 & 4 & 4 & 4 & 4 & 4 & 4 & 4 & 4 & 4 & 4 \\
\hline
\end{tabular}

